\title{
Osteoporosis in chronic obstructive pulmonary disease
}

Citation for published version (APA):

Graat-Verboom, L. (2012). Osteoporosis in chronic obstructive pulmonary disease. [Doctoral Thesis, Maastricht University]. Maastricht University. https://doi.org/10.26481/dis.20120316lg

Document status and date:

Published: 01/01/2012

DOI:

10.26481/dis.20120316lg

Document Version:

Publisher's PDF, also known as Version of record

\section{Please check the document version of this publication:}

- A submitted manuscript is the version of the article upon submission and before peer-review. There can be important differences between the submitted version and the official published version of record.

People interested in the research are advised to contact the author for the final version of the publication, or visit the DOI to the publisher's website.

- The final author version and the galley proof are versions of the publication after peer review.

- The final published version features the final layout of the paper including the volume, issue and page numbers.

Link to publication

\footnotetext{
General rights rights.

- You may freely distribute the URL identifying the publication in the public portal. please follow below link for the End User Agreement:

www.umlib.nl/taverne-license

Take down policy

If you believe that this document breaches copyright please contact us at:

repository@maastrichtuniversity.nl

providing details and we will investigate your claim.
}

Copyright and moral rights for the publications made accessible in the public portal are retained by the authors and/or other copyright owners and it is a condition of accessing publications that users recognise and abide by the legal requirements associated with these

- Users may download and print one copy of any publication from the public portal for the purpose of private study or research.

- You may not further distribute the material or use it for any profit-making activity or commercial gain

If the publication is distributed under the terms of Article $25 \mathrm{fa}$ of the Dutch Copyright Act, indicated by the "Taverne" license above, 


\section{Osteoporosis in Chronic Obstructive Pulmonary Disease}

Lidwien Graat-Verboom 
Graat-Verboom, L

Osteoporosis in chronic obstructive pulmonary disease

Thesis University Medical Centre Maastricht

Cover design: CR-Creative te Eindhoven www.cr-creative.nl

Printing: Drukkerij van Tuijl te Eindhoven

The studies for this thesis were performed at $\mathrm{CIRO}_{+}$, centre of expertise for chronic organ failure Horn and Catharina Hospital Eindhoven.

This thesis was financially supported by the Pulmonology Research Education and Development Foundation of the Catharina Hospital Eindhoven, the Netherlands; AstraZeneca the Netherlands and GlaxoSmithKline the Netherlands.

Printing and distribution of this thesis was made possible by additional financial support by the Catharina Hospital Eindhoven, the Netherlands; the Pulmonology Research Education and Development Foundation of the Catharina Hospital Eindhoven, the Netherlands; CIRO, centre of expertise for chronic organ failure, Horn, the Netherlands; department of pulmonology Maastricht University Hospital, Maastricht, the Netherlands; Astma Fonds (binnenkort Longfonds), Amersfoort, the Netherlands; AstraZeneca the Netherlands and GlaxoSmithKline the Netherlands.

ISBN 978-90-9026629-9

(c) copyright Lidwien Graat-Verboom, Eindhoven 2012 


\title{
Osteoporosis in Chronic Obstructive Pulmonary Disease
}

\author{
PROEFSCHRIFT \\ ter verkrijging van de graad doctor aan de Universiteit van Maastricht, \\ op gezag van de Prof. mr. G.P.M.F. Mols, Rector Magnificus \\ volgens het besluit van het College van Decanen, \\ in het openbaar te verdedigen \\ op vrijdag 16 maart 2012 om 12:00 uur
}

door

Lidwien Graat-Verboom

Geboren te Eindhoven 


\section{Promotor:}

Prof. dr. E.F.M. Wouters

\section{Copromoteres:}

Dr. M.A. Spruit, $\mathrm{ClRO}+$, Horn

Dr. B.E.E.M. Van den Borne, Catharina Ziekenhuis, Eindhoven

\section{Beoordelingscommissie:}

Prof. Dr. A.C. Nieuwenhuijzen Kruseman, voorzitter

Prof. Dr. P. Geusens

Prof. Dr. W. Janssens, Universitair Ziekenhuis Leuven, België

Prof. Dr. med. H. Magnussen, Hospital Grosshans, Duitsland

Prof. Dr. A. A.M. Masclee 
Lieve Loek en Femke, dit proefschrift is voor ons. 

Table of contents 
Chapter I General introduction and outline of the thesis.

Chapter II Current status of research on osteoporosis in COPD: a systematic review.

European Respiratory Journal 2009;34:209-218

Chapter III Correlates of osteoporosis in chronic obstructive pulmonary disease: An underestimated systemic component.

Respiratory Medicine 2009;103:1143-1151

Chapter IV Whole-body versus local DXA-scan for the diagnosis of osteoporosis in COPD patients.

Journal of Osteoporosis 2010; doi: 10.4061/2010/640878

Chapter V Osteoporosis in COPD outpatients based on bone 93 mineral density and vertebral fractures.

Journal of Bone and Mineral Research 2011;26:561-568

Chapter VI Risk factors for osteoporosis in patients with moderate COPD: A case control study.

(Submitted)

Chapter VII Progression of osteoporosis in patients with COPD: 129 A 3-year follow up study.

(Accepted for publication by Respiratory Medicine) 
Chapter VIII General discussion and conclusions

Summary

Samenvatting

Dankwoord 195

Curriculum Vitae 



\section{Chapter I}

\section{General Introduction and Outline of the Thesis}




\section{Chronic Obstructive Pulmonary Disease (COPD)}

\section{Definition of COPD}

Chronic obstructive pulmonary disease (COPD) is characterized by a progressive airflow limitation that is not fully reversible and associated with an abnormal inflammatory response of the lung to noxious particles and gasses ${ }^{1}$. In addition, there are some significant extrapulmonary effects that may contribute to the severity in the individual patient. The degree of airflow limitation can be assessed by spirometry and a classification of COPD can be made according to the Global Strategy for the Diagnosis, Management and Prevention of COPD (GOLD) ${ }^{1}$ (table 1). This classification uses the measured forced expiratory volume in 1 second $\left(F E V_{1}\right)$ as percentage of the predicted $F E V_{1}$ to classify COPD patients. Characteristic symptoms of COPD are progressive dyspnea, cough and sputum production.

Table 1: Classification of COPD based on post bronchodilator spirometry.

\begin{tabular}{ll}
\hline GOLD I: mild & $\mathrm{FEV}_{1} / \mathrm{FVC}<0.70$ \\
& $\mathrm{FEV}_{1} \geq 80 \%$ predicted \\
GOLD II: moderate & $\mathrm{FEV}_{1} / \mathrm{FVC}<0.70$ \\
& $50 \% \leq \mathrm{FEV} 1<80 \%$ predicted \\
GOLD III: severe & $\mathrm{FEV}_{1} / \mathrm{FVC}<0.70$ \\
& $30 \% \leq \mathrm{FEV}<50 \%$ predicted \\
GOLD IV: very severe & $\mathrm{FEV}_{1} / \mathrm{FVC}<0.70$ \\
& $\mathrm{FEV}_{1}<30 \%$ predicted OR $\mathrm{FEV}_{1}<50 \%$ \\
& and respiratory failure* \\
\hline
\end{tabular}

${ }^{*}$ Respiratory failure: arterial partial pressure of oxygen $<8.0 \mathrm{kPa}(60 \mathrm{~mm} \mathrm{Hg})$ with or without arterial partial pressure of carbondioxide $>6.7 \mathrm{kPa}(50 \mathrm{~mm} \mathrm{Hg})$ while breathing air at sea level. Rabe e.a. Am J Respir Crit Care Med 2007; 176(6):532-555

\section{Epidemiology and burden of COPD}

COPD is a major health problem with significant medical and financial impact on society. The estimated global prevalence is about $10 \%$ in adults aged 40 years or older ${ }^{2 ; 3}$.

COPD was ranked $12^{\text {th }}$-leading cause of disability-adjusted life years (DALYS, defined as 'the number of years lost due to ill-health, disability or early death') in 1990 and is expected to become $5^{\text {th }}$ by 2020 . In the Netherlands COPD is ranked fifth of diseases with the most DALYS (after 
coronary artery diseases, anxiety disorders, cerebral vascular events and depression $)^{4}$.

In 200522,440 patients were admitted to the hospital for COPD in the Netherlands; mean duration of stay was 11 days $^{5}$. Total health care costs for COPD in 2000 added up to 280 million Euros per year in the Netherlands ${ }^{6}$. Hospital admissions, medication and homecare days contributed most to these health care costs $(27 \%, 22 \%$ and $19 \%$ respectively). In a more recent study including only GOLD 2 and 3 COPD patients from two general hospitals in the Netherlands mean total costs, irrespective of whether they were related to COPD or not, were 10,814 Euros per 2 years (in 2007 Euros) ${ }^{7}$.

In 1990 COPD was reported as sixth leading cause of death and it is estimated to become third by the year $2020^{3}$. Most important causes of death in COPD patients are COPD itself, other respiratory causes, cardiovascular disease, and lung cancer ${ }^{8}$. The TORCH trial confirmed these results: of 911 deaths $35 \%$ were attributed to respiratory causes (75\% of these occurring after a COPD exacerbation), $26 \%$ to cardiovascular events and $21 \%$ to cancer ${ }^{9}$.

Besides the significant burden on society of COPD, there is a high impact on the individual patient. COPD patients are physically less active ${ }^{10}$, have a high morbidity (also due to co-morbidities) and often have high scores on anxiety and depression scales ${ }^{11 ; 12}$. This can lead to a situation of social isolation, which in turn can lead to worsening of the aforementioned problems.

\section{Aetiology of COPD}

The most important risk factor for COPD is cigarette smoking. However, only $15-20 \%$ of all smoking subjects and up to $50 \%$ of elderly smokers (age $>75$ years) will develop $\mathrm{COPD}^{13}$. Therefore, there must be an individual susceptibility to cigarette smoke as well as an influence of age. Environmental and prenatal exposition to tobacco smoke also increase the risk of COPD $^{14}$.

Besides tobacco smoke occupational dusts and chemicals as well as indoor and outdoor air pollution increase the risk of COPD ${ }^{1}$. 
A well known genetic risk factor for COPD is $\alpha-1$ antitrypsin deficiency. Despite the fact that other genes have been studied, the results of these genetic association studies proved to be inconsistent and therefore, no other genes could be identified with certainty yet ${ }^{15}$.

Respiratory tract infections during childhood may predispose to changes in airway responsiveness or bronchiectasis and hence increase the risk of COPD ${ }^{16}$.

\section{Pathology of COPD}

The pathological changes in COPD are located in the proximal airways, peripheral airways, the lung parenchyma and lung vasculature ${ }^{17}$. These pathological changes include chronic inflammation with an increase in different inflammatory cell types in the different parts of the lung. For instance, increased numbers of macrophages, $\mathrm{CD}^{+}{ }^{+} \mathrm{T}$-lymphocytes and B-lymphocytes, increased epithelial goblet cell numbers, squamous cell metaplasia and enlarged submucosal glands are found in the central airway wall ${ }^{18}$, whereas increased numbers of macrophages, Tlymphocytes, B-lymphocytes and mast cells are found in the peripheral airways $^{19}$. In addition, due to repeated injury and repair structural changes of the airways occur. These structural changes include thickening of the airway wall with increased extracellular matrix components $^{20}$ and smooth muscle mass ${ }^{21 ; 22}$, peribronchial fibrosis and airway narrowing ${ }^{17}$.

\section{Pathogenesis of COPD}

The abnormal inflammatory response plays an important role in the pathogenesis of COPD. The innate response can cause proteolytic damage to the extracellular matrix, involving neutrophils and macrophages. This innate response was held responsible for the occurrence of emphysema ${ }^{23 ; 24}$. Another component of disease pathogenesis is activation of the adaptive immune response in the lung ${ }^{17 ; 25-27}$. This response is mediated by dendritic cells as well as $T$ - and B-lymphocytes. Indeed, a 3 step series of mechanisms was proposed to be responsible for the development of $\mathrm{COPD}^{28}$. In step 1 there is an 
innate immune response to cigarette smoke with immature dendritic cells as a result. In step 2 dendritic cells mature and present antigens to Tcells in the lymph nodes. In step 3 an adaptive immune inflammation leads to necrosis and apoptosis of endothelial and epithelial cells with lung destruction in COPD as a consequence. Progression to the next step depends on enhanced dendritic-cell function, genetic predisposition and failure of immune regulation. Recently, Polverino and colleagues encountered increased expression of B-cell activating factor belonging to the tumor necrosis factor family (BAFF) in the peripheral lung of COPD patients ${ }^{29}$. Because this expression was most prominent in macrophages and lymphoid follicles BAFF might occupy a position between the innate and adaptive immune response in COPD.

The inflammation in the lung is found throughout the tracheobronchial tree. In addition, there is increasing evidence of chronic systemic inflammation in $\mathrm{COPD}^{30}$, which will be discussed in the COPD and systemic effects section.

\section{Heterogeneity of COPD}

The airflow limitation in COPD is generally the physiological consequence of a mixture of small airway disease (obstructive bronchiolitis) and parenchymal destruction (emphysema). Although chronic bronchitis and emphysema overlap and the relative contribution varies from person to person, COPD is currently approached as a clinical syndrome made up by different phenotypes leading to different levels of morbidity in COPD. Recently, Han and colleagues suggested the following definition for phenotypes in COPD: "a single or combination of disease attributes that describe differences between individuals with COPD as they relate to clinically meaningful outcomes (symptoms, exacerbations, response to therapy, rate of disease progression, or death) ${ }^{31}$." They argue that phenotypes should have real predictive value and any proposed phenotype must be prospectively validated. There are different ways to identify these phenotypes, e.g. a proposed phenotype may be prospectively validated and show to have a clinically important effect on outcome, or responders to a certain therapy can be investigated and a specific phenotype might be found. Clinically different COPD phenotypes that have been identified, but were not all prospectively validated, are: patients with or without weight loss, frequent exacerbations, airway 
hyperresponsiveness and rapid lung function decline. Also, pathophysiological and pathological findings differ between COPD patients. The broad scatter in COPD in reported symptoms, exacerbations, reported health status, the number of co-morbidities and other patient related outcomes, independent of the degree of airflow limitation, was recently confirmed by the so-called ECLIPSE study, an international Evaluation of COPD Longitudinally to Identify Predictive Surrogate Endpoints ${ }^{32}$.

\section{COPD and systemic effects}

Besides the pulmonary effects, COPD also causes significant systemic effects as is incorporated in the definition of COPD according to the GOLD guidelines ${ }^{1}$. Distinguishing co-morbidities from systemic effects of COPD is difficult because there is no consensus definition. An operational definition is that co-morbidities are diseases that occur associated with COPD, perhaps in the line of shared risk factors. Systemic effects, however, are direct consequences of the disease itself with a definite cause-and-effect relationship ${ }^{33}$. Nevertheless, disorders like osteoporosis in COPD could be a co-morbidity due to shared risk factors or a systemic consequence due to a cause-and-effect relationship. In addition, a co-morbidity can contribute to a systemic consequence in COPD (figure 1).

Figure 1: Interrelationships between COPD, systemic consequences, and co-morbidities.

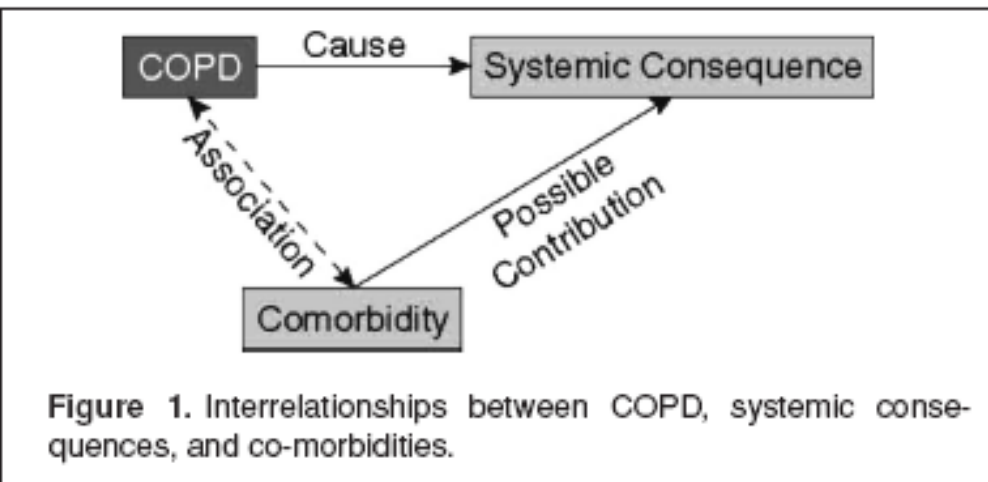

Adapted with permission from: Decramer and colleagues, Journal of Chronic Obstructive Pulmonary Disease 2008;5:235-256 
Mapel and colleagues included COPD patients and controls from a large database of Mexican patients (including hospitals as well as primary care centres) $)^{34}$. COPD was defined as International Classification of Diseases Ninth revision (ICD-9) codes 491.x (chronic bronchitis), 492.x (emphysema) and 496 (COPD unspecified). They found an average of 3.7 co-morbid conditions in COPD patients compared with 1.8 in controls. Examples of these co-morbidities are anxiety and depression ${ }^{35 ; 36}$, metabolic syndrome ${ }^{37}$, heart failure ${ }^{34}$, loss of muscle mass ${ }^{38}$, arterial stiffness $^{39}$ and osteoporosis ${ }^{40}$. Crisafulli and colleagues found that $62 \%$ of COPD patients entering a pulmonary rehabilitation program had at least one coexisting co-morbidity ${ }^{41}$. The six most prevalent co-morbidities $(89 \%$ of total co-morbidities) were systemic hypertension, dyslipidemia, diabetes, coronary disease, chronic heart failure and osteoporosis. In the ECLIPSE-data the higher prevalence of co-morbidities in COPD patients as compared to smokers with normal lung function and to non-smokers was confirmed $(38 \%, 23 \% \text { and } 16 \% \text { respectively, } p<0.001)^{32}$. Moreover, co-morbidities were independent of the degree of airflow limitation.

Co-morbidities like cardiovascular disease, depression, osteoporosis and lung cancer increase the impact of COPD. In addition, mortality is increased where the most important causes of death in COPD patients consist of COPD itself, cor pulmonale, cardiovascular diseases and lung cancer, being important co-morbidities in COPD themselves ${ }^{8}$. Indeed, the presence of COPD combined with one or more co-morbidities predicted a higher mortality rate ${ }^{42}$.

The connections between co-morbidities or systemic effects and COPD are complicated and not fully understood yet. Therefore, it cannot be predicted which subgroup of COPD patients will develop one or more comorbidities eventually. Chronic systemic inflammation might be an important factor in terms of these connections. However, the relationship between systemic and pulmonary inflammation remains unclear. One theory holds that there occurs spill over of inflammatory mediators from the airways to the circulation. This theory is supported by the fact that surfactant protein $D$, which plays a role in the innate defence against micro-organisms, is elevated in serum of COPD patients, whereas it is produced mainly by type II pneumocytes ${ }^{43 ; 44}$.

However, other investigators could not confirm this "spill over theory" because they found no correlation between markers of inflammation in 
sputum and plasma ${ }^{30}$. Therefore, they assumed that the inflammatory processes in the local and systemic compartment are regulated in a different way.

Other connections between COPD and co-morbidities could be attributed to common risk factors or even a genetic susceptibility. More research is needed to clarify these connections in order classify the individual COPD patient correctly.

This thesis focuses on osteoporosis in patients with COPD.

\section{Osteoporosis}

\section{Definition of osteoporosis}

Osteoporosis is a systemic skeletal disease characterized by a decreased bone mineral density (BMD) and/or deterioration of the microarchitecture, resulting in increased bone fragility and hence an increased susceptibility to fractures ${ }^{45}$.

The gold standard to diagnose osteoporosis is dual energy absorptiometry (DXA) scan ${ }^{45}$. With this technique the amount of mineral in the scanned area of bone is measured in grams and divided by the measured bone surface in square centimetres to acquire a definite bone mineral density (BMD). The BMD score of patients is expressed as $T$ score. This $T$ score is calculated by measuring how many standard deviations the patient's BMD differs from the mean BMD of a young control population. The definition of osteoporosis according to the WHO is based on this T-score ${ }^{45}$ (table 2). BMD is measured at different skeletal areas. The hip, lumbar spine and total body are most frequently used. The location of BMD assessment is the best predictor for a fracture at that same location ${ }^{46}$. The WHO advises to measure BMD at the hip ${ }^{45}$, whereas the International Society for Clinical Densitometry advocates to measure BMD of the lumbar spine and the hip both. The diagnosis of osteoporosis is based on the lowest T-score of all measured locations ${ }^{47}$. In case of a whole body DXA-scan the cut-off values for osteoporosis and osteopenia should be adjusted according to Boyanov to obtain a good sensitivity to specificity ratio ${ }^{48}$ (table 3 ). 
Table 2: Classification of BMD according to the WHO

\begin{tabular}{lll}
\hline Normal & $\begin{array}{l}\text { Value of BMD 1 SD below the reference mean } \\
\text { or higher }\end{array}$ & T-score $\geq-1$ \\
Osteopenia & $\begin{array}{l}\text { Value of BMD more than 1 SD below the } \\
\text { reference mean, but less than 2.5 SD below } \\
\text { this value }\end{array}$ & $\begin{array}{l}\text { Value of BMD 2.5 SD or more below the } \\
\text { reference mean }\end{array}$ \\
Osteoporosis & $\begin{array}{l}\text { Value of BMD 2.5 SD or more below the } \leq-2.5 \\
\text { reference mean in the presence of one or fragility fracture(s) } \\
\text { more fragility fractures. }\end{array}$ \\
\hline $\begin{array}{l}\text { Established } \\
\text { osteoporosis }\end{array}$ &
\end{tabular}

$\mathrm{SD}=$ standard deviation

Reference mean=young adult population of the NHANES III database

http;//whqlibdoc who int/trs/WHO_TRS_921 pdf

Table 3: Classification of whole body BMD according to Boyanov

\begin{tabular}{ll}
\hline Normal & T-score $>-0.90$ \\
Osteopenia & $-0.90<\mathrm{T}$-score $<-2.35$ \\
Osteoporosis & T-score $<-2.35$ \\
\hline
\end{tabular}

Boyanov, Br J Radiol 2008; 81(968):637-642

DXA-scan only measures BMD, however, as described before, osteoporosis is characterized not only by a decreased BMD but also by deterioration of the microarchitecture of bone. This last feature is not measured by DXA-scan. Fragility fractures are a result of osteoporosis and can, therefore, be the result of a decreased BMD, deteriorated microarchitecture or a combination of these two.

An indirect way to assess a deteriorated microarchitecture is a vertebral fracture without a high energy trauma in the past. Vertebral deformities can be assessed on X-rays of the spine by a morphometric method according to Genant ${ }^{49}$. Of each vertebra anterior, medial and posterior heights are measured. These heights are compared to each other and to the heights of the vertebrae above and beneath that vertebra. Fractures can be classified as grade 1 (20-25\% reduction in anterior, middle and/or posterior height and $10-20 \%$ reduction of the projected vertebral area), grade $2(25-40 \%$ reduction in height and $20-40 \%$ reduction of the projected vertebral area) and grade 3 ( $\geq 40 \%$ reduction in height). In addition, fractures can be classified according to their shape: wedge (reduction in anterior height), biconcave (reduction in middle height) or crush (reduction in posterior height) (figure 2). 
Patients with a normal BMD as determined by DXA-scan did have vertebral fractures ${ }^{50-52}$ supporting the idea that osteoporosis can be a result of deteriorated microarchitecture in the presence of a normal bone mineral density.

Figure 2: Classification of vertebral fractures

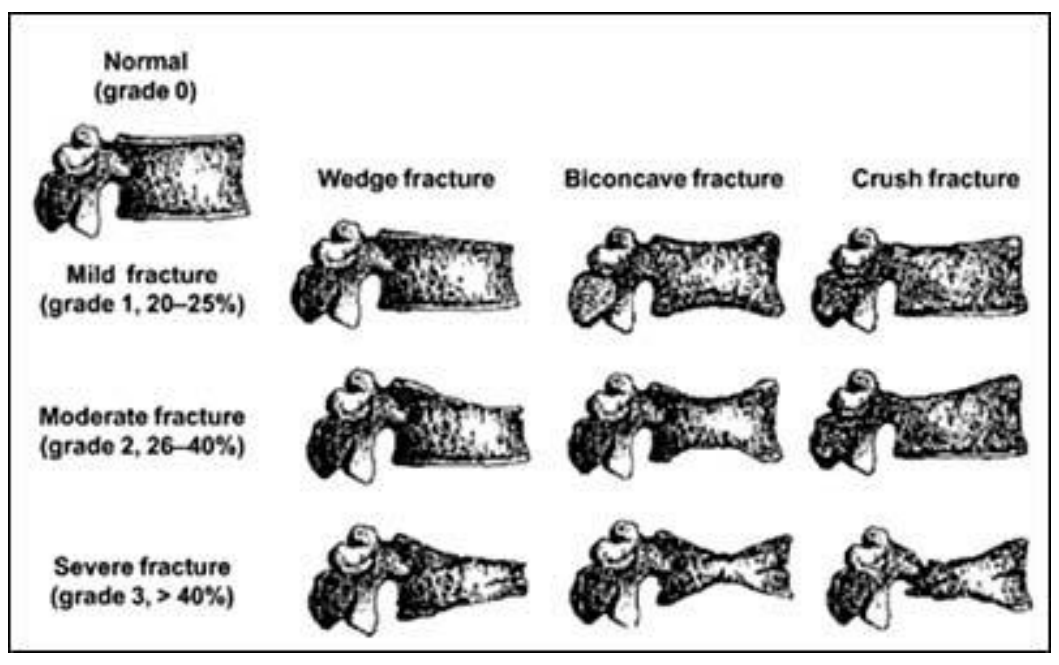

\section{Epidemiology and impact of osteoporosis}

According to the World Health Organisation (WHO) osteoporosis affects more than 75 million people in Europe, Japan and the USA ${ }^{45}$. The lifetime risk for osteoporotic fractures has been estimated to be approximately $40 \%$, which is similar to that for coronary heart disease ${ }^{45}$. In addition, osteoporosis causes loss of height, back pain and decreased quality of life ${ }^{45}$. Moreover, mortality is increased after fractures e.g. the risk of death is increased over ten-fold in the first week following fracture ${ }^{53}$.

\section{Aetiology of osteoporosis}

Risk factors for osteoporosis and osteoporotic fractures are increased age, lower body mass index, a previous fracture before 50 years of age, parents with a fracture, smoking, $>3$ units of alcohol per day, immobility, 
use of glucocorticoids and rheumatoid arthritis ${ }^{45}$. In addition, there exist several diseases with secondary osteoporosis. Indeed, in the third revised guideline on osteoporosis and fracture prevention in the Netherlands, COPD was included as a risk factor for vertebral fractures ${ }^{54}$.

\section{Pathology of osteoporosis}

Bone is constantly being remodelled. This remodelling is initiated on the bone surface, were lining cells respond to local and systemic cytokines and hormones. Bone remodelling is the result of the coordinate action of bone resorption by osteoclasts and bone formation by osteoblasts. Osteoclast differentiation is stimulated in interaction with the osteoblastic cells. In this interaction the receptor activator of nuclear factor kappa B (RANK) expressed by osteoclasts binds to its ligand (RANKL) expressed by osteoblast cells (figure 3). This RANK-RANKL binding promotes the differentiation and activity of osteoclasts. In the initial event of the signal transduction pathway induced by RANK the tumor necrosis factor Receptor-Associated Factor (TRAF) adaptor proteins play an important role. TRAF proteins may act by transmitting the RANK signal to downstream targets (including nuclear factor kappa B). Osteoblasts secrete osteoprotegerin (OPG) which binds to RANKL thus inhibiting the binding of RANK to RANKL ${ }^{55}$. Therefore, OPG acts as a natural decoy receptor. Indeed, OPG prevents bone loss in postmenopausal osteoporosis. The Wnt signalling pathway plays an important role in bone formation by activating osteoblasts ${ }^{56 ; 57}$. In the case of increased bone remodelling, the risk of fracture is increased due to multiple factors. Primarily, bone stiffness is reduced because more densely mineralized bone is replaced with younger less densely mineralised bone ${ }^{58}$. Secondly, fragility of bone is increased because of impaired maturation of collagen probably as an effect of altering the cross linking between adjacent collagen fibrils ${ }^{59}$. Finally, resorption sites remain temporarily naked, hereby predisposing the bone to microdamage due to stress concentrators. Calcium and vitamin D deficiency increase bone remodelling due to secondary hyperparathyroidism. 
Figure 3: Key mechanisms in the pathogenesis of osteoporosis in COPD

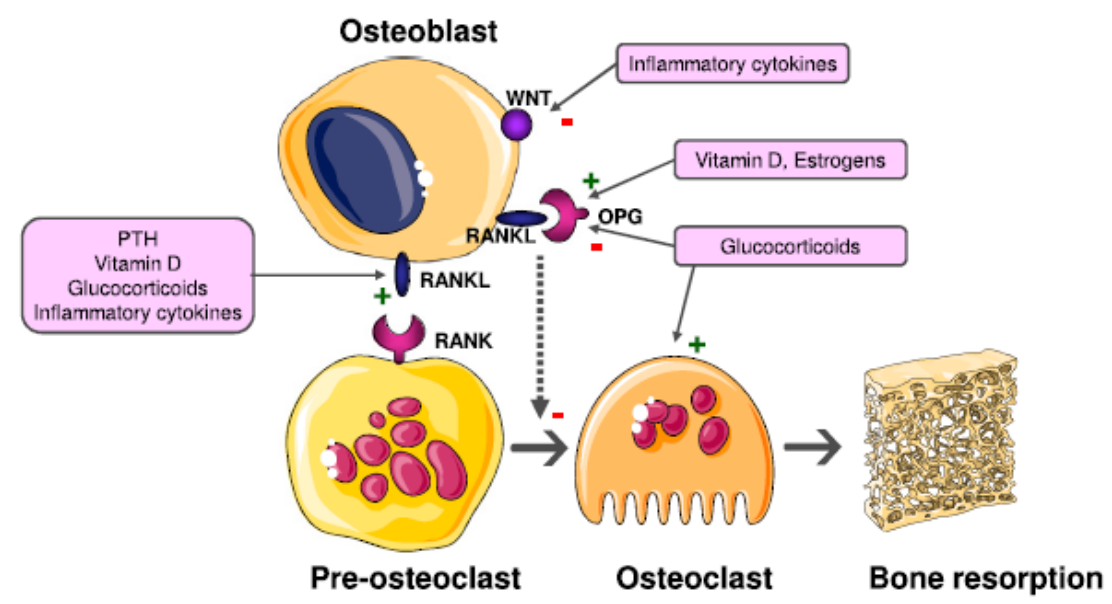

Adapted with permission from: Lehouck and colleagues, Chest 2011;139(3):648-657

\section{Osteoporosis and other chronic diseases}

The prevalence of osteoporosis has been found to be high in inflammatory bowel disease, sarcoidosis and $\mathrm{COPD}^{60-62}$. The common link in these diseases might be systemic inflammation. Indeed, chronic inflammatory diseases lead to the production of cytokines that stimulate bone turnover ${ }^{63}$. This increased bone turnover may increase bone fragility and hence may be associated with an increased fracture risk ${ }^{59}$. Indeed, Bon and colleagues found a significant correlation between Ctelopeptides of type I collagen (a marker of bone resorption) and interleukine-4 (IL-4) and tumor necrosis factor $\alpha$ (TNF- $\alpha$ ) in COPD patients $^{64}$. Moreover, they found a significant correlation between $\mathrm{N}$ terminal procollagen propeptide (a marker of bone formation) and both IL4 and TNF- $\alpha$. Another link could be physical inactivity due to the underlying disease, which in turn gives rise to a lower BMD. Another explanation could be that osteoporosis has the same risk factors as some chronic diseases e.g. smoking ${ }^{1: 45}$. Anyhow, the pathogenesis of osteoporosis in chronic diseases is complicated and not fully understood yet. 


\section{Osteoporosis and COPD}

The prevalence of osteoporosis is estimated to be 2 to 5 times higher in COPD patients as compared to healthy subjects ${ }^{39 ; 60}$. Indeed, in the third revision of the guideline on osteoporosis and fracture prevention COPD is marked as a disease associated with osteoporosis and should be included in the fracture risk assessment ${ }^{54}$.

Previously, this increased prevalence of osteoporosis in COPD was attributed to the use of corticosteroids ${ }^{65-67}$. However, also in corticosteroid naive COPD patients the prevalence of osteoporosis is high, suggesting a more complex underlying mechanism. Correlates of osteoporosis in COPD that have been found are measures of a low body composition $^{60 ; 68 ; 69}$ and measures of disease severity ${ }^{69-72}$. Most studies, however, used DXA-scan only to assess osteoporosis. Moreover, most studies are cross sectional. Recently, Hancock and colleagues found a significant relation between the ADAM-19 gene and $F E V_{1} / F V C C^{73}$. Previously, a relation between bone mineral density and the ADAM-19 gene was found ${ }^{74}$. Therefore, loci on the ADAM-19 gene could be responsible for COPD aswell as osteoporosis. However, there is still a great paucity in knowledge of osteoporosis in COPD.

The prevention of osteoporotic fractures and vertebral fractures particularly is important in COPD patients given the fact that hip fractures pose an increased operative risk in COPD patients as compared to healthy subjects ${ }^{75-77}$. In addition, vertebral fractures might result in a decreased forced vital capacity ${ }^{78}$. Therefore, an early treatment of osteoporosis seems reasonable to consider. This treatment should consist of lifestyle advises (eg physical weight baring physical exercise, smoking cessation, use of dairy products) and pharmacological treatment. The latter should consist bisphosphonates in combination with calcium and/or vitamin $\mathrm{D}^{45}$. To date, it remains unknown whether and to what extend osteoporotic COPD patients are treated with physician prescribed bone medication.

In summary, the prevalence of osteoporosis appears to be high in COPD patients when compared to healthy peers. Currently, the gold standard to assess osteoporosis non-invasively is DXA-scan. However, the preferred location to measure differs between organisations and national guidelines. In addition, DXA-scan alone might underestimate the prevalence of osteoporosis, because microarchitectural deterioration 
cannot be measured. At the start of the present project there existed only limited data regarding osteoporosis in well characterized COPD cohorts from pulmonary rehabilitation centres and pulmonary outpatient clinics of hospitals. Therefore, the prevalence and correlating factors of osteoporosis were unclear in these COPD patients. In addition, the best method to diagnose osteoporosis was not determined in COPD patients.

\section{Outline of the thesis}

The purpose of the present project was primarily to assess the current knowledge on osteoporosis in COPD patients in terms of prevalence and determining factors of this comorbidity in COPD. As well as to assess the outcome of different diagnostic procedures. Besides cross sectional studies the incidence of osteoporosis was assessed longitudinally in a 3year follow up study.

Chapter II describes the results of a systemic review of the literature guided by the following questions: What is the prevalence of osteoporosis in COPD? What are identified correlates of osteoporosis in COPD? What are the effects of treatment of osteoporosis in COPD?

Chapter III describes the result of a cross sectional study in COPD patients entering pulmonary rehabilitation. The prevalence, treatment and correlating factors for osteoporosis based on whole body DXA-scan were assessed.

In Chapter IV the best location to measure BMD in COPD patients was investigated by comparing whole body DXA-scan to local DXA-scan in COPD patients entering pulmonary rehabilitation.

In chapter $\mathrm{V}$ the results of a cross sectional study in COPD outpatients are described. Prevalence, treatment and correlating factors for osteoporosis based on both local DXA-scan and X-rays of the spine were assessed.

Chapter VI describes a case control study in GOLD II COPD patients. Cases (COPD patients with osteoporosis based on DXA-scan and Xspine) were compared to matched controls (COPD patients without osteoporosis) to assess correlating factors for osteoporosis in moderate COPD. 
Chapter VII describes the results of a 3 year follow up study in COPDoutpatients to assess the incidence of osteoporosis based on DXA-scan and X-spine after 3 years and to assess risk factors for osteoporosis in COPD.

Chapter VIII is the general discussion and conclusions section of this thesis. 


\section{Reference List}

(1) Rabe KF, Hurd S, Anzueto A, Barnes PJ, Buist SA, Calverley P et al. Global strategy for the diagnosis, management, and prevention of chronic obstructive pulmonary disease: GOLD executive summary. Am J Respir Crit Care Med 2007; 176(6):532-555.

(2) Lopez AD, Mathers CD, Ezzati M, Jamison DT, Murray CJ. Global and regional burden of disease and risk factors, 2001: systematic analysis of population health data. Lancet 2006; 367(9524):1747-1757.

(3) Murray CJ, Lopez AD. Global mortality, disability, and the contribution of risk factors: Global Burden of Disease Study. Lancet 1997; 349(9063):1436-1442.

(4) Hoeymans N., Gommer A.M., Poos M.J.J.C. Wat is de ziektelast in Nederland? http://www nationaalkompas nl [ 2010 [cited 2010 Aug. 16];

(5) Landelijke LMR-informatie. http://www prismant nl [ 2010

(6) Nederlandse longstichting. Longziekten Feiten en Cijfers 2008. 2008.

(7) Hoogendoorn M, van Wetering CR, Schols AM, Rutten-van Molken M.P.M.H., $\square$ Is INTERdisciplinary COMmunity-based COPD management (INTERCOM) cost-effective? Eur Respir J 2010; 35:79-87.

(8) Mannino DM, Kiriz VA. Changing the burden of COPD mortality. Int J Chron Obstruct Pulmon Dis 2006; 1(3):219-233.

(9) McGarvey LP, John M, Anderson JA, Zvarich M, Wise RA. Ascertainment of cause-specific mortality in COPD: operations of the TORCH Clinical Endpoint Committee. Thorax 2007; 62(5):411-415.

(10) Pitta F, Troosters T, Spruit MA, Probst VS, Decramer M, Gosselink R. Characteristics of physical activities in daily life in chronic obstructive pulmonary disease. Am J Respir Crit Care Med 2005; 171(9):972-977.

(11) Janssen DJ, Spruit MA, Leue C, Gijsen C, Hameleers H, Schols JM et al. Symptoms of anxiety and depression in COPD patients entering pulmonary rehabilitation. Chron Respir Dis 2010; 7(3):147-157.

(12) Maurer J, Rebbapragada V, Borson S, Goldstein R, Kunik ME, Yohannes AM et al. Anxiety and depression in COPD: current understanding, unanswered questions, and research needs. Chest 2008; 134(4 Suppl):43S-56S.

(13) Lundback B, Lindberg A, Lindstrom M, Ronmark E, Jonsson AC, Jonsson E et al. Not 15 but $50 \%$ of smokers develop COPD?--Report from the Obstructive Lung Disease in Northern Sweden Studies. Respir Med 2003; 97(2):115-122.

(14) Salvi SS, Barnes PJ. Chronic obstructive pulmonary disease in non-smokers. Lancet 2009; 374(9691):733-743. 
(15) Silverman EK, Palmer LJ, Mosley JD, Barth M, Senter JM, Brown A et al. Genomewide linkage analysis of quantitative spirometric phenotypes in severe early-onset chronic obstructive pulmonary disease. Am J Hum Genet 2002; 70(5):1229-1239.

(16) Wedzicha JA, Seemungal TA. COPD exacerbations: defining their cause and prevention. Lancet 2007; 370(9589):786-796.

(17) Hogg JC, Chu F, Utokaparch S, Woods R, Elliott WM, Buzatu L et al. The nature of small-airway obstruction in chronic obstructive pulmonary disease. $\mathrm{N}$ Engl J Med 2004; 350(26):2645-2653.

(18) Saetta M, Turato G, Maestrelli P, Mapp CE, Fabbri LM. Cellular and structural bases of chronic obstructive pulmonary disease. Am J Respir Crit Care Med 2001; 163(6):1304-1309.

(19) Grashoff WF, Sont JK, Sterk PJ, Hiemstra PS, de Boer WI, Stolk J et al. Chronic obstructive pulmonary disease: role of bronchiolar mast cells and macrophages. Am J Pathol 1997; 151(6):1785-1790.

(20) Kranenburg AR, Willems-Widyastuti A, Moori WJ, Sterk PJ, Alagappan VK, de Boer WI et al. Enhanced bronchial expression of extracellular matrix proteins in chronic obstructive pulmonary disease. Am J Clin Pathol 2006; 126(5):725735.

(21) Cosio MG, Hale KA, Niewoehner DE. Morphologic and morphometric effects of prolonged cigarette smoking on the small airways. Am Rev Respir Dis 1980; 122(2):265-21.

(22) Saetta M, Di SA, Turato G, Facchini FM, Corbino L, Mapp CE et al. CD8+ Tlymphocytes in peripheral airways of smokers with chronic obstructive pulmonary disease. Am J Respir Crit Care Med 1998; 157(3 Pt 1):822-826.

(23) Barnes PJ. Alveolar macrophages as orchestrators of COPD. COPD 2004; 1(1):59-70.

(24) Stockley RA. Neutrophils and the pathogenesis of COPD. Chest 2002; 121(5 Suppl):151S-155S.

(25) Demedts IK, Bracke KR, Van PG, Testelmans D, Verleden GM, Vermassen FE et al. Accumulation of dendritic cells and increased CCL20 levels in the airways of patients with chronic obstructive pulmonary disease. Am J Respir Crit Care Med 2007; 175(10):998-1005.

(26) Kelsen SG, Aksoy MO, Georgy M, Hershman R, Ji R, Li X et al. Lymphoid follicle cells in chronic obstructive pulmonary disease overexpress the chemokine receptor CXCR3. Am J Respir Crit Care Med 2009; 179(9):799805.

(27) Saetta M, Baraldo S, Corbino L, Turato G, Braccioni F, Rea F et al. CD8+ve cells in the lungs of smokers with chronic obstructive pulmonary disease. Am J Respir Crit Care Med 1999; 160(2):711-717. 
(28) Cosio MG, Saetta M, Agusti A. Immunologic aspects of chronic obstructive pulmonary disease. N Engl J Med 2009; 360(23):2445-2454.

(29) Polverino F, Baraldo S, Bazzan E, Agostini S, Turato G, Lunardi F et al. A novel insight into adaptive immunity in chronic obstructive pulmonary disease: $B$ cell activating factor belonging to the tumor necrosis factor family. Am J Respir Crit Care Med 2010; 182(8):1011-1019.

(30) Wouters EF, Reynaert NL, Dentener MA, Vernooy JH. Systemic and local inflammation in asthma and chronic obstructive pulmonary disease: is there a connection? Proc Am Thorac Soc 2009; 6(8):638-647.

(31) Han MK, Agusti A, Calverley PM, Celli BR, Criner G, Curtis JL et al. Chronic obstructive pulmonary disease phenotypes: the future of COPD. Am J Respir Crit Care Med 2010; 182(5):598-604.

(32) Agusti A, Calverley PM, Celli B, Coxson HO, Edwards LD, Lomas DA et al. Characterisation of COPD heterogeneity in the ECLIPSE cohort. Respir Res 2010; 11:122.

(33) Decramer M, Rennard S, Troosters T, Mapel DW, Giardino N, Mannino D et al. COPD as a lung disease with systemic consequences--clinical impact, mechanisms, and potential for early intervention. COPD 2008; 5(4):235-256.

(34) Mapel DW, Hurley JS, Frost FJ, Petersen HV, Picchi MA, Coultas DB. Health care utilization in chronic obstructive pulmonary disease. A case-control study in a health maintenance organization. Arch Intern Med 2000; 160(17):26532658.

(35) Di MF, Verga M, Reggente M, Maria CF, Santus P, Blasi F et al. Anxiety and depression in COPD patients: The roles of gender and disease severity. Respir Med 2006; 100(10):1767-1774.

(36) Yohannes AM, Baldwin RC, Connolly MJ. Depression and anxiety in elderly patients with chronic obstructive pulmonary disease. Age Ageing 2006; 35(5):457-459.

(37) Marquis K, Maltais F, Duguay V, Bezeau AM, LeBlanc P, Jobin J et al. The metabolic syndrome in patients with chronic obstructive pulmonary disease. $\mathrm{J}$ Cardiopulm Rehabil 2005; 25(4):226-232.

(38) Schols AM, Broekhuizen R, Weling-Scheepers CA, Wouters EF. Body composition and mortality in chronic obstructive pulmonary disease. Am J Clin Nutr 2005; 82(1):53-59.

(39) Sabit R, Bolton CE, Edwards PH, Pettit RJ, Evans WD, McEniery CM et al. Arterial stiffness and osteoporosis in chronic obstructive pulmonary disease. Am J Respir Crit Care Med 2007; 175(12):1259-1265.

(40) Biskobing DM. COPD and osteoporosis. Chest 2002; 121(2):609-620. 
(41) Crisafulli E, Gorgone P, Vagaggini B, Pagani M, Rossi G, Costa F et al. Efficacy of standard rehabilitation in COPD outpatients with co-morbidities. Eur Respir J 2010.

(42) Mannino DM, Thorn D, Swensen A, Holguin F. Prevalence and outcomes of diabetes, hypertension and cardiovascular disease in COPD. Eur Respir J 2008; 32:962-969.

(43) Lomas DA, Silverman EK, Edwards LD, Locantore NW, Miller BE, Horstman $\mathrm{DH}$ et al. Serum surfactant protein $\mathrm{D}$ is steroid sensitive and associated with exacerbations of COPD. Eur Respir J 2009; 34(1):95-102.

(44) Sin DD, Leung R, Gan WQ, Man SP. Circulating surfactant protein D as a potential lung-specific biomarker of health outcomes in COPD: a pilot study. BMC Pulm Med 2007; 7:13.

(45) WHO Scientific Group on the Prevention and Management of Osteoporosis. Prevention and Management of Osteoporosis: report of a WHO scientific group. http;//whqlibdoc who int/trs/WHO_TRS_921 pdf [ 2007

(46) Marshall D, Johnell O, Wedel H. Meta-analysis of how well measures of bone mineral density predict occurrence of osteoporotic fractures. BMJ 1996; 312(7041):1254-1259.

(47) 2007 official positions of The International Society For Clinical Densitometry. 2008. 10-7-2008.

Ref Type: Internet Communication

(48) Boyanov M. Estimation of lumbar spine bone mineral density by dual-energy Xray absorptiometry: standard anteroposterior scans vs sub-regional analyses of whole-body scans. Br J Radiol 2008; 81(968):637-642.

(49) Genant HK, Wu CY, van KC, Nevitt MC. Vertebral fracture assessment using a semiquantitative technique. J Bone Miner Res 1993; 8(9):1137-1148.

(50) Cummings SR, Nevitt MC, Browner WS, Stone K, Fox KM, Ensrud KE et al. Risk factors for hip fracture in white women. Study of Osteoporotic Fractures Research Group. N Engl J Med 1995; 332(12):767-773.

(51) Schuit SC, van der KM, Weel AE, de Laet CE, Burger H, Seeman E et al. Fracture incidence and association with bone mineral density in elderly men and women: the Rotterdam Study. Bone 2004; 34(1):195-202.

(52) Siris ES, Brenneman SK, Miller PD, Barrett-Connor E, Chen YT, Sherwood LM et al. Predictive value of low BMD for 1-year fracture outcomes is similar for postmenopausal women ages 50-64 and 65 and Older: results from the National Osteoporosis Risk Assessment (NORA). J Bone Miner Res 2004; 19(8):1215-1220.

(53) Melton LJ, III, Therneau TM, Larson DR. Long-term trends in hip fracture prevalence: the influence of hip fracture incidence and survival. Osteoporos Int 1998; 8(1):68-74. 
(54) CBO Richtlijn Osteoporose en Fractuur Preventie. Derde herziening (2011). http://www.cbo.nl/Downloads/1318/Definitieve\%20richtlijn\%20osteoporose\%20 28-04-2011 pdf [ 2011]

(55) Chavassieux P, Seeman E, Delmas PD. Insights into material and sttructural basis of bone fragility from diseases associated with fractures. How determinants of the biomechanical properties of bone are compromised by disease. Endocr Rev 2007; 28:151-164.

(56) Hardy R, Cooper MS. Bone loss in inflammatory disorders. J Endocrinol 2009; 201(3):309-320.

(57) Patel MS, Karsenty G. Regulation of bone formation and vision by LRP5. N Engl J Med 2002; 346(20):1572-1574.

(58) Boivin G, Lips P, Ott SM, Harper KD, Sarkar S, Pinette KV et al. Contribution of raloxifene and calcium and vitamin D3 supplementation to the increase of the degree of mineralization of bone in postmenopausal women. J Clin Endocrinol Metab 2003; 88(9):4199-4205.

(59) Viguet-Carrin S, Garnero P, Delmas PD. The role of collagen in bone strength. Osteoporos Int 2006; 17(3):319-336.

(60) Bolton CE, Ionescu AA, Shiels KM, Pettit RJ, Edwards PH, Stone MD et al. Associated loss of fat-free mass and bone mineral density in chronic obstructive pulmonary disease. Am J Respir Crit Care Med 2004; 170(12):1286-1293.

(61) Heijckmann AC, Huijberts MS, de VJ, Menheere PP, van d, V, Kruseman AC et al. Bone turnover and hip bone mineral density in patients with sarcoidosis. Sarcoidosis Vasc Diffuse Lung Dis 2007; 24(1):51-58.

(62) Heijckmann AC, Huijberts MS, Schoon EJ, Geusens P, de VJ, Menheere PP et al. High prevalence of morphometric vertebral deformities in patients with inflammatory bowel disease. Eur J Gastroenterol Hepatol 2008; 20(8):740-747.

(63) Hofbauer LC, Schoppet M. Clinical implications of the osteoprotegerin/RANKL/RANK system for bone and vascular diseases. JAMA 2004; 292(4):490-495.

(64) Bon JM, Zhang Y, Duncan SR, Pilewski JM, Zaldonis D, Zeevi A et al. Plasma inflammatory mediators associated with bone metabolism in COPD. J Cron Obstruct Pulmon Dis 2010; 7:186-191.

(65) Dubois EF, Roder E, Dekhuijzen PN, Zwinderman AE, Schweitzer DH. Dual energy X-ray absorptiometry outcomes in male COPD patients after treatment with different glucocorticoid regimens. Chest 2002; 121(5):1456-1463.

(66) Gluck O, Colice G. Recognizing and treating glucocorticoid-induced osteoporosis in patients with pulmonary diseases. Chest 2004; 125(5):18591876. 
(67) Goldstein MF, Fallon JJ, Jr., Harning R. Chronic glucocorticoid therapy-induced osteoporosis in patients with obstructive lung disease. Chest 1999; 116(6):1733-1749.

(68) Incalzi RA, Caradonna P, Ranieri P, Basso S, Fuso L, Pagano F et al. Correlates of osteoporosis in chronic obstructive pulmonary disease. Respir Med 2000; 94(11):1079-1084.

(69) Vrieze A, de Greef MH, Wijkstra PJ, Wempe JB. Low bone mineral density in COPD patients related to worse lung function, low weight and decreased fatfree mass. Osteoporos Int 2007; 18(9):1197-1202.

(70) Bikle DD, Halloran B, Fong L, Steinbach L, Shellito J. Elevated 1,25dihydroxyvitamin $\mathrm{D}$ levels in patients with chronic obstructive pulmonary disease treated with prednisone. J Clin Endocrinol Metab 1993; 76(2):456-461.

(71) Dimai HP, Domej W, Leb G, Lau KH. Bone loss in patients with untreated chronic obstructive pulmonary disease is mediated by an increase in bone resorption associated with hypercapnia. J Bone Miner Res 2001; 16(11):21322141.

(72) Kjensli A, Mowinckel P, Ryg MS, Falch JA. Low bone mineral density is related to severity of chronic obstructive pulmonary disease. Bone 2007; 40(2):493497.

(73) Hancock DB, Eijgelsheim M, Wilk JB, Gharib SA, Loehr LR, Marciante KD et al. Meta-analyses of genome-wide association studies identify multiple loci associated with pulmonary function. Nat Genet 2010; 42(1):45-52.

(74) Styrkarsdottir U, Halldorsson BV, Gretarsdottir S, Gudbjartsson DF, Walters GB, Ingvarsson T et al. New sequence variants associated with bone mineral density. Nat Genet 2009; 41(1):15-17.

(75) Bapoje SR, Whitaker JF, Schulz T, Chu ES, Albert RK. Preoperative evaluation of the patient with pulmonary disease. Chest 2007; 132(5):1637-1645.

(76) Smetana GW. Preoperative pulmonary evaluation. N Engl J Med 1999; 340(12):937-944.

(77) Trayner E Jr, Celli BR. Postoperative pulmonary complications. Med Clin North Am 2001; 85(5):1129-1139.

(78) Leech JA, Dulberg C, Kellie S, Pattee L, Gay J. Relationship of lung function to severity of osteoporosis in women. Am Rev Respir Dis 1990; 141(1):68-71 
Chapter I 


\section{Chapter II}

\section{Current status of research on osteoporosis in COPD: A systematic review}

Lidwien Graat-Verboom, Emiel F.M. Wouters, Frank W.J.M. Smeenk, Ben. E.E.M. van den Borne,

Ragnar Lunde and Martijn A. Spruit

European Respiratory Journal 2009;34:209-218 


\begin{abstract}
Patients with chronic obstructive pulmonary disease (COPD) are at increased risk of osteoporosis. However, the prevalence, correlates and effectiveness of treatment of osteoporosis in COPD patients remain unclear.
\end{abstract}

We performed a systematic review of the literature to answer three uestions: 1) What is the prevalence of osteoporosis in COPD? 2) What are identified correlates of osteoporosis in COPD? 3) What are the effects of treatment of osteoporosis in COPD? A computerized literature search in MEDLINE/PubMed and the Cochrane database carried out. In addition, reference lists were searched by hand and authors were contacted if necessary.

The prevalence of osteoporosis and osteopenia varied $9-69 \%$ and $27-$ $67 \%$, respectively. Prevalence of osteoporosis was generally higher than in healthy subjects and to some other chronic lung diseases. Correlates of osteoporosis in COPD are mainly measures of body composition, disease severity and the use of corticosteroids, although causality has not been proven. Effects of treatment of osteoporosis have not been investigated in samples consisting of COPD patients only.

Longitudinal follow-up to assess determinants of osteoporosis in COPD and randomized placebo-controlled trials on the effects of treatment of osteoporosis in patients with COPD only are warranted. 


\section{Introduction}

Chronic obstructive pulmonary disease (COPD) is characterized by a progressive airflow limitation that is not fully reversible and is associated with an abnormal inflammatory response of the lung to noxious particles and gases ${ }^{1}$. The degree of airflow limitation can be assessed by spirometry and stratified in accordance with the Global Initiative for Chronic Obstructive Pulmonary Disease (GOLD) ${ }^{1}$. Although primarily a pulmonary disease, there are significant extrapulmonary effects in COPD $2-5$. Indeed, the GOLD guidelines incorporated these extra pulmonary effects in their definition of COPD ${ }^{1}$. Examples of extrapulmonary effects are increased arterial stiffness ${ }^{3}$, skeletal muscle atrophy ${ }^{4}$, systemic hypertension ${ }^{6}$ and osteoporosis ${ }^{7}$.

Osteoporosis is a systemic skeletal disease characterized by a low bone mass and/or microarchitectural deterioration of bone tissue leading to increased bone fragility and increased fracture risk ${ }^{8}$. Known risk factors for osteoporosis in the general population are, amongst others, female sex, advanced age, low body weight, chronic glucocorticoid therapy and endocrinological disorders like hyperthyroidism and primary hyperparathyroidism ${ }^{8-11}$. In COPD, the prevalence of osteoporosis is assumed to be two- to five-fold higher than in age-matched subjects without airflow obstruction ${ }^{3 ; 12}$. Indeed, in a recently developed screening tool for males at risk for osteoporosis, the presence of COPD is one of the parameters increasing this risk almost four times ${ }^{13}$.

The burden of osteoporosis varies with the incidence of fractures risk ${ }^{8}$. Fractures of the hip, vertebrae and forearm are the most common fractures in patients with osteoporosis, although fractures of other body parts can also be the result of osteoporosis ${ }^{8}$. The treatment of osteoporosis aims at fracture prevention and, according to the World Health Organization (WHO), should consist of lifestyle modification (such as smoking cessation, weight-bearing physical exercise and adequate calcium intake) and drug treatment ${ }^{8}$. The latter should consist of bisphosphonates, calcium supplementation (in the case of low dietary intake) and vitamin D supplementation (in the case of vitamin D deficiency). Especially in COPD patients it is important to prevent vertebral fractures since they might result in a decreased forced vital capacity ${ }^{14}$. In addition, (osteoporotic) hip fractures in COPD patients 
pose a greater problem than hip fractures in otherwise healthy subjects because of the increased operative risk in COPD patients ${ }^{15-17}$.

The aim of this article was to perform a systematic review of the literature in order to answer the following questions. 1) What is the prevalence of osteoporosis in COPD? 2) What are identified correlates of osteoporosis in COPD? 3) What are the effects of treatment of osteoporosis in COPD?

\section{Methods}

A computerized literature search of the MEDLINE/PubMed and the Cochrane databases was performed. The time span was January 1988 to April 2008. For each question two groups of keywords were used to search for relevant articles.

To determine the prevalence of osteoporosis in COPD the keywords were: 1) COPD, chronic obstructive pulmonary disease, emphysema, chronic bronchitis; 2) osteoporosis, osteopenia, dual-energy X-ray absorptiometry (DXA) scan, bone mineral density, prevalence of osteoporosis, prevalence of osteopenia

To identify correlates of osteoporosis in COPD the keywords were: 1) COPD, chronic obstructive pulmonary disease, emphysema, chronic bronchitis; 2) osteoporosis, osteopenia, risk factors for osteoporosis, determining factors for osteoporosis, screening for osteoporosis

Finally, to determine the effects of treatment of osteoporosis in COPD the keywords were: 1) COPD, chronic obstructive pulmonary disease, emphysema, chronic bronchitis; 2) treatment of osteoporosis, lifestyle interventions in osteoporosis, bisphosphonates, calcium supplementation, vitamin $\mathrm{D}$.

For each of the three searches, keywords from group 1 were combined with the keywords from group 2 by "AND". Within each group, the keywords were combined using "OR". In addition, reference lists of the identified articles were searched by hand in order to find relevant articles that were missed in the initial search strategy. 


\section{Article selection}

Non-English articles were excluded. In addition, we excluded review articles, although we did search their reference lists by hand for relevant articles. Finally, editorials, congress abstracts and case reports were not included.

\section{Prevalence of osteoporosis in COPD}

Only studies that enrolled COPD patients or where COPD patients could be isolated from the studied sample (in case of inclusion of patients with other diseases besides COPD) were included. One of the outcomes had to be the prevalence of osteoporosis based on bone mineral density (BMD) measurements, thereby excluding studies with a prevalence of osteoporosis based on (osteoporotic) fractures. Moreover, a definition of osteoporosis had to be given by the authors. Cross-sectional, longitudinal and intervention trials were included. When the prevalence of osteoporosis was given per site only (e.g. hip or lumbar spine), we contacted the authors by e-mail to ask for the prevalence of the combined sites (i.e. if one of the sites was diagnosed as osteoporosis than the patient was defined as having osteoporosis). We determined the overall mean prevalence of osteoporosis in 13 identified studies (see online supplementary material).

\section{Correlates of osteoporosis in COPD}

Only studies investigating correlates of osteoporosis in COPD patients, or where COPD patients could be isolated from studied samples (in the case of inclusion of patients with other diseases besides COPD) were included. Correlation and/or regression analysis had to be carried out by searching for clinical outcomes associated with osteoporosis or BMD (thereby excluding studies with fractures as primary end-points). Crosssectional, longitudinal and intervention trials were included. 


\section{Treatment of osteoporosis in COPD}

Again, only studies were the results for COPD patients could be isolated from other groups of patients were included. In addition, only randomized placebo-controlled trials studying the effects of lifestyle-interventions (e.g. more weight-bearing exercise, smoking cessation) and/or "osteoporosis medication" (e.g. bisphosphonates, calcium supplementation, vitamin D) were included.

To assess the methodological quality of identified trials, the Delphi list was used ${ }^{18}$. The Delphi list is a comprehensive criteria list for quality assessment of randomized controlled trials (RCTs) for conducting systematic reviews. It consists of 9 items all having a "yes", "no" or "don't know" answer. If bias was unlikely, the criterion was rated positive ("yes"). In cases where information was lacking or insufficient and/or if bias was likely, the criterion was rated negative ("no" or "don't know", respectively). All "yes" scores ( 1 point per "yes") were summed to produce an overall quality score.

\section{Results}

\section{Prevalence of osteoporosis in COPD}

The search resulted in 240 articles. Of these 42 articles were not in the English language, 48 were review articles and six were editorials or letters. Another 94 articles were excluded because they were about other topics (clear from the abstracts only). After reading the remaining articles, another 36 were excluded: 12 because COPD patients could not be isolated from other groups under investigation and 24 because they were about other topics. One article was excluded because a subgroup of patients used in a previous paper was investigated (see online supplement). Finally, 13 studies with a total of 775 COPD patients were included. In total, there were more male patients (67 versus $33 \%, n=759$ ). Moreover, patients had a mean \pm SD age (if reported) was $63.4 \pm 5.2$ years $(n=775)$, a forced expiratory volume in $1 \mathrm{~s}$ (FEV1) of $46.7 \pm 13.5 \%$ predicted $(n=514)$, a body mass index (BMI) of $24.9 \pm 2.3 \mathrm{~kg} / \mathrm{m}^{2}(\mathrm{n}=721)$ and a fat-free mass index (FFMI) of $16.7 \pm 0.9 \mathrm{~kg} / \mathrm{m}^{2}$ ( $\mathrm{n}=311$ ) (table 1). 
The prevalence of osteoporosis varies from 9 to $69 \%$ depending on the patients under study, the method used to assess BMD and the definition used to define osteoporosis (table 1). The overall mean prevalence of osteoporosis for the 13 identified studies was $35.1 \%$ (272 of 775 patients). Patients with osteoporosis consisted of a higher proportion of women. In addition, FEV1 (\% pred), BMI and FFMI were lower in the osteoporotic COPD patients (table 2).

Univariate binary logistic regression analysis showed that females had an odds ratio $(\mathrm{OR})$ of 1.968 for osteoporosis $(p<0.001)$. A lower FEV1, BMI and FFMI increased the OR of osteoporosis, while age had no significant influence on osteoporosis in COPD (see online supplementary material, table E1).

Eight studies determined the prevalence of osteopenia, which varies 27$67 \%$, resulting in an overall mean prevalence of osteopenia of $38.4 \%$ in COPD (table 1).

Four studies included an age-matched control group of healthy subjects $3 ; 12 ; 19 ; 20$. The prevalence of osteoporosis in COPD was increased compared with the healthy subjects in three trials (overall mean prevalence of osteoporosis of $31.7 \%$ in COPD versus $5.8 \%$ in healthy subjects, $p<0.001)^{3 ; 12 ; 19}$. However, Karadag et al. ${ }^{20}$ did not find a significant difference in prevalence of osteoporosis between COPD patients and healthy subjects (figure 1). Nevertheless, the significant difference in the prevalence of osteoporosis between COPD patients and healthy subjects still remained after analyses of the four trials together: 32.5 versus $11.4 \%$, respectively, $p<0.001$.

\section{Correlates of osteoporosis in COPD}

In total, 207articles were found. Of these, 43 were not in the English language, 45 were review articles and three were editorials, comments or letters. In addition, eight articles were excluded because COPD could not be isolated from other patient groups, 92 because they were not about the topic and another four based on their statistical methods (no correlation and/or regression analysis performed). Twelve studies were included for this review.

Correlates of osteoporosis and/or (a low) BMD in COPD identified in mainly cross-sectional studies were body composition measures ${ }^{12 ; 22 ; 24-}$ 
26;28;30;31, measures of disease severity ${ }^{19 ; 22 ; 31 ; 32}$ and corticosteroids $25 ; 31$ (table 3). In addition, two longitudinal studies investigating change in BMD were identified (table 3). Scanlon et al. found inhaled corticosteroids to be a risk factor for decreasing BMD at both femoral neck and lumbar spine ${ }^{33}$. In addition, they found an age of $>56$ yrs to be a predictor for decreasing BMD at the femoral neck, while >65 yrs of age and female sex to be predictors for decreasing BMD at the lumbar spine (table 3). Mineo et al. investigated COPD patients before and after lung volume 
Table 1: Prevalence of Osteoporosis and Osteopenia in patients with chronic obstructive pulmonary disease (COPD)

\begin{tabular}{|c|c|c|c|c|c|c|c|c|c|c|}
\hline First author ${ }^{\text {ref }}$ & $\begin{array}{l}\text { Setting/patient group } \\
\text { selection }\end{array}$ & $\mathbf{N}$ & $\begin{array}{l}\text { Age } \\
\text { yrs }\end{array}$ & $\begin{array}{l}\text { Sex } \\
M / F \text { n }\end{array}$ & $\begin{array}{l}\text { FEV }_{1} \\
\% \text { pred }^{\#}\end{array}$ & $\begin{array}{l}\mathrm{BMI} \\
\mathrm{kg} / \mathrm{m}^{2}\end{array}$ & $\begin{array}{l}\mathrm{FFMI} \\
\mathrm{kg} / \mathrm{m}^{2}\end{array}$ & $\begin{array}{l}\text { BMD measurement/ } \\
\text { interpretation }\end{array}$ & Osteopenia & Osteoporosis \\
\hline Førli $^{21}$ & $\begin{array}{l}\text { Patients with advanced } \\
\text { pulmonary disease } \\
\text { considered for lung trans- } \\
\text { plantation and referred to } \\
\text { the Dept of Thoracic } \\
\text { Medicine, Rikshospitalet, } \\
\text { Oslo, Norway }\end{array}$ & 40 & 52 & $19 / 21$ & 19 & 19.0 & 14.8 & $\begin{array}{l}\text { BMD at LS and FN by } \\
\text { DXA; T-scores. } \\
\text { Interpretation } \\
\text { according to WHO. }\end{array}$ & $\begin{array}{l}\text { LS 33\% } \\
\text { FN } 45 \% \\
\text { LS and FN } \\
\text { combined: } \\
38 \%\end{array}$ & $\begin{array}{l}\text { LS: } 48 \% \\
\text { FN: } 48 \% \\
\text { LS and FN } \\
\text { combined: } \\
59 \%\end{array}$ \\
\hline Sabit $^{3}$ & Not specified, UK & 75 & 65 & $42 / 33$ & 56.7 & 27.6 & 17.5 & $\begin{array}{l}\text { BMD at lumbar spine } \\
\text { and hip by DXA; } \\
\text { T-scores. } \\
\text { Interpretation } \\
\text { according to WHO. }\end{array}$ & Not reported & $24 \%$ \\
\hline Vrieze $^{22}$ & $\begin{array}{l}\text { Rehabilitation Centre of } \\
\text { the University Medical } \\
\text { Centre Groningen, } \\
\text { Groningen, the } \\
\text { Netherlands }\end{array}$ & 115 & 60 & $62 / 53$ & 43.4 & 26.4 & 17.3 & $\begin{array}{l}\text { Calcaneal QUS; T- } \\
\text { scores. Interpretation } \\
\text { of T-scores according } \\
\text { to WHO. }\end{array}$ & $40.9 \%$ & $8.7 \%$ \\
\hline Jørgensen ${ }^{23}$ & $\begin{array}{l}\text { Respiratory outpatient } \\
\text { clinic at H:S Bispebjerg } \\
\text { Hospital }\end{array}$ & 54 & 63 & $14 / 40^{\| \prime}$ & 32.1 & NA & NA & $\begin{array}{l}\text { BMD LS and FN; T- } \\
\text { scores. Interpretation } \\
\text { according to WHO. }\end{array}$ & $29.6 \%$ & $40.7 \%$ \\
\hline Mineo $^{24}$ & $\begin{array}{l}\text { Patients selected for lung } \\
\text { volume reduction surgery. }\end{array}$ & 70 & 61 & $\begin{array}{l}\text { Males } \\
\text { only }\end{array}$ & $1.06 \mathrm{~L}$ & 22.9 & NA & $\begin{array}{l}\text { BMD total body, LS } \\
\text { and left hip by DXA; T- } \\
\text { scores. Interpretation } \\
\text { according to WHO. }\end{array}$ & $35 \%$ & $49 \%$ \\
\hline Bolton $^{12}$ & $\begin{array}{l}\text { Primary care and } \\
\text { respiratory outpatients } \\
\text { before pulmonary } \\
\text { rehabilitation. }\end{array}$ & 81 & 66 & $43 / 38$ & 44 & 24.0 & 16.2 & $\begin{array}{l}\text { BMD total body, LS } \\
\text { and hip by DXA; T- } \\
\text { scores. Interpretation } \\
\text { according to WHO. }\end{array}$ & $\begin{array}{l}\text { LS: } 38 \% \\
\text { Hip: } 52 \%\end{array}$ & $\begin{array}{l}\text { LS: } 27 \% \\
\text { Hip: } 20 \% \\
\text { LS and hip } \\
\text { combined: }\end{array}$ \\
\hline
\end{tabular}




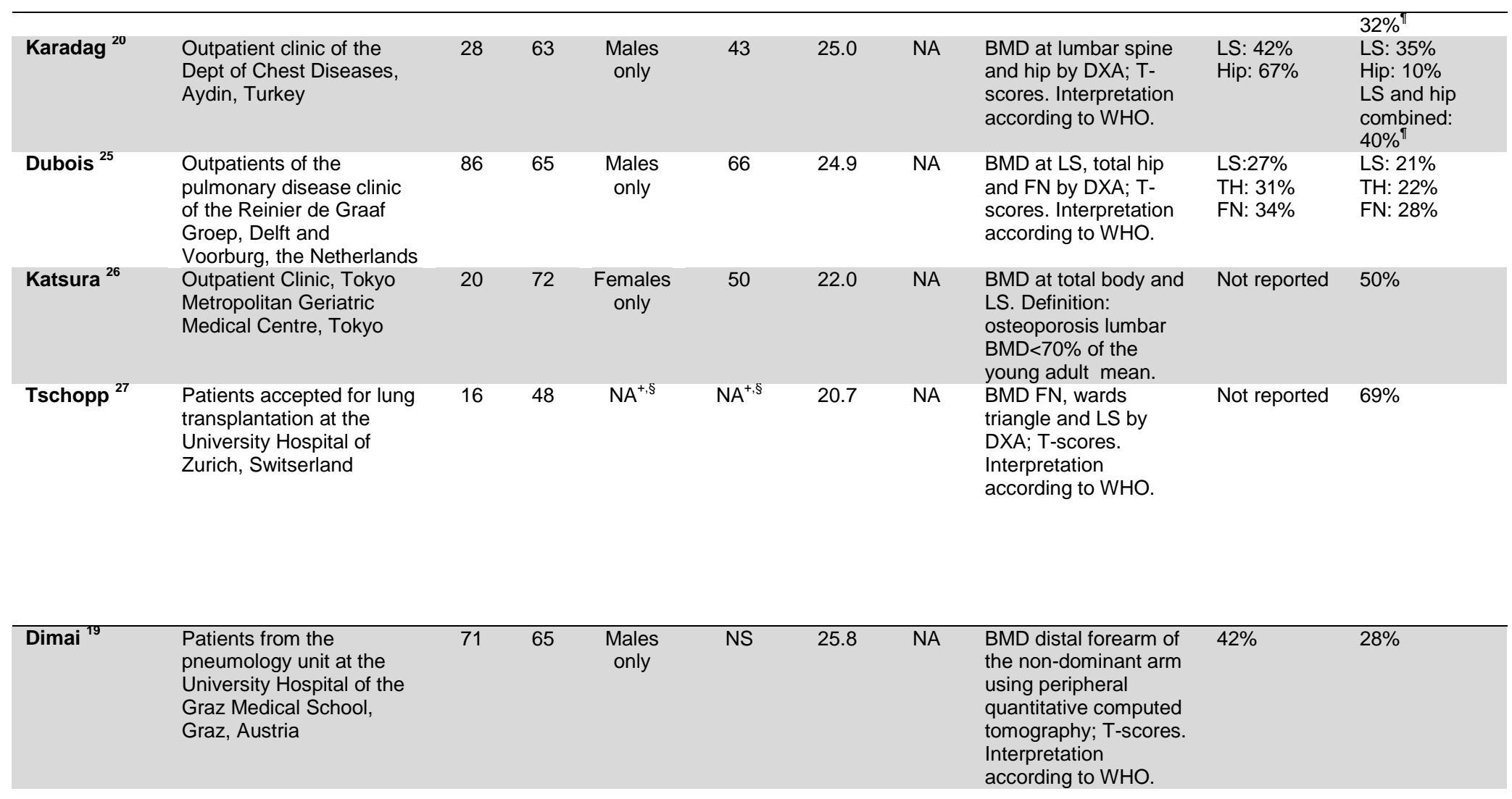




\begin{tabular}{|c|c|c|c|c|c|c|c|c|c|c|}
\hline Incalzi ${ }^{28}$ & $\begin{array}{l}\text { Patients admitted to the } \\
\text { respiratory ward of the } \\
\text { University Hospital Rome, } \\
\text { Rome, Italy, for an } \\
\text { exacerbation of COPD. } \\
\text { Studied after resolution of } \\
\text { their acute exacerbation. }\end{array}$ & 104 & 71 & $68 / 36$ & NS & 26.3 & NA & $\begin{array}{l}\text { BMD LS and FN by } \\
\text { DXA; T-scores. } \\
\text { Interpretation } \\
\text { according to WHO. }\end{array}$ & $\begin{array}{l}\text { Not } \\
\text { assessed }\end{array}$ & $60 \%$ \\
\hline Aris ${ }^{29}$ & $\begin{array}{l}\text { Patients on the waiting list } \\
\text { for lung transplantation } \\
\text { and went to the University } \\
\text { of North Carolina, Chapel } \\
\text { Hill, NC, USA, for } \\
\text { evaluation; and post } \\
\text { transplantation patients } \\
\text { who came to University of } \\
\text { North Carolina, for follow- } \\
\text { up }\end{array}$ & 15 & $53^{\natural 1}$ & $7 / 8^{\|}$ & $23 \% "$ & $22^{\prime \prime}$ & NA & $\begin{array}{l}\text { BMD LS, non- } \\
\text { dominant FN and total } \\
\text { body. Interpretation } \\
\text { according to } \mathrm{WHO}^{\#} \text {. }\end{array}$ & $\begin{array}{l}\text { Not } \\
\text { assessed }\end{array}$ & $40 \%$ \\
\hline
\end{tabular}

M: male; F: female; FEV1: forced expiratory volume in $1 \mathrm{~s} ; \%$ pred: \% predicted; BMI: body mass index; FFMI: fat free mass index; BMD: bone mineral density; LS: lumbar spine; FN: femoral neck; DXA: dual-energy absorptiometry; WHO: World Health Organization; QUS: quantitative ultrasound; NA: not assessed; TH: total hip; NS: not shown. \#: FEV1 is in \% predicted, with the exception of the data for Mineo [22]; ๆ: information provided by the author (by e-mail); ${ }^{+}$: for total group (not for COPD patients only); ${ }^{\S}$ : Not provided by the author. 
reduction surgery and found significant correlations between the increase in lumbar BMD and the changes in the following parameters: residual volume (RV), diffusing capacity of the lung for carbon monoxide (DL,CO), $\mathrm{BMI}$, fat-free mass (FFM), bone alkaline phosphatase (bone-AF), $\beta$ crosslaps, methylprednisolone ${ }^{24}$ (table 3 ).

Table 2: No osteoporosis versus osteoporosis in patients with chronic obstructive pulmonary disease

\begin{tabular}{llll}
\hline & No osteoporosis & Osteoporosis & $p$-value \\
\hline Age yrs & $63.4 \pm 4.1(503)$ & $63.4 \pm 6.7(272)$ & 0.917 \\
Gender M/F \% (n) & $77 / 23(336)$ & $63 / 37(233)$ & $<0.001^{* *}$ \\
FEV1 \% pred & $47.5 \pm 12.0(369)$ & $41.1 \pm 15.8(145)$ & $<0.001^{\star \star}$ \\
BMI kg/m & $25.5 \pm 2.1(471)$ & $23.7 \pm 2.3(250)$ & $<0.001^{\star *}$ \\
FFMI kg/m & $16.9 \pm 0.7(235)$ & $16.2 \pm 1.1(76)$ & $<0.001^{* \star}$ \\
\hline
\end{tabular}

Data are presented as mean $\pm S D(n)$, unless otherwise indicated. M: males; $F$ : females; $\mathrm{FEV}_{1}$ : forced expiratory volume in $1 \mathrm{~s}$; BMI: body mass index; FFMI: fat-free mass index. ${ }^{* *}$ : significant at $\mathrm{p}<0.01$.

\section{Treatment of osteoporosis in COPD}

The search resulted in 136 articles, 27 were excluded because they were not in the English language, 34 because they were reviews, three were editorials, letters or comments and 69 because they were about another topic. No studies were identified investigating the treatment of osteoporosis in COPD patients alone. 
Figure 1: Prevalence of osteoporosis in COPD patients versus healthy subjects

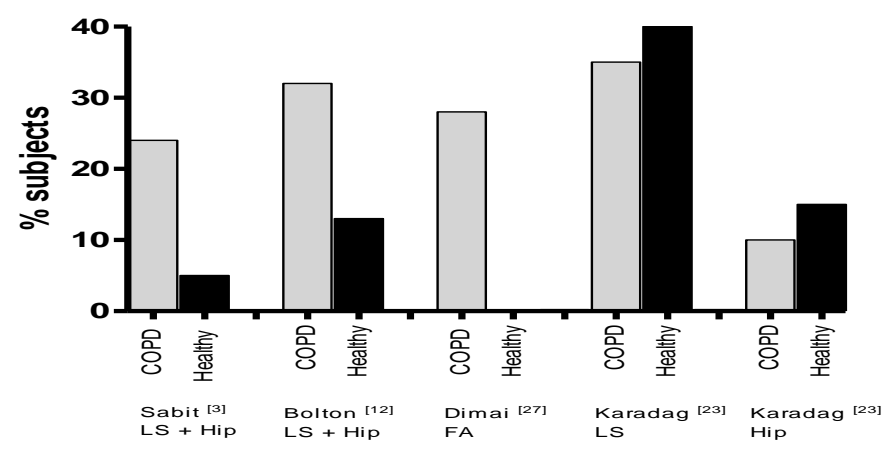

Absolute numbers included in the studies: Sabit ${ }^{3} n=75$ COPD patients, $n=42$ healthy subjects; Bolton ${ }^{12} \mathrm{n}=81$ COPD patients, $\mathrm{n}=38$ healthy subjects; Dimai ${ }^{27} \mathrm{n}=71$ COPD patients, $n=40$ healthy subjects; Karadag ${ }^{23} n=28$ COPD patients, $n=20$ healthy subjects. For Karadag et $\mathrm{al}^{23}$ prevalence for lumbar spine (LS) and hip are displayed separately (the author provided us with the combined prevalence of osteoporosis in the COPD patients (40\%); however this combined prevalence in the healthy sugjects was not provided). FA: forarm.

Figure 2: Prevalence of osteoporosis in COPD versus other respiratory disorders

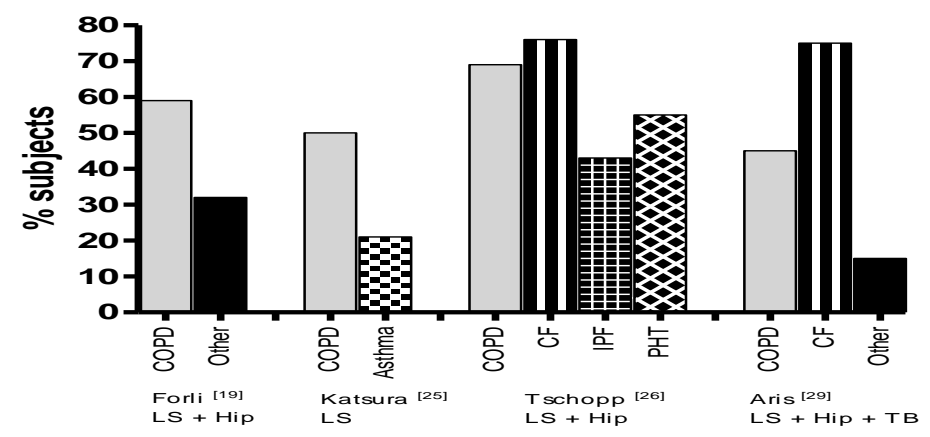

Absolute numbers of patients included: Forli ${ }^{19} \mathrm{n}=40$ COPD patients, $n=31$ other; Katsura ${ }^{25}$ $n=20$ COPD patients, $n=24$ asthma patients; Tschopp $^{26} n=16$ COPD patients, $n=24$ cystic fibrosis (CF) patients, $n=14$ idiopathic pulmonary fibrosis (IPF) patients, $n=11$ pulmonary hypertension (PTH) patients, $n=9$ other; Aris $^{29} n=15$ COPD patients, $n=20$ CF patients, $n=20$ other. 
Table 3: Correlates of osteoporosis in COPD

\begin{tabular}{|c|c|c|c|c|c|c|c|c|c|}
\hline First author ${ }^{\text {ref }}$ & $\mathbf{N}$ & $\begin{array}{l}\text { Age } \\
\text { yrs }\end{array}$ & $\begin{array}{l}\text { Sex } \\
M / F n\end{array}$ & $\begin{array}{l}\text { FEV1 } \\
\% \text { pred }^{\#}\end{array}$ & $\begin{array}{l}\mathrm{BMI} \\
\mathrm{kg} / \mathrm{m}^{2}\end{array}$ & $\begin{array}{l}\text { FFMI } \\
\mathrm{kg} / \mathrm{m}^{2}\end{array}$ & $\begin{array}{l}\text { Dependent variable/ } \\
\text { correlation with }\end{array}$ & $\begin{array}{l}\text { Covariables/ } \\
\text { adjusted for }\end{array}$ & Significant correlate(s) \\
\hline Bolton $^{30}$ & 58 & 67 & $31 / 27$ & 54 & 25.6 & 17.21 & Osteoporosis & $\begin{array}{l}\text { Age, sex, daily dose of } \\
\text { inhaled steroids, pack yrs, } \\
\text { FEV1, BMI, SFA FFMI, } \\
\text { MAC, \%IBW }\end{array}$ & $\begin{array}{l}\text { BMI (OR:0.79), \%IBW } \\
\text { (OR:0.93) }\end{array}$ \\
\hline Vrieze ${ }^{22}$ & 115 & 60 & $62 / 53$ & 43.4 & 26.4 & 17.3 & $\begin{array}{l}\text { Abnormal BMD (T-score } \\
<-1 \text { based on QUS) }\end{array}$ & $\begin{array}{l}3 \text { models, all adjusted for } \\
\text { age and sex: 1) GOLD } \\
\text { stages, 2) normal and low } \\
\text { FFM, 3) normal and low BMI }\end{array}$ & $\begin{array}{l}\text { GOLD III (OR:2.4) } \\
\text { GOLD IV (OR:7.6) } \\
\text { low FFM (OR:4.9) } \\
\text { low BMI (OR:4.7) }\end{array}$ \\
\hline Kjensli $^{31}$ & 88 & 64 & $57 / 31$ & 44.4 & 25.7 & NA & $\begin{array}{l}3 \text { models : 1) ZL2-4; } \\
\text { 2) ZFN; 3) ZTB }\end{array}$ & BMI and steroid use & $\begin{array}{l}\text { 1) GOLD II-IV (SE:0.3), } \\
\text { BMI (SE:0.0), Steroids } \\
\text { (SE:0.1) } \\
\text { 2) BMI (SE:0.0) } \\
\text { 3) BMI (SE:0.0) }\end{array}$ \\
\hline Mineo ${ }^{24} \mathbb{q}$ & 40 & 61 & $\begin{array}{l}\text { Males } \\
\text { only }\end{array}$ & $1.06 \mathrm{~L}$ & 22.9 & $\begin{array}{l}\text { NA } \\
\text { (FFM: } \\
48.6)\end{array}$ & $\begin{array}{l}\text { Increase in } \\
\text { lumbar BMD }\end{array}$ & NA & $\begin{array}{l}\Delta \text { RV }(\rho=-0.51), \Delta \text { DLCO } \\
(\rho=0.52), \Delta \text { BMI }(\rho=0.50) \\
\Delta \text { FFM }(\rho=0.52), \Delta \text { bone APH }^{+} \\
(\rho=-0.42), \Delta \beta \text {-crosslaps }(\rho=- \\
0.61), \\
\Delta \text { methylprednisolone }(\rho=-0.41)\end{array}$ \\
\hline Komerik ${ }^{34}$ & 30 & 66 & $20 / 10$ & $\begin{array}{l}\text { Not } \\
\text { shown }\end{array}$ & 24.0 & NA & Mandibular BMD & NA & $\begin{array}{l}\text { Serum calcium (pos corr; } \\
r=0.37 \text { ), APH (neg corr; } \\
r=0.52 \text { ) }\end{array}$ \\
\hline Bolton ${ }^{12}$ & 81 & 66 & $43 / 38$ & 44 & 24.0 & 16.2 & BMD & $\begin{array}{l}\text { FFMI, FMI, pack yrs, age, } \\
\text { sex, IL-6, inhaled } \\
\text { corticosteroid dose and } \\
\text { FEV1 }\end{array}$ & FFMI $\left(r^{2}=0.60\right)$ \\
\hline
\end{tabular}




\begin{tabular}{|c|c|c|c|c|c|c|c|c|c|}
\hline Scanlon $^{33}$ & 412 & 56 & $217 / 195$ & 69.3 & 26.3 & NA & $\begin{array}{l}\text { Change in BMD } 2 \\
\text { places: 1) FN; 2) LS }\end{array}$ & $\begin{array}{l}\text { Drug (ICS versus placebo), } \\
\text { age group ( } \geq 56 \text { yrs versus } \\
<56 \text { yrs), sex, cigarettes a } \\
\text { day; calcium use, vitamin D } \\
\text { use, multivitamin use }\end{array}$ & $\begin{array}{l}\text { 1) Drug }(E S=-1.72 \%) \text {, age } \\
\text { group }(E S=-1.14 \%), 2) \text { drug } \\
(E S=-1.21 \%) \text {, sex }(E S=- \\
1.19 \%)\end{array}$ \\
\hline Dubois ${ }^{25}$ & 86 & 65 & $\begin{array}{l}\text { Males } \\
\text { only }\end{array}$ & NS & 25.8 & NA & $\begin{array}{l}\text { 1) LS BMD 2) TH BMD } \\
\text { 3) FN BMD }\end{array}$ & $\begin{array}{l}\text { BMI, FEV1, RV, TLC, } \\
\text { treatment group }\end{array}$ & $\begin{array}{l}\text { 1) Treatment group } 2^{\S}(r= \\
0.48) \text {, } \\
\text { 2) } B M I(r=0.65), 3) B M I(r=0.58)\end{array}$ \\
\hline Katsura ${ }^{26}$ & 20 & 72 & $\begin{array}{l}\text { Females } \\
\text { only }\end{array}$ & 50 & 22.0 & NA & $\begin{array}{l}\text { 1) Total body BMD } \\
\text { 2) LS BMD }\end{array}$ & NA & $\begin{array}{l}\text { 1) BMI (pos corr; } r=0.49 \text { ), } \\
\text { 2) BMI (pos corr; } r=0.55 \text { ) }\end{array}$ \\
\hline Dimai $^{19}$ & 71 & 65 & $\begin{array}{l}\text { Males } \\
\text { only }\end{array}$ & NS & 25.8 & NA & BMD & NA & $\begin{array}{l}\text { Partial correlation coefficient of } \\
\mathrm{pH}(\mathrm{r} \text { not shown) }\end{array}$ \\
\hline Incalzi ${ }^{28}$ & 104 & 71 & $68 / 36$ & NS & 26.3 & NA & Osteoporosis & $\begin{array}{l}\text { Age, male gender, } \\
\mathrm{PaCO}_{2}>6.93 \mathrm{kPa}, \mathrm{BMI} \\
\leq 22 \mathrm{~kg} / \mathrm{m}^{2}, \mathrm{FEV}_{1} / \mathrm{FVC}<34 \% \text {, } \\
\mathrm{MAMC}<201,34\end{array}$ & $\mathrm{BMI} \leq 22 \mathrm{~kg} / \mathrm{m}^{2}$ (OR: 4.18$)$ \\
\hline Bikle ${ }^{32}$ & 36 & 63 & $\begin{array}{l}\text { Males } \\
\text { only }^{f}\end{array}$ & $1.5 \mathrm{~L}$ & NA & NA & BMD & NA & FEV1 ( $r=0.77)$ \\
\hline
\end{tabular}

M: male; F: female; $\mathrm{FEV}_{1}$ : forced expiratory volume in $1 \mathrm{~s}$; BMl: body mass index; FFMl: fat free mass index; OR: odds ratio; SFA: skinfold

anthropometry; MA(M)C: midarm (muscle) circumference; \%IBW: \% of ideal body weight; BMD: bone mineral density; QUS: quantitative ultrasound;

GOLD: Global Initiative for Chronic Obstructive Lung Disease; FFM: fat-free mass; ZL2-4: Z-score at lumbar spine vertebra L2-L4; ZFN: Z-score femoral neck; ZTB: Z-score total body; NA: not assessed or not applicable; $\Delta$ : change; RV: residual volume; DLCO: diffusing capacity of the lung for carbon monoxide; (bone-)APH: (bone specific) alkaline phosphatase; pos corr: positive correlation; neg corrr: negative correlation; IL: interleukin; ICS: inhaled corticosteroids; FN: femoral neck; LS: lumbar spine; ES: effect size; TH: total hip; TLC: total lung capacity; Pa,CO2: arterial carbon dioxide tension; FVC: forced vital capacity. ": FEV1 is in \% predicted, with the exception of the data for Mineo [22]; " : only COPD patients from the lung volume reduction sugery group (no correlation determined in pulmonary rehabilitation group, $\mathrm{n}=30$ ); ${ }^{+}$: cross-linked $\mathrm{C}$-terminal telopeptide of type I collagen; ${ }^{\S}$ : group 1 : continues oral corticosteroids; group 2: multiple courses of prednisone, cumulative dose $\geq 1,000 \mathrm{mg}$; group 3: multiple courses of prednisone, cumulative dose $<1,000 \mathrm{mg}$; group 4: never systemic corticosteroids; ${ }^{f}$ : confirmed by the author 


\section{Discussion}

The prevalence of osteoporosis in COPD patients varies 9-69\%. In addition, the prevalence of osteopenia varies $27-67 \%$. The prevalence of osteoporosis was higher in COPD patients than in healthy subjects. Identified correlates of osteoporosis or a low BMD in COPD patients are body composition measures, disease severity and treatment with corticosteroids. Treatment of osteoporosis has not been investigated in random samples consisting of only patients with COPD.

\section{Prevalence of osteoporosis in COPD}

Vrieze et al. ${ }^{22}$ found a low prevalence of osteoporosis compared with other studies (table 1). This may, at least in part, be because none of the GOLD stage II patients had osteoporosis. In contrast, Bolton et al. found a prevalence of osteoporosis in $20 \%$ of GOLD stage II patients ${ }^{12}$. A possible explanation for these conflicting results could be the use of quantitative ultrasound by Vrieze et al. instead of DXA-scan, which is the gold standard to assess osteoporosis ${ }^{8}$. The highest prevalence $(69 \%)$ of osteoporosis in COPD was reported by Tschopp et al. ${ }^{27}$. In two other studies conducted in COPD patients considered for lung transplantation, the prevalence of osteoporosis was lower (48\% and 59\%) ${ }^{21 ; 29}$. This difference in prevalence may be due to differences in patient characteristics. However, in the absence of clinical characteristics for COPD patients only, this was hard to check ${ }^{27}$. Three other studies ${ }^{24 ; 26 ; 28}$ found a relatively high prevalence of osteoporosis in COPD $(50 \%, 49 \%$ and $60 \%$, respectively). However, the mean age of these patients was 72, 70 and $71 \mathrm{yrs}$, respectively, whereas in other studies the mean age was $\leq 67 \mathrm{yrs}$ (table 1). In addition, Katsura and Kida defined osteoporosis according to the Japanese guidelines whereas most other studies used the WHO-criteria to define osteoporosis (table 1).

We found differences in sex distribution, $\mathrm{FEV}_{1}, \mathrm{BMI}$ and FFMI after stratification for presence / absence of osteoporosis. In addition, in a logistic regression analysis we identified male sex, decreasing $\mathrm{FEV}_{1}$, BMI and FFMI as possible determinants of osteoporosis in COPD. Nevertheless, heterogeneity of the study designs makes it somewhat difficult to draw strong conclusions from these analyses. 
On average, the prevalence of osteoporosis and / or a low BMD was significantly higher in COPD patients than in healthy subjects (figure 1). Only one study did not find a significant difference in prevalence of osteoporosis in Turkish COPD outpatients (40\% for lumbar spine and hip combined, $35 \%$ and $10 \%$ for lumbar spine and hip respectively) compared with their healthy peers $(40 \%$ at lumbar spine and $15 \%$ at the hip) ${ }^{20}$. Nevertheless, the prevalence of osteoporosis in the healthy group appears to be higher than the prevalence of osteoporosis in healthy subjects in other studies $(0-25 \%)^{3 ; 12 ; 19 ; 35}$. Indeed, the Turkish population has BMD values $\sim 1$ SD lower than the Swedish population ${ }^{36}$. The decreased BMD in the Turkish population may partly explain the lack of difference in prevalence of osteoporosis between COPD patients and healthy subjects ${ }^{20}$.

\section{Correlates of osteoporosis in COPD}

To determine risk factors for osteoporosis longitudinal (intervention) studies are preferred. To date, only two longitudinal studies that met the inclusion criteria have been identified ${ }^{24 ; 33}$. The other studies are crosssectional (table 3). For this reason, interpretation of the results should be with caution as causality of the correlates (table 3 ) needs to be confirmed. Several studies found body composition measures (low BMI, low FFMI and \% of ideal body weight) to have a significant correlation with osteoporosis and / or BMD ${ }^{12 ; 2 ; 26 ; 28 ; 30}$. In the general population, low body weight and / or low BMI have also been identified as risk factors for osteoporosis and incorporated in guidelines ${ }^{8 ; 13}$. The link between low body composition and osteoporosis or low BMD in COPD could be increased inflammation, decreased physical activity, and / or other mechanisms leading to proteolysis ${ }^{37-42}$. Another explanation for more osteoporosis in patients with lower body composition measurements could be that bone formation is decreased because there is relatively low mechanical loading on these bones. Indeed, astronauts lose as much bone mass in a 1-month spaceflight as postmenopausal females in $1 \mathrm{yr}$ ${ }^{43}$. In addition, COPD patients have been shown to be physically inactive compared to age-matched healthy subjects ${ }^{44}$.

Mineo et al. have found a significant correlation between an increase in $\mathrm{BMD}$ and an increase in BMI and FFM after lung volume reduction 
surgery ${ }^{24}$. More longitudinal studies are needed to investigate the influence of change in BMI and / or FFMI on change in BMD in COPD.

A higher GOLD stage and / or a lower FEV1 have been shown to be correlated with osteoporosis and / or a low BMD 22;31;32. Also, in subjects without COPD, significant correlations between FEV1 and BMD have been found ${ }^{45-47}$. These relationships between lung function parameters and BMD are complex and not clear yet. Again, in COPD patients, systemic inflammation can be a key factor as reduced lung function has been found to be associated with increased inflammatory markers, which is a risk factor for osteoporosis ${ }^{48}$. A strong relationship between serum 25-hydroxyvitamin $D$ and pulmonary function parameters was found in patients from the third National Health and Nutrition Examination Survey 49. This could be another link between lung function and BMD. It is also possible that there is no causal relationship between lung function and BMD. Perhaps reduced physical activity because of impaired lung function is the reason for reduced BMD ${ }^{50}$. More longitudinal studies are needed to investigate the possible causality between lung function and BMD.

Only Scanlon et al. have found age $>56 \mathrm{yrs}$ and female sex to be independent correlates of osteoporosis in COPD ${ }^{33}$. Indeed, in the general population higher age and female sex are two of the most important risk factors for osteoporosis ${ }^{8}$. In COPD patients these risk factors may disappear after correction for other risk factors that are more important in COPD and less important in the general population. Other explanations could be limited sample size, cross-sectional design of most of the trials, inclusion of only males or only females and / or a selected age category. More large longitudinal trials are needed to investigate the influence of a higher age and / or female sex on BMD in COPD patients.

\section{Treatment of osteoporosis in COPD}

The pharmacological treatment of osteoporosis should consist of bisphosphonates in combination with calcium supplementation (in case of low dietary calcium intake) and with vitamin $D$ supplements (in case of vitamin $D$ deficiency) ${ }^{8}$. The protective effect of bisphosphonates has been found in multiple studies ${ }^{51-54}$. However, no studies were found investigating the drug treatment to prevent fractures in patients with 
osteoporotic COPD only. Two studies investigated alendronate in patients with asthma or COPD ${ }^{55 ; 56}$. Both studies treated the patients for 1 yr. Smith et al. found a significant improvement in T- and Z-scores for lumbar spine BMD, but not for BMD at the hip in the alendronate group ${ }^{56}$. Lau et al. found an increase in BMD in the alendronate group and a decrease in the placebo group, and these changes in BMD were significantly different between the two groups ${ }^{55}$. In these studies different eligibility criteria were used (males and females versus females only, patients with high fracture risk versus patients on inhaled corticosteroids). In addition, patient characteristics were different (age 67 versus 49 years, percentage asthma and COPD unknown versus majority asthma patients). The results of the two studies could not be pooled. These two studies may indicate that alendronate improves BMD in COPD patients.

Mirzai et al. investigated the effect of rocaltrol in patients with a T-score $<-1$ and compared this with control patients ${ }^{57}$. However, patients and treating physicians were not blinded for treatment because the patients were assigned to the control group if they had contra-indications for rocaltrol or if they were unwilling to use rocaltrol. Again, nothing can be concluded about the effect of rocaltrol in COPD patients only. Considering the methodological quality of the three described trials, only Smith et al. ${ }^{56}$ scored high on the Delphi scoring list (8 points) whereas the other two studies scored very low ${ }^{55 ; 57}$ (4 and 2 points, respectively see online supplementary material, table E2). RCTs in COPD patients only and with a long-term follow-up are needed.

No studies were found that investigated the effect of lifestyle changes on BMD in COPD patients. However, in an RCT, lung transplantation patients who performed 6 months of exercise on a lumbar extensor machine significantly gained lumbar BMD in contrast to the control patients (also after lung transplantation without exercise) who lost lumbar BMD ${ }^{58}$. Another RCT compared the effect of alendronate plus mechanical loading to alendronate alone and to control patients (without alendronate and without mechanical loading) in lung transplant recipients ${ }^{59}$. Again, in control patients a significant decrease in BMD as compared with baseline BMD was found after 8 months $(-14.1 \%)$. In patients treated with alendronate the BMD increased (1.4\%) and in the alendronate plus mechanical loading group the BMD increased even more $(10.8 \%)$. In contrast, in a 4-yr RCT in middle-aged men regular aerobic exercise training had no significant effect on femoral BMD ${ }^{60}$. 
Intervention studies in COPD patients are needed to investigate the possible short- and long-term effects of progressive resistance training on $\mathrm{BMD}^{61}$.

\section{Conclusions}

Prevalence of osteoporosis and osteopenia seems to be high in COPD patients. Correlates of osteoporosis in COPD are body composition measurements, measures of disease severity and corticosteroids. Although causality has not been proven, based on the current results it seems reasonable to advise (chest) physicians to screen for osteoporosis in COPD patients with a low BMI $\left(<21 \mathrm{~kg} / \mathrm{m}^{2}\right)$ and / or a low FFMI $(<16$ $\mathrm{kg} / \mathrm{m}^{2}$ in men and $<15 \mathrm{~kg} / \mathrm{m}^{2}$ in females). The effects of treatment of osteoporosis have not been investigated in COPD patients only.

\section{Further areas where research is needed}

To determine risk factors of osteoporosis in COPD, more prospective studies are needed. Moreover, randomized (placebo-) controlled trials on the effects of pulmonary rehabilitation (including progressive resistance training and nutritional modulation ${ }^{62}$ and / or relevant drug treatment on BMD and fracture risk reduction are warranted in osteoporotic patients with COPD. 


\section{Reference List}

(1) Rabe KF, Hurd S, Anzueto A, Barnes PJ, Buist SA, Calverley P et al. Global strategy for the diagnosis, management, and prevention of chronic obstructive pulmonary disease: GOLD executive summary. Am J Respir Crit Care Med 2007; 176(6):532-555.

(2) Agusti AG. Systemic effects of chronic obstructive pulmonary disease. Proc Am Thorac Soc 2005; 2(4):367-370.

(3) Sabit R, Bolton CE, Edwards PH, Pettit RJ, Evans WD, McEniery CM et al. Arterial stiffness and osteoporosis in chronic obstructive pulmonary disease. Am J Respir Crit Care Med 2007; 175(12):1259-1265.

(4) Schols AM, Broekhuizen R, Weling-Scheepers CA, Wouters EF. Body composition and mortality in chronic obstructive pulmonary disease. Am J Clin Nutr 2005; 82(1):53-59.

(5) Wouters EF. Introduction: systemic effects in chronic obstructive pulmonary disease. Eur Respir J Suppl 2003; 46:1s.

(6) Holguin F, Folch E, Redd SC, Mannino DM. Comorbidity and mortality in COPD-related hospitalizations in the United States, 1979 to 2001. Chest 2005; 128(4):2005-2011.

(7) Biskobing DM. COPD and osteoporosis. Chest 2002; 121(2):609-620.

(8) WHO Scientific Group on the Prevention and Management of Osteoporosis. Prevention and Management of Osteoporosis: report of a WHO scientific group. http;//whqlibdoc who int/trs/WHO_TRS_921 pdf [ 2007

(9) Abe E, Sun L, Mechanick J, Iqbal J, Yamoah K, Baliram R et al. Bone loss in thyroid disease: role of low TSH and high thyroid hormone. Ann N Y Acad Sci 2007; 1116:383-391.

(10) Compston JE. Risk factors for osteoporosis. Clin Endocrinol (Oxf) 1992; 36(3):223-224.

(11) Lumachi F, Camozzi V, Ermani M, DE LF, Luisetto G. Bone mineral density improvement after successful parathyroidectomy in pre- and postmenopausal women with primary hyperparathyroidism: a prospective study. Ann N Y Acad Sci 2007; 1117:357-361.

(12) Bolton CE, lonescu AA, Shiels KM, Pettit RJ, Edwards PH, Stone MD et al. Associated loss of fat-free mass and bone mineral density in chronic obstructive pulmonary disease. Am J Respir Crit Care Med 2004; 170(12):1286-1293.

(13) Shepherd AJ, Cass AR, Carlson CA, Ray L. Development and internal validation of the male osteoporosis risk estimation score. Ann Fam Med 2007; 5(6):540-546. 
(14) Leech JA, Dulberg C, Kellie S, Pattee L, Gay J. Relationship of lung function to severity of osteoporosis in women. Am Rev Respir Dis 1990; 141(1):68-71.

(15) Bapoje SR, Whitaker JF, Schulz T, Chu ES, Albert RK. Preoperative evaluation of the patient with pulmonary disease. Chest 2007; 132(5):1637-1645.

(16) Smetana GW. Preoperative pulmonary evaluation. N Engl J Med 1999; 340(12):937-944.

(17) Trayner E Jr, Celli BR. Postoperative pulmonary complications. Med Clin North Am 2001; 85(5):1129-1139.

(18) Verhagen AP, de Vet HC, de Bie RA, Kessels AG, Boers M, Bouter LM et al. The Delphi list: a criteria list for quality assessment of randomized clinical trials for conducting systematic reviews developed by Delphi consensus. J Clin Epidemiol 1998; 51(12):1235-1241.

(19) Forli L, Mellbye OJ, Halse J, Bjortuft O, Vatn M, Boe J. Cytokines, bone turnover markers and weight change in candidates for lung transplantation. Pulm Pharmacol Ther 2008; 21(1):188-195.

(20) Vrieze A, de Greef MH, Wijkstra PJ, Wempe JB. Low bone mineral density in COPD patients related to worse lung function, low weight and decreased fatfree mass. Osteoporos Int 2007; 18(9):1197-1202.

(21) Jorgensen NR, Schwarz P, Holme I, Henriksen BM, Petersen LJ, Backer V. The prevalence of osteoporosis in patients with chronic obstructive pulmonary disease: a cross sectional study. Respir Med 2007; 101(1):177-185.

(22) Mineo TC, Ambrogi V, Mineo D, Fabbri A, Fabbrini E, Massoud R. Bone mineral density improvement after lung volume reduction surgery for severe emphysema. Chest 2005; 127(6):1960-1966.

(23) Karadag F, Cildag O, Yurekli Y, Gurgey O. Should COPD patients be routinely evaluated for bone mineral density? J Bone Miner Metab 2003; 21(4):242-246.

(24) Dubois EF, Roder E, Dekhuijzen PN, Zwinderman AE, Schweitzer DH. Dual energy X-ray absorptiometry outcomes in male COPD patients after treatment with different glucocorticoid regimens. Chest 2002; 121(5):1456-1463.

(25) Katsura H, Kida K. A comparison of bone mineral density in elderly female patients with COPD and bronchial asthma. Chest 2002; 122(6):1949-1955.

(26) Tschopp O, Boehler A, Speich R, Weder W, Seifert B, Russi EW et al. Osteoporosis before lung transplantation: association with low body mass index, but not with underlying disease. Am J Transplant 2002; 2(2):167-172.

(27) Dimai HP, Domej W, Leb G, Lau KH. Bone loss in patients with untreated chronic obstructive pulmonary disease is mediated by an increase in bone resorption associated with hypercapnia. J Bone Miner Res 2001; 16(11):21322141. 
(28) Incalzi RA, Caradonna P, Ranieri P, Basso S, Fuso L, Pagano F et al. Correlates of osteoporosis in chronic obstructive pulmonary disease. Respir Med 2000; 94(11):1079-1084.

(29) Aris RM, Neuringer IP, Weiner MA, Egan TM, Ontjes D. Severe osteoporosis before and after lung transplantation. Chest 1996; 109(5):1176-1183.

(30) Bolton CE, Cannings-John R, Edwards PH, lonescu AA, Evans WD, Pettit RJ et al. What community measurements can be used to predict bone disease in patients with COPD? Respir Med 2008; 102(5):651-657.

(31) Kjensli A, Mowinckel P, Ryg MS, Falch JA. Low bone mineral density is related to severity of chronic obstructive pulmonary disease. Bone 2007; 40(2):493497.

(32) Bikle DD, Halloran B, Fong L, Steinbach L, Shellito J. Elevated 1,25dihydroxyvitamin $\mathrm{D}$ levels in patients with chronic obstructive pulmonary disease treated with prednisone. J Clin Endocrinol Metab 1993; 76(2):456-461.

(33) Scanlon PD, Connett JE, Wise RA, Tashkin DP, Madhok T, Skeans M et al. Loss of bone density with inhaled triamcinolone in Lung Health Study II. Am J Respir Crit Care Med 2004; 170(12):1302-1309.

(34) Komerik N, Akkaya A, Yildiz M, Buyukkaplan US, Kuru L. Oral health in patients on inhaled corticosteroid treatment. Oral Dis 2005; 11(5):303-308.

(35) Szymanski P, Mosiewicz J, Myslinski W, Dzida G, Rymarz E. The influence of chronic obstructive pulmonary disease on the occurrence rate and intensification of osteoporosis. Ann Univ Mariae Curie Sklodowska [Med ] 2002; 57(1):187-195.

(36) Tuzun S, Akarirmak U, Uludag M, Tuzun F, Kullenberg R. Is BMD sufficient to explain different fracture rates in Sweden and Turkey? J Clin Densitom 2007; 10(3):285-288.

(37) Balasubramanian VP, Varkey B. Chronic obstructive pulmonary disease: effects beyond the lungs. Curr Opin Pulm Med 2006; 12(2):106-112.

(38) Eid AA, lonescu AA, Nixon LS, Lewis-Jenkins V, Matthews SB, Griffiths TL et al. Inflammatory response and body composition in chronic obstructive pulmonary disease. Am J Respir Crit Care Med 2001; 164(8 Pt 1):1414-1418.

(39) Kardos P, Keenan J. Tackling COPD: a multicomponent disease driven by inflammation. MedGenMed 2006; 8(3):54.

(40) Roth M. Pathogenesis of COPD. Part III. Inflammation in COPD. Int J Tuberc Lung Dis 2008; 12(4):375-380.

(41) Wouters EF. Local and systemic inflammation in chronic obstructive pulmonary disease. Proc Am Thorac Soc 2005; 2(1):26-33. 
(42) Yawn BP, Kaplan A. Co-morbidities in people with COPD: a result of multiple diseases, or multiple manifestations of smoking and reactive inflammation? Prim Care Respir J 2008.

(43) Cavanagh PR, Licata AA, Rice AJ. Exercise and pharmacological countermeasures for bone loss during long-duration space flight. Gravit Space Biol Bull 2005; 18(2):39-58.

(44) Van VM, Spruit MA, Verleden G, Kasran A, Van HE, Pitta F et al. Hypogonadism, quadriceps weakness, and exercise intolerance in chronic obstructive pulmonary disease. Am J Respir Crit Care Med 2005; 172(9):11051111.

(45) Choi JW, Pai SH. Association between respiratory function and osteoporosis in pre- and postmenopausal women. Maturitas 2004; 48(3):253-258.

(46) Lekamwasam S, Trivedi DP, Khaw KT. An association between respiratory function and bone mineral density in women from the general community: a cross sectional study. Osteoporos Int 2002; 13(9):710-715.

(47) Lekamwasam S, Trivedi DP, Khaw KT. An association between respiratory function and hip bone mineral density in older men: a cross-sectional study. Osteoporos Int 2005; 16(2):204-207.

(48) Gan WQ, Man SF, Senthilselvan A, Sin DD. Association between chronic obstructive pulmonary disease and systemic inflammation: a systematic review and a meta-analysis. Thorax 2004; 59(7):574-580.

(49) Black PN, Scragg R. Relationship between serum 25-hydroxyvitamin d and pulmonary function in the third national health and nutrition examination survey. Chest 2005; 128(6):3792-3798.

(50) Watz H, Waschki B, Boehme C, Claussen M, Meyer T, Magnussen H. Extrapulmonary effects of chronic obstructive pulmonary disease on physical activity: a cross-sectional study. Am J Respir Crit Care Med 2008; 177(7):743751.

(51) Black DM, Schwartz AV, Ensrud KE, Cauley JA, Levis S, Quandt SA et al. Effects of continuing or stopping alendronate after 5 years of treatment: the Fracture Intervention Trial Long-term Extension (FLEX): a randomized trial. JAMA 2006; 296(24):2927-2938.

(52) Bone HG, Hosking D, Devogelaer JP, Tucci JR, Emkey RD, Tonino RP et al. Ten years' experience with alendronate for osteoporosis in postmenopausal women. N Engl J Med 2004; 350(12):1189-1199.

(53) Fogelman I, Ribot C, Smith R, Ethgen D, Sod E, Reginster JY. Risedronate reverses bone loss in postmenopausal women with low bone mass: results from a multinational, double-blind, placebo-controlled trial. BMD-MN Study Group. J Clin Endocrinol Metab 2000; 85(5):1895-1900. 
(54) McClung MR, Geusens P, Miller PD, Zippel H, Bensen WG, Roux C et al. Effect of risedronate on the risk of hip fracture in elderly women. Hip Intervention Program Study Group. N Engl J Med 2001; 344(5):333-340.

(55) Lau EM, Woo J, Chan YH, Li M. Alendronate for the prevention of bone loss in patients on inhaled steroid therapy. Bone 2001; 29(6):506-510.

(56) Smith BJ, Laslett LL, Pile KD, Phillips PJ, Phillipov G, Evans SM et al. Randomized controlled trial of alendronate in airways disease and low bone mineral density. Chron Respir Dis 2004; 1(3):131-137.

(57) Mirzaei S, Zajicek HK, Knoll P, Hahn M, Levi M, Kohn H et al. Effect of rocaltrol on bone mass in patients with pulmonary disease treated with corticosteroids. $J$ Asthma 2003; 40(3):251-255.

(58) Mitchell MJ, Baz MA, Fulton MN, Lisor CF, Braith RW. Resistance training prevents vertebral osteoporosis in lung transplant recipients. Transplantation 2003; 76(3):557-562.

(59) Braith RW, Conner JA, Fulton MN, Lisor CF, Casey DP, Howe KS et al. Comparison of alendronate vs alendronate plus mechanical loading as prophylaxis for osteoporosis in lung transplant recipients: a pilot study. J Heart Lung Transplant 2007; 26(2):132-137.

(60) Huuskonen J, Vaisanen SB, Kroger H, Jurvelin JS, Alhava E, Rauramaa R. Regular physical exercise and bone mineral density: a four-year controlled randomized trial in middle-aged men. The DNASCO study. Osteoporos Int 2001; 12(5):349-355.

(61) Spruit MA, Gosselink R, Troosters T, De PK, Decramer M. Resistance versus endurance training in patients with COPD and peripheral muscle weakness. Eur Respir J 2002; 19(6):1072-1078.

(62) Spruit MA, Wouters EF. New modalities of pulmonary rehabilitation in patients with chronic obstructive pulmonary disease. Sports Med 2007; 37(6):501-518. 
Chapter II 


\section{Chapter III}

Correlates of osteoporosis in Chronic Obstructive Pulmonary Disease: An underestimated systemic component

Lidwien Graat-Verboom, Martijn A. Spruit, Ben E.E.M. van den Borne, Frank W.J.M. Smeenk, Elisabeth J. Martens, Ragnar Lunde, Emiel F.M. Wouters, On behalf of the CIRO Network

Respiratory Medicine 2009; 103: 1143-1151 


\section{Abstract}

Chronic obstructive pulmonary disease (COPD) patients are at increased risk of osteoporosis. Osteoporosis is under diagnosed and under treated in these patients and the underlying mechanisms remain unclear. To date, screening recommendations for osteoporosis in COPD patients are not available.

To examine the prevalence of drug treatment of bone abnormalities as well as the clinical determinants of osteoporosis in COPD.

COPD patients $(n=554)$ consecutively entering pulmonary rehabilitation were included in this cross-sectional study. Medical history, current medication use, smoking status, lung function, bone mineral density, body composition and other clinical characteristics were assessed before entering pulmonary rehabilitation.

Univariate- and multivariate multinomial logistic regression analyses were used to determine correlates of osteoporosis.

Twenty-one percent of patients had osteoporosis and $41 \%$ had osteopenia. Osteoporosis was pharmacologically under treated $(82 \%$ of osteoporotic patients were not receiving bone medication). Independent predictors of osteoporosis were cachexia (OR: $12.1 ; 95 \% \mathrm{Cl}: 4.5-32.7$; $\mathrm{p}<0.001$ ), age between 55 and 65 years (OR: 6.0 ; 95\%Cl: 2.2-16.3; $\mathrm{p}<0.001)$ and over 65 years (OR: 11.7; 95\%Cl: 4.1-33.1; $\mathrm{p}=<0.001)$. Overweight (OR: $0.1 ; 95 \% \mathrm{Cl}: 0.05-0.4 ; \mathrm{p}=0.001$ ) and obesity (OR: 0.78 ; $95 \% \mathrm{Cl}: 0.02-0.4 ; \mathrm{p}=0.002$ ) showed a substantial protective effect.

The majority of COPD patients with osteoporosis entering pulmonary rehabilitation did not receive pharmacological treatment for osteoporosis. Cachectic COPD patients should be screened for osteoporosis, especially when over 55 years of age. 


\section{Introduction}

Chronic Obstructive Pulmonary Disease (COPD) is characterized by a usually progressive airflow limitation that is not fully reversible according to the Global Strategy for the Diagnosis, Management, and Prevention of COPD (GOLD) ${ }^{1}$. COPD comprises a major health burden with an estimated global prevalence of $9-10 \%$ in adults of 40 years and older ${ }^{2 ; 3}$.

The GOLD guidelines include "significant extrapulmonary effects" in the definition of COPD ${ }^{1}$, indicating that COPD can be considered a multicomponent disease with marked extra-pulmonary effects ${ }^{4-7}$. Examples of these effects are loss of muscle mass (with and without abnormal loss of body weight) ${ }^{8}$, increased fat mass ${ }^{9}$ and arterial stiffness ${ }^{10}$. Moreover, COPD patients have a higher risk of osteoporosis as compared to healthy subjects ${ }^{11}$. Indeed, COPD has been included in the male osteoporosis risk estimation score ${ }^{12}$.

Osteoporosis is a systemic skeletal disease characterized by low bone mineral density (BMD) and microarchitectural changes in bone tissue that increases the susceptibility to fractures ${ }^{13}$. In patients with established osteoporosis and patients at high risk of developing osteoporosis (e.g. in case of oral corticosteroid use of $7.5 \mathrm{mg}$ prednisolone equivalent a day for at least 6 months), treatment aims at maintaining BMD and reducing the incidence of osteoporotic fractures ${ }^{13}$. In addition to behavioral intervention, treatment should include bisphosphonates in combination with calcium supplementation and vitamin $D$ in case of vitamin D deficiency ("bone medication") ${ }^{13}$.

Recent studies have found an abnormal low BMD in COPD patients entering pulmonary rehabilitation ${ }^{14-16}$. Unfortunately, the external and internal validity of these studies is limited due to small sample sizes and various methodological issues. Indeed, the prevalence of pharmacological treatment of osteoporosis has not been investigated in COPD patients. Therefore, its prevalence remains currently unknown. Nevertheless, under diagnosis and, in turn, under treatment of osteoporosis in these patients in the clinical routine seems reasonable. Indeed, under treatment of osteoporosis has been reported in elderly subjects without airflow limitation and even in patients with fragility fracture ${ }^{17-20}$.

Previously, the increased prevalence of osteoporosis in COPD was attributed to the use of oral corticosteroids ${ }^{21-23}$. Later, attention was 
focused on the effects of inhaled steroids ${ }^{24-26}$. Several studies demonstrated that these drugs have no effect on BMD ${ }^{27 ; 27-30}$. At present, the focus of investigation is more on factors besides corticosteroids to explain the increased prevalence of osteoporosis in COPD: low body mass index (BMI) and low fat free mass index (FFMI) are known risk factors for osteoporosis in COPD ${ }^{14 ; 16 ; 31}$. None of the aforementioned studies have taken into account possible effects of factors such as an overweight or obese BMI ${ }^{32}$, cardiac drug therapies ${ }^{33-36}$, serotonin reuptake inhibitors (SSRI's) ${ }^{37}$ and C-reactive protein (CRP) ${ }^{38}$ on the prevalence of osteoporosis in COPD. Moreover, insight into these factors may help explain the underlying mechanisms for the increased risk of osteoporosis in COPD patients.

Given the relative paucity in knowledge about osteoporosis in COPD, the present study aims to examine the prevalence of drug treatment of osteoporosis and to determine clinical correlates of osteoporosis and osteopenia in COPD patients.

\section{Methods}

\section{Patient population and study design}

COPD patients $(n=554)$ consecutively entering pulmonary rehabilitation were recruited between January 2005 and April 2007 from the Centre for Integrated Rehabilitation of Organ Failure (CIRO) in Horn, the Netherlands. All patients were clinically stable outpatients referred to CIRO by chest physicians working in respiratory departments of general hospitals in the south eastern part of the Netherlands. A cross-sectional design was used. Diagnosis of COPD was made according to the ATS guidelines ${ }^{4}$, severity classified according to the GOLD guidelines ${ }^{1}$. All assessments were made before entering a comprehensive pulmonary rehabilitation ${ }^{39}$. The institutional review board of the University Hospital of Maastricht approved the study protocol and written consent was obtained from all study participants.

\section{Clinical Characteristics}

Medical history, current medication use and smoking status were assessed by reviewing the medical charts and by interviewing all 
patients. Age was divided into three categories: $\leq 55,56-65$ and $>65$ years.

Forced expiratory volume in the first second $\left(\mathrm{FEV}_{1}\right)$ and forced vital capacity (FVC) were assessed using the Jaeger MASTERLAB BODY® (VIASYS Healthcare) and $F E V_{1} / F V C$ was determined. Arterial blood gases were collected to determine $\mathrm{pH}$, arterial carbondioxide tension (PaCO2) and arterial oxygen tension (PaO2).

BMI was defined as low $\left(<21 \mathrm{~kg} / \mathrm{m}^{2}\right)$, normal $\left(21-25 \mathrm{~kg} / \mathrm{m}^{2}\right)$, overweight $\left(>25-30 \mathrm{~kg} / \mathrm{m}^{2}\right)$ and obese $\left(>30 \mathrm{~kg} / \mathrm{m}^{2}\right)$. Bio-impedance analysis was done using the BODYSTAT® 1500 medical, single frequency (Xitron Technologies). FFMI was defined as depleted (men $<16 \mathrm{~kg} / \mathrm{m}^{2}$ and women $<15 \mathrm{~kg} / \mathrm{m}^{2}$ ) or normal ${ }^{40}$. The combination of BMI and FFMI resulted into six categories: cachexia (low BMI and depleted FFMI), muscle atrophy (normal BMI and depleted FFMI), semi starvation (low $\mathrm{BMI}$ and normal FFMI), normal (normal BMI and normal FFMI), overweight (overweight BMI and normal FFMI) and obese (obese BMI and normal $\mathrm{FFMI})^{8}$. Whole-body BMD was determined using a DXA-scan (Lunar Prodigy ${ }^{\circledR}$ Ge-Lunar), with osteoporosis being defined by a T-score $<-2.35$, osteopenia: T-score between -2.35 and -0.9 , normal BMD: Tscore $>-0.9^{41}$.

CRP was determined in duplicate by high-sensitivity particle enhanced immunoassay (LABAS micra, radiometer).

A six-minute walking distance test was conducted twice on 2 separate days. The longest distance was used in further analysis ${ }^{42}$.

\section{Statistical analyses}

Discrete variables were compared with the Chi-square test and presented as percentages. Continuous variables were compared with ANOVA and presented as means \pm standard error of mean (SEM).

Univariate- and multivariate multinomial logistic regression analyses (enter procedure) were performed to investigate determinants of osteoporosis and osteopenia in COPD patients without bone medication. Univariate analyses were used to test for the potentially confounding effect of biomedical and demographic factors. If significant at $p<0.05$, the 
variables were included into the multivariate analyses. In addition, several covariates were selected based on the literature. Specific interactions were tested within the regression model. A posteriori, specificity of osteoporosis stratified by the two most important risk factors for osteoporosis as found in the current study was determined. A $p$-value $<0.05$ was used to indicate statistical significance. Odds ratio (OR) with $95 \%$ confidence intervals $(\mathrm{Cl})$ are reported. All statistical analyses were performed using Statistical Package for Social Sciences (SPSS) version 15.0.

\section{Results}

\section{Patient characteristics}

We included 554 patients with moderate to very severe COPD. Since only 16 patients $(2.9 \%)$ were classified as mild COPD we merged patients with GOLD I and GOLD II into one category. BMI and / or FFMI were abnormal in $85 \%$ of the patients. The prevalence of osteoporosis was $21 \%$, the prevalence of osteopenia $41 \%$ (Table 1 ).

Significant differences were found in gender, age, body composition and functional exercise capacity between patients with osteoporosis, osteopenia and / or normal BMD (table 1).

\section{Bone medication}

Eighteen percent of the patients used bisphosphonates, calcium supplementation, vitamin $D$ or a combination thereof. Surprisingly, patients with osteoporosis were not using significantly more bone medication as compared to patients with a normal BMD. Moreover, almost $82 \%$ of patients with osteoporosis were not treated with bone medication and almost $14 \%$ and $23 \%$ of patients with a normal BMD and osteoporosis respectively did receive pharmacological treatment (table 2). Of patients without osteoporosis treated with bone medication only $8.1 \%$ was using $\geq 7.5 \mathrm{mg}$ prednisolone equivalents a day. 
Table 1: Patients characteristics

\begin{tabular}{|c|c|c|c|c|}
\hline & $\begin{array}{l}\text { Total group } \\
\mathrm{N}=554\end{array}$ & $\begin{array}{l}\text { Normal BMD } \\
\mathrm{N}=212\end{array}$ & $\begin{array}{l}\text { Osteopenia } \\
\mathrm{N}=227\end{array}$ & $\begin{array}{l}\text { Osteoporosis } \\
\mathrm{N}=115\end{array}$ \\
\hline Male/Female, \% & $62 / 38$ & $60 / 40$ & $59 / 41$ & $70 / 30^{\ddagger}$ \\
\hline Age, yr & $65.6 \pm 0.4$ & $61.3 \pm 0.6$ & $64.5 \pm 0.6^{*}$ & $65.8 \pm 0.9^{*}$ \\
\hline Age $\leq 55, \%$ & 45 & 30 & $19^{\dagger}$ & $11^{*}$ \\
\hline Age $>55$ and $\leq 65, \%$ & 34 & 35 & 31 & 38 \\
\hline Age $>65, \%$ & 21 & 35 & $50^{*}$ & $51^{*}$ \\
\hline $\mathrm{FEV}_{1}, \%$ pred & $42.1 \pm 0.7$ & $41.9 \pm 1.0$ & $43.6 \pm 1.2$ & $39.6 \pm 1.5$ \\
\hline GOLD I+II, \% & 22 & 24 & 23 & 16 \\
\hline GOLD III, \% & 34 & 36 & 34 & 30 \\
\hline GOLD IV, \% & 44 & 40 & 43 & $54^{\dagger}$ \\
\hline Ex-smoker, \% & 73 & 74 & 75 & 80 \\
\hline Pack years & $39.7 \pm 0.8$ & $40.3 \pm 1.2$ & $38.9 \pm 1.2$ & $40.1 \pm 1.6$ \\
\hline BMI, $\mathrm{kg} / \mathrm{m}^{2}$ & $24.7 \pm 0.2$ & $27.1 \pm 0.3$ & $24.3 \pm 0.3^{*}$ & $21.2 \pm 0.3^{\star \S}$ \\
\hline Low, \% & 24 & 9 & $25^{\star}$ & $51 * \S$ \\
\hline Normal, \% & 33 & 27 & $36^{\dagger}$ & 37 \\
\hline High, \% & 29 & 41 & $29^{\dagger}$ & $9^{\star \S}$ \\
\hline Obese, \% & 14 & 23 & $10^{*}$ & $3^{* \ddagger}$ \\
\hline \multicolumn{5}{|l|}{ FFMI } \\
\hline Male, $\mathrm{kg} / \mathrm{m}^{2}$ & $16.9 \pm 0.1$ & $17.9 \pm 0.2$ & $16.8 \pm 0.2^{*}$ & $15.3 \pm 0.2^{\star \S}$ \\
\hline Female, $\mathrm{kg} / \mathrm{m}^{2}$ & $14.9 \pm 0.1$ & $15.7 \pm 0.2$ & $14.7 \pm 0.2^{*}$ & $13.7 \pm 0.2^{\star \S}$ \\
\hline Low, \% & 43 & 24 & $46^{\star}$ & $75^{\star \S}$ \\
\hline Normal, \% & 57 & 76 & $54^{*}$ & $25^{\star \S}$ \\
\hline \multicolumn{5}{|l|}{ Body composition } \\
\hline Cachexia, \% & 23 & 9 & $23^{*}$ & $49^{* \S}$ \\
\hline Muscle atrophy, \% & 18 & 13 & $20^{\dagger}$ & $23^{\dagger}$ \\
\hline Semi starvation, \% & 1 & 0 & 2 & 2 \\
\hline Normal, \% & 15 & 14 & 16 & 14 \\
\hline Overweight, \% & 29 & 41 & $29^{\dagger}$ & $9 * \S$ \\
\hline Obese, $\%$ & 14 & 23 & $10^{*}$ & $3^{\star \ddagger}$ \\
\hline \multicolumn{5}{|l|}{ DXA-scan } \\
\hline BMD, $\mathbf{g} / \mathbf{c m}^{2}$ & $1.081 \pm 0.005$ & $1.188 \pm 0.005$ & $1.055 \pm 0.004^{*}$ & $0.933 \pm 0.007^{\star \S}$ \\
\hline T-score & $-1.29 \pm 0.06$ & $0.028 \pm 0.05$ & $-1.58 \pm 0.03$ & $-3.26 \pm 0.07$ \\
\hline CRP & $8.4 \pm 0.5$ & $8.1 \pm 0.7$ & $9.0 \pm 1.0$ & $7.5 \pm 0.9$ \\
\hline 6 MWD, meters & $421.4 \pm 5.3$ & $432.5 \pm 8.5$ & $419.8 \pm 8.4$ & $404.1 \pm 11.7$ \\
\hline 6 MWD, \% pred & $64.8 \pm 0.8$ & $66.0 \pm 1.2$ & $65.3 \pm 1.2$ & $61.7 \pm 1.7^{\dagger}$ \\
\hline
\end{tabular}

Values are expressed as mean \pm standard error of mean, unless otherwise indicated.

Abbreviations: $\mathrm{FEV}_{1}=$ forced expiratory volume in the first second, $\mathrm{BMI}=$ body mass index,

$\mathrm{FFMI}=$ fat free mass index, $\mathrm{BMD}=$ bone mineral density, $\mathrm{Ca}=$ calcium, $\mathrm{CRP}=\mathrm{C}$-reactive protein, $6 \mathrm{MWD}=$ six minutes walking distance, Post hoc tests: ${ }^{*} p<0.01$ compared to normal BMD; ${ }^{\dagger} p<0.05$ compared to normal BMD; ${ }^{\S} p<0.01$ compared to osteopenia; ${ }^{\ddagger}$ $p<0.05$ compared to osteopenia 
Table 2: Medication use

\begin{tabular}{|c|c|c|c|c|}
\hline & $\begin{array}{l}\text { Total group } \\
\mathbf{N}=\mathbf{5 5 4}\end{array}$ & $\begin{array}{l}\text { Normal BMD } \\
\mathbf{N}=\mathbf{2 1 2}\end{array}$ & $\begin{array}{l}\text { Osteopenia } \\
\mathbf{N}=\mathbf{2 2 7}\end{array}$ & $\begin{array}{l}\text { Osteoporosis } \\
\mathbf{N}=115\end{array}$ \\
\hline & 18 & & & \\
\hline Bone medication, \% & & 14 & $22^{*}$ & 18 \\
\hline Bisphosphonates, \% & 6 & 4 & $9^{*}$ & 5 \\
\hline Calcium, \% & 3 & 1 & 4 & 2 \\
\hline Vitamin D, \% & 0 & 1 & 0 & 0 \\
\hline Any Combination, \% & 9 & 8 & 9 & 11 \\
\hline \multicolumn{5}{|l|}{ Corticosteroids } \\
\hline Oral, \% & 21 & 19 & 23 & 18 \\
\hline Inhalation, \% & 75 & 77 & 73 & 77 \\
\hline Beta mimetics (inh), \% & 72 & 72 & 70 & 74 \\
\hline Anticholinergics (inh), \% & 89 & 90 & 89 & 89 \\
\hline \multicolumn{5}{|l|}{ Diuretics } \\
\hline Thiazide, \% & 9 & 11 & 8 & 6 \\
\hline Loop, \% & 19 & 21 & 18 & 16 \\
\hline $\mathrm{K}^{+}$saving, \% & 4 & 3 & 5 & 3 \\
\hline Statins & 19 & 19 & 20 & 15 \\
\hline$\beta$-blockers, \% & 12 & 12 & 12 & 8 \\
\hline SSRI's, \% & 9 & 12 & 8 & $5^{*}$ \\
\hline
\end{tabular}

Determinants of osteoporosis in patients without bone medication $(n=453)$

Univariate analysis showed an almost 3 -fold increased risk of osteoporosis in patients between 55 and 65 years as compared to patients $\leq 55$, increasing to an OR of 4.5 in patients over 65 years. To be sure this was not due to an interaction effect of age and GOLD-stage we repeated the analyses after stratification for GOLD. Indeed, in all GOLDcategories age $>65$ years significantly increased the OR for osteoporosis. In addition, in GOLD IV patients age between 55 and 65 increased the risk 4-fold (table 3).

Patients between 55 and 65 years had a 6-fold increased risk of osteoporosis as compared to patients $\leq 55$ years, which even increased to a nearly 12 -fold risk in patients over 65 years. Cachectic patients had a 12-fold increased risk of osteoporosis as compared to patients with a normal body composition, whereas overweight and obesity showed a substantial protective effect (table 4). Specific testing for interactions within the regression model did not show any significant results. Cachectic patients over 55 years of age had an increased risk of 
osteoporosis as compared to patients $\leq 55$ years and/or no cachexia (OR 28.2; $95 \% \mathrm{Cl}$ 10.4-76.9; $\mathrm{p}<0.0001$ ).

The specificity of not having osteoporosis in low-risk COPD patients (noncachectic and age $\leq 55$ ) without bone medication was $91 \%$.

Table 3: Age effects on osteoporosis after stratification for GOLD-stage

\begin{tabular}{|c|c|c|c|c|}
\hline & $\mathbf{N}$ & OR & $95 \% \mathrm{Cl}$ & p-value \\
\hline GOLD I and II & 114 & & & \\
\hline$<55$ years $^{\star}$ & 27 & & & \\
\hline $55-65$ years & 31 & 2.353 & $0.398-13.900$ & .345 \\
\hline$>65$ years & 56 & 5.500 & $1.047-28.879$ & .044 \\
\hline GOLD III & 166 & & & \\
\hline$<55$ years $^{*}$ & 38 & & & \\
\hline $55-65$ years & 57 & 2.173 & $0.514-9.183$ & .291 \\
\hline$>65$ years & 71 & 5.739 & $1.481-22.245$ & .011 \\
\hline GOLD IV & 173 & & & \\
\hline$<55$ years $^{\star}$ & 37 & & & \\
\hline $55-65$ years & 59 & 3.789 & $1.173-12.247$ & .026 \\
\hline$>65$ years & 77 & 3.168 & $1.009-9.951$ & .048 \\
\hline Total group & 453 & & & \\
\hline$<55$ years $^{\star}$ & 102 & & & \\
\hline $55-65$ years & 147 & 2.933 & $1.326-6.488$ & .008 \\
\hline$>65$ years & 205 & 4.463 & 2.073-9.608 & $<.0001$ \\
\hline
\end{tabular}

Determinants of osteopenia in patients without bone medication $(n=453)$

Patients over 65 years of age had a more than 3-fold increased risk of osteopenia as compared to patients $\leq 55$ years (table 5). In addition, cachectic patients had a more than3-fold increased risk of osteopenia as compared to patients with a normal body composition, whereas obesity showed a substantial protective effect of osteopenia.

\section{Discussion}

In a large cohort of COPD patients entering pulmonary rehabilitation the prevalence of osteoporosis was $21 \%$ and of osteopenia $41 \%$. Surprisingly, the majority of the osteoporotic patients were not treated with BMD medication (82\%). Older patients had an increased risk of osteoporosis compared to younger patients. Additionally, cachectic COPD patients had a higher risk of osteoporosis whereas overweight and 
Table 4: Correlates of osteoporosis in patients without bone medication (results of multivariate analysis) $(n=453)$

\begin{tabular}{|c|c|c|c|c|}
\hline & $\mathbf{N}$ & OR & $95 \% \mathrm{Cl}$ & p-value \\
\hline Male & 290 & 1.732 & $0.850-3.529$ & .130 \\
\hline \multicolumn{5}{|l|}{ Age } \\
\hline$<55$ years ${ }^{*}$ & 102 & & & \\
\hline $55-65$ years & 147 & 6.020 & $2.226-16.281$ & $<.0001^{\dagger}$ \\
\hline$>65$ years & 204 & 11.703 & $4.140-33.082$ & $<.0001^{\dagger}$ \\
\hline GOLD I and II* & 114 & & & \\
\hline GOLD III & 166 & 1.086 & $0.464-2.542$ & .850 \\
\hline GOLD IV & 173 & 1.864 & $0.738-4.707$ & .188 \\
\hline Pack Years & 453 & 0.992 & $0.973-1.011$ & .393 \\
\hline \multicolumn{5}{|l|}{ Body composition } \\
\hline Normal $^{*}$ & 69 & & & \\
\hline Cachexia & 109 & 12.088 & $4.469-32.697$ & $<.0001^{\dagger}$ \\
\hline Muscle atrophy & 81 & 2.112 & $0.808-5.524$ & .127 \\
\hline Semi starvation & 6 & 5.399 & $0.406-71.874$ & .202 \\
\hline Overweight & 127 & 0.145 & $0.047-0.440$ & $0.001^{\dagger}$ \\
\hline Obese & 61 & 0.078 & $0.015-0.399$ & $0.002^{\dagger}$ \\
\hline hs-CRP & 453 & 0.979 & $0.952-1.008$ & .148 \\
\hline 6 MWD & 452 & 0.999 & 0.996-1.002 & 388 \\
\hline \multicolumn{5}{|l|}{ Corticosteroids } \\
\hline Oral & 59 & 0.901 & $0.331-2.457$ & .839 \\
\hline Inhaled & 337 & 1.133 & $0.553-2.320$ & .732 \\
\hline Diuretics & 110 & 1.410 & $0.618-3.217$ & .414 \\
\hline Statins & 83 & 0.609 & $0.252-1.473$ & 271 \\
\hline$\beta$-blocking agents & 53 & 0.784 & $0.264-2.329$ & .661 \\
\hline SSRI's & 39 & 0.746 & $0.215-2.584$ & .644 \\
\hline
\end{tabular}

obese COPD patients had a decreased risk of osteoporosis as compared to their normal weight peers. This risk increased even more in cachectic patients $>55$ years of age irrespective of the severity of COPD. In lowrisk patients (non-cachectic and age $\leq 55$ ) only a very small percentage of osteoporosis $(9 \%)$ will be missed when not referred for a DXA-scan.

\section{Prevalence}

The prevalence of osteoporosis of $21 \%$ in this study is in line with previous studies. In brief, prevalence of osteoporosis is higher in COPD patients as compared to healthy subjects $(24-32 \%$ in COPD versus 0 $13 \%$ in healthy subjects) ${ }^{10 ; 14 ; 4}$. Moreover, in COPD patients entering pulmonary rehabilitation a prevalence of osteoporosis of about $23 \%$ was found ${ }^{14}$. In the latter study DXA of the hip and lumbar spine was used whereas we used whole body DXA-scan. However, this difference in methodology was corrected for by defining osteoporosis according to 
Boyanov in order to have a good sensitivity-to-specificity ratio in the diagnosis of osteoporosis ${ }^{41}$. Prevalence of osteoporosis of the current study differed from two other studies investigating COPD patients starting pulmonary rehabilitation ${ }^{15 ; 16}$. Vrieze and colleagues found a prevalence ranging from $0 \%$ to $18 \%$, however they used quantitative ultrasound, which is not the gold standard to measure BMD, and in addition, is hard to compare to studies using DXA-scanning ${ }^{16}$. Engelen and colleagues used Z-scores, instead of T-scores as recommended by the WHO ${ }^{13}$. They found $36 \%$ of patients with a Z-score of $<-2$, and $56 \%$ with a Zscore of $<-1^{15}$.

\section{Pharmacological treatment}

This is the first study to determine proportion of osteoporotic COPD patients who were treated with bone medication. In fact, most studies a priori excluded patients using bone medication ${ }^{15 ; 31 ; 44}$ or did not report on the prevalence of bone medication ${ }^{14 ; 16 ; 45}$. In the present study, a majority of COPD patients with osteoporosis was not treated with bone medication, indicating that these patients were not recognized as osteoporotic patients by the referring chest physicians. In the elderly, a high prevalence of under treatment of osteoporosis has been found, ranging between 59 and $91 \%{ }^{20 ; 46}$. Additionally, screening for and/or treatment of osteoporosis is low in $\operatorname{men}^{18}$, and even in patients with fragility fractures diagnosis and/or treatment is often inadequate ${ }^{17 ; 19}$.

More than $18 \%$ of 439 COPD patients without osteoporosis were treated with bone medication. A possible explanation could be that these patients with former osteoporosis were successfully treated with bone medication and continued their treatment. Another explanation could be daily use of oral corticosteroids for at least 6 months with $7.5 \mathrm{mg}$ prednisolone equivalents a day or more, since the WHO advises to treat these patients with bone medication ${ }^{13}$. In the current study, only $8.1 \%$ of 80 patients without osteoporosis treated with bone medication used $\geq 7.5 \mathrm{mg}$ prednisolone. Since osteonecrosis of the jaw is one of the potential side effects of treatment with bisphosphonates ${ }^{47 ; 48}$ we recommend a DXAscan to confirm diagnosis of osteoporosis before starting treatment with bone medication. In addition, we had no information on previous fragility fractures in the patients or their parents, therefore we do not know 
whether or not these patients met criteria for treatment based on the WHO FRAX 10-year fracture risk calculator ${ }^{49}$.

Table 5: Correlates of osteopenia in patients without bone medication (results of multivariate analysis) $(n=453)$

\begin{tabular}{|c|c|c|c|c|}
\hline & $\mathbf{N}$ & OR & $95 \% \mathrm{Cl}$ & p-value \\
\hline Male & 290 & 1.080 & $0.636-1.836$ & .775 \\
\hline \multicolumn{5}{|l|}{ Age } \\
\hline$<55$ years ${ }^{*}$ & 102 & & & \\
\hline $55-65$ years & 147 & 1.694 & $0.886-3.238$ & .111 \\
\hline$>65$ years & 204 & 3.398 & $1.695-6.811$ & $.001^{\dagger}$ \\
\hline GOLD I and II* & 114 & & & \\
\hline GOLD III & 166 & 0.938 & $0.518-1.696$ & .831 \\
\hline GOLD IV & 173 & 1.127 & $0.578-2.199$ & .725 \\
\hline Pack Years & 453 & 0.991 & $0.978-1.004$ & .175 \\
\hline \multicolumn{5}{|l|}{ Body composition } \\
\hline Normal $^{*}$ & 69 & & & \\
\hline Cachexia & 109 & 3.247 & $1.392-7.572$ & $.006^{\dagger}$ \\
\hline Muscle atrophy & 81 & 1.321 & $0.609-2.862$ & .481 \\
\hline Semi starvation & 6 & 2.852 & $0.264-30.842$ & .388 \\
\hline Overweight & 127 & 0.522 & $0.266-1.024$ & .059 \\
\hline Obese & 61 & 0.364 & $0.158-0.842$ & $.018^{\dagger}$ \\
\hline hs-CRP & 453 & 0.995 & $0.976-1.015$ & .631 \\
\hline 6 MWD & 452 & 0.999 & 0.997-1.002 & .539 \\
\hline \multicolumn{5}{|l|}{ Corticosteroids } \\
\hline Oral & 59 & 1.065 & $0.520-2.180$ & .863 \\
\hline Inhaled & 337 & 0.915 & $0.540-1.552$ & .742 \\
\hline Diuretics & 110 & 0.691 & $0.382-1.251$ & 222 \\
\hline Statins & 83 & 1.162 & $0.633-2.134$ & .629 \\
\hline$\beta$-blocking agents & 53 & 1.044 & $0.503-2.166$ & .908 \\
\hline SSRI'S & 39 & 0.780 & $0.338-1.800$ & .560 \\
\hline
\end{tabular}

\section{Correlates of osteopenia}

No previous studies have focused on risk factors for osteopenia in COPD. We found age $>65$ years and cachexia to be independent correlates. In addition, obesity was protective of osteopenia. More longitudinal studies are needed investigating potential risk factors for osteopenia in order to identify these patients and perform regular DXAscanning in order to detect progression to osteoporosis in an early stage. 


\section{Correlates of osteoporosis}

The WHO indicates that the onset of substantial bone loss starts at 65 years in men and 50 years in women ${ }^{13}$. In the present study, patients between 55 and 65 years had a 6 -fold increased risk of osteoporosis compared to younger peers, which even increased to a more than 11 -fold risk in patients over 65 years. This is the first study to find age to be a significant, independent risk factor for osteoporosis in COPD. In addition, cachectic patients had an increased risk of osteoporosis. This is in line with other studies ${ }^{16 ; 31 ; 44 ; 50}$. In the current study we combined FFMI with $\mathrm{BMI}$ in order to make a more precise risk estimation of osteoporosis in COPD patients. Indeed, Bolton and colleagues found the highest prevalence of osteoporosis (50\%) and osteopenia (50\%) in cachectic COPD patients ${ }^{14}$. Unfortunately, they did not investigate the influence of overweight or obesity on osteoporosis. In the present study, overweight and obese COPD patients had a decreased risk of osteoporosis, as compared to normal weight peers. At first this finding seems somewhat surprising, since obesity has been linked to an increased production of inflammatory cytokines which may impair bone formation ${ }^{51}$. However, an increased daily physiological mechanical loading of the cortical skeleton may prevent an abnormal loss of BMD in obese subject ${ }^{52}$.

No previous study investigated the combined effect of age and body composition on BMD in COPD patients. In the present study the combination of cachexia and age $>55$ increased the risk of osteoporosis even more than either of the two variables separately.

Female gender was not a significant risk factor for osteoporosis although in the overall population women are at increased risk of osteoporosis as compared to their male peers ${ }^{13}$. This may in part be explained by the fact that female patients were significantly younger than male patients (mean age: 59 versus 66 years). In addition we did not find an independent effect of CRP, cardiac medication and SSRl's on osteoporosis in the present sample. There are no studies in COPD patients that included the previously mentioned covariates in their analyses. However, in patients without COPD, circulating levels of high sensitivity CRP (hs-CRP) were found to be significantly higher in healthy women with the lowest BMD ${ }^{38}$. Possibly, this higher hs-CRP was not found in COPD patients with osteoporosis since hs-CRP levels are already elevated as compared to healthy subjects due to chronic low-grade systemic inflammation in COPD. In addition, thiazide diuretics, beta-blocking agents and statins 
decrease the risk of osteoporosis ${ }^{33-36}$, whereas SSRIs ${ }^{37}$ increase this risk in subjects without COPD. We found no significant influence of corticosteroids on osteoporosis. This could be due to the fact that we corrected for several other covariates including degree of airflow obstruction. Indeed, de Vries and colleagues found the influence of inhaled corticosteroids to disappear after correcting for airflow obstruction 27. In addition, the duration of treatment with oral corticosteroids, the number of courses and the cumulative dose were unknown, and different corticosteroid regimens had different effects on BMD ${ }^{21}$. Further (longitudinal) research regarding these potential confounders of osteoporosis in COPD patients is needed.

\section{Clinical considerations}

In the integrated care of COPD patients the importance of recognizing and treating extrapulmonary features is stressed ${ }^{1 ; 53}$. Based on the present results, it seems reasonable to conclude that the awareness regarding diagnosis and/or pharmacological treatment of osteoporosis in COPD patients entering pulmonary rehabilitation is rather low amongst referring chest physicians. An extensive phenotyping of complex and (mostly) extra-pulmonary features in COPD patients entering pulmonary rehabilitation seems necessary ${ }^{39}$. Recently, Shepherd and colleagues advised to screen for osteoporosis in men with COPD over 55 years of age and/or having a body weight $<80 \mathrm{~kg}^{12}$. Based on the current results, we would advise chest physicians to screen for osteoporosis in cachectic COPD patients older than 55 years, irrespective of gender or GOLD classification.

\section{Methodological considerations}

Some limitations of the current study should be noted. First, the external validity may be limited to COPD patients entering pulmonary rehabilitation. However, a comparable prevalence of osteoporosis has been found in COPD patients in primary care settings as well as in outpatients ${ }^{43 ; 45}$. Whether or not COPD patients entering rehabilitation are representative for the whole population remains currently unknown. At least the patients starting pulmonary rehabilitation form a representative sample of COPD patients referred to chest physicians. The included 
patients represent different stages of COPD severity as reflected by the GOLD stages. Second, a control group was lacking. Nevertheless, previous studies did already find an increased prevalence of osteoporosis as compared to healthy subjects ${ }^{11}$. The third limitation is that we did not have information on duration of treatment with oral corticosteroids and treatment courses in the past. However, no differences were found in prevalence of patients on maintenance oral corticosteroids between normal BMD, osteopenia and osteoporosis (table 2). Moreover, not all current oral steroid users had osteoporosis and not all osteoporotic patients used oral steroids at the time of the study. Therefore, it seems reasonable to conclude that oral steroid use may partially explain the presence of osteoporosis in patients with COPD. Then again, the pathophysiology of osteoporosis in COPD is clearly multi-factorial.

Another limitation is that we did not gather information about previous fractures in patients and their parents; important known risk factors in the general population for fractures and incorporated in the FRAX fracture calculation tool of the $\mathrm{WHO}^{49}$. However, the aim of the study was not to estimate 10-year fracture risk but to investigate prevalence, prevalence of treatment and correlates of osteoporosis as defined by DXA. More studies are needed investigating this 10-year fracture risk in COPD patients. On the other hand, more research has to be done to investigate whether or not COPD in itself should be incorporated in the FRAX scoring system like rheumatoid arthritis. Indeed, in the male osteoporosis risk estimation score COPD was included as a risk factor ${ }^{12}$. Furthermore, we did not measure daily physical (in)activity in COPD. We did use the six minutes walking distance in our analyses which can be used as a surrogate marker of daily physical activity, particularly in COPD patients with a walking distance of about 400 meters ${ }^{42}$. Finally, we used wholebody DXA instead of DXA at lumbar spine or hip and the diagnosis of osteoporosis according to the WHO is based on T-scores measured at the hip or lumbar spine ${ }^{13}$. Therefore, we used recently determined cut-off values by Boyanov in order to have a good sensitivity-to-specificity ratio in the diagnosis of lumbar spine osteoporosis and low bone mass ${ }^{41}$.

In conclusion, more than 1 out of every 5 COPD patients entering pulmonary rehabilitation has osteoporosis. However, most of these osteoporotic COPD patients do not receive WHO-advised treatment to prevent fractures. Higher age and cachexia increase the risk of osteoporosis in COPD patients, irrespective of other clinically relevant factors. In contrast, overweight and obese COPD patients have a 
decreased risk of osteoporosis. Based on our findings we advise chest physicians to refer cachectic COPD patients for a DXA-scan, especially when they are older than 55 years of age irrespective of gender or COPD severity. 


\section{Reference List}

(1) Rabe KF, Hurd S, Anzueto A, Barnes PJ, Buist SA, Calverley P et al. Global Strategy for the Diagnosis, Management, and Prevention of Chronic Obstructive Pulmonary Disease: GOLD Executive Summary. Am J Respir Crit Care Med 2007; 176(6):532-555.

(2) Murray CJ, Lopez AD. Global mortality, disability, and the contribution of risk factors: Global Burden of Disease Study. Lancet 1997; 349(9063):1436-1442.

(3) Lopez AD, Mathers CD, Ezzati M, Jamison DT, Murray CJ. Global and regional burden of disease and risk factors, 2001: systematic analysis of population health data. Lancet 2006; 367(9524):1747-1757.

(4) Standards for the diagnosis and care of patients with chronic obstructive pulmonary disease. American Thoracic Society. Am J Respir Crit Care Med 1995; 152(5 Pt 2):S77-121.

(5) Agusti AG. Systemic effects of chronic obstructive pulmonary disease. Proc Am Thorac Soc 2005; 2(4):367-370.

(6) Andreassen $\mathrm{H}$, Vestbo J. Chronic obstructive pulmonary disease as a systemic disease: an epidemiological perspective. Eur Respir J Suppl 2003; 46:2s$4 s .: 2 s-4 s$.

(7) Wouters EF. Introduction: systemic effects in chronic obstructive pulmonary disease. Eur Respir J Suppl 2003; 46:1s.:1s.

(8) Schols AM, Broekhuizen R, Weling-Scheepers CA, Wouters EF. Body composition and mortality in chronic obstructive pulmonary disease. Am J Clin Nutr 2005; 82(1):53-59.

(9) Vestbo J, Prescott E, Almdal T, Dahl M, Nordestgaard BG, Andersen T et al. Body mass, fat-free body mass, and prognosis in patients with chronic obstructive pulmonary disease from a random population sample: findings from the Copenhagen City Heart Study. Am J Respir Crit Care Med 2006; 173(1):79-83.

(10) Sabit R, Bolton CE, Edwards PH, Pettit RJ, Evans WD, McEniery CM et al. Arterial stiffness and osteoporosis in chronic obstructive pulmonary disease. Am J Respir Crit Care Med 2007; 175(12):1259-1265.

(11) Graat-Verboom L, Wouters EF, Smeenk FW, Borne van den BE, Lunde R, Spruit MA. Current status of research on osteoporosis in COPD: a systematic review. Eur Respir J. In press 2009.

(12) Shepherd AJ, Cass AR, Carlson CA, Ray L. Development and internal validation of the male osteoporosis risk estimation score. Ann Fam Med 2007; $5(6): 540-546$.

(13) WHO Scientific Group on the Prevention and Management of Osteoporosis. Prevention and management of osteoporosis: report of a WHO scientific group. (WHO technical report series; 921). http://whqlibdoc who int/trs/WHO_TRS_921 pdf [ 2007 [cited 2007 Sept. 13]; 
(14) Bolton CE, lonescu AA, Shiels KM, Pettit RJ, Edwards PH, Stone MD et al. Associated loss of fat-free mass and bone mineral density in chronic obstructive pulmonary disease. Am J Respir Crit Care Med 2004; 170(12):1286-1293.

(15) Engelen MP, Schols AM, Heidendal GA, Wouters EF. Dual-energy X-ray absorptiometry in the clinical evaluation of body composition and bone mineral density in patients with chronic obstructive pulmonary disease. Am J Clin Nutr 1998; 68(6):1298-1303.

(16) Vrieze A, de Greef MH, Wijkstra PJ, Wempe JB. Low bone mineral density in COPD patients related to worse lung function, low weight and decreased fatfree mass. Osteoporos Int 2007; 18(9):1197-1202.

(17) Freedman BA, Potter BK, Nesti LJ, Cho T, Kuklo TR. Missed opportunities in patients with osteoporosis and distal radius fractures. Clin Orthop Relat Res 2007; 454:202-206.

(18) Gruntmanis U. Male osteoporosis: deadly, but ignored. Am J Med Sci 2007; 333(2):85-92.

(19) Hajcsar EE, Hawker G, Bogoch ER. Investigation and treatment of osteoporosis in patients with fragility fractures. CMAJ 2000; 163(7):819-822.

(20) Wright RM. Use of osteoporosis medications in older nursing facility residents. J Am Med Dir Assoc 2007; 8(7):453-457.

(21) Dubois EF, Roder E, Dekhuijzen PN, Zwinderman AE, Schweitzer DH. Dual energy X-ray absorptiometry outcomes in male COPD patients after treatment with different glucocorticoid regimens. Chest 2002; 121(5):1456-1463.

(22) Gluck O, Colice G. Recognizing and treating glucocorticoid-induced osteoporosis in patients with pulmonary diseases. Chest 2004; 125(5):18591876.

(23) Goldstein MF, Fallon JJ, Jr., Harning R. Chronic glucocorticoid therapy-induced osteoporosis in patients with obstructive lung disease. Chest 1999; 116(6):1733-1749.

(24) Effect of inhaled triamcinolone on the decline in pulmonary function in chronic obstructive pulmonary disease. N Engl J Med 2000; 343(26):1902-1909.

(25) Israel E, Banerjee TR, Fitzmaurice GM, Kotlov TV, LaHive K, LeBoff MS Effects of inhaled glucocorticoids on bone density in premenopausal women. $\mathrm{N}$ Engl J Med 2001; 345(13):941-947.

(26) Wong CA, Walsh LJ, Smith CJ, Wisniewski AF, Lewis SA, Hubbard R et al. Inhaled corticosteroid use and bone-mineral density in patients with asthma. Lancet 2000; 355(9213):1399-1403.

(27) de Vries F, van Staa TP, Bracke MS, Cooper C, Leufkens HG, Lammers JW. Severity of obstructive airway disease and risk of osteoporotic fracture. Eur Respir J 2005; 25(5):879-884. 
(28) Elmstahl S, Ekstrom H, Galvard H, Johnell O, Gerhardsson d, V, Norjavaara E. Is there an association between inhaled corticosteroids and bone density in postmenopausal women? J Allergy Clin Immunol 2003; 111(1):91-96.

(29) Li JT, Ford LB, Chervinsky P, Weisberg SC, Kellerman DJ, Faulkner KG et al. Fluticasone propionate powder and lack of clinically significant effects on hypothalamic-pituitary-adrenal axis and bone mineral density over 2 years in adults with mild asthma. J Allergy Clin Immunol 1999; 103(6):1062-1068.

(30) Pauwels RA, Lofdahl CG, Laitinen LA, Schouten JP, Postma DS, Pride NB et al. Long-term treatment with inhaled budesonide in persons with mild chronic obstructive pulmonary disease who continue smoking. European Respiratory Society Study on Chronic Obstructive Pulmonary Disease. N Engl J Med 1999; 340(25):1948-1953.

(31) Incalzi RA, Caradonna P, Ranieri P, Basso S, Fuso L, Pagano F et al. Correlates of osteoporosis in chronic obstructive pulmonary disease. Respir Med 2000; 94(11):1079-1084.

(32) Looker AC, Flegal KM, Melton LJ, III. Impact of increased overweight on the projected prevalence of osteoporosis in older women. Osteoporos Int 2007; 18(3):307-313.

(33) Bonnet N, Gadois C, McCloskey E, Lemineur G, Lespessailles E, Courteix D et al. Protective effect of â blockers in postmenopausal women: Influence on fracures, bone density, micro and macroarchitecture. Bone 2007; 40(1):12091216.

(34) Pasco JA, Henry MJ, Sanders KM, Kotowicz MA, Seeman E, Nicholson GC. Beta-adrenergic blockers reduce the risk of fracture partly by increasing bone mineral density: Geelong Osteoporosis Study. J Bone Miner Res 2004; 19:1924.

(35) Schoofs MW, van der Klift M, Hofman A, de Laet CE, Herings RM, Stijnen T et al. Thiazide diuretics and the risk for hip fracture. Ann Intern Med 2003; 139:476-482.

(36) Schoofs MW, Sturkenboom MC, van der KM, Hofman A, Pols HA, Stricker BH. HMG-CoA reductase inhibitors and the risk of vertebral fracture. J Bone Miner Res 2004; 19(9):1525-1530.

(37) Haney EM, Chan BK, Diem SJ, Ensrud KE, Cauley JA, Barrett-Connor E et al. Association of low bone mineral density with selective serotonin reuptake inhibitor use by older men. Arch Intern Med 2007; 167(12):1246-1251.

(38) Koh JM, Khang YH, Jung CH, Bae S, Kim DJ, Chung YE et al. Higher circulating hsCRP levels are associated with lower bone mineral density in healthy pre- and postmenopausal women: evidence for a link between systemic inflammation and osteoporosis. Osteoporos Int 2005; 16(10):12631271.

(39) Spruit MA, Vanderhoven-Augustin I, Janssen PP, Wouters EF. Integration of pulmonary rehabilitation in COPD. Lancet 2008; 371(9606):12-13. 
(40) Baarends EM, Schols AM, Mostert R, Wouters EF. Peak exercise response in relation to tissue depletion in patients with chronic obstructive pulmonary disease. Eur Respir J 1997; 10(12):2807-2813.

(41) Boyanov M. Estimation of lumbar spine bone mineral density by dual-energy $X$ ray absorptiometry: standard anteroposterior scans vs sub-regional analyses of whole-body scans. Br J Radiol 2008; 81(968):637-642.

(42) Pitta F, Troosters T, Spruit MA, Probst VS, Decramer M, Gosselink R. Characteristics of physical activities in daily life in chronic obstructive pulmonary disease. Am J Respir Crit Care Med 2005; 171(9):972-977.

(43) Dimai HP, Domej W, Leb G, Lau KH. Bone loss in patients with untreated chronic obstructive pulmonary disease is mediated by an increase in bone resorption associated with hypercapnia. J Bone Miner Res 2001; 16(11):21322141.

(44) Iqbal F, Michaelson J, Thaler L, Rubin J, Roman J, Nanes MS. Declining bone mass in men with chronic pulmonary disease: contribution of glucocorticoid treatment, body mass index, and gonadal function. Chest 1999; 116(6):16161624.

(45) Sin DD, Man JP, Man SF. The risk of osteoporosis in Caucasian men and women with obstructive airways disease. Am J Med 2003; 114(1):10-14.

(46) Vik SA, Jantzi M, Poss J, Hirdes J, Hanley DA, Hogan DB et al. Factors associated with pharmacologic treatment of osteoporosis in an older home care population. J Gerontol A Biol Sci Med Sci 2007; 62(8):872-878.

(47) Pazianas M, Miller P, Blumentals WA, Bernal M, Kothawala P. A review of the literature on osteonecrosis of the jaw in patients with osteoporosis treated with oral bisphosphonates: prevalence, risk factors, and clinical characteristics. Clin Ther 2007; 29(8):1548-1558.

(48) Reid IR, Bolland MJ, Grey AB. Is bisphosphonate-associated osteonecrosis of the jaw caused by soft tissue toxicity? Bone 2007; 41(3):318-320.

(49) Kanis JA, Johnell O, Oden A, Johansson H, McCloskey E. FRAX and the assessment of fracture probability in men and women from the UK. Osteoporos Int 2008; 19(4):385-397.

(50) Engelen MP, Schols AM, Lamers RJ, Wouters EF. Different patterns of chronic tissue wasting among patients with chronic obstructive pulmonary disease. Clin Nutr 1999; 18(5):275-280.

(51) Weisberg SP, McCann D, Desai M, Rosenbaum M, Leibel RL, Ferrante AW, Jr. Obesity is associated with macrophage accumulation in adipose tissue. J Clin Invest 2003; 112(12):1796-1808.

(52) Reid IR. Obesity and osteoporosis. Ann Endocrinol (Paris) 2006; 67(2):125129. 
(53) Nici L, Donner C, Wouters E, Zuwallack R, Ambrosino N, Bourbeau J et al. American Thoracic Society/European Respiratory Society statement on pulmonary rehabilitation. Am J Respir Crit Care Med 2006; 173(12):1390-1413. 


\section{Chapter IV}

\section{Whole-body versus local DXA- scan for the diagnosis of osteoporosis in COPD patients}

Lidwien Graat-Verboom, Martijn A. Spruit, Ben E.E.M. van den Borne, Frank W.J.M. Smeenk and Emiel F.M. Wouters

Journal of Osteoporosis 2010; doi: 10.4061/2010/640878 


\section{Abstract}

Osteoporosis is an important extrapulmonary effect of chronic obstructive pulmonary disease (COPD). To diagnose osteoporosis bone mineral density (BMD) should be assessed by dual energy absorptiometry (DXA)scan. The best location for BMD measurement in COPD patients has not been determined. Aim of the current study was to assess whole-body BMD and BMD of the hip and lumbar spine (local DXA) in COPD patients and compare the prevalence of osteoporosis at these locations.

Whole body as well as local DXA-scan were made in 168 COPD patients entering pulmonary rehabilitation. Body composition measures, lung function, medical history, and other patient relevant characteristics were assessed. Prevalence of osteoporosis per location was determined. Patient characteristics of patients without osteoporosis were compared to patients with osteoporosis on local DXA.

A higher prevalence of osteoporosis was found using local DXA compared to whole-body DXA (39\% versus $21 \%$ ). One quarter of patients without osteoporosis on whole body-DXA did have osteoporosis on local DXA. Whereas only $4 \%$ of patients without osteoporosis on local DXA had osteoporosis on whole-body DXA. Significant differences in patient characteristics between patients without osteoporosis based on both DXA measurements and patients with osteoporosis based on local DXA only were found.

DXA of the hip and lumbar spine should be made to assess bone mineral density in COPD patients. The lowest T-score of these locations should be used to diagnose osteoporosis. 


\section{Introduction}

Chronic obstructive pulmonary disease (COPD) is characterized by a progressive airflow obstruction ' ${ }^{1}$. In addition, there are significant extrapulmonary effects, like osteoporosis. Osteoporosis is a systemic skeletal disease characterized by a low bone mineral density (BMD) and microarchitectural changes in bones leading to an increased bone fragility and, in turn, resulting in an increased fracture risk ${ }^{2}$.

The prevalence of osteoporosis in COPD is higher than in healthy agematched control subjects ${ }^{3}$. Moreover, COPD patients have a 60 to $70 \%$ higher risk of death following hip fracture than people without COPD ${ }^{4}$. It is therefore of high clinical importance to diagnose and treat osteoporosis in COPD according to international guidelines ${ }^{2}$.

The gold standard for the diagnosis of osteoporosis is dual energy absorptiometry (DXA) ${ }^{2}$. Multiple sites can be used to measure BMD by DXA. The sites most frequently used are the hip, the lumbar spine, forearm and/or whole-body. Several studies investigated the best location for DXA-scanning to diagnose osteoporosis ${ }^{5-10}$. DXA-scanning of the hip and the lumbar spine resulted in a higher prevalence of osteoporosis than whole-body DXA-scanning in pre- and post-menopausal women ${ }^{6}$. Indeed, the International Society for Clinical Densitometry advocates to measure BMD of the lumbar spine and the hip and to diagnose osteoporosis based on the lowest T-score of the measured locations ${ }^{11}$. To date, a comparison of BMD of various skeletal sites has not been performed in patients with clinically stable COPD. Therefore, the aim of this study was to compare the prevalence of osteoporosis using wholebody DXA-scanning versus local DXA-scanning (hip and lumbar spine) in male and female COPD patients. To identify risk factors for osteoporosiss, patients without osteoporosis based on both DXA measurements were compared to patients with osteoporosis based on local DXA only.

\section{Methods}

The results of 168 consecutive COPD patients between November 2007 and May 2008 at Ciro, a centre of expertise for chronic organ failure in Horn (the Netherlands) were included in this retrospective study. All 
patients underwent all the tests during a 3-day baseline assessment before entering a patient-tailored pulmonary rehabilitation program ${ }^{12}$. Therefore, our manuscript does not include a statement of patient consent and the approval of Internal Review Boards.

Medical history, current medication use and smoking status were assessed. Post-bronchodilator pulmonary function tests were performed (Jaeger MASTERLABBODY® , VIASYS Healthcare) and COPD was diagnosed and classified according to the GOLD guidelines ${ }^{1}$. Body mass index (BMI) was defined as low $\left(<21 \mathrm{~kg} / \mathrm{m}^{2}\right)$, normal $\left(21-25 \mathrm{~kg} / \mathrm{m}^{2}\right)$, overweight $\left(>25-30 \mathrm{~kg} / \mathrm{m}^{2}\right)$ and obese $\left(>30 \mathrm{~kg} / \mathrm{m}^{2}\right)$. Fat free mass index (FFMI) was assessed by bio-impedance analysis (BODYSTAT ${ }^{\circledR} 1500$ medical, single frequency; Xitron Technologies) and classified as depleted (men $<16 \mathrm{~kg} / \mathrm{m}^{2}$ and women $<15 \mathrm{~kg} / \mathrm{m}^{2}$ ) or normal ${ }^{13}$. A sixminute walking distance test was performed to estimate functional exercise capacity ${ }^{14}$. Arterial blood gases were collected to determine $\mathrm{pH}$, arterial carbon dioxide tension $\left(\mathrm{PaCO}_{2}\right)$ and arterial oxygen tension $\left(\mathrm{PaO}_{2}\right)$.

Whole-body BMD as well as BMD at the femur and the lumbar spine (L1L4) were assessed for each patient using a DXA-scan (Lunar Prodigy ${ }^{\circledR}$ Ge-Lunar). Because the risk of hip and vertebral fractures are similar in men and women for any given BMD we used the NHANES III data to calculate T-scores for both men and women ${ }^{15 ; 16}$. For whole-body DXA osteoporosis was defined by a T-score $<-2.35$, osteopenia: T-score between -2.35 and -0.9 , normal BMD: T-score $>-0.9^{17}$. For local DXA osteoporosis was defined by a $T$-score of $\leq-2.5$, osteopenia as $T$-score between -1 and -2.5 and normal BMD: T-score $>-1^{2}$. To compare different locations of DXA-scan we divided groups in osteoporosis and no osteoporosis (osteopenia and normal BMD combined) because only patients with osteoporosis need to be treated pharmacologically.

\section{Statistical analyses}

Discrete variables were compared with the Chi-square test and presented as percentages. Continuous variables were compared with independent t-test and presented as means \pm standard deviation (SD). Pearson correlation was used. To estimate the relative risk a McNemars test was used. A p-value of $<0.05$ was considered significant. All statistical analyses were performed using Statistical Package for Social Sciences (SPSS) version 16.0. 


\begin{tabular}{|c|c|c|c|c|}
\hline & $\begin{array}{ll}\begin{array}{l}\text { Total } \\
(\mathrm{N}=168)\end{array} & \text { Group } \\
\end{array}$ & Men ( $\mathrm{N}=103)$ & Women $(\mathrm{N}=65)$ & p-value \\
\hline Age, years & $63.6 \pm 9.1(39-85)$ & $65.9 \pm 8.6$ & $60.0 \pm 8.7$ & $<0.001$ \\
\hline FEV1, \%predicted & $44.3 \pm 18.5$ & $45.06 \pm 18.1$ & $43.12 \pm 19.2$ & 0.0510 \\
\hline GOLD I, \% & 6.0 & 6.8 & 4.6 & \\
\hline GOLD II, \% & 24.6 & 24.3 & 26.2 & \\
\hline GOLD III, \% & 26.3 & 30.1 & 20.0 & 0.402 \\
\hline GOLD IV, \% & 43.1 & 38.8 & 49.2 & \\
\hline \multicolumn{5}{|l|}{ Arterial blood gas } \\
\hline $\mathrm{pH}$ & $7.43 \pm 0.03$ & $7.44 \pm 0.03$ & $7.43 \pm 0.03$ & 0.078 \\
\hline $\mathrm{PaCO}_{2}, \mathrm{kPa}$ & $5.4 \pm 0.8$ & $5.4 \pm 0.9$ & $5.6 \pm 0.7$ & 0.106 \\
\hline $\mathrm{PaO}_{2}, \mathrm{kPa}$ & $9.5 \pm 1.4$ & $9.5 \pm 1.5$ & $9.4 \pm 1.3$ & 0.466 \\
\hline $\mathrm{SO}_{2}, \%$ & $95 \pm 3$ & $94 \pm 3$ & $95 \pm 2$ & 0.536 \\
\hline \multicolumn{5}{|l|}{ Smoking } \\
\hline Ex-Smoker*, \% & 66.7 & 71.8 & 58.5 & 0.073 \\
\hline Pack Years & $38.8 \pm 15.5$ & $38.9 \pm 15.0$ & $38.8 \pm 1603$ & 0.960 \\
\hline BMI, $\mathbf{k g} / \mathrm{m}^{2}$ & $24.7 \pm 4.4$ & $24.7 \pm 4.4$ & $24.7 \pm 4.5$ & 0.960 \\
\hline Low, \% & 20.8 & 21.4 & 20.0 & \\
\hline Normal, \% & 30.4 & 33.0 & 26.2 & 0.561 \\
\hline High, \% & 38.1 & 34.0 & 44.6 & \\
\hline Obese, \% & 10.7 & 11.7 & 9.2 & \\
\hline FFMI, $\mathrm{kg} / \mathrm{m}^{2}$ & $16.1 \pm 2.1$ & $16.8 \pm 2.0$ & $15.1 \pm 1.8$ & $<0.001$ \\
\hline Normal/Low, \% & $58.9 / 41.1$ & $61.2 / 38.8$ & $55.4 / 44.6$ & 0.458 \\
\hline \multicolumn{5}{|l|}{ Whole body DXA } \\
\hline BMD, $\mathbf{g} / \mathrm{cm}^{2}$ & $1.079 \pm 0.118$ & $1.113 \pm 0.114$ & $1.025 \pm 0.103$ & $<0.001$ \\
\hline T-score & $-1.3 \pm 1.4$ & $-1.3 \pm 1.4$ & $-1.3 \pm 1.3$ & 0.762 \\
\hline Normal BMD, \% & 40.5 & 41.7 & 38.5 & 0.075 \\
\hline Osteopenia, \% & 36.9 & 31.1 & 46.2 & 0.217 \\
\hline Osteoporosis, \% & 22.6 & 27.2 & 15.4 & 0.081 \\
\hline \multicolumn{5}{|l|}{ DXA hip } \\
\hline BMD, $\mathrm{g} / \mathrm{cm}^{2}$ & $0.827 \pm 0.149$ & $0.858 \pm 0.146$ & $0.779 \pm 0.143$ & 0.001 \\
\hline T-score & $-1.7 \pm 1.1$ & $-1.6 \pm 1.1$ & $-1.9 \pm 1.0$ & 0.151 \\
\hline Normal BMD, \% & 22.6 & 25.2 & 18.5 & \\
\hline Osteopenia, \% & 52.4 & 53.4 & 52.3 & 0.400 \\
\hline Osteoporosis, \% & 25.0 & 21.4 & 29.2 & \\
\hline \multicolumn{5}{|l|}{ DXA LS } \\
\hline BMD, $\mathbf{g} / \mathbf{c m}^{2}$ & $1.065 \pm 0.215$ & $1.088 \pm 0.211$ & $1.027 \pm 0.218$ & 0.074 \\
\hline T-score & $-1.3 \pm 1.8$ & $-1.2 \pm 1.8$ & $-1.4 \pm 1.8$ & 0.471 \\
\hline Normal BMD, \% & 39.3 & 44.7 & 30.8 & \\
\hline Osteopenia, \% & 33.3 & 30.1 & 38.5 & 0.198 \\
\hline Osteoporosis, \% & 27.4 & 25.2 & 30.8 & \\
\hline \multicolumn{5}{|l|}{ DXA hip and LS } \\
\hline Normal BMD, \% & 15.5 & 19.4 & 10.8 & \\
\hline Osteopenia, \% & 45.8 & 46.6 & 43.1 & 0.175 \\
\hline Osteoporosis, \% & 38.7 & 34.0 & 46.2 & \\
\hline 6MWD, m (n=165) & $420.61 \pm 135.66$ & $454.41 \pm 132.57$ & $368.62 \pm 124.28$ & $<0.001$ \\
\hline Oral corticosteroids, \% & 17,9 & 18.4 & 16.9 & 0.802 \\
\hline Daily dose ${ }^{\#}, \mathrm{mg}$ & $5.9 \pm 2.1(2.5-10)$ & $6.1 \pm 2.1$ & $5.7 \pm 2.3$ & 0.653 \\
\hline Inh corticosteroids, \% & $85.7 \%$ & 83.5 & 89.2 & 0.301 \\
\hline \multicolumn{5}{|c|}{ 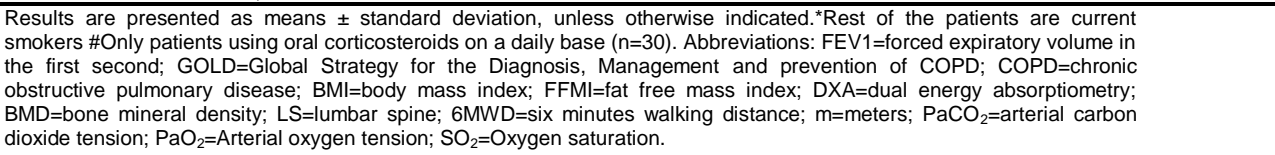 } \\
\hline
\end{tabular}




\section{Results}

Mostly male patients with clinically stable, mild to very severe COPD were studied. Based on whole-body DXA-scan prevalence of osteoporosis was $22.6 \%$ versus $38.7 \%$ based on hip and/or the lumbar spine DXA-scan (local DXA) (table 1).

Twenty-five percent of the 130 patients with a T-score $>-2.35$ as determined by whole-body DXA did have osteoporosis based on local DXA. In contrast, only $3.7 \%$ of the 103 patients with a T-score $>-2.5$ as determined by local DXA did have osteoporosis based on whole-body DXA (table 2). This difference in prevalence was highly significant $(p<0.0001)$. The relative risk of having osteoporosis on local DXA in case of no osteoporosis on whole-body DXA was 6.4 times higher than the risk of having osteoporosis on whole-body DXA in case of no osteoporosis at local spine DXA (table 2).

Table 2: Osteoporosis versus no osteoporosis based on local DXA and whole body DXA.

\begin{tabular}{l|ll}
\hline & Local DXA \\
Whole body DXA & Osteoporosis & No osteoporosis \\
\hline Osteoporosis & 33 & 5 \\
No osteoporosis & 32 & 98 \\
\hline $\begin{array}{l}\text { Post Hoc test (McNemar): Relative risk 6.4; 95\% confidence interval 2.93-32.06; } p<0.0001 . \\
\text { (Relative risk: the risk of having osteoporosis on local DXA in case of a normal whole-body } \\
\text { DXA is 6.4 times higher than the risk of having osteoporosis on whole body DXA in case of } \\
\text { a normal local DXA). }\end{array}$
\end{tabular}

Table 3: Osteoporosis versus no osteoporosis based on DXA of the lumbar spine and of the hip.

\begin{tabular}{l|ll}
\hline DXA Hip & & \\
\hline Osteoporosis & Osteoporosis & No osteoporosis \\
No osteoporosis & 23 & 19 \\
& 23 & 103 \\
\hline
\end{tabular}

Post hoc test (McNemar): Relative risk 1.21; $\mathrm{p}=0.644$. (Relative risk: the risk of having osteoporosis on lumbar spine DXA in case of a normal hip DXA is 1.21 times higher than the risk of having osteoporosis on hip DXA in case of a normal lumbar spine DXA). Abbreviations: LS=lumbar spine. 
Almost $16 \%$ of 122 patients with T-scores $>-2.5$ as determined by DXA at the lumbar spine did have osteoporosis based on DXA at the hip. In addition, a little over $18 \%$ of 126 patients with T-scores $>-2.5$ based on hip DXA-scanning did have osteoporosis on DXA-scan of the lumbar spine (table 3). This difference was not significant $(p=0.644)$.

Significant differences were found in gender-distribution, proportion of GOLD IV patients, arterial blood gases, and functional exercise capacity between COPD patients without osteoporosis on whole-body DXA as well as local (hip and lumbar spine) DXA (group I) and those without osteoporosis on whole body DXA and with osteoporosis on local DXA (group II) (table 4).

\section{Discussion}

Appreciating the possible impact of osteoporosis on fractures and survival in COPD ${ }^{4}$, it is clinically important to have an early and accurate diagnosis. In the present study a method-specific difference in diagnosing osteoporosis has been found in patients with COPD. Indeed, whole-body DXA-scanning underestimates the prevalence of osteoporosis in COPD (table 1). This finding is in accordance with the findings in pre- and postmenopausal women without COPD $^{6}$.

The prevalence of osteoporosis has been shown to differ when the same cut-off value for the T-score is used to define osteoporosis ${ }^{18 ; 19}$. This leads to an over- or under estimation of osteoporosis depending on the method used to asses BMD. In order to compare whole-body DXA to local DXA we corrected for this difference in methodology by defining osteoporosis according to Boyanov ${ }^{17}$ and the $\mathrm{WHO}^{2}$, respectively. In turn, a good sensitivity-to-specificity ratio in the diagnosis of osteoporosis was obtained $^{17}$.

A possible explanation for the method-specific differences in prevalence of osteoporosis may be age-related. Indeed, loss of BMD of the lumbar spine occurs at a younger age than loss of BMD of the hip ${ }^{6 ; 20}$. In addition, due to degenerative changes of the spine at higher age, lumbar BMD could even be increased in the elderly. In the present trial the prevalence of osteoporosis was slightly higher using lumbar spine DXA (27.4\%) compared to hip DXA (25.0\%), while the prevalence of 
osteopenia was clearly higher in the latter group (33.3\% vs $52.4 \%$ ). Consequently, these patients may be at risk to develop osteoporosis.

Table 4: Differences between patients without osteoporosis and osteoporosis on local DXA

\begin{tabular}{|c|c|c|c|}
\hline & Group I (N=98) & Group II (N=32) & p-value \\
\hline Male/Female, \% & $64 / 36$ & $38 / 62$ & 0.008 \\
\hline Age, years & $64.0 \pm 9.2$ & $61.7 \pm 9.2$ & 0.229 \\
\hline FEV1, \% predicted & $46.6 \pm 17.3$ & $40.7 \pm 20.9$ & 0.110 \\
\hline GOLD I, \% & 5 & 6 & 0.803 \\
\hline GOLD II, \% & 29 & 19 & 0.272 \\
\hline GOLD III, \% & 31 & 16 & 0.097 \\
\hline GOLD IV, \% & 36 & 59 & 0.018 \\
\hline \multicolumn{4}{|l|}{ Arterial blood gas } \\
\hline $\mathrm{pH}$ & $7.43 \pm 0.03$ & $7.42 \pm 0.03$ & 0.267 \\
\hline $\mathrm{PaCO}_{2}(\mathrm{kPa})$ & $5.38 \pm 0.72$ & $5.71 \pm 0.85$ & 0.033 \\
\hline $\mathrm{PaO}_{2}(\mathrm{kPa})$ & $9.62 \pm 1.28$ & $9.00 \pm 1.51$ & 0.024 \\
\hline $\mathrm{SO}_{2}(\%)$ & $94.91 \pm 2.54$ & $93.73 \pm 3.03$ & 0.032 \\
\hline BMI & $25.88 \pm 3.93$ & $25.11 \pm 4.03$ & 0.342 \\
\hline Low BMI,\% & 8 & 19 & 0.093 \\
\hline Normal BMI, \% & 35 & 25 & 0.309 \\
\hline High BMI, \% & 43 & 47 & 0.691 \\
\hline Obese BMI, \% & 14 & 9 & 0.474 \\
\hline 6MWD, meters & $443 \pm 128$ & $354 \pm 146$ & 0.002 \\
\hline \multicolumn{4}{|c|}{$\begin{array}{l}\text { Group I = Patients without osteoporosis on total body DXA-scan and without osteoporosis } \\
\text { on local DXA-scan. } \\
\text { Group II = Patients without osteoporosis on total body DXA-scan and with osteoporosis on } \\
\text { local DXA-scan. } \\
\text { Results are presented as mean } \pm \text { standard deviation or as } \% \text { of the group. } \\
\text { Abbreviations: FEV1 = forced vital capacity in the first second; GOLD = Global Strategy for } \\
\text { the Diagnosis, Management and prevention of COPD; COPD = chronic obstructive } \\
\text { pulmonary disease; PaCO } 2=\text { arterial blood carbon dioxide tension; } \mathrm{PaO} 2=\text { arterial blood } \\
\text { oxygen tension; SO } 2=0 x y g e n \text { saturation in arterial blood; BMI = body mass index. } 6 \mathrm{MWD} \\
=6 \text { minutes walking distance. }\end{array}$} \\
\hline
\end{tabular}

The International Society for Clinical Densitometry stated that the BMD of the spine and the hip should be measured and diagnosis of osteoporosis should be based on the lowest T-score of either the spine or the hip ${ }^{11}$. Indeed, in our COPD patients we found the prevalence of osteoporosis based on DXA of the hip to be $25 \%$, of the lumbar spine $27.4 \%$ and of the hip and lumbar spine combined $38.7 \%$ (table 1). In combination with the fact that $25 \%$ of patients without osteoporosis on whole-body DXA had osteoporosis on local DXA it seems reasonable to advise DXA of the hip and the lumbar spine and diagnose osteoporosis based on the lowest $\mathrm{T}$ score in COPD patients. The costs of a whole-body DXA are the same as a local DXA scan. In addition, the cost of a DXA of the hip or the lumbar spine only are equal to the costs of a DXA scan of both the hip and lumbar spine. Therefore, there are no economical reasons to limit DXA- 
scan to the hip only. In addition, the time to make a local DXA scan is less than the time to make a whole body DXA. More research is needed to assess risk factors for osteoporosis in COPD in order to determine which patients should be evaluated for osteoporosis.

The current study showed that the group of patients without osteoporosis on whole-body DXA but with osteoporosis on local DXA consisted of significantly more females than males, patients with a lower six minutes walking distance and more patients with GOLD IV and higher paCO2 and lower paO2 levels as compared to patients without osteoporosis on both total body- and local DXA (table 4). Therefore, in this group of patients it seems even more important to use local DXA to determine BMD instead of whole-body DXA. Even more because in the general population the fracture risk is increased in females ${ }^{21}$ and in COPD patients a higher prevalence of osteoporosis has been found in patients with higher GOLD classification and/or hypercapnic patients ${ }^{22-26}$. In the current study, the increased number of patients with GOLD IV COPD in group I is probably not due to increased airway obstruction (FEV1 was not significantly different in both groups), but to hypercapnia and/or hypoxemia (table 4). Indeed, Dimai and colleagues found a significantly lower BMD and increased serum cross-linked telopeptide of type I collagen (a bone resorption marker) in hypercapnic patients suggesting that hypercapnia induces increased bone resorption ${ }^{23}$. With decreased daily physical activity hip BMD especially will be decreased, which will be compensated by the BMD of other non-weight baring body parts when whole body BMD is assessed.

When results of whole body DXA-scanning were added to local DXAscanning only 4 extra patients without osteoporosis on local DXA had a T-score of $\leq-2.5$ on the whole body DXA-scan (2.4\%).

To conclude, future COPD trials, in which the diagnosis and/or treatment of osteoporosis is a primary outcome measure and in daily clinical practice, the most sensitive procedure for diagnosing osteoporosis should be used. On the basis of our findings we advise to assess the BMD at the hip and lumbar spine and finally take the lowest T-score of these 2 locations to determine the prevalence of osteoporosis. 


\section{Reference List}

(1) Rabe KF, Hurd S, Anzueto A, Barnes PJ, Buist SA, Calverley P et al. Global strategy for the diagnosis, management, and prevention of chronic obstructive pulmonary disease: GOLD executive summary. Am J Respir Crit Care Med 2007; $176(6): 532-555$.

(2) WHO Scientific Group on the Prevention and Management of Osteoporosis. Prevention and Management of Osteoporosis: report of a WHO scientific group. http;//whqlibdoc who int/trs/WHO_TRS_921 pdf [ 2007

(3) Graat-Verboom L, Wouters EF, Smeenk FW, Borne van den BE, Lunde R, Spruit MA. Current status of research on osteoporosis in COPD: a systematic review. Eur Respir J. In press 2009.

(4) de LC, Brimacombe M, Pedersen L, Sorensen HT. Chronic obstructive pulmonary disease and mortality following hip fracture: a population-based cohort study. Eur J Epidemiol 2008; 23(2):115-122.

(5) Arabi A, Baddoura R, Awada H, Khoury N, Haddad S, Ayoub G et al. Discriminative ability of dual-energy $\mathrm{X}$-ray absorptiometry site selection in identifying patients with osteoporotic fractures. Bone 2007; 40(4):1060-1065.

(6) Arlot ME, Sornay-Rendu E, Garnero P, Vey-Marty B, Delmas PD. Apparent preand postmenopausal bone loss evaluated by DXA at different skeletal sites in women: the OFELY cohort. J Bone Miner Res 1997; 12(4):683-690.

(7) Franck H, Munz M. Total body and regional bone mineral densitometry (BMD) and soft tissue measurements: correlations of BMD parameter to lumbar spine and hip. Calcif Tissue Int 2000; 67(2):111-115.

(8) Leslie WD, Tsang JF, Caetano PA, Lix LM. Number of osteoporotic sites and fracture risk assessment: a cohort study from the Manitoba Bone Density Program. J Bone Miner Res 2007; 22(3):476-483.

(9) Nelson DA, Molloy R, Kleerekoper M. Prevalence of osteoporosis in women referred for bone density testing: utility of multiple skeletal sites. J Clin Densitom 1998; 1(1):5-11.

(10) Nickols-Richardson SM, Miller LE, Wootten DF, Beiseigel JM, Zack MK, Ramp WK et al. Distal tibia areal bone mineral density: use in detecting low aBMD of the hip in young women. J Clin Densitom 2005; 8(1):74-79.

(11) 2007 official positions of The International Society For Clinical Densitometry. 2008. 10-7-2008.

Ref Type: Internet Communication

(12) Spruit MA, Vanderhoven-Augustin I, Janssen PP, Wouters EF. Integration of pulmonary rehabilitation in COPD. Lancet 2008; 371(9606):12-13.

(13) Schols AM, Soeters PB, Dingemans AM, Mostert R, Frantzen PJ, Wouters EF. Prevalence and characteristics of nutritional depletion in patients with stable 
COPD eligible for pulmonary rehabilitation. Am Rev Respir Dis 1993; 147(5):1151-1156.

(14) Pitta F, Troosters T, Spruit MA, Probst VS, Decramer M, Gosselink R. Characteristics of physical activities in daily life in chronic obstructive pulmonary disease. Am J Respir Crit Care Med 2005; 171(9):972-977.

(15) Looker AC, Orwoll ES, Johnston CC, Jr., Lindsay RL, Wahner HW, Dunn WL et al. Prevalence of low femoral bone density in older U.S. adults from NHANES III. J Bone Miner Res 1997; 12(11):1761-1768.

(16) Looker AC, Wahner HW, Dunn WL, Calvo MS, Harris TB, Heyse SP et al. Updated data on proximal femur bone mineral levels of US adults. Osteoporos Int 1998; 8(5):468-489.

(17) Boyanov M. Estimation of lumbar spine bone mineral density by dual-energy Xray absorptiometry: standard anteroposterior scans vs sub-regional analyses of whole-body scans. Br J Radiol 2008; 81(968):637-642.

(18) Faulkner KG, von SE, Miller P. Discordance in patient classification using Tscores. J Clin Densitom 1999; 2(3):343-350.

(19) Lu Y, Genant HK, Shepherd J, Zhao S, Mathur A, Fuerst TP et al. Classification of osteoporosis based on bone mineral densities. J Bone Miner Res 2001; 16(5):901-910.

(20) Blumsohn A, Eastell R. Osteoporosis: etiology, diagnosis, and management. Second ed. ed. Philadelphia: Lippincott-Raven; 1995.

(21) Kanis JA, Johnell O, Oden A, Johansson H, McCloskey E. FRAX and the assessment of fracture probability in men and women from the UK. Osteoporos Int 2008; 19(4):385-397.

(22) Bikle DD, Halloran B, Fong L, Steinbach L, Shellito J. Elevated 1,25dihydroxyvitamin $D$ levels in patients with chronic obstructive pulmonary disease treated with prednisone. J Clin Endocrinol Metab 1993; 76(2):456-461.

(23) Dimai HP, Domej W, Leb G, Lau KH. Bone loss in patients with untreated chronic obstructive pulmonary disease is mediated by an increase in bone resorption associated with hypercapnia. J Bone Miner Res 2001; 16(11):2132-2141.

(24) Kjensli A, Mowinckel P, Ryg MS, Falch JA. Low bone mineral density is related to severity of chronic obstructive pulmonary disease. Bone 2007; 40(2):493-497.

(25) Mineo TC, Ambrogi V, Mineo D, Fabbri A, Fabbrini E, Massoud R. Bone mineral density improvement after lung volume reduction surgery for severe emphysema. Chest 2005; 127(6):1960-1966.

(26) Vrieze A, de Greef MH, Wijkstra PJ, Wempe JB. Low bone mineral density in COPD patients related to worse lung function, low weight and decreased fat-free mass. Osteoporos Int 2007; 18(9):1197-1202. 
Chapter IV 


\section{Chapter V}

\section{Osteoporosis in COPD outpatients based on bone mineral density and vertebral fractures}

Lidwien Graat-Verboom, Ben E.E.M. van den Borne, Frank W.J.M. Smeenk, Martijn A. Spruit and Emiel F.M. Wouters

Journal of Bone and Mineral Research 2011; 26: 561-568 


\section{Abstract}

One of the extrapulmonary effects of chronic obstructive pulmonary disease (COPD) is osteoporosis. Osteoporosis is characterized by a low bone mineral density (BMD) and microarchitectural deterioration. Most studies in COPD patients use dual energy absorptiometry (DXA) scan only to determine osteoporosis, therefore microarchitectural changes without a low BMD are missed.

Aim of the current study was to determine the prevalence and correlates of osteoporosis in COPD patients based on DXA-scan, X-ray of the spine (X-spine) and the combination thereof.

DXA-scan, X-spine, pulmonary function testing, body composition, 6minutes walking distance, medical history and medication use were assessed in 255 clinically stable COPD outpatients of a large teaching hospital in the Netherlands.

Half of all patients had radiological evidence for osteoporosis. Combining the results of DXA-scans with X-spine augmented the proportion of COPD patients with osteoporosis compared to both methods separately. The prevalence of osteoporosis was not significantly different after stratification for GOLD-stage. Most patients with osteoporosis did not receive pharmacological treatment. Age, body mass index (BMI) and parathormone (PTH) were significant independent correlates for osteoporosis.

Chest physicians should be aware of the high prevalence of osteoporosis in COPD even in case of a low GOLD score. Especially in elder COPD patients with a low BMI and/or an increased PTH. 


\section{Introduction}

Although primarily a pulmonary disease, chronic obstructive pulmonary disease (COPD) has important systemic features ${ }^{1}$, like skeletal muscle atrophy and weakness ${ }^{2}$, arterial stiffness ${ }^{3}$ and osteoporosis. Indeed, COPD patients have been found to have an increased prevalence of osteoporosis as compared to healthy subjects ${ }^{4}$.

Osteoporosis is a systemic skeletal disease characterized by a low bone mineral density (BMD) and/or microarchitectural deterioration resulting in an increased bone fragility and hence an increased fracture risk $^{5}$. Currently, the gold standard to diagnose osteoporosis is a dual energy absorptiometry (DXA) scan ${ }^{5}$.

The major disadvantage of a DXA-scan is that only a decreased BMD can be assessed and not changes in microarchitecture. Theoretically, in case of vertebral fracture, the BMD of the lumbar spine as measured by DXA-scan might even be falsely elevated. Therefore, the ideal diagnostic test for osteoporosis has the potential to assess microarchitectural changes as well as changes in BMD.

Unfortunately, microarchitectural changes can be assessed by histomorphometric or micro-CT analysis of bone-biopsy samples ${ }^{6}$, which is too invasive to be considered in a clinical routine setting. Fragility fractures can be the result of a decreased BMD as well as changes in microarchitecture. Indeed, subjects without osteoporosis as determined by DXA-scan have been found to have vertebral fractures ${ }^{7-9}$ and should therefore be considered osteoporotic as well. Vertebral fractures can be assessed on an X-ray of the vertebral spine (X-spine) by a semiquantitative method according to Genant ${ }^{10}$. Indeed, a strong relationship between severity of vertebral fracture and microarchitectural deterioration assessed by bone biopsies has been found ${ }^{6}$.

Based on DXA-scans, the prevalence of osteoporosis in COPD patients with GOLD stage II to IV varies between 9 to $69 \%{ }^{4}$. In addition, the prevalence of vertebral fractures of the thoracic spine was $42 \%$ in a group of 2981 COPD patients ${ }^{11}$. Then again, the proportion of osteoporotic COPD patients will increase when combining local DXAscans with vertebral fractures as shown in the study by Jørgensen and colleagues $^{12}$. However, in the latter study only 62 patients with severe to very severe COPD were studied. Moreover, patients were not extensively 
characterized and patients with mild or moderate COPD were not included. Indeed, the degree of airflow limitation, together with measures of body composition and the use of corticosteroids have been identified as possible clinical correlates of osteoporosis in COPD ${ }^{4}$.

To date, it remains unknown whether and to what extent these correlates of osteoporosis are interrelated in patients with COPD. Therefore, we aimed to determine the prevalence of osteoporosis in a wellcharacterized cohort of clinically stable COPD outpatients (GOLD stages I to IV). Moreover, we explored the importance of these factors relating to the presence of osteoporosis in a single study using local DXA scans and $\mathrm{X}$-rays of the spine. Early identification of correlates of osteoporosis may allow chest physicians to better monitor and stabilize the impaired bone mineral density and/or micro architectural changes in patients with COPD.

\section{Methods}

Patient population and study design

Clinically stable patients with a history of COPD were recruited at the outpatient respiratory department of a large clinical teaching hospital (Catharina Hospital) in Eindhoven (the Netherlands) and included in this cross-sectional study. Recruiting period was from May 2005 till July 2008. Diagnosis of COPD was made according to the American Thoracic Society (ATS $)^{13}$ and categorized in accordance with the GOLDguidelines ${ }^{1}$. Written informed consent was obtained of all patients and the study was approved of by the Medical Ethical Committee of the Catharina Hospital Eindhoven (METC number: M05-1522; clinical trials.gov ID number: NCT 00231127).

\section{Clinical characteristics}

Medical history, medication use, smoking history, alcohol use, fractures in the past of the patient or their parents and daily calcium intake were assessed with a questionnaire and by reviewing the medical charts. Cumulative oral and intravenous corticosteroid use were assessed by reviewing the medical charts from the start of referral to the chest 
physician until start of the study. The charlson co-morbidity index was used to score the presence and severity of co-morbidities ${ }^{14}$ (see online supplement). All patients had COPD, therefore the minimum score was 1 point.

Height and weight were measured and body mass index (BMI) was calculated and defined as low $\left(<21 \mathrm{~kg} / \mathrm{m}^{2}\right)$, normal $\left(21-25 \mathrm{~kg} / \mathrm{m}^{2}\right)$, overweight $\left(>25-30 \mathrm{~kg} / \mathrm{m}^{2}\right)$ and obese $\left(>30 \mathrm{~kg} / \mathrm{m}^{2}\right)$. Bio-impedance analysis was done using the BODYSTAT® 1500 medical, single frequency (Xitron Technologies) and fat free mass index (FFMI) was defined as depleted (men $<16 \mathrm{~kg} / \mathrm{m}^{2}$ and women $<15 \mathrm{~kg} / \mathrm{m}^{2}$ ) or normal ${ }^{15}$.

Lung function parameters were assessed using the Jaeger MASTERLAB BODY® (VIASYS Healthcare), post-bronchodilator forced expiratory volume in the first second $\left(\mathrm{FEV}_{1}\right)$ and forced vital capacity (FVC) were measured and $\mathrm{FEV}_{1} / \mathrm{FVC}$ was calculated. All included patients had an $\mathrm{FEV}_{1} / \mathrm{FVC}$ of $<70 \%$. According to the GOLD guidelines patients with an $\mathrm{FEV}_{1} \geq 80 \%$ predicted were classified as GOLD I, patients with an $\mathrm{FEV}_{1}$ between $50 \%$ and $80 \%$ of predicted as GOLD II, patients with an $\mathrm{FEV}_{1}$ between $30 \%$ and $50 \%$ as GOLD III and finally, patients with an $\mathrm{FEV}_{1}<$ $30 \%$ as GOLD IV ${ }^{1}$. In addition, total lung capacity (TLC), residual volume $(\mathrm{RV})$ and the diffusing capacity for carbon monoxide corrected for the alveolar volume (TLCO $\left.\mathrm{VA}_{\mathrm{A}}\right)$ were assessed and RV as percentage of TLC (RV\%TLC) was calculated.

A six minutes walking distance (6MWD) was determined according to the most recent ATS guidelines ${ }^{16}$ to assess functional exercise tolerance.

Venous blood was obtained and total leucocytes and C-reactive protein (CRP) were determined to assess inflammatory status. In addition, vitamin-D, parathyroid hormone (PTH) and thyroid stimulating hormone (TSH) were assessed since they are known to influence bone-turnover ${ }^{17-}$ 19. Vitamin-D deficiency was defined as 25-hydroxyvitamin D3 $(25 \mathrm{OH}$ D3) $<50 \mathrm{nmol} / \mathrm{L}^{20 ; 21}$.

\section{Bone status}

BMD of the neck and trochanter of the hip and of the lumbar spine (L1L4) were measured on a Delphi upgraded to Discovery W (S/N 70991) 
DXA-scan. Diagnosis of osteoporosis was based on the lowest T-score of the 3 measured locations and defined according to the WHO (osteoporosis: T-score $\leq-2.5$; osteopenia: T-score between -2.5 and -1 ; normal BMD: T-score $>-1)^{5}$. In case of vertebral fractures (see below) or significant osteoarthritis of the lumbar spine, BMD at the lumbar spine was not assessed.

X-rays of the lumbar spine were performed using a digital Bucky system (Digital Diagnost or H-Diagnost-Om65-CS64, Philips Medical Systems). For the thoracic spine a lateral chest $X$-ray was used when made within 1 month of inclusion in the study. If no lateral chest X-ray was available or if the end-plates of the vertebrae could not be clearly visualized, an X-ray of the thoracic spine was made. In all patients X-rays of the lumbar spine were made. Vertebral bodies of T4 to L4 were measured independently by two investigators (LG-V and JvE), both of them were trained by a radiologist (FJ) with special knowledge in this field.

Vertebral fractures were defined according to Genant ${ }^{10}$. Fractures were classified as 'mild' (20-25\% reduction in anterior, middle and/or posterior height and $10-20 \%$ reduction of the projected vertebral area), 'moderate' (25-40\% reduction in heights and $20-40 \%$ reduction of the projected vertebral area) and 'severe' ( $\geq 40 \%$ reduction in heights). In addition, fractures were classified according to their shape: wedge (reduction in anterior height), biconcave (reduction in middle height) or crush (reduction in posterior height). In case of disagreement between the two assessors of vertebral fractures the radiologist made the final decision. In case of one or more vertebral fractures without a high energy trauma, patients were diagnosed to have osteoporosis.

In addition, the 10-year fracture risk was calculated by using the FRAXscore $^{22}$ (see online supplement).

\section{Statistical analysis}

To compare patient characteristics between different GOLD stages discrete variables were presented as percentages and compared with the Chi-square test. Moreover, continuous variables were presented as means \pm standard deviation (SD) and compared with analysis of variance, post hoc LSD-test. 
Univariate- and multivariate multinomial logistic regression analyses (enter procedure) were performed to investigate determinants of osteopenia and osteoporosis based on DXA and X-spine. Only patients without bone medication were analyzed. Univariate analyses with osteoporosis, osteopenia and normal BMD as dependent variable were used to test for the potentially confounding effect of biomedical and demographic factors. If significant at $p<0.05$, the variables were included into the multivariate analyses. A $p$-value $<0.05$ was used to indicate statistical significance. Odds ratio (OR) with $95 \%$ confidence intervals (Cl) are reported. All statistical analyses were performed using Statistical Package for Social Sciences (SPSS) version 16.0.

\section{Results}

Characteristics

Two-hundred fifty five patients with COPD were included $(62 \%$ men; GOLD stage I; II; III; IV: $n=71 ; 100 ; 57 ; 27$, respectively). A majority of the patients were ex-smokers, had an overweight BMI, a normal FFMI and clear functional exercise intolerance (table 1). Moreover, $44 \%$ of the COPD patients had $\geq 1$ self-reported co-morbidities. Gender distribution, current smoking status, self-reported co-morbidities, mean age, mean $\mathrm{BMI}$ and mean FFMI were not significantly different between the GOLD stages. Vitamin D deficiency significantly increased from 34\% in GOLD I to $65 \%$ in GOLD IV patients.

\section{DXA-scan and $X$-spine}

Prevalence of osteoporosis based on DXA-scan, X-spine and the combination thereof was $23.6 \%, 36.5 \%$ and $51.4 \%$, respectively (table 1 ).

Seventy (36.1\%) patients without osteoporosis as assessed by DXA did have vertebral fractures without an identified history of trauma likely to cause these fractures. Of these 68 patients 43 were osteopenic and 27 had a normal BMD. In addition, 38 (23.5\%) patients without vertebral fractures had osteoporosis on DXA-scan. The mean 10-year fracture risk was $10.6 \pm 6.6 \%$ for a major fracture and $3.5 \pm 4$. $\% 1$ for a hip fracture. Moreover, the majority of patients with osteoporosis did not use 
Table 1: Patient Characteristics

\begin{tabular}{|c|c|c|c|c|c|}
\hline & $\begin{array}{l}\text { Total group } \\
(\mathrm{n}=255)\end{array}$ & $\begin{array}{l}\text { GOLD I } \\
(n=71)\end{array}$ & $\begin{array}{l}\text { GOLD II } \\
(n=100)\end{array}$ & $\begin{array}{l}\text { GOLD III } \\
(n=57)\end{array}$ & $\begin{array}{l}\text { GOLD IV } \\
(\mathrm{n}=27)\end{array}$ \\
\hline Male/Female, \% & $62 / 38$ & $63 / 37$ & $59 / 41$ & $68 / 32$ & $56 / 44$ \\
\hline Age, years & $68.05 \pm 0.55$ & $67.15 \pm 1.02$ & $69.90 \pm 0.89$ & $66.51 \pm 1.11$ & $66.78 \pm 1.6$ \\
\hline FEV1, \%pred & $64 \pm 1.3$ & $90 \pm 0.9$ & $65 \pm 0.8^{\mathrm{a}}$ & $41 \pm 0.8^{\mathrm{ab}}$ & $29 \pm 2.7^{\mathrm{abc}}$ \\
\hline RV\%TLC & $51 \pm 0.7$ & $42 \pm 0.9$ & $51 \pm 0.8^{a}$ & $58 \pm 1.1^{\mathrm{ab}}$ & $62 \pm 1.8^{\mathrm{abc}}$ \\
\hline $\mathrm{TLCO}_{\mathrm{VA}}$ \% \%red & $80 \pm 1.6$ & $83 \pm 2.3$ & $84 \pm 2.5$ & $80 \pm 3.5$ & $62 \pm 4.6^{\mathrm{abc}}$ \\
\hline $\mathrm{BMI}, \mathrm{kg} / \mathrm{m}^{2}$ & $27.06 \pm 0.30$ & $27.38 \pm 0.49$ & $27.26 \pm 0.50$ & $26.96 \pm 0.62$ & $26.51 \pm 1.18$ \\
\hline Low, \% & 8.6 & 4.2 & 10.0 & 5.3 & 18.5 \\
\hline Overweight, \% & 43.9 & 50.7 & 41.0 & 47.4 & 29.6 \\
\hline \multirow{2}{*}{\multicolumn{6}{|c|}{ FFMI, $\mathrm{kg} / \mathrm{m}^{2}$}} \\
\hline & & & & & \\
\hline Males & $19.2 \pm 0.6$ & $18.7 \pm 0.3$ & $18.6 \pm 0.7$ & $21.0 \pm 2.0$ & $19.3 \pm 2.1$ \\
\hline Females & $16.1 \pm 0.2$ & $17.0 \pm 0.4$ & $16.0 \pm 0.4$ & $15.8 \pm 0.5$ & $15.3 \pm 0.8$ \\
\hline Low, \% & 21.1 & 7.7 & $25.6^{\mathrm{a}}$ & 18.8 & $40.0^{a}$ \\
\hline \multicolumn{6}{|l|}{ DXA-scan } \\
\hline Normal BMD, \% & 30.3 & 32.4 & 33.3 & 22.8 & 29.6 \\
\hline Osteopenia, \% & 46.1 & 47.9 & 48.5 & 43.9 & 37.1 \\
\hline Osteoporosis, \% & 23.6 & 19.7 & 18.2 & 33.3 & 33.3 \\
\hline \multicolumn{6}{|l|}{ X-spine } \\
\hline Fracture(s), \% & 36.5 & 31.0 & 41.0 & 36.8 & 33.3 \\
\hline Fractures TS & $0.54 \pm 0.06$ & $0.51 \pm 0.12$ & $0.50 \pm 0.08$ & $0.54 \pm 0.12$ & $0.67 \pm 0.23$ \\
\hline Fractures LS & $0.13 \pm 0.03$ & $0.07 \pm 0.05$ & $0.22 \pm 0.06$ & $0.07 \pm 0.03$ & $0.22 \pm 0.10$ \\
\hline Fractures total & $0.67 \pm 0.07$ & $0.58 \pm 0.14$ & $0.72 \pm 0.12$ & $0.61 \pm 0.13$ & $0.89 \pm 0.27$ \\
\hline \multicolumn{6}{|l|}{ Osteoporosis } \\
\hline DXA and $X$-spine, $\%$ & 51.4 & 42.3 & 53.0 & 56.1 & 59.3 \\
\hline \multicolumn{6}{|l|}{ Smoking status } \\
\hline Current/ex, \% & $26.3 / 73.7$ & 23.9/76.1 & $27.0 / 73.0$ & $31.6 / 68.4$ & $18.5 / 81.5$ \\
\hline Pack years & $36.5 \pm 1.6$ & $34.2 \pm 3.3$ & $34.5 \pm 1.1$ & $44.3 \pm 4.2$ & $33.9 \pm 3.3$ \\
\hline Alcohol, units/day & $1.1 \pm 1.7$ & $1.2 \pm 1.6$ & $1.0 \pm 1.4$ & $1.2 \pm 2.2$ & $0.8 \pm 1.3$ \\
\hline Leucocytes, no/nL & $7.9 \pm 0.2$ & $7.3 \pm 0.2$ & $7.8 \pm 0.2$ & $8.1 \pm 0.3$ & $9.2 \pm 0.7^{a}$ \\
\hline CRP, $\mathrm{mg} / \mathrm{L}$ & $9.4 \pm 0.9$ & $8.1 \pm 0.8$ & $10.4 \pm 2.0$ & $8.8 \pm 0.8$ & $10.2 \pm 1.7$ \\
\hline $25 \mathrm{OH} \mathrm{D3}, \mathrm{nmol} / \mathrm{L}$ & $55 \pm 1.6$ & $58.0 \pm 2.9$ & $57.6 \pm 2.3$ & $51.7 \pm 4.0$ & $44.3 \pm 4.3$ \\
\hline Vitamin D def', \% & 44 & 33.8 & 39.4 & $54.5^{\mathrm{a}}$ & $65.4^{\mathrm{ab}}$ \\
\hline PTH, pmol/L & $5.7 \pm 3.4$ & $5.5 \pm 2.6$ & $5.5 \pm 3.7$ & $5.9 \pm 3.0$ & $6.4 \pm 4.7$ \\
\hline Bone medication ${ }^{2}, \%$ & 12.5 & 5.6 & 10.0 & $19.3^{a}$ & $25.9^{a b}$ \\
\hline Oral corticosteroids, $\%$ & 9 & 0 & $9^{a}$ & $12^{\mathrm{a}}$ & $30^{\mathrm{a}}$ \\
\hline Cumulative dose ${ }^{3}, \mathrm{mg}$ & $3424 \pm 809$ & $611 \pm 149$ & $4354 \pm 1847$ & $2780 \pm 1015$ & $8801 \pm 2508^{\text {ac }}$ \\
\hline $\begin{array}{l}\text { Inhaled } \\
\text { corticosteroids,\% }\end{array}$ & 64 & 54 & $64^{\mathrm{a}}$ & $68^{\mathrm{a}}$ & $85^{\mathrm{a}}$ \\
\hline 6MWD, meters & $353 \pm 7.5$ & $395 \pm 9.9$ & $342 \pm 12.0^{a}$ & $353 \pm 18.4^{a}$ & $293 \pm 23.1^{\text {ac }}$ \\
\hline Charlson score & $1.80 \pm 0.71$ & $1.77 \pm 0.15$ & $1.73 \pm 0.12$ & $1.86 \pm 0.14$ & $2.04 \pm 0.20$ \\
\hline FRAX major fracture, \% & $10.6 \pm 6.6$ & $10.4 \pm 7.6$ & $10.5 \pm 6.3$ & $10.1 \pm 5.3$ & $12.3 \pm 7.6$ \\
\hline FRAX hip fracture, \% & $3.5 \pm 4.1$ & $3.4 \pm 4.4$ & $3.5 \pm 4.0$ & $3.3 \pm 3.2$ & $4.3 \pm 5.5$ \\
\hline
\end{tabular}

Values are expressed as mean \pm standard error of mean, unless otherwise indicated.

Abbreviations: FEV1=forced expiratory volume in the first second; $G O L D=$ Global Strategy for the Diagnosis, Management, and Prevention of COPD; BMI=body mass index; FFMI=fat free mass index; $\mathrm{CRP}=\mathrm{C}$-reactive protein; $25 \mathrm{OH} \mathrm{D} 3=25$ hydroxy vitamin D3; PTH=parathormone. ${ }^{1}$ Defined as $25 \mathrm{OH}$ D3 $<50 \mathrm{nmol} / \mathrm{L}$. ${ }^{2}$ Bisphosphonates and/or Calcium and/or Vitamin D (bisphosphonates alone 3.1\%, calcium alone 3.1\%, bisphosphonates and calcium $3.5 \%$, calcium and vitamin D $2.4 \%$, all three $0.4 \%)$. ${ }^{3}$ Cumulative dose of oral and intravenous corticosteroids in prednisolone equivalents from referral to chest physician until

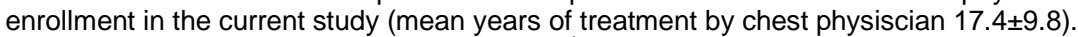

${ }^{a}$ Significant as compared to GOLD I $(p<0.05){ }^{b}$ Significant as compared to GOLD II $(p<0.05)$

'Significant as compared to GOLD III $(p<0.05)$ 
physician-prescribed bone medication: $78 \%, 78 \%$ and $80 \%$ for osteoporosis based on DXA-scan, X-spine or the combination thereof, respectively. In addition, $41 \%$ of patients with osteopenia should be treated with bone medication according to the National Osteoporosis Foundation (NOF)-guidelines ${ }^{23}$ (10-year hip fracture risk $\geq 3 \%$ and major fracture risk $\geq 20 \%)$. Of these 48 patients 42 were not using bone medication (87.5\%).

\section{Fractures}

There were 93 patients (36.5\%) with one or more vertebral fractures resulting in a total of 172 fractures. Most patients had 1,2 or 3 vertebral fractures $(52.7 \%, 25.8 \%$ and $14 \%$, respectively), while there were some patients with 4, 5, 6 and even 7 vertebral fractures (3.2\%, 1.1\%, 2.2\% and $1.1 \%$ respectively).

Most of these fractures were wedge shaped $(n=123 ; 71.5 \%)$. In addition, 41 fractures $(23.8 \%)$ were biconcave and only 8 were crush fractures $(4.7 \%)$. There were 110 mild (64\%), 50 moderate (29\%) and 12 severe fractures $(7 \%)$. Location of the fractures showed a bimodal distribution with a peak at the level of thoracic vertebra 8 and one peak at the level of thoracic vertebra 12. Type and location of fractures did not differ significantly between GOLD stages. Before the study only 27 patients $(10.6 \%)$ were diagnosed on routine chest $\mathrm{X}$-ray of these only 8 patients knew they had a vertebral fracture. The current study showed that 80 patients $(31.4 \%)$ should have been diagnosed with a fracture of the thoracic spine.

\section{DXA-scan and $X$-spine after stratification for GOLD stages}

Using the DXA-scan, GOLD-stage I had the highest proportion of patients with osteopenia, while the GOLD stage II and IV had the highest proportion of patients with osteoporosis. Nevertheless, differences between GOLD stages were non-significant $(p=0.314)$

GOLD stage II had the highest proportion of patients with vertebral fractures, while GOLD stage IV had the highest mean number of vertebral fractures. Again, differences between GOLD stages were non- 
significant ( $p=0.588$ for proportion of patients with vertebral fractures; and $p=0.631$ for mean number of vertebral fractures).

Prevalence of osteoporosis (DXA-scan $+X$-spine) increased from 42 to $59 \%$ in GOLD I to GOLD IV, but was not statistically significantly different between GOLD stages ( $p=0.301$, table 1$)$.

\section{Determinants of osteopenia and osteoporosis in COPD}

To assess risk factors for osteopenia and osteoporosis only patients without bone medication were analysed ( $n=223 ; 87 \%$ of total). Of these patients 69 had osteopenia and 105 had osteoporosis based on DXAscan and X-spine. Univariate multinomial regression analysis showed that lower BMI and a myocardial infarction in the history significantly increased the odds ratio for osteopenia (table 2). In addition, higher age, lower BMI, lower 6 minutes walking distance, lower FEV1, higher $\mathrm{RV} / \mathrm{TLC}$, higher PTH and a myocardial infarction significantly increased the odds ratio for osteoporosis (table 2). Multivariate multinomial regression analysis with gender, age, BMI, 6MWD, FEV1, RV/TLC, PTH and myocardial infarction as covariables showed that only BMI is an independent significant predictor of osteopenia (table 3). Age, BMI and PTH were independent predictors of osteoporosis (table 3). There was no significant correlation between PTH and corticosteroid use $(r=0.148$; $\mathrm{p}=0.512$ ). PTH had no significant influence when corticosteroid use was used as dependent variable.

\section{Discussion}

The current study has several main findings:

1. Fifty-one $\%$ of patients with clinically stable COPD attending a regular visit at the respiratory outpatient consultation in a general hospital had radiological evidence for osteoporosis;

2. Combining the results of local DXA-scans with X-spine augmented the proportion of COPD patients with osteoporosis compared to both methods separately; 
Table 2: Correlates of osteopenia and osteoporosis in COPD, results from univariate multinomial regression analysis.

\begin{tabular}{|c|c|c|c|c|c|c|}
\hline & \multicolumn{3}{|c|}{ Osteopenia } & \multicolumn{3}{|c|}{ Osteoporosis } \\
\hline & OR & $95 \% \mathrm{Cl}$ & $p$-value & OR & $95 \% \mathrm{Cl}$ & $p$-value \\
\hline Male & 1.379 & $0.646-2.944$ & 0.406 & 1.322 & $0.658-2.656$ & 0.433 \\
\hline Age & 1.030 & 0.988-1.075 & 0.165 & 1.080 & $1.036-1.126$ & $<0.001$ \\
\hline BMI & 0.862 & $0.795-0.936$ & $<0.001$ & 0.889 & $0.827-0.955$ & 0.001 \\
\hline FFMI & 1.001 & $0.935-1.071$ & 0.988 & 1.001 & $0.940-1.067$ & 0.967 \\
\hline 6 MWD & 1.002 & 0.998-1.005 & 0.353 & 0.996 & 0.993-1.000 & 0.034 \\
\hline FEV1 & 0.993 & $0.975-1.011$ & 0.415 & 0.982 & 0.966-0.999 & 0.038 \\
\hline RV/TLC & 0.999 & $0.962-1.038$ & 0.977 & 1.062 & $1.024-1.101$ & 0.001 \\
\hline \multicolumn{7}{|l|}{ GOLD I* } \\
\hline GOLD II & 0.806 & $0.344-1.892$ & 0.621 & 1.259 & $0.569-2.785$ & 0.569 \\
\hline GOLD III & 2.094 & $0.682-6.432$ & 0.197 & 2.414 & $0.816-7.137$ & 0.111 \\
\hline GOLD IV & 0.924 & $0.215-3.965$ & 0.915 & 1.731 & $0.474-6.324$ & 0.406 \\
\hline ESR & 0.973 & 0.938-1.009 & 0.139 & 0.995 & 0.964-1.026 & 0.728 \\
\hline CRP & 0.993 & $0.995-1.032$ & 0.704 & 1.007 & $0.980-1.034$ & 0.630 \\
\hline Vitamin D & 1.009 & $0.995-1.024$ & 0.207 & 0.996 & $0.982-1.010$ & 0.558 \\
\hline PTH & 1.005 & $0.863-1.170$ & 0.951 & 1.184 & $1.034-1.355$ & 0.014 \\
\hline Charlson & 1.033 & $0.722-1.477$ & 0.860 & 1.264 & 0.919-1.739 & 0.149 \\
\hline MI & 3.903 & $1.056-14.422$ & 0.041 & 5.046 & $1.447-17.599$ & 0.011 \\
\hline Corticosteroid & $N A^{b}$ & & & 2.379 & $0.786-7.202$ & 0.125 \\
\hline $\begin{array}{l}\text { Cummulative } \\
\text { coricosteroids }\end{array}$ & 1.000 & $1.000-1.000$ & 0.649 & 1.000 & $1.000-1.000$ & 0.108 \\
\hline
\end{tabular}

${ }^{*}$ Reference category ${ }^{b}$ There are no patients without osteoporosis and only 5 patients with osteopenia that used oral corticosteroids, therefore binomial regression analysis had to be done with no osteoporosis and osteopenia as one category. Abbreviations: $\mathrm{BMI}=$ body mass index; $6 \mathrm{MWD}=6$ minutes walking distance; FEV1=forced expiratory volume in the first second; RV/TLC=residual volume as percentage of the total lung capacity; ESR=erythrocyte sedimentation rate; $\mathrm{CRP}=\mathrm{C}$-reactive protein; $\mathrm{PTH}=$ parathormone; Charlson=charlson score; $\mathrm{Ml}=$ myocardial infarction. corticosteroid= oral corticosteroids (maintenance therapy) 
3. The proportion of COPD patients with osteoporosis was not statistically significantly different after stratification for GOLD stages;

4. A large proportion of the osteoporotic COPD patients did not use physician-prescribed bone medication;

5. Age, BMI, and PTH were clear correlates of osteoporosis in COPD patients who did not use physician-prescribed bone medication;

\section{Prevalence of osteoporosis}

In the current study, the combination of local DXA-scan and X-spine resulted in an osteoporosis prevalence of $51 \%$ in outpatients with COPD (table 1). This is completely in line with the findings of Jørgensen and colleagues $^{12}$, who only included COPD outpatients with a FEV1 $<45 \%$ predicted and mainly female patients.

Table 3: Correlates of osteopenia and osteoporosis, results of multivariate multinomial regression analysis

\begin{tabular}{lllllll}
\hline & \multicolumn{2}{l}{ Osteopenia } & \multicolumn{4}{l}{ Osteoporosis } \\
& OR & $\mathbf{9 5 \%} \mathbf{C l}$ & p-value & OR & $\mathbf{9 5 \%} \mathbf{C l}$ & p-value \\
\hline Age & 1.031 & $0.976-1.088$ & 0.272 & 1.054 & $1.000-1.111$ & $\mathbf{0 . 0 4 8}$ \\
BMI & 0.858 & $0.783-0.942$ & $\mathbf{0 . 0 0 1}$ & 0.869 & $0.798-0.946$ & $\mathbf{0 . 0 0 1}$ \\
6MWD & 1.003 & $0.998-1.008$ & 0.260 & 1.001 & $0.997-1.006$ & 0.603 \\
FEV1 & 0.989 & $0.963-1.016$ & 0.430 & 0.999 & $0.973-1.025$ & 0.916 \\
RV/TLC & 0.989 & $0.931-1.052$ & 0.731 & 1.061 & $0.999-1.126$ & 0.053 \\
PTH & 1.042 & $0.880-1.234$ & 0.634 & 1.174 & $1.005-1.370$ & $\mathbf{0 . 0 4 3}$ \\
MI & 3.248 & $0.829-1.735$ & 0.091 & 3.801 & $0.999-13.952$ & 0.051 \\
\hline
\end{tabular}

Abbreviations: $\mathrm{BMI}=$ body mass index; $6 \mathrm{MWD}=6$ minutes walking distance; $\mathrm{FEV} 1=$ forced expiratory volume in the first second; RV/TLC=residual volume as percentage of the total lung capacity; PTH=parathormone; $\mathrm{Ml}=$ myocardial infarction.

In the present trial, a large consecutive sample consisting of COPD outpatients representing all GOLD stages were screened for osteoporosis. Non-significant differences were found in the proportion of osteoporotic COPD patients after stratification for GOLD stages. These findings suggest that extra-pulmonary features like osteoporosis are poorly predicted by the degree of airflow limitation.

Indeed, $42 \%$ of the GOLD stage I outpatients had osteoporosis. Even though an age-matched control group is lacking in the current design, it 
seems reasonable to conclude that the prevalence of osteoporosis is higher than in healthy elderly ${ }^{4}$. These results suggest that the increased prevalence of osteoporosis in COPD patients is not, or only partly dependent on the degree of airflow limitation. Indeed, there are more factors involved in the prognosis and morbidity in COPD patients ${ }^{2}$. The question is what the link is between COPD and extra-pulmonary features like osteoporosis, arterial stiffness and muscle atrophy, if any, besides airflow limitation. This could be chronic inflammation, reduced physical activity, a common genetic susceptibility or maybe these features are just comorbidities in COPD patients. More research is needed to clarify these links.

Prevalence of osteoporosis in GOLD stages I to IV in the current study were higher as compared to prevalence of osteoporosis in the same GOLD stages in COPD patients entering pulmonary rehabilitation ${ }^{24}$. Fiftyeight $\%$ versus $16 \%, 56 \%$ versus $30 \%$ and $59 \%$ versus $54 \%$ in GOLD stages I/II, III and IV, respectively. These differences may be due to a referral bias, which probably will occur when referring complex and symptomatic COPD patients from a general hospital to a specialized rehabilitation centre ${ }^{25}$. However, in the pulmonary rehabilitation patients vertebral fractures were not assessed and therefore not included in the diagnosis of osteoporosis. In addition, whole body DXA-scan was used as opposed to DXA-scan of the hip and lumbar spine in the current study which is a more sensitive method to assess osteoporosis in COPD patients ${ }^{26}$.

Prevalence of vitamin D deficiency increased from 34\% to $65 \%$ in GOLD I trough GOLD IV. This is in line with the recent study by Janssens and colleagues who found vitamin D prevalences of $39 \%, 47 \%, 60 \%$ and $77 \%$ for GOLD stages I, II, III and IV respectively ${ }^{27}$. The prevalence in COPD patients was higher as compared to healthy subjects with a minimum of 15 pack years $(31 \%)$.

\section{Vertebral fractures}

About one third of the patients had $\geq 1$ vertebral fracture, mostly located at thoracic vertebrae 8 and 12. This is in line with previous studies in patients with COPD, inflammatory bowel disease but also in post menopausal women and healthy men ${ }^{11 ; 28-33}$. This bimodal distribution is 
probably due to different patterns of spinal loading in different segments of the spine and to variations in biomechanical and material properties of vertebral bodies ${ }^{28 ; 32}$.

Based on routine chest X-ray only $34 \%$ of the thoracic vertebral fractures were diagnosed. Moreover, only 8 patients were made aware of these vertebral fractures. Radiologists and (chest)physicians should be made aware of the high prevalence of vertebral fractures in COPD patients so they know that they should be paying attention to the vertebrae.

\section{Treatment of osteoporosis}

Under treatment of patients with osteoporosis was high. This is in line with COPD patients entering pulmonary rehabilitation ${ }^{24}$. In the Netherlands there is no FRAX cut off recommended for treatment. Therefore, we used the NOF cut off values to assess the percentage of osteopenic COPD patients that should receive treatment to prevent osteoporotic fractures ${ }^{23}$. However, these are guidelines for the United States of America and treatment threshold should take into account that the 10-year fracture risk in case of the same risk fractures differs per country $^{34}$. The 10-year probability of a hip fracture for men and women at ages 50,60, 70 and 80 does not differ that much between the US and the Netherlands (difference of $0.1 \%-1.3 \%$ for men and $0.2 \%-1.7 \%$ for women $)^{34}$. Therefore, we felt that using the NOF cut off values can be justified. Adjustment of the Dutch Guidelines for Prevention and Treatment of Osteoporosis is necessary to implicate the FRAX-score.

\section{Correlates of osteopenia}

Increasing BMI independently decreased the risk of osteopenia in this study. Indeed, in COPD patients entering pulmonary rehabilitation cachectic body composition independently increased the odds ratio for osteopenia ${ }^{24}$. No other studies were found investigating correlates of osteopenia in COPD patients.

Univariate analyses showed that previous myocardial infarction was a significant predictor for osteopenia as well as osteoporosis. The link between osteoporosis and cardiovascular diseases and osteoporosis and 
COPD respectively could be age, a hormonal link, a common susceptibility due to the same risk factors (e.g. smoking), chronic systemic inflammation or even a common genetic susceptibility. More research is needed to clarify this link. In multivariate analyses the significance disappeared.

\section{Correlates of osteoporosis}

Increasing age, PTH and a decreasing BMI independently increased the odds ratio for osteoporosis. Higher age is a risk factor for osteoporosis in the general population ${ }^{5}$. When osteoporosis is based on DXA-scan only age is usually not an independent predictor of osteoporosis ${ }^{4}$. However, increasing age is associated with an increasing risk of vertebral fractures in COPD patients ${ }^{11 ; 35-37}$. Therefore, the increased risk of osteoporosis in older COPD patients might be the results of more vertebral fractures due to a deteriorated microarchitecture at this age.

The finding that a decreasing $\mathrm{BMI}$ is associated with an increasing risk of osteoporosis is in line with several other studies in COPD patients ${ }^{24 ; 31 ; 38-}$ ${ }^{42}$. The link between low BMI and osteoporosis in COPD patients is not entirely clear yet. It might be decreased physical activity, increased inflammation or other mechanisms leading to proteolysis ${ }^{43-45}$. More studies are needed investigating this link.

Increasing PTH significantly increased the OR for osteoporosis. Patients with high PTH-levels all had normal calcium levels, hence they had secondary hyperparathyroidism. Secondary hyperparathyroidism is caused by vitamin $\mathrm{D}$ deficiency ${ }^{46}$. Indeed, we found a significant negative correlation between vitamin $\mathrm{D}$ and PTH in our study population $(r=-0.28$; $\mathrm{p}<0.001)$. This is in line with Kuchuc and colleagues who found an increasing vitamin $\mathrm{D}$ significantly decreasing $\mathrm{PTH}^{19}$. In addition, markers of bone turnover significantly decreased. Combined with our results, decreasing PTH may cause decreasing speed of bone turnover resulting in a better microarchitecture and hence less osteoporosis.

Because there is still a lot of discussion about the best cut off value for vitamin $D$ deficiency, we also used $80 \mathrm{nmol} / \mathrm{L}$ as cut off which is used in postmenopausal women with osteoporosis. The prevalence of vitamin D deficiency increased to $86 \%$. The significant difference between COLD 
stages disappeared (GOLD I 87\%; GOLD II 84\%; GOLD III 89\%; GOLD IV $85 \%$; $p=0.829$ ) however, the possible correlation with osteoporosis was still not found.

There was no significant influence of FEV1 on osteoporosis. Indeed, the prevalence of osteoporosis did not differ between GOLD stages. These result suggest that there are more factors involved in the prognosis and morbidity in COPD patients besides airflow limitation ${ }^{47}$.

\section{Methodological considerations}

The present cross-sectional study has some methodological considerations. Interpretation of clinical correlates of osteoporosis should be with caution in a cross-sectional design. Second, there could be a selection bias because we included COPD outpatients treated by chest physicians and not patients treated by family physicians. However, the current consecutive sample of clinically stable COPD patients has been collected prospectively in a general hospital, including all GOLD stages. Consequently, it can be considered as a representative sample of Dutch COPD outpatients attending a regular outpatient COPD clinic.

\section{Conclusions and future research}

Half of patients with clinically stable COPD attending a regular outpatient COPD clinic have osteoporosis as determined by local DXA-scan and Xray of the spine independent of GOLD classification. Correlates of osteoporosis in COPD are age, BMI and PTH. Given the current definition of COPD as a multi-component disease the awareness of a high prevalence of osteoporosis should be raised. Chest physicians should not only describe the lung parenchyma on a chest X-ray but also the vertebrae. In addition, especially in older patients with a low BMI and/or a secondary hyperparathyroidism a DXA-scan and an X-ray of the total spine should be made. Future studies are needed to assess the external validity of the present findings in a primary care setting. In addition, follow up studies are needed to determine risk factors for osteoporosis in COPD patients based on DXA-scan and X-spine. 


\section{Reference List}

(1) Rabe KF, Hurd S, Anzueto A, Barnes PJ, Buist SA, Calverley P et al. Global strategy for the diagnosis, management, and prevention of chronic obstructive pulmonary disease: GOLD executive summary. Am J Respir Crit Care Med 2007; 176(6):532-555.

(2) Wouters EF. Management of severe COPD. Lancet 2004; 364(9437):883-895.

(3) Sabit R, Bolton CE, Edwards PH, Pettit RJ, Evans WD, McEniery CM et al. Arterial stiffness and osteoporosis in chronic obstructive pulmonary disease. Am J Respir Crit Care Med 2007; 175(12):1259-1265.

(4) Graat-Verboom L, Wouters EF, Smeenk FW, van den Borne BE, Lunde R, Spruit MA. Current status of research on osteoporosis in COPD: a systematic review. Eur Respir J 2009; 34(1):209-218.

(5) WHO Scientific Group on the Prevention and Management of Osteoporosis. Prevention and Management of Osteoporosis: report of a WHO scientific group. http;//whqlibdoc who int/trs/WHO_TRS_921 pdf [ 2007

(6) Genant HK, Delmas PD, Chen P, Jiang Y, Eriksen EF, Dalsky GP et al. Severity of vertebral fracture reflects deterioration of bone microarchitecture. Osteoporos Int 2007; 18(1):69-76.

(7) Cummings SR, Nevitt MC, Browner WS, Stone K, Fox KM, Ensrud KE et al. Risk factors for hip fracture in white women. Study of Osteoporotic Fractures Research Group. N Engl J Med 1995; 332(12):767-773.

(8) Schuit SC, van der KM, Weel AE, de Laet CE, Burger H, Seeman E et al. Fracture incidence and association with bone mineral density in elderly men and women: the Rotterdam Study. Bone 2004; 34(1):195-202.

(9) Siris ES, Brenneman SK, Miller PD, Barrett-Connor E, Chen YT, Sherwood LM et al. Predictive value of low BMD for 1-year fracture outcomes is similar for postmenopausal women ages 50-64 and 65 and Older: results from the National Osteoporosis Risk Assessment (NORA). J Bone Miner Res 2004; 19(8):12151220.

(10) Genant HK, Wu CY, van KC, Nevitt MC. Vertebral fracture assessment using a semiquantitative technique. J Bone Miner Res 1993; 8(9):1137-1148.

(11) Nuti R, Siviero P, Maggi S, Guglielmi G, Caffarelli C, Crepaldi G et al. Vertebral fractures in patients with chronic obstructive pulmonary disease: the EOLO Study. Osteoporos Int 2008; 20(6):989-998.

(12) Jorgensen NR, Schwarz P, Holme I, Henriksen BM, Petersen LJ, Backer V. The prevalence of osteoporosis in patients with chronic obstructive pulmonary disease: a cross sectional study. Respir Med 2007; 101(1):177-185. 
(13) American Thoracic Society and European Respiratory Society. COPD Guidelines. Standards for the diagnosis and treatment. http://www ersnet org/lrPresentations/copd/files/main/index html [ 2004 [cited 2007 Aug. 23]; Available from:

URL:http://www.ersnet.org/lrPresentations/copd/files/main/index.html

(14) Charlson M, Szatrowski TP, Peterson J, Gold J. Validation of a combined comorbidity index. J Clin Epidemiol 1994; 47(11):1245-1251.

(15) Baarends EM, Schols AM, Mostert R, Wouters EF. Peak exercise response in relation to tissue depletion in patients with chronic obstructive pulmonary disease. Eur Respir J 1997; 10(12):2807-2813.

(16) ATS statement: guidelines for the six-minute walk test. Am J Respir Crit Care Med 2002; 166(1):111-117.

(17) Allain TJ, McGregor AM. Thyroid hormones and bone. J Endocrinol 1993; 139(1):9-18.

(18) Inaba M. Secondary osteoporosis: thyrotoxicosis, rheumatoid arthritis, and diabetes mellitus. J Bone Miner Metab 2004; 22(4):287-292.

(19) Kuchuk NO, van Schoor NM, Pluijm SM, Chines A, Lips P. Vitamin D Status, Parathyroid Function, Bone Turnover and Bone Mineral Density in Postmenopausal Women with Osteoporosis in Global Perspective. J Bone Miner Res 2008.

(20) Holick MF. Vitamin D deficiency. N Engl J Med 2007; 357(3):266-281.

(21) Norman AW, Bouillon R, Whiting SJ, Vieth R, Lips P. 13th Workshop consensus for vitamin D nutritional guidelines. J Steroid Biochem Mol Biol 2007; 103(35):204-205.

(22) Kanis JA, Johnell O, Oden A, Johansson H, McCloskey E. FRAX and the assessment of fracture probability in men and women from the UK. Osteoporos Int 2008; 19(4):385-397.

(23) Clinician's Guide to Prevention and Treatment of Osteoporosis. http://www nof org/professionals/pdfs/NOF_ClinicianGuide2009_v7 pdf [ 2010 [cited 2010 Aug. 1];

(24) Graat-Verboom L, Spruit MA, van den Borne BE, Smeenk FW, Martens EJ, Lunde $\mathrm{R}$ et al. Correlates of osteoporosis in chronic obstructive pulmonary disease: An underestimated systemic component. Respir Med 2009; 103(8):11431151.

(25) Spruit MA, Vanderhoven-Augustin I, Janssen PP, Wouters EF. Integration of pulmonary rehabilitation in COPD. Lancet 2008; 371(9606):12-13.

(26) Graat-Verboom L, Spruit MA, Borne van den BEEM, Smeenk FWJM, Wouters EFM. Whole-body versus local DXA-scan for the diagnosis of osteoporosis in COPD patients. Journal of Osteoporosis 2010. 
(27) Janssens W, Bouillon R, Claes B, Carremans C, Lehouck A, Buysschaert I et al. Vitamin $D$ deficiency is highly prevalent in COPD and correlates with variants in the vitamin D-binding gene. Thorax 2010; 65(3):215-220.

(28) Cooper C, O'Neill T, Silman A. The epidemiology of vertebral fractures. European Vertebral Osteoporosis Study Group. Bone 1993; 14 Suppl 1:S89-S97.

(29) El MA, Mounach A, Gassim S, Ghazi M. Vertebral fracture assessment in healthy men: prevalence and risk factors. Bone 2008; 43(3):544-548.

(30) Heijckmann AC, Huijberts MS, Schoon EJ, Geusens P, de VJ, Menheere PP et al. High prevalence of morphometric vertebral deformities in patients with inflammatory bowel disease. Eur J Gastroenterol Hepatol 2008; 20(8):740-747.

(31) Kjensli A, Falch JA, Ryg M, Blenk T, Armbrecht G, Diep LM et al. High prevalence of vertebral deformities in COPD patients: relation to disease severity. Eur Respir J 2009; 33(5):1018-1024.

(32) Nevitt MC, Ross PD, Palermo L, Musliner T, Genant HK, Thompson DE. Association of prevalent vertebral fractures, bone density, and alendronate treatment with incident vertebral fractures: effect of number and spinal location of fractures. The Fracture Intervention Trial Research Group. Bone 1999; 25(5):613619.

(33) Stockbrugger RW, Schoon EJ, Bollani S, Mills PR, Israeli E, Landgraf L et al. Discordance between the degree of osteopenia and the prevalence of spontaneous vertebral fractures in Crohn's disease. Aliment Pharmacol Ther 2002; 16(8):1519-1527.

(34) Kanis JA, Johnell O, De Laet C, Jonsson B, Oden A, Ogelsby AK. International variations in hip fracture probabilities: implications for risk assessment. J Bone Miner Res 2002; 17(7):1237-1244.

(35) Carter JD, Patel S, Sultan FL, Thompson ZJ, Margaux H, Sterrett A et al. The recognition and treatment of vertebral fractures in males with chronic obstructive pulmonary disease. Respir Med 2008; 102(8):1165-1172.

(36) McEvoy CE, Ensrud KE, Bender E, Genant HK, Yu W, Griffith JM et al. Association between corticosteroid use and vertebral fractures in older men with chronic obstructive pulmonary disease. Am J Respir Crit Care Med 1998; 157(3 Pt 1):704-709.

(37) Papaioannou A, Parkinson W, Ferko N, Probyn L, loannidis G, Jurriaans E et al. Prevalence of vertebral fractures among patients with chronic obstructive pulmonary disease in Canada. Osteoporos Int 2003; 14(11):913-917.

(38) Bolton CE, Cannings-John R, Edwards PH, lonescu AA, Evans WD, Pettit RJ et al. What community measurements can be used to predict bone disease in patients with COPD? Respir Med 2008; 102(5):651-657.

(39) Dubois EF, Roder E, Dekhuijzen PN, Zwinderman AE, Schweitzer DH. Dual energy X-ray absorptiometry outcomes in male COPD patients after treatment with different glucocorticoid regimens. Chest 2002; 121(5):1456-1463. 
(40) Incalzi RA, Caradonna P, Ranieri P, Basso S, Fuso L, Pagano F et al. Correlates of osteoporosis in chronic obstructive pulmonary disease. Respir Med 2000; 94(11):1079-1084.

(41) Mineo TC, Ambrogi V, Mineo D, Fabbri A, Fabbrini E, Massoud R. Bone mineral density improvement after lung volume reduction surgery for severe emphysema. Chest 2005; 127(6):1960-1966.

(42) Vrieze A, de Greef MH, Wijkstra PJ, Wempe JB. Low bone mineral density in COPD patients related to worse lung function, low weight and decreased fat-free mass. Osteoporos Int 2007; 18(9):1197-1202.

(43) Balasubramanian VP, Varkey B. Chronic obstructive pulmonary disease: effects beyond the lungs. Curr Opin Pulm Med 2006; 12(2):106-112.

(44) Wouters EF. Local and systemic inflammation in chronic obstructive pulmonary disease. Proc Am Thorac Soc 2005; 2(1):26-33.

(45) Yawn BP, Kaplan A. Co-morbidities in people with COPD: a result of multiple diseases, or multiple manifestations of smoking and reactive inflammation? Prim Care Respir J 2008.

(46) Lips P. Vitamin D physiology. Prog Biophys Mol Biol 2006; 92(1):4-8.

(47) Wouters EF. COPD: a chronic and overlooked pulmonary disease. Lancet 2007; 370(9589):715-716. 


\section{Chapter VI}

\section{Risk factors for osteoporosis in patients with moderate COPD: A case control study}

Lidwien Graat-Verboom, Frank W.J.M. Smeenk, Ben E.E.M. van den Borne, Martijn A. Spruit, Astrid B. Donkers-van Rossum, Renske P.M. Aarts, Emiel F.M. Wouters 


\section{Abstract}

The prevalence of osteoporosis is high in Chronic Obstructive Pulmonary Disease (COPD) patients. The diagnosis of osteoporosis should be based on bone mineral density (BMD) measurements as assessed by Dual Energy Absorptiometry (DXA) scanning as well as vertebral fractures as assessed by Instant Vertebral Assessment (IVA). The aim of this study was to compare COPD GOLD II patients (that is, patients with moderate COPD, stage II, according to the GOLD classification) with osteoporosis (cases) to COPD GOLD II patients without osteoporosis (controls) to identify risk factors for osteoporosis.

The diagnosis of osteoporosis was based on BMD and vertebral fractures. Cases $(n=49)$ were matched for gender, age and forced expiratory volume in the first second to controls $(n=49)$. Pulmonary function, body composition, vitamin D, emphysema score (by highresolution computer tomography), medical history and medication use were assessed in all patients. Variables that were significantly different between the cases and controls were included in a logistic regression analysis.

COPD patients with osteoporosis had a significantly lower body mass index (BMI) and higher residual volume as the percentage of total lung capacity (RV\%TLC) compared to COPD patients without osteoporosis. Decreasing $\mathrm{BMI}$ and increasing RV\%TLC increased the odds ratio for osteoporosis. Overweight and obese BMI values were protective for osteoporosis.

Screening for osteoporosis should be performed even in moderate COPD patients, especially in those with a low BMI and/or a high RV\%TLC. 


\section{Introduction}

Chronic Obstructive Pulmonary Disease (COPD) is characterised by a progressive airflow limitation that is not fully reversible as well as significant extrapulmonary effects ${ }^{1}$. The degree of airflow obstruction can be assessed by spirometry and stratified in accordance with the Global Initiative for COPD (GOLD) ${ }^{1}$. Osteoporosis is one of the many extrapulmonary effects of COPD, ${ }^{2}$ and the prevalence of osteoporosis is clearly higher in COPD patients compared to healthy subjects and even compared to those with some other chronic pulmonary diseases ${ }^{3}$.

Risk factors for osteoporosis in COPD patients that have been identified by previous studies are an abnormally low body mass index (BMI) and/or fat-free mass index (FFMI) and a worse degree of airflow limitation. ${ }^{3}$ In addition, patients with emphysema as observed by High Resolution Computer Tomography (HRCT) had a lower bone mineral density (BMD) compared to patients with chronic bronchitis ${ }^{4}$. Indeed, the extent of emphysema was inversely related to $\mathrm{BMD}^{5}$. However, Ohara et al. ${ }^{5}$ diagnosed osteoporosis based on the BMD of vertebrae T4,T7, T10 and L1 as assessed by CT scans, whereas osteoporosis is characterised not only by a low BMD but also by microarchitectural deterioration ${ }^{6}$. Therefore, a diagnosis of osteoporosis should be based on BMD and vertebral deformities ${ }^{7}$. Indeed, the proportion of osteoporotic COPD patients will increase when combining local DXA scans with vertebral fractures ${ }^{8 ; 9}$. Moreover, patients with severe to very severe COPD were mostly studied, whereas a large proportion of the COPD population is classified as GOLD stage $\|^{10 ; 11}$. Therefore, the risk factors that may contribute to osteoporosis in patients with moderate COPD remain unknown.

The main aim of our study was to assess risk factors for osteoporosis in GOLD II COPD patients in a case control study. Osteoporotic patients with GOLD stage II COPD (cases) were compared with GOLD stage II patients without osteoporosis (controls) to identify possible risk factors for osteoporosis.

\section{Methods}

Patients with GOLD II COPD who were seen in the outpatient clinic of a large teaching hospital in Eindhoven, the Netherlands, were included in 
this study. Informed consent forms were signed by all patients, and the study was approved by the medical ethical committee of Catharina Hospital Eindhoven (METC number M07-1752). All patients were Caucasian.

COPD was assessed according to the American Thoracic Society ${ }^{12}$ and severity was defined according to the GOLD guidelines ${ }^{1}$.

BMD values of the femoral neck and trochanter of the hip and of the lumbar spine (L1-L4) were assessed using a Hologic A Discovery DXA scan and expressed as T-scores. The DXA scan was calibrated on a daily basis using a Hologic phantom. In addition, an instant vertebral assessment (IVA) of the spine was made using the same DXA scan method, and vertebral deformities were defined according to the Genant method $^{13}$. Patients were diagnosed with osteoporosis when a T-score of $\leq-2.5$ and/or a vertebral deformity was observed. Patients with a T-score $>-2.5$ and no vertebral deformities were not diagnosed with osteoporosis. Patients were divided into cases (with osteoporosis) and controls (no osteoporosis: normal BMD or osteopenia and no fractures). A gender and age matched control was included for every case.

Medical history, medication use and smoking history were assessed from the medical charts and with a questionnaire. Moreover, height and weight were measured and body mass index (BMI) was calculated and defined as low $\left(<21 \mathrm{~kg} / \mathrm{m}^{2}\right)$, normal $\left(21-25 \mathrm{~kg} / \mathrm{m}^{2}\right)$, overweight $\left(>25-30 \mathrm{~kg} / \mathrm{m}^{2}\right)$ or obese $\left(>30 \mathrm{~kg} / \mathrm{m}^{2}\right)$. Using the BODYSTAT® 1500 Medical analyser, single frequency (Xitron Technologies) bio-impedance analysis was performed and FFMI was defined as depleted (men $<16 \mathrm{~kg} / \mathrm{m}^{2}$ and women $<15 \mathrm{~kg} / \mathrm{m}^{2}$ ) or normal ${ }^{14}$.

Using the Jaeger MASTERLAB BODY® (VIASYS Healthcare) lung function analyser, forced expiratory volume in the first second $\left(F E V_{1}\right)$ and forced vital capacity (FVC) were assessed and $F E V_{1} / F V C$ was determined. In addition, total lung capacity (TLC), residual volume (RV) and the diffusing capacity for carbon dioxide corrected for the alveolar volume (TLCOVA) were assessed and RV as percentage of TLC (RV\%TLC) was calculated.

To determine whether and to what extent patients had emphysema, standard high resolution CT scans were performed on a Philips Brilliance $16 \mathrm{CT}$ scanner using $120 \mathrm{kV}, 100 \mathrm{mAs}$, high resolution data acquisition and 0.625 collimation. All scans were viewed in the lung window setting 
(-550/1500 window width and window level). Two radiologist (ADR and $\mathrm{PL}$ ), both unaware of the osteoporosis status of the subjects, independently assessed emphysema status using a modified visual scoring system based on the methods of Bhalla et al. in which they assigned scores of 0 to 3 points for no emphysema to severe emphysema, respectively, in six different lung segments ${ }^{15}$ (see online data supplement).

Arterial blood gasses were collected to determine $\mathrm{pH}$, arterial carbon dioxide tension $\left(\mathrm{paCO}_{2}\right)$, arterial oxygen tension $\left(\mathrm{paO}_{2}\right)$ and oxygen saturation $\left(\mathrm{s}_{2}\right)$. Venous blood was obtained, and 25-hydroxyvitamin D3 (25-OH D3), parathyroid hormone (PTH) and thyroid stimulating hormone (TSH) were assessed because they are known to influence bone turnover ${ }^{16-18}$. Vitamin D deficiency was defined as a $25-\mathrm{OH}$ D3 level $<50$ $\mathrm{nmol} / \mathrm{L}^{19 ; 20}$. In addition, C-reactive protein (CRP) was assessed to determine the inflammatory status. Finally, a six-minute walking distance (6MWD) test was performed according to the latest ATS guidelines to assess functional exercise capacity ${ }^{21}$.

\section{Statistical analyses}

Continuous variables were compared with the independent $\mathrm{t}$-test and presented as the means \pm standard deviations (SD). Discrete variables were compared with the Chi-squared test and presented as percentages.

Two radiologists scored for emphysema based on HRCTs, and a Cohen's kappa coefficient was assessed.

Variables that differed significantly between cases and controls were used in multivariate logistic regression analysis with osteoporosis based on both DXA-scan and X-spine as the dependent variable. Multivariate logistic regression analyses were performed with BMI as the continuous variable and were repeated with $\mathrm{BMI}$ as the ordinal variable. The results were presented as odds ratios (OR) and 95\% confidence interval values $(95 \% \mathrm{Cl})$.

A p-value of $<0.05$ was considered significant. All statistical analyses were performed using the Statistical Package for Social Sciences (SPSS) version 16.0. 


\section{Results}

Characteristics of cases and controls

Ninety- eight GOLD II patients (49 cases and 49 controls) were included. These patients were mostly elderly male COPD patients (mean age \pm SD was $69 \pm 8$ years) with a poor functional exercise capacity (6MWD \pm SD: $359 \pm 96$ ). Based on HRCT, $69 \%$ of the patients had emphysema. The Cohen's kappa coefficient between the two radiologists was high (0.922, p-value <0.0001). Sixty percent of all patients used inhaled corticosteroids, whereas only $3 \%$ used oral corticosteroids.

\section{Osteoporosis}

Of the 49 cases based on DXA-scan and IVA, 22, 19 and 8 patients had osteoporosis, osteopenia and normal BMD values, respectively, based on DXA-scan only (Figure 1). In addition, 38 patients $(78 \%)$ had vertebral fractures with a total of 85 fractures. Most vertebral fractures were of thoracic vertebrae 8 and 11 ( $37 \%$ of all fractures for both). The majority of the fractures were mild (Figure 2). Of the 49 patients with osteoporosis, $84 \%$ of them were not using physician prescribed osteoporosis medication (Table 1).

Figure 1: Bone status of cases.

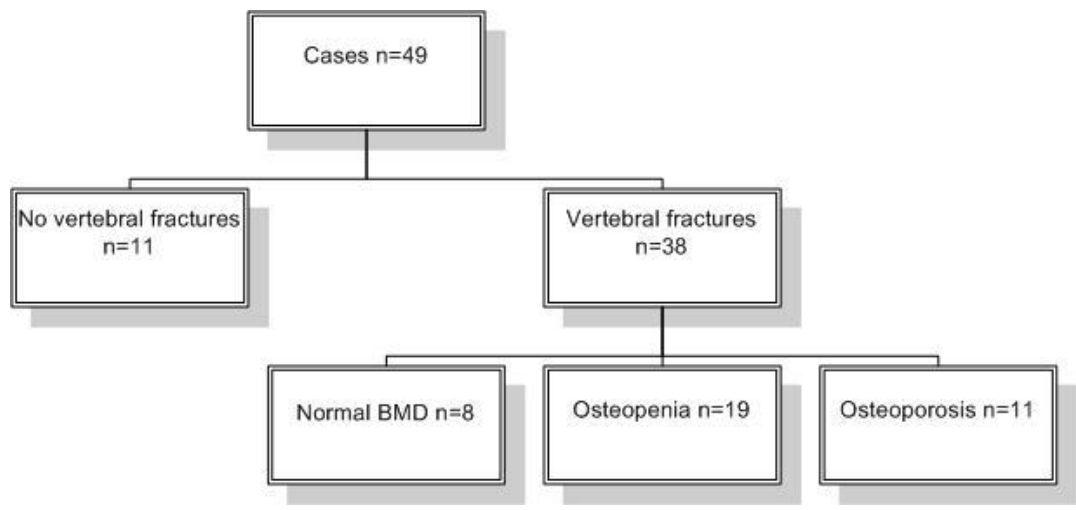


Figure 2: Classification of vertebral fractures

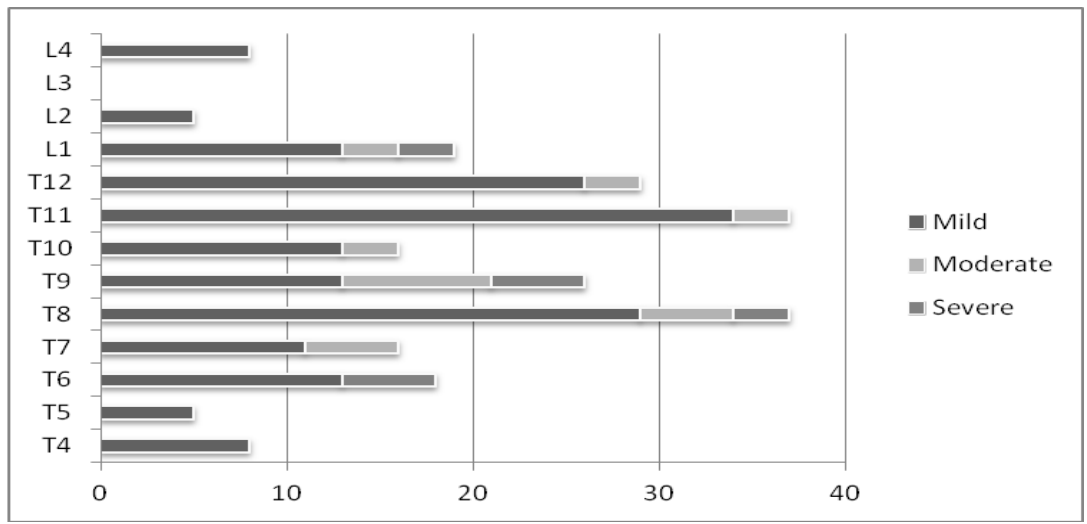

Only in patients with vertebral fractures $n=38$

\section{Cases versus controls}

Osteoporotic patients had a significantly lower BMI and higher RV\%TLC compared to control patients (Table 1). There were no differences between cases and controls in the degree of emphysema, fat-free mass index, gas transfer capacity, functional exercise tolerance, smoking status, levels of vitamin D, PTH, TSH and CRP, the use of corticosteroids or use of physician prescribed bone medication (Table 1).

A lower BMI and a higher RV\%TLC significantly and independently increased the OR for osteoporosis (Table 2a). Moreover, an overweight and obese BMI were both protective for osteoporosis (Table 2b). Nothing could be concluded from a low BMI because none of the patients without osteoporosis had a low BMI (Table 1).

\section{Discussion}

To the best of our knowledge, this study is the first case control study in GOLD stage II patients. Therefore, we excluded the influence of age, gender, $\mathrm{FEV}_{1}$, hypoxemia and hypercapnia as possible risk factors for osteoporosis in COPD ${ }^{22-25}$.

Once more, the effect of a low BMI on osteoporosis was found based on 
Table 1: Patient characteristics after stratification for no osteoporosis and osteoporosis

based on DXA and X-spine.

\begin{tabular}{|c|c|c|c|}
\hline & No osteoporosis $n=49$ & Osteoporosis $n=49$ & p-value \\
\hline Age, years & $68.55 \pm 9.31$ & $70.06 \pm 6.58$ & 0.356 \\
\hline Men/Women, \% & $65 / 35$ & $65 / 35$ & 1.000 \\
\hline Emphysema, \% & 65 & 74 & 0.381 \\
\hline Total score ${ }^{a}$ & $6.3 \pm 4.1$ & $7.3 \pm 6.0$ & 0.391 \\
\hline Centrilobular $^{a}$ & $5.8 \pm 3.7$ & $5.7 \pm 0.9$ & 0.090 \\
\hline Panlobular ${ }^{\mathrm{a}}$ & $0.4 \pm 1.1$ & $0.9 \pm 2.6$ & 0.248 \\
\hline Paraseptal ${ }^{a}$ & $0.1 \pm 0.4$ & $0.7 \pm 1.9$ & 0.076 \\
\hline $\mathrm{BMI}, \mathrm{kg} / \mathrm{m}^{2}$ & $28.81 \pm 4.60$ & $25.26 \pm 3.85$ & $<0.0001$ \\
\hline Low, \% & 0 & 10 & \\
\hline Normal, \% & 20 & 43 & 0.002 \\
\hline Overweight, \% & 45 & 35 & \\
\hline Obese, $\%$ & 35 & 12 & \\
\hline \multicolumn{4}{|l|}{ FFMI, $\mathrm{kg} / \mathrm{m}^{2}$} \\
\hline Men & $19.49 \pm 2.45$ & $18.74 \pm 6.35$ & 0.537 \\
\hline Women & $16.69 \pm 1.78$ & $15.71 \pm 1.99$ & 0.169 \\
\hline Low, \% & 11 & 23 & 0.100 \\
\hline \multicolumn{4}{|l|}{ Lung function } \\
\hline $\mathrm{FEV}_{1}, \%$ of predicted & $66.80 \pm 8.30$ & $64.04 \pm 8.00$ & 0.097 \\
\hline $\mathrm{FEV}_{1} / \mathrm{FVC}, \%$ & $53.27 \pm 6.84$ & $52.43 \pm 7.81$ & 0.570 \\
\hline RV/TLC, $\%$ & $49.08 \pm 6.44$ & 52.02 & 0.038 \\
\hline TLCO ${ }_{V A}, \%$ of predicted & $87.45 \pm 25.31$ & $84.48 \pm 21.27$ & 0.533 \\
\hline 6MWD, meters & $356 \pm 92$ & $363 \pm 100$ & 0.717 \\
\hline \multicolumn{4}{|l|}{ Smoking status } \\
\hline Pack years & $31.79 \pm 15.57$ & $32.00 \pm 19.26$ & \\
\hline Current/ex & $31 / 69$ & $35 / 65$ & 0.667 \\
\hline Osteoporosis DXA, \% & 0 & 45 & $<0.0001$ \\
\hline Osteopenia DXA, \% & 43 & 39 & 0.681 \\
\hline Vertebral fractures, \% & 0 & 78 & $<0.0001$ \\
\hline No of vertebral fractures & 0 & $1.63 \pm 1.40$ & $<0.0001$ \\
\hline $25(\mathrm{OH}) \mathrm{D} 3, \mathrm{nmol} / \mathrm{L}$ & $54.89 \pm 25.48$ & $50.50 \pm 23.72$ & 0.380 \\
\hline Vitamin D deficiency, \% & 47 & 51 & 0.686 \\
\hline PTH, pmol/L & $6.53 \pm 4.63$ & $6.60 \pm 4.61$ & 0.937 \\
\hline $\mathrm{TSH}, \mathrm{mIU} / \mathrm{L}$ & $1.94 \pm 2.02$ & $1.60 \pm 1.05$ & 0.304 \\
\hline $\mathrm{CRP}, \mathrm{mg} / \mathrm{L}$ & $7.29 \pm 5.51$ & $11.24 \pm 15.66$ & 0.098 \\
\hline Charlson score & $1.90 \pm 1.23$ & $1.65 \pm 0.99$ & 0.280 \\
\hline \multicolumn{4}{|l|}{ Corticosteroids } \\
\hline Oral, \% & 2 & 4 & 0.558 \\
\hline Daily dose ${ }^{\mathrm{b}}, \mathrm{mg}$ & $5.0 \pm 0$ & $8.75 \pm 5.30$ & 0.667 \\
\hline Inhaled, \% & 61 & 59 & 0.836 \\
\hline Daily dose ${ }^{c}, \mathrm{mcg}$ & $904 \pm 282$ & $689 \pm 278$ & 0.058 \\
\hline Osteoporosis medication, \% & $4^{\mathrm{d}}$ & $16^{\mathrm{e}}$ & 0.142 \\
\hline
\end{tabular}

${ }^{a}$ Only in patients with emphysema; ${ }^{b}$ Only in patients on maintenance oral corticosteroids;

${ }^{\mathrm{C}}$ Only in patients using inhaled corticosteroids; ${ }^{\mathrm{d} O n l y}$ bisphosphonates; ${ }^{\mathrm{e}} \mathrm{Of}$ these patients: $25 \%$ only bisphosphonates, $25 \%$ only calcium, $25 \%$ calcium and bisphosphonates, $25 \%$ calcium and vitamin D.

DXA-scan, IVA and the combination thereof. This finding is in line with several other studies ${ }^{24-30}$. However, the link between osteoporosis and a low BMI has not yet been clarified. The link might be explained by 
decreased mechanical loading leading to decreased bone formation as was observed in astronauts ${ }^{31}$, increased inflammation and/or other mechanisms leading to proteolysis ${ }^{32 ; 33}$. It is well known that one of the extrapulmonary effects of emphysema is muscle wasting ${ }^{34}$, which in turn leads to a decrease in BMD either through proteolysis or decreased mechanical loading or a combination thereof ${ }^{35}$. It was quite interesting that overweight and obese patients had a decreased risk of osteoporosis. This finding is in line with our study in COPD patients who are starting pulmonary rehabilitation ${ }^{36}$. In the general population, a positive correlation between BMI and BMD has been found. Increased mechanical loading of the cortical skeleton and the secretion of bone active hormones (e.g., leptin) from the adipocytes or from the pancreatic beta cells (including insulin) are suggested mechanisms that may contribute to this correlation ${ }^{37 ; 38}$. Indeed, in a study of 23 men with severe COPD a positive correlation between increased body composition and BMD values were found ${ }^{39}$. Perhaps the focus of research should not be on patients with a low BMI and their higher risk of developing osteoporosis but on patients with a high or obese BMI which could be protective of osteoporosis in COPD patients to find a treatment to prevent osteoporosis. In conclusion, more research is necessary to clarify the link between BMI and osteoporosis in COPD patients, and thus research investigating changes in body composition in relation to changes in BMD is warranted.

An increasing RV/TLC ratio increased the OR for osteoporosis in COPD patients with the same mean $\mathrm{FEV}_{1}$. Therefore, it seems reasonable to conclude that hyperinflation is a better predictor of osteoporosis in COPD than $\mathrm{FEV}_{1}$. Indeed, hyperinflation worsens during the performance of problematic daily activities independent of GOLD stage ${ }^{40}$. Moreover, exercise-induced hyperinflation adversely affects daily physical activity patterns $^{41}$, which may in turn contribute to the development of osteoporosis in COPD.

In contrast, Culham and colleagues compared 15 women with kyphosis resulting from spinal osteoporosis (without COPD) to 15 healthy women and found that TLC was significantly lower in the osteoporotic group ${ }^{42}$. In our study, an increasing RV\%TLC increased the OR for the combination of vertebral fractures and osteoporosis based on BMD. This increase was not only found in patients with spinal osteoporosis. Therefore, the question of cause and consequence can be raised: is osteoporosis a 
consequence of a lower TLC or is a lower TLC the consequence of osteoporosis. More research is needed to clarify this relationship.

Table 3a and 3b: Multivariate regression analysis with osteoporosis as dependent variable.

\begin{tabular}{|c|c|c|c|c|}
\hline & $\mathrm{B}$ & OR & $95 \% \mathrm{Cl}$ & p-value \\
\hline $\mathrm{BMI}, \mathrm{kg} / \mathrm{m}^{2}$ & -0.251 & 0.778 & $0.681-0.888$ & $<0.0001$ \\
\hline RV/TLC, \% & 0.090 & 1.095 & 1.022-1.172 & 0.010 \\
\hline \multicolumn{5}{|l|}{$3 b$} \\
\hline & $\mathrm{B}$ & OR & $95 \% \mathrm{Cl}$ & $p$-value \\
\hline \multicolumn{5}{|l|}{ BMI } \\
\hline \multicolumn{5}{|l|}{ Normal $^{\mathrm{a}}, \%$} \\
\hline \multicolumn{5}{|l|}{ Low $^{b}, \%$} \\
\hline Overweight,\% & -1.282 & 0.277 & 0.096-0.806 & 0.018 \\
\hline Obese, \% & -2.188 & 0.112 & $0.030-0.413$ & 0.001 \\
\hline RV/TLC, \% & 0.094 & 1.099 & $1.023-1.180$ & 0.010 \\
\hline
\end{tabular}

The high prevalence of patients with radiological evidence of emphysema seems in line with the findings of Makita and colleagues ${ }^{43}$. In contrast to the current study, Engelen and colleagues found a positive association between emphysema as observed on HRCT and osteoporosis ${ }^{4}$. This difference might be due to the difference in diagnosing osteoporosis (e.g., DXA and IVA in the current study versus only DXA and osteoporosis diagnoses based on Z-scores in the study by Engelen and colleagues). Indeed, when we assessed osteoporosis only by DXA scan, $85 \%$ of the patients with osteoporosis $(n=20)$ had emphysema compared with $45 \%$ of the patients without osteoporosis $(n=20 ; p=0.008)$. More research is needed to investigate the relationship between emphysema based on HRCT and the diagnosis of osteoporosis based on DXA scan as well as IVA. The observation that RV\%TLC was independently correlated to osteoporosis whereas emphysema based on HRCT did not differ between cases and controls might be because RV\%TLC reflects air trapping (and not emphysema only) which is better assessed by the expiration/inspiration ratio ${ }^{44}$.

The lack of influence of inhaled corticosteroids in the current study is in agreement with de Vries and colleagues who found that the influence of inhaled corticosteroids on BMD disappeared after correction for disease severity ${ }^{45}$. Moreover, Ferguson and colleagues did not find an effect of inhaled corticosteroids on BMD in the TORCH study ${ }^{46}$. 
The lack of influence of vitamin D deficiency and levels on osteoporosis in COPD could be due to the fact that the selected cases had the same mean FEV 1 as the controls, as $\mathrm{FEV}_{1}$ has been found to correlate with vitamin $\mathrm{D}$ in the third national health and nutritional examination survey ${ }^{47}$. In addition, this correlation between vitamin D levels and FEV1 has recently been confirmed ${ }^{48}$.

In women without COPD, higher CRP levels were found in women with the lowest $B M D^{49}$. The lack of influence of CRP on osteoporosis in the current study might be because CRP levels are higher in COPD patients compared to healthy subjects due to chronic systemic inflammation. Another explanation could be that CRP does not reflect the systemic inflammation in COPD patients, and perhaps interleukins should be used as markers of inflammation in COPD. More research is needed to investigate the influence of vitamin $D$ and CRP on bone formation and resorption.

Osteoporosis is under-diagnosed in COPD patients given the high prevalence of osteoporotic COPD patients without bone medication. This finding is in line with observation of COPD patients entering pulmonary rehabilitation ${ }^{36}$, suggesting that this problem is common in daily clinical practice. Hence, pulmonologists should increase their awareness of the high prevalence of osteoporosis, even in low GOLD stages of COPD.

\section{Methodological considerations}

One limitation of this study is that it could suffer from some selection bias due to the inclusion of patients who are treated by pulmonologists and not by their family physicians. However, because all patients were recruited from a general hospital, this study sample can be considered a representative sample of Dutch GOLD II COPD patients attending a regular outpatient COPD clinic.

Another limitation to the current study was that the classification of emphysema on HRCT was a visual assessment by two radiologists and not by an automated quantification. However, both radiologists independently interpreted the HRCTs and the Cohen's kappa coefficient between the two of them was high. Moreover, studies showed that the visual assessment of HRCT correlates well with the pathologic changes $^{50 ; 51}$. Automated quantification of emphysema seems attractive; 
however, this method is also prone to measurement error ${ }^{52 ; 53}$. In addition, Desai and colleagues showed that correlations between visually estimated emphysema and individual physiologic indices were in some instances stronger than those with automated emphysema scoring ${ }^{54}$.

Finally, we have divided patients into osteoporosis versus no osteoporosis groups based on a T-score of -2.5. Therefore, of the 49 control patients, 21 had osteopenia (and thus bone loss) as assessed by DXA scan. This finding may have influenced the results. However, the aim of the study was to assess differences between patients with and without osteoporosis based on DXA and X-spine.

\section{Clinical implications}

Because the prevalence of osteoporosis in COPD patients is rather high ${ }^{3}$ and because these patients frequently seem to be undertreated, it is important to improve the physician awareness of this high prevalence even in patients with moderate COPD. It is also important to assess risk factors to give advice about which COPD patients should be screened for osteoporosis. From the current results, we would advise physicians to screen for osteoporosis in COPD patients, especially those with a low $\mathrm{BMI}$ and/or an increased RV\%TLC even in cases of moderate COPD. 


\section{Reference List}

(1) Rabe KF, Hurd S, Anzueto A, Barnes PJ, Buist SA, Calverley P et al. Global Strategy for the Diagnosis, Management, and Prevention of Chronic Obstructive Pulmonary Disease: GOLD Executive Summary. Am J Respir Crit Care Med 2007; 176(6):532-555.

(2) Wouters EF, Celis MPM, Breyer MK, Rutten EPA, Graat-Verboom L, Spruit MA. Co-morbid manifestations in COPD. Respir Med: COPD Update 3 2007;135-151.

(3) Graat-Verboom L, Wouters EF, Smeenk FW, van den Borne BE, Lunde R, Spruit MA. Current status of research on osteoporosis in COPD: a systematic review. Eur Respir J 2009; 34(1):209-218.

(4) Engelen MP, Schols AM, Lamers RJ, Wouters EF. Different patterns of chronic tissue wasting among patients with chronic obstructive pulmonary disease. Clin Nutr 1999; 18(5):275-280.

(5) Ohara T, Hirai T, Muro S, Haruna A, Terada K, Kinose D et al. Relationship between pulmonary emphysema and osteoporosis assessed by $\mathrm{CT}$ in patients with COPD. Chest 2008; 134(6):1244-1249.

(6) WHO Scientific Group on the Prevention and Management of Osteoporosis. Prevention and Management of Osteoporosis: report of a WHO scientific group. http;//whqlibdoc who int/trs/WHO_TRS_921 pdf [ 2007

(7) The international society for clinical densitometry: Official positions 2007. 2009. Ref Type: Internet Communication

(8) Graat-Verboom L, van den Borne BE, Smeenk FW, Spruit MA, Wouters EF. Osteoporosis in COPD outpatients based on bone mineral density and vertebral fractures. J Bone Miner Res 2010.

(9) Jorgensen NR, Schwarz P, Holme I, Henriksen BM, Petersen LJ, Backer V. The prevalence of osteoporosis in patients with chronic obstructive pulmonary disease-A cross sectional study. Respir Med 2006; .

(10) Buist AS, McBurnie MA, Vollmer WM, Gillespie S, Burney P, Mannino DM et al. International variation in the prevalence of COPD (the BOLD Study): a populationbased prevalence study. Lancet 2007; 370(9589):741-750.

(11) Hoogendoorn M, Feenstra TL, Schermer TR, Hesselink AE, Rutten-van Molken MP. Severity distribution of chronic obstructive pulmonary disease (COPD) in Dutch general practice. Respir Med 2006; 100(1):83-86.

(12) Standards for the diagnosis and care of patients with chronic obstructive pulmonary disease. American Thoracic Society. Am J Respir Crit Care Med 1995; 152(5 Pt 2):S77-121.

(13) Genant HK, Wu CY, van KC, Nevitt MC. Vertebral fracture assessment using a semiquantitative technique. J Bone Miner Res 1993; 8(9):1137-1148. 
(14) Baarends EM, Schols AM, Mostert R, Wouters EF. Peak exercise response in relation to tissue depletion in patients with chronic obstructive pulmonary disease. Eur Respir J 1997; 10(12):2807-2813.

(15) Bhalla M, Turcios N, Aponte V, Jenkins M, Leitman BS, McCauley DI et al. Cystic fibrosis: scoring system with thin-section CT. Radiology 1991; 179(3):783-788.

(16) Allain TJ, McGregor AM. Thyroid hormones and bone. J Endocrinol 1993; 139(1):9-18.

(17) Inaba M. Secondary osteoporosis: thyrotoxicosis, rheumatoid arthritis, and diabetes mellitus. J Bone Miner Metab 2004; 22(4):287-292.

(18) Kuchuk NO, van Schoor NM, Pluijm SM, Chines A, Lips P. Vitamin D Status, Parathyroid Function, Bone Turnover and Bone Mineral Density in Postmenopausal Women with Osteoporosis in Global Perspective. J Bone Miner Res 2008.

(19) Holick MF. Vitamin D deficiency. N Engl J Med 2007; 357(3):266-281.

(20) Norman AW, Bouillon R, Whiting SJ, Vieth R, Lips P. 13th Workshop consensus for vitamin D nutritional guidelines. J Steroid Biochem Mol Biol 2007; 103(35):204-205.

(21) ATS statement: guidelines for the six-minute walk test. Am J Respir Crit Care Med 2002; 166(1):111-117.

(22) Bikle DD, Halloran B, Fong L, Steinbach L, Shellito J. Elevated 1,25dihydroxyvitamin $\mathrm{D}$ levels in patients with chronic obstructive pulmonary disease treated with prednisone. J Clin Endocrinol Metab 1993; 76(2):456-461.

(23) Dimai HP, Domej W, Leb G, Lau KH. Bone loss in patients with untreated chronic obstructive pulmonary disease is mediated by an increase in bone resorption associated with hypercapnia. J Bone Miner Res 2001; 16(11):2132-2141.

(24) Kjensli A, Mowinckel P, Ryg MS, Falch JA. Low bone mineral density is related to severity of chronic obstructive pulmonary disease. Bone 2007; 40(2):493-497.

(25) Vrieze A, de Greef MH, Wijkstra PJ, Wempe JB. Low bone mineral density in COPD patients related to worse lung function, low weight and decreased fat-free mass. Osteoporos Int 2007; 18(9):1197-1202.

(26) Bolton CE, Cannings-John R, Edwards PH, lonescu AA, Evans WD, Pettit RJ et al. What community measurements can be used to predict bone disease in patients with COPD? Respir Med 2008; 102(5):651-657.

(27) Dubois EF, Roder E, Dekhuijzen PN, Zwinderman AE, Schweitzer DH. Dual energy $\mathrm{X}$-ray absorptiometry outcomes in male COPD patients after treatment with different glucocorticoid regimens. Chest 2002; 121(5):1456-1463.

(28) Incalzi RA, Caradonna P, Ranieri P, Basso S, Fuso L, Pagano F et al. Correlates of osteoporosis in chronic obstructive pulmonary disease. Respir Med 2000; 94(11):1079-1084. 
(29) Katsura H, Kida K. A comparison of bone mineral density in elderly female patients with COPD and bronchial asthma. Chest 2002; 122(6):1949-1955.

(30) Mineo TC, Ambrogi V, Mineo D, Fabbri A, Fabbrini E, Massoud R. Bone mineral density improvement after lung volume reduction surgery for severe emphysema. Chest 2005; 127(6):1960-1966.

(31) Cavanagh PR, Licata AA, Rice AJ. Exercise and pharmacological countermeasures for bone loss during long-duration space flight. Gravit Space Biol Bull 2005; 18(2):39-58.

(32) Wouters EF. Local and systemic inflammation in chronic obstructive pulmonary disease. Proc Am Thorac Soc 2005; 2(1):26-33.

(33) Yawn BP, Kaplan A. Co-morbidities in people with COPD: a result of multiple diseases, or multiple manifestations of smoking and reactive inflammation? Prim Care Respir J 2008.

(34) Vestbo J, Prescott E, Almdal T, Dahl M, Nordestgaard BG, Andersen T et al. Body mass, fat-free body mass, and prognosis in patients with chronic obstructive pulmonary disease from a random population sample: findings from the Copenhagen City Heart Study. Am J Respir Crit Care Med 2006; 173(1):79-83.

(35) Bolton CE, lonescu AA, Shiels KM, Pettit RJ, Edwards PH, Stone MD et al. Associated loss of fat-free mass and bone mineral density in chronic obstructive pulmonary disease. Am J Respir Crit Care Med 2004; 170(12):1286-1293.

(36) Graat-Verboom L, Spruit MA, van den Borne BE, Smeenk FW, Martens EJ, Lunde $\mathrm{R}$ et al. Correlates of osteoporosis in chronic obstructive pulmonary disease: An underestimated systemic component. Respir Med 2009; 103(8):11431151.

(37) Reid IR. Relationships between fat and bone. Osteoporos Int 2008; 19(5):595606.

(38) Zillikens MC, Uitterlinden AG, van Leeuwen JP, Berends AL, Henneman P, van Dijk KW et al. The role of body mass index, insulin, and adiponectin in the relation between fat distribution and bone mineral density. Calcif Tissue Int 2010; 86(2):116-125.

(39) Vondracek SF, Voelkel NF, McDermott MT, Valdez C. The relationship between adipokines, body composition, and bone density in men with chronic obstructive pulmonary disease. Int J Chron Obstruct Pulmon Dis 2009; 4:267-277.

(40) Watz H, Waschki B, Boehme C, Claussen M, Meyer T, Magnussen H. Extrapulmonary effects of chronic obstructive pulmonary disease on physical activity: a cross-sectional study. Am J Respir Crit Care Med 2008; 177(7):743751.

(41) Garcia-Rio F, Lores V, Mediano O, Rojo B, Hernanz A, Lopez-Collazo E et al. Daily physical activity in patients with chronic obstructive pulmonary disease is mainly associated with dynamic hyperinflation. Am J Respir Crit Care Med 2009; 180(6):506-512. 
(42) Culham EG, Jimenez HA, King CE. Thoracic kyphosis, rib mobility, and lung volumes in normal women and women with osteoporosis. Spine (Phila Pa 1976 ) 1994; 19(11):1250-1255.

(43) Makita H, Nasuhara Y, Nagai K, Ito Y, Hasegawa M, Betsuyaku T et al. Characterisation of phenotypes based on severity of emphysema in chronic obstructive pulmonary disease. Thorax 2007; 62(11):932-937.

(44) Eda S, Kubo K, Fujimoto K, Matsuzawa Y, Sekiguchi M, Sakai F. The relations between expiratory chest CT using helical CT and pulmonary function tests in emphysema. Am J Respir Crit Care Med 1997; 155(4):1290-1294.

(45) de Vries F, van Staa TP, Bracke MS, Cooper C, Leufkens HG, Lammers JW. Severity of obstructive airway disease and risk of osteoporotic fracture. Eur Respir J 2005; 25(5):879-884.

(46) Ferguson GT, Calverley PM, Anderson JA, Jenkins CR, Jones PW, Willits LR et al. Prevalence and progression of osteoporosis in patients with COPD: results from the TOwards a Revolution in COPD Health study. Chest 2009; 136(6):14561465.

(47) Black PN, Scragg R. Relationship between serum 25-hydroxyvitamin d and pulmonary function in the third national health and nutrition examination survey. Chest 2005; 128(6):3792-3798.

(48) Janssens W, Bouillon R, Claes B, Carremans C, Lehouck A, Buysschaert I et al. Vitamin $\mathrm{D}$ deficiency is highly prevalent in COPD and correlates with variants in the vitamin D-binding gene. Thorax 2010; 65(3):215-220.

(49) Koh JM, Khang YH, Jung CH, Bae S, Kim DJ, Chung YE et al. Higher circulating hsCRP levels are associated with lower bone mineral density in healthy pre- and postmenopausal women: evidence for a link between systemic inflammation and osteoporosis. Osteoporos Int 2005; 16(10):1263-1271.

(50) Stern EJ, Frank MS. CT of the lung in patients with pulmonary emphysema: diagnosis, quantification, and correlation with pathologic and physiologic findings. AJR Am J Roentgenol 1994; 162(4):791-798.

(51) Thurlbeck WM, Muller NL. Emphysema: definition, imaging, and quantification. AJR Am J Roentgenol 1994; 163(5):1017-1025.

(52) Boedeker KL, Nitt-Gray MF, Rogers SR, Truong DA, Brown MS, Gjertson DW et al. Emphysema: effect of reconstruction algorithm on CT imaging measures. Radiology 2004; 232(1):295-301.

(53) Stoel BC, Vrooman HA, Stolk J, Reiber JH. Sources of error in lung densitometry with CT. Invest Radiol 1999; 34(4):303-309.

(54) Desai SR, Hansell DM, Walker A, MacDonald SL, Chabat F, Wells AU. Quantification of emphysema: a composite physiologic index derived from CT estimation of disease extent. Eur Radiol 2007; 17(4):911-918. 


\section{Chapter VII}

\section{Progression of osteoporosis in patients with COPD: A 3 year follow up study}

Lidwien Graat-Verboom, Frank W.J.M. Smeenk, Ben E.E.M. van den Borne, Martijn A. Spruit, Frits H. Jansen, Joris W.T. van Enschot, Emiel F.M. Wouters

Accepted for publication in Respiratory Medicine 


\section{Abstract}

Currently, our knowledge on the progression of osteoporosis and its determinants is limited in patients with chronic obstructive pulmonary disease (COPD). Bone mineral density generally remains stable in patients with COPD over a period of 3 years. Nevertheless, the progression of vertebral fractures was not assessed, while an increase of vertebral fractures over time may be reasonable.

Aims of the current study were to determine the percentage of newlydiagnosed osteoporotic patients after a follow up of 3 years and to identify baseline risk factors for the progression of osteoporosis in COPD.

Clinically stable COPD outpatients were included. Lung function parameters, body composition measures, six minute walk distance, DXAscan and X-spine were assessed at baseline and repeated after 3 years.

Prevalence of osteoporosis in COPD patients increased from $47 \%$ to $61 \%$ in 3 years mostly due to an increase of vertebral fractures. Lower baseline $\mathrm{T}$-score at the trochanter independently increased the risk for the development of osteoporosis. Additionally, baseline vitamin D deficiency increased this risk 7.5 fold.

In conclusion, the prevalence of osteoporosis increased over a 3-year period in patients with COPD. Baseline risk factors for the development of osteoporosis are osteopenia at the trochanter and vitamin D deficiency. 


\section{Introduction}

Chronic Obstructive Pulmonary Disease (COPD) is characterized by a progressive not fully reversible airflow limitation. ${ }^{1}$ Besides this pulmonary component significant extra-pulmonary effects are to be considered, ${ }^{2 ; 3}$ including osteoporosis. Indeed, COPD patients have a higher prevalence of osteoporosis than healthy elderly subjects. ${ }^{4 ; 5}$

Osteoporosis is characterized by a decreased bone mineral density (BMD) and/or changes of the microarchitecture, resulting in an increased fragility of bones with an increased fracture risk as a consequence. ${ }^{6}$ Local dual energy absorptiometry (DXA)-scans measure BMD of the hip and the lumbar spine. Generally this is considered to be the gold standard to assess osteoporosis ${ }^{6 ; 7}$. However, (non-symptomatic) vertebral fractures can be present in COPD patients with a normal BMD on DXA-scan.; Therefore, the combination of local DXA-scans and the assessment of vertebral fractures using $x$-ray should be used to diagnose osteoporosis in patients with COPD. ${ }^{8}$

Our knowledge on the progression of osteoporosis in COPD is currently limited to three studies. In the Lung Health Study II, a decline of $-0.9 \%$ of baseline BMD was found in COPD patients on inhaled corticosteroids as compared to a stable BMD in the placebo group ${ }^{10}$. Moreover, BMD remained stable one year after a pulmonary rehabilitation program, as opposed to an improved BMD after lung volume reduction surgery (LVRS) ${ }^{11}$. Finally, BMD did not change during 3 -year follow up in the TORCH study, irrespective of treatment allocation ${ }^{12}$.

Summarizing, BMD generally remains stable in patients with COPD over a period of 3 years. Nevertheless, in the above mentioned studies the prevalence of vertebral fractures was not assessed, while an increase of prevalence of vertebral fractures with $12 \%$ was found during 4-year follow up in patients with sarcoidosis ${ }^{13}$. Therefore, observational studies including local DXA scans and X-ray of the lumbar spine will extent our current knowledge on the prevalence and incidence of osteoporosis in patients with COPD.

Various determinants of osteoporosis have been identified in numerous cross-sectional studies. ${ }^{4 ; 8}$ Moreover, improvements in BMD following LVRS were associated with a decline in residual volume (RV), an increase in diffusing capacity for carbon monoxide, an increase in lean 
body mass, a decrease in bone alkaline phosphatase, a decrease in $\beta$ crosslaps and a decrease in methylprednisolone ${ }^{11}$. Furthermore, a small but accelerated 3-year decline in BMD has been suggested following the use of inhaled corticosteroids compared to placebo in patients with $\operatorname{COPD}^{10}$, which was not corroborated by others ${ }^{12}$. Consequentley, determinants of the progression of osteoporosis in patients with COPD are partially recognized and warrant further investigation.

The aim of this study was twofold: 1) To determine changes in BMD and number of vertebral fractures during 3-year follow up in patients with COPD; and 2) To identify possible baseline risk factors for the development of osteoporosis in these COPD patients.

\section{Methods}

COPD patients were recruited from the outpatient pulmonary clinic of the Catharina Hospital in Eindhoven, the Netherlands from May 2005 until December 2005. Diagnosis of COPD was made according to the American Thoracic Society (ATS) Guidelines ${ }^{14}$ and classified according to the Global Strategy for the Diagnosis, Management, and Prevention of COPD (GOLD) guidelines. ${ }^{1}$ Patients were clinically stable, defined as not treated for an acute COPD exacerbation in the previous 6 months. Informed consent was obtained from all patients and the study was approved by the internal review board of the Catharina Hospital Eindhoven. Some of the baseline data were used in a previous publication. $^{8}$

Inclusion criteria were: age $>18$ years, COPD according to the ATS and classified according to the GOLD guidelines, and written informed consent.

Medical history, medication use and smoking status were assessed with a questionnaire and by reviewing the medical charts. To report medical history the Charlson co-morbitity index was used. ${ }^{15}$ To assess dyspnoea the Medical Research Counsel (MRC) dyspnoea score was used (see online data supplement).

Height and weight were assessed and body mass index(BMI) was calculated and defined as low $\left(<21 \mathrm{~kg} / \mathrm{m}^{2}\right)$, normal $\left(21-25 \mathrm{~kg} / \mathrm{m}^{2}\right)$, 
overweight $\left(>25-30 \mathrm{~kg} / \mathrm{m}^{2}\right)$ and obese $\left(>30 \mathrm{~kg} / \mathrm{m}^{2}\right)$. Bio-impedance analysis was performed using the BODYSTAT ${ }^{\circledR} 1500$ medical, single frequency (Xitron Technologies) and FFMI was defined as depleted (men $<16 \mathrm{~kg} / \mathrm{m}^{2}$ and women $<15 \mathrm{~kg} / \mathrm{m}^{2}$ ) or normal.

Lung function parameters were assessed using the Jaeger MASTERLAB BODY® (VIASYS Healthcare). The forced expiratory volume in the first second $\left(F E V_{1}\right)$ and the forced vital capacity (FVC) were measured and $\mathrm{FEV}_{1} / \mathrm{FVC}$ was calculated. A 6 min walking test was performed according to the ATS guidelines. ${ }^{16}$ BMD was assessed at the femoral neck and trochanter of the hip and at the lumbar spine using a Delphi upgraded to Discovery W (S/N 70991) DXA-scan. X-rays of the thoracic and lumbar spine were perfomed using a digital Bucky system (Digital Diagnost or $\mathrm{H}$ Diagnost-Om65-CS64, Philips Medical Systems). Vertebral fractures were assessed according to Genant ${ }^{17}$ (see online data supplement). Osteoporosis was defined as a T-score $\leq-2.5$ and/or a vertebral fracture. ${ }^{6}$

Assessments were repeated after 3 years (May 2008 - December 2008). The 3-year BMD measurements were obtained on the Hologic A discovery DXA scan (see online data supplement). Vertebral fractures were assessed by instant vertebral assessment by means of lateral DXAscan (see online data supplement). Hospital admissions during the study were assessed. At baseline venous blood samples were obtained to assess 25-hydroxyvitamin D3 (25-OH-D3) levels. Vitamin D deficiency was defined as $25-\mathrm{OH}-\mathrm{D} 3<50 \mathrm{nmol} / \mathrm{L}^{18 ; 19}$

\section{Statistical analyses}

Discrete variables were compared with Chi-square test and presented as percentages. Continuous variables were compared with students t-test and presented as mean \pm standard error of mean (SEM). Variables at baseline and follow up were compared with paired sample t-test, McNemar and Wilcoxon tests for continue, nominal and ordinal variables, respectively.

Patients without osteoporosis at baseline were divided into 2 subgroups: without- and with osteoporosis at 3-year follow up. Their baseline variables were compared using independent sample t-test and chi-square tests. Univariate binary logistic regression analysis was performed. 
Dependent variable was osteoporosis at follow up. Baseline variables were used as covariates. If significant at the $p<0.05$ level variables were included in the multivariate analysis. Odds ratio (OR) with $95 \%$ confidence intervals $(\mathrm{Cl})$ are reported. A $p$-value $<0.05$ was used to indicate statistical significance. All statistical analyses were performed using Statistical Package for Social Sciences (SPSS) version 16.0.

\section{Results}

Of the 133 patients investigated in 2005, 90 patients $(68 \%)$ were reassessed after 3 years. Of the 43 patients not included in the follow up 16 died and 27 were unable or unwilling to be re-assessed. There were no significant differences in gender, age, body composition and GOLD stage between patients that were re-assessed, and those who were lost to follow up (see online supplement for details). Patients lost to follow up had a significantly higher prevalence of osteoporosis as compared to the studied group ( $67 \%$ versus $47 \% p=0.025)$.

\section{Baseline characteristics}

The patients who were assessed at baseline and 3 years later, generally were elderly patients with moderate to very severe COPD (table 1). A majority of these patients were overweight and had a poor functional exercise capacity. Forty patients (44\%) reported 1 or more co-morbidities on the Charlson co-morbidity index, while 28 patients $(32 \%)$ had a vitamin D deficiency. Moreover, 42 patients (47\%) showed osteoporosis based on DXA and X-spine, while only 9 osteoporotic patients $(21 \%)$ received physician-prescribed bone medication. In another 24 patients of this group bone medication was newly started $(57 \%)$, while the remaining 9 osteoporotic patients refused any bone medication (22\%).

\section{Three-year follow up data}

The mean FEV1 (\% of predicted) decreased significantly compared to baseline (table 1). Consequently, significantly more patients showed a higher GOLD-score: $11 \%$ more patients with GOLD IV. Moreover, body 
Table 1: Patients characteristics at baseline and follow up.

\begin{tabular}{|c|c|c|c|}
\hline & Baseline & Follow up & p-value \\
\hline Age, years (range) & $68.7 \pm 0.9(50-88)$ & $71.7 \pm 0.9(53-91)$ & NA \\
\hline Male/Female, \% & $60 / 40$ & $60 / 40$ & NA \\
\hline FEV1, \% of predicted & $63.4 \pm 1.9$ & $59.5 \pm 2.1$ & 0.001 \\
\hline RV\%TLC, \% & $51.9 \pm 1.1$ & $53.4 \pm 1.0$ & 0.050 \\
\hline \multicolumn{4}{|l|}{ GOLD } \\
\hline I, \% & 14 & 11 & \\
\hline II, \% & 60 & 49 & $<0.001$ \\
\hline III, \% & 19 & 22 & \\
\hline IV, \% & 7 & 18 & \\
\hline BMI, $\mathrm{kg} / \mathrm{m}^{2}$ & $26.8 \pm 0.5$ & $26.5 \pm 0.5$ & 0.135 \\
\hline Normal, \% & 22 & 28 & \\
\hline Low, \% & 8 & 9 & 0.495 \\
\hline Overweight, \% & 48 & 45 & \\
\hline Obese, $\%$ & 22 & 18 & \\
\hline FFMI, males/females, $\mathrm{kg} / \mathrm{m}^{2}$ & $17.7 \pm 0.3 / 15.9 \pm 0.3$ & $18.2 \pm 0.3 / 16.1 \pm 0.4$ & $0.002 / 0.214$ \\
\hline Low, \% & 22 & 14 & 0.125 \\
\hline 6MWD, meters & $369 \pm 12$ & $332 \pm 12$ & $<0.001$ \\
\hline \multicolumn{4}{|l|}{ Smoking } \\
\hline Ex-smokers, \% & 71 & 66 & $<0.001$ \\
\hline Pack years & $35.7 \pm 2.5$ & $38.2 \pm 3.7$ & $<0.001$ \\
\hline \multicolumn{4}{|l|}{ Corticosteroids } \\
\hline Oral (chronic) , \% & 12 & 11 & 1.000 \\
\hline Inhaled, \% & 67 & 66 & 0.791 \\
\hline Vitamin D deficiency,\% & 32 & NA & \\
\hline Bone medication, \% & 14 & 41 & $<0.001$ \\
\hline Osteoporosis, \% & 47 & 61 & 0.004 \\
\hline DXA alone, \% & 22 & 22 & 1.000 \\
\hline X-spine alone, \% & 32 & 52 & $<0.001$ \\
\hline Osteopenia, \% & 48 & 50 & $<0.001$ \\
\hline \multicolumn{4}{|l|}{ T-score } \\
\hline $\mathrm{LS}, \mathrm{g} / \mathrm{cm}^{2}$ & $-0.8 \pm 0.2$ & $-0.6 \pm 0.2$ & $<0.001$ \\
\hline Femoral neck, $\mathrm{g} / \mathrm{cm}^{2}$ & $-1.3 \pm 0.1$ & $-1.5 \pm 0.1$ & $<0.001$ \\
\hline Trochanter, $\mathrm{g} / \mathrm{cm}^{2}$ & $-0.5 \pm 0.1$ & $-0.8 \pm 0.1$ & $<0.001$ \\
\hline \multicolumn{4}{|l|}{ Number of fractures } \\
\hline Thoracic spine & $0.4 \pm 0.09$ & $0.80 \pm 0.13$ & $<0.001$ \\
\hline Lumbar spine & $0.10 \pm 0.04$ & $0.16 \pm 0.05$ & 0.025 \\
\hline Total & $0.51 \pm 0.10$ & $0.96 \pm 0.14$ & $<0.001$ \\
\hline Charlson score & $1.68 \pm 0.10$ & $2.03 \pm 0.12$ & $<0.001$ \\
\hline MRC dyspnoe scale & $1.66 \pm 0.13$ & $1.78 \pm 0.15$ & 0.284 \\
\hline $0, \%$ & 19 & 20 & \\
\hline $1, \%$ & 28 & 22 & 0.302 \\
\hline $2, \%$ & 30 & 30 & \\
\hline $3, \%$ & 15 & 15 & \\
\hline $4, \%$ & 8 & 13 & \\
\hline
\end{tabular}

Results are presented as mean \pm standard error of mean unless otherwise indicated. Abbreviations: FEV1=forced expiratory volume in the First second; RV\%TLC=residual volume as percentage of the Total lung capacity; GOLD=classification of disease severity in 4 stages; $\mathrm{BMI}=$ body mass index; $\mathrm{FFMl}=$ fat free mass index; $6 \mathrm{MWD}=6$ minutes walking distance; $\mathrm{NA}=$ not applicable; $\mathrm{T}$-score=measured bone mineral density compared to the bone mineral density of the Young gender matched population expressed in standard deviation. MRC=Medical Research Council. 
weight remained stable while the 6MWD decreased significantly compared to baseline with a mean 37 meters over 3 years (table 1).

Prevalence of osteoporosis increased from $47 \%$ at baseline to $61 \%$ at $3-$ year follow up. Of the 48 patients who did not show osteoporosis at baseline, 16 patients (33\%) developed osteoporosis during 3-year follow up. Thirteen of these new cases $(81 \%)$ could be identified by X-spine, while only 3 were exclusively identified by DXA (figure 1a). Forty-two patients had osteoporosis at baseline. In this group only 3 patients $(7 \%)$ did not meet the criteria for osteoporosis at follow up. On the DXA scan these 3 patients were classified as osteopenic (T-score between -1 and 2.5) (figure 1b).

Of the 24 patients we prescribed bone medication at baseline only 13 patients continued to use this medication for 3 years. Both patients that used their medication and patients that discontinued showed a significant increase in vertebral fractures and BMD of the lumbar spine and a nonsignificant decrease in BMD of the collum and trochanter (see online data supplement). There was no significant difference when comparing change in BMD and change in vertebral fractures between patients with and without continuing to use their bone medication (see online data supplement).

Figure 1 a: Bone status at baseline and follow up for patients without osteoporosis at baseline

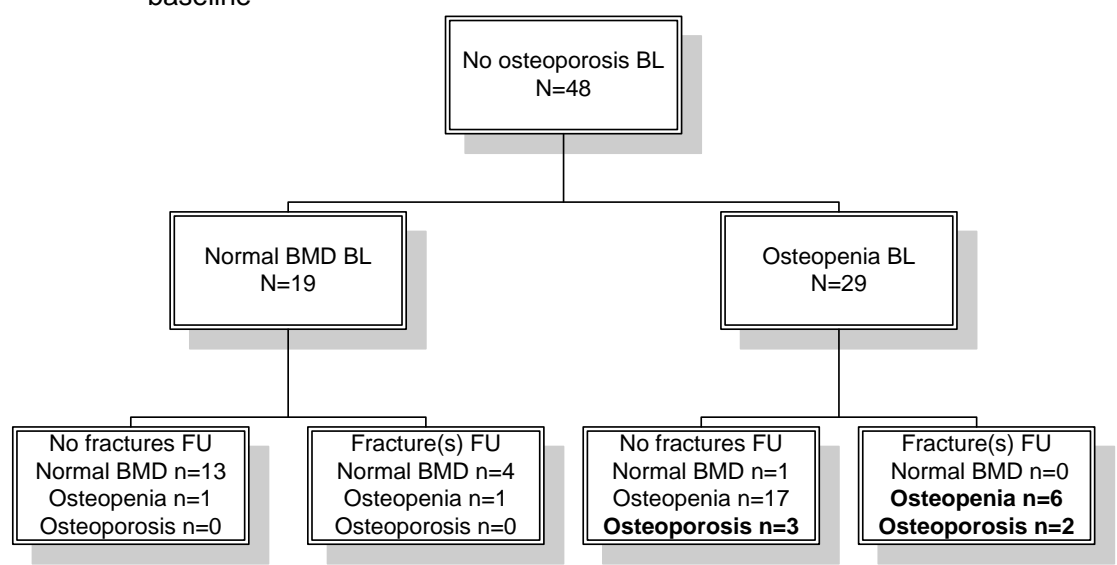

Abbreviations: $\mathrm{BL}=$ baseline; $\mathrm{FU}=$ follow up (3 years after baseline); $\mathrm{BMD}=$ bone mineral density. Bold denotation identifies patients who moved from no osteoporosis at baseline to osteoporosis at follow up. 
Figure $1 \mathrm{~b}$ : Bone status at baseline and follow up for patients with osteoporosis at baseline

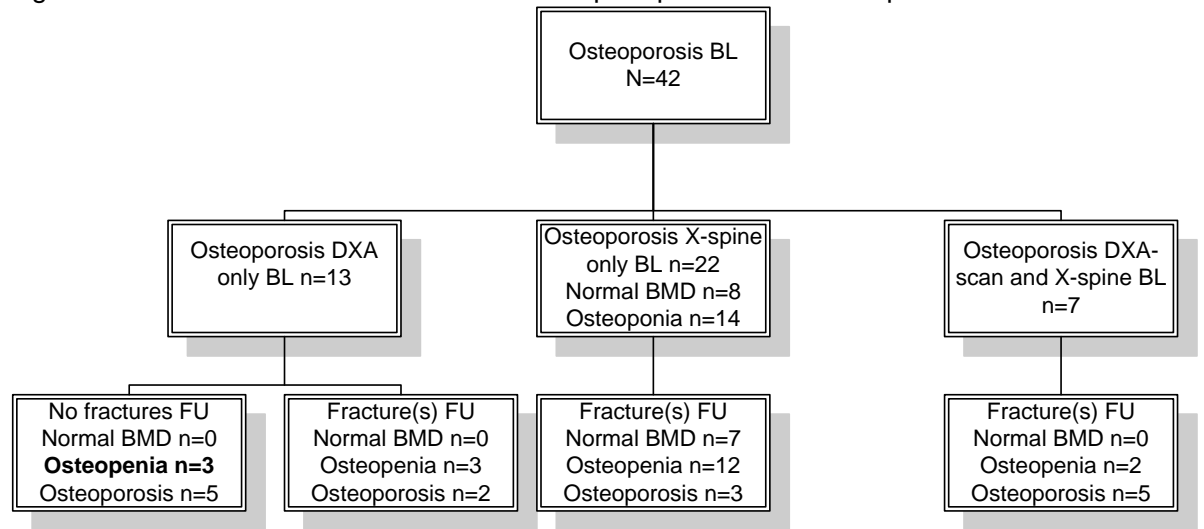

Abbreviations: $\mathrm{BL}=$ baseline; $\mathrm{FU}=$ follow up ( 3 years after baseline); $\mathrm{BMD}=$ bone mineral density. Bold denotation identifies patients who moved from having osteoporosis at baseline to no osteoporosis at follow up.

\section{Newly diagnosed osteoporosis}

Patients without osteoporosis at baseline $(n=48)$ were divided into a group with $(n=16)$ or without $(n=32)$ osteoporosis at 3-year follow up (table 2).

At baseline, gender distribution and mean age were comparable between groups. However, patients with osteoporosis at follow up had more pack years at baseline as compared to patients without osteoporosis at follow up. In addition, these patients had a lower T-score at the trochanter and were more frequently vitamin $\mathrm{D}$-deficient.

Patients who developed osteoporosis during 3-year follow up showed a significant decrease in $\mathrm{FEV}_{1}$, whereas lung function of patients without osteoporosis at follow up remained stable: delta $\mathrm{FEV}_{1}-8$ versus $-2 \%$ of predicted, respectively $(p=0.041)$. Other changes over 3 years were not significantly different between groups.

\section{Univariate and multivariate logistic regression analyses}

Results of univariate logistic regression analysis with osteoporosis at 3 years as dependent variable are shown in figure 2. More pack years and 
Table 2: Patients without osteoporosis at baseline $(n=48)$ baseline and follow up data after stratification for no-osteoporosis versus osteoporosis after follow up

\begin{tabular}{|c|c|c|c|c|c|c|c|}
\hline & \multicolumn{3}{|c|}{$\begin{array}{l}\text { No osteoporosis baseline; } \\
\text { no osteoporosis follow up } \\
(n=32)\end{array}$} & \multicolumn{3}{|c|}{$\begin{array}{l}\text { No osteoporosis baseline; } \\
\text { osteoporosis follow up }(n=16)\end{array}$} & \multirow{2}{*}{$\begin{array}{l}\text { p-value } \\
\text { baseline } \\
\text { both } \\
\text { groups }\end{array}$} \\
\hline & Baseline & $\begin{array}{l}\text { Follow } \\
\text { up }\end{array}$ & p-value & Baseline & $\begin{array}{l}\text { Follow } \\
\text { up }\end{array}$ & p-value & \\
\hline Age, years & $67.6 \pm 1.7$ & & & $68.2 \pm 1.6$ & & & 0.826 \\
\hline Male/female, \% & $63 / 38$ & & & $63 / 38$ & & & 1.000 \\
\hline $\begin{array}{l}\text { FEV1, \% of } \\
\text { predicted }\end{array}$ & $64.3 \pm 3.4$ & $62.8 \pm 3.8$ & 0.462 & $70.1 \pm 0.4$ & $62.1 \pm 4.0$ & $<0.0001$ & 0.422 \\
\hline RV\%TLC, \% & $61.0 \pm 1.9$ & $51.4 \pm 1.6$ & 0.767 & $48.6 \pm 1.9$ & $50.4 \pm 2.0$ & 0.157 & 0.658 \\
\hline \multicolumn{8}{|l|}{ GOLD } \\
\hline I, \% & 19 & 13 & & 19 & 6 & & \\
\hline II, \% & 56 & 53 & 0.071 & 69 & 69 & 0.025 & 0.554 \\
\hline III, \% & 22 & 17 & & 6 & 13 & & \\
\hline IV, \% & 3 & 17 & & 6 & 12 & & \\
\hline BMI, $\mathrm{kg} / \mathrm{m}^{2}$ & $27.6 \pm 0.8$ & $27.4 \pm 0.9$ & 0.653 & $28.1 \pm 1.2$ & $27.2 \pm 1.3$ & 0.055 & 0.719 \\
\hline Normal, \% & 16 & 13 & & 25 & 25 & & \\
\hline Low, \% & 6 & 9 & 0.357 & 0 & 6 & 0.705 & 0.673 \\
\hline Overweight,\% & 50 & 59 & & 50 & 44 & & \\
\hline Obese, \% & 28 & 19 & & 25 & 25 & & \\
\hline \multicolumn{8}{|l|}{ FFMI } \\
\hline Males, kg/m² & $17.4 \pm 0.4$ & $18.0 \pm 0.4$ & 0.074 & $18.2 \pm 0.7$ & $18.8 \pm 0.8$ & 0.136 & 0.362 \\
\hline $\begin{array}{l}\text { Females, } \\
\qquad \mathrm{kg} / \mathrm{m}^{2}\end{array}$ & $16.4 \pm 0.6$ & $17.2 \pm 0.8$ & 0.137 & $16.5 \pm 0.4$ & $16.3 \pm 0.7$ & 0.743 & 0.824 \\
\hline Low, \% & 25 & 10 & 0.125 & 7 & 6 & 1.000 & 0.141 \\
\hline 6MWD, meters & $373 \pm 16$ & $321 \pm 17$ & $<0.0001$ & $388 \pm 18$ & $361 \pm 17$ & 0.030 & 0.696 \\
\hline \multicolumn{8}{|l|}{ Smoking } \\
\hline Ex-smokers,\% & 75 & 70 & 0.500 & 69 & 57 & 1.000 & 0.646 \\
\hline Pack years & $29.5 \pm 4.3$ & $30.0 \pm 4.4$ & 0.023 & $43.0 \pm 5.1$ & $44.1 \pm 5.1$ & 0.029 & 0.034 \\
\hline \multicolumn{8}{|l|}{ Corticosteroids } \\
\hline Oral , \% & 13 & 6 & 0.500 & 6 & 0 & 1.000 & 0.504 \\
\hline $\begin{array}{r}\text { Cummulative, } \\
\mathrm{mg}\end{array}$ & $1440 \pm 421$ & $1913 \pm 927$ & 0.653 & $2632 \pm 1259$ & $2770 \pm 668$ & 0.264 & 0.269 \\
\hline Inhaled, \% & 66 & 65 & 1.000 & 63 & 56 & 1.000 & 0.831 \\
\hline $\begin{array}{l}\text { Vitamin D } \\
\quad \text { deficiency, \% }\end{array}$ & 10 & & & 38 & & & 0.022 \\
\hline $\begin{array}{l}\text { Bone } \\
\text { medication, \% }\end{array}$ & 3 & 6 & 0.655 & 19 & 25 & 1.000 & 0.065 \\
\hline Osteoporosis,\% & 0 & 0 & & 0 & 100 & $<0.0001$ & 1.000 \\
\hline DXA , \% & 0 & 0 & 1.000 & 0 & 31 & 0.063 & 1.000 \\
\hline X-spine, \% & 0 & 0 & 1.000 & 0 & 81 & $<0.0001$ & 1.000 \\
\hline \multicolumn{8}{|l|}{ T-score } \\
\hline LS & $-0.2 \pm 0.3$ & $-0.1 \pm 0.3$ & 0.380 & $-0.6 \pm 0.3$ & $-0.6 \pm 0.3$ & 0.960 & 0.434 \\
\hline $\begin{array}{l}\text { Femoral } \\
\text { neck }\end{array}$ & $-0.9 \pm 0.2$ & $-1.1 \pm 0.2$ & 0.007 & $-1.3 \pm 0.2$ & $-1.7 \pm 0.2$ & $<0.0001$ & 0.133 \\
\hline Trochanter & $0.1 \pm 0.2$ & $-0.2 \pm 0.2$ & $<0.0001$ & $-0.6 \pm 0.2$ & $-0.9 \pm 0.3$ & 0.010 & 0.019 \\
\hline
\end{tabular}


Table 2 continued

\begin{tabular}{|c|c|c|c|c|c|c|c|}
\hline $\begin{array}{l}\text { Thoracic } \\
\text { spine }\end{array}$ & 0 & 0 & & 0 & 1.06 & 0.004 & 1.000 \\
\hline Lumbar spine & 0 & 0 & & 0 & 0.19 & 0.083 & 1.000 \\
\hline Total & 0 & 0 & & 0 & 1.25 & 0.001 & 1.000 \\
\hline Charlson score & $1.56 \pm 0.18$ & $1.81 \pm 0.20$ & 0.030 & $1.56 \pm 0.20$ & $2.06 \pm 0.28$ & 0.027 & 1.000 \\
\hline MRC-scale & $1.59 \pm 0.18$ & $1.68 \pm 0.23$ & 0.823 & $1.63 \pm 0.30$ & $1.85 \pm 0.37$ & 0.367 & 0.925 \\
\hline \multicolumn{8}{|l|}{$\begin{array}{l}\text { Hospital } \\
\text { admission } 3 \text { yrs }\end{array}$} \\
\hline $\begin{array}{l}\text { Pulmonary } \\
\text { problem, \% }\end{array}$ & NA & 7 & & NA & 15 & & NA \\
\hline Other, \% & NA & 28 & & NA & 7 & & NA \\
\hline
\end{tabular}

Results are presented as mean \pm standard error of mean unless otherwise indicated. Osteoporosis is based on DXA-scan and X-spine. Abbreviations: FEV1=forced expiratory volume in the First second; RV\%TLC=residual volume as percentage of the Total lung capacity; GOLD=classification of disease severity in 4 stages; BMl=body mass index; $\mathrm{FFMl}=$ fat free mass index; $6 \mathrm{MWD}=6$ minutes walking distance; $\mathrm{T}$-score=measured bone mineral density compared to the bone mineral density of the Young gender matched population expressed in standard deviation; MRC-scale=Medical Research Councel Dyspnoea scale; NA=not applicable.

the presence of vitamin $\mathrm{D}$ deficiency increased the risk of developing osteoporosis in 3 years, whereas a higher T-score at the trochanter decreased this risk (figure 2). Multivariate analysis showed that vitamin $\mathrm{D}$ deficiency and T-score at the trochanter kept their significance independently of each other and of the number of pack years smoked (table 3a). Moreover, osteopenia at the trochanter at baseline independently increased the odds ratio for osteoporosis at follow up (table 3b).

\section{Discussion}

Our study is the first longitudinal study in COPD patients diagnosing osteoporosis based on both DXA-scan and X-spine. Prevalence of osteoporosis increased from $47 \%$ to $61 \%$ in a period of 3 years mostly due to an increase in vertebral fractures. Vitamin $D$ deficiency at baseline and lower T-score at the trochanter were independent risk factors for the development of osteoporosis during 3-year follow up in patients with COPD. 
Figure 2: Forrest plot of the results of univariate regression analysis with osteoporosis at 3 years as dependent variable.

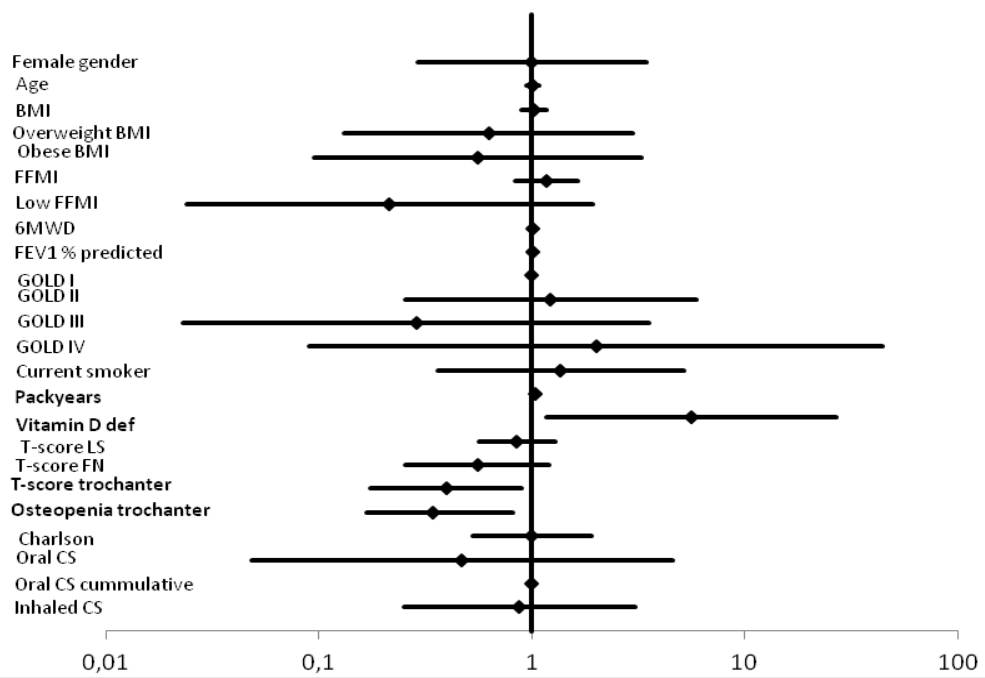

Univariate regression analysis were done in patients without osteoporosis at baseline $(n=48)$ with osteoporosis at follow up as dependent variable. Results are presented as odds ratio's and $95 \%$ confidence intervals on a logarithmic scale. Abbreviations: BMI=body mass index; $F F M I=f a t$ free mass index; $6 \mathrm{MWD}=6$ minutes walking distance; $F E V 1=$ forced expiratory volume in the first second; GOLD=classification of chronic obstructive pulmonary disease in 4 stages; def=deficiency; $L S=l u m b a r$ spine; $F N=$ femoral neck.

\section{Progression of osteoporosis}

The significant increase in prevalence of osteoporosis in COPD patients over a period of 3 years demonstrated in our study is in contrast with the results of Ferguson and colleagues. ${ }^{12}$ This observation is probably due to the fact that in the latter study results were based exclusively on DXAscan data. Indeed, the increase in prevalence of osteoporosis in our study could mostly be contributed to an increase in vertebral fractures over time. This observation is in concordance with the study of Heijckman and colleagues who also encountered an increased prevalence of vertebral deformities (from $20 \%$ to $32 \%$ ) despite an unchanged BMD after 4 years in patients with sarcoidosis. ${ }^{13}$ Therefore, in patients with chronic inflammatory disease like sarcoidosis and COPD the increase in prevalence of osteoporosis is most likely due to deterioration of the microarchitecture, without a significant impact on bone mineral density. 
Indeed, chronic inflammation leads to the production of cytokines ${ }^{20 ; 21}$, stimulating bone turnover, which is associated with an increased fracture risk due to increased bone fragility. ${ }^{22}$ Indeed, in COPD patients evidence of low-grade systemic inflammation had been found. ${ }^{23}$ However, this systemic inflammation is very heterogeneous with different levels of increased cytokines, acute phase proteins and other circulating cells identified in various studies. ${ }^{23-25}$ Microarchitectural changes can be noninvasively assessed by microcomputed tomography which seems to correlate well with histology of bone biopsies, which is the gold standard. ${ }^{26}$ Indeed, in osteoporosis research altered microarchitecture is now considered an important component of osteoporosis. ${ }^{27}$ Studies investigating this deteriorated microarchitecture and inflammation markers in COPD patients are warranted to further clarify the influence of inflammation on bone status.

Table 3a: Multivariate analysis.

\begin{tabular}{llll}
\hline & OR & $95 \% \mathrm{Cl}$ & $\mathrm{p}$-value \\
\hline Pack years & 1.032 & $0.994-1.072$ & 0.099 \\
T-score trochanter & $\mathbf{0 . 0 3 4 3}$ & $0.129-0.911$ & $\mathbf{0 . 0 3 2}$ \\
Vitamin D deficiency $^{*}$ & $\mathbf{7 . 4 8 7}$ & $1.175-47.705$ & $\mathbf{0 . 0 3 3}$ \\
\hline
\end{tabular}

Only patients without osteoporosis at baseline were included $(n=48)$. Osteoporosis at 3 years was used as dependent variable. Only variables significant at $p<0.05$ in univariate regression analysis were included. Included variables are therefore corrected for packyears, vitamin $\mathrm{D}$ deficiency and $\mathrm{T}$-score at the trochanter (all at baseline).

*as compared to normal vitamin D (25 OH D3 levels $\geq 50 \mathrm{ng} / \mathrm{L})$

Table 3b: Multivariate analysis.

\begin{tabular}{llll}
\hline & OR & $95 \% \mathrm{Cl}$ & $\mathrm{p}$-value \\
\hline Pack years & 1.038 & $0.998-1.080$ & 0.061 \\
Osteopenia trochanter $^{*}$ & $\mathbf{9 . 9 1 6}$ & $1.511-65.050$ & $\mathbf{0 . 0 1 7}$ \\
Vitamin D deficiency $^{\dagger}$ & $\mathbf{7 . 9 3 1}$ & $1.269-49.551$ & $\mathbf{0 . 0 2 7}$ \\
\hline
\end{tabular}

Only patients without osteoporosis at baseline were included $(n=48)$. Osteoporosis at 3 years was used as dependent variable. Only variables significant at $p<0.05$ in univariate regression analysis were included. Included variables are therefore corrected for packyears, vitamin $\mathrm{D}$ deficiency and osteopenia at the trochanter .

*as compared to a normal BMD at the trochanter (T-score $\geq-1$ )

${ }^{\dagger}$ as compared to normal vitamin D ( $25 \mathrm{OH}$ D3 levels $\left.\geq 50 \mathrm{ng} / \mathrm{L}\right)$

Especially in COPD patients it is important to diagnose and to prevent vertebral fractures since they are known to deteriorate pulmonary function. ${ }^{28}$ Indeed, kyphoplasty has been shown to partially improve pulmonary function in patients with a vertebral fracture. ${ }^{29}$ Currently, no other longitudinal studies in COPD patients exist investigating the 
prevalence of osteoporosis based on DXA-scan and X-spine. However, the awareness that vertebral fractures are common in COPD patients and that these fractures should be assessed in diagnosing osteoporosis is rising. ${ }^{5 ; 30-32}$

Because only a small group of patients used bone medication during the 3 years, no conclusions about the effect of this medication in COPD patient can be drawn. More (randomized) follow up studies including more COPD patients are warranted.

\section{Risk factors for osteoporosis in COPD}

In the current sample of patients with COPD, vitamin D deficiency and lower T-score at the trochanter were independent risk factors for the development of osteoporosis during 3-year follow up.

Vitamin D deficiency induces osteoporosis. ${ }^{33}$ Indeed, prevalence of low vitamin $\mathrm{D}$ levels in postmenopausal women with osteoporosis was found to be high. ${ }^{34}$ Vitamin D intake in COPD patients was shown to be below the recommended intake. ${ }^{35 ; 36}$ Vitamin $D$ deficiency was found to correlate with $\mathrm{FEV}_{1}{ }^{37}$ Moreover, Førli and colleagues found an association between vitamin $\mathrm{D}$ deficiency and low $\mathrm{T}$-scores at the femoral neck in underweight candidates for lung transplantation. ${ }^{38}$ However, they did not assess vertebral fractures. Although we only investigated a moderatesize group of patients with COPD, the high prevalence of vitamin D deficiency $(32 \%)$ and the fact that decreased vitamin $D$ levels independently increases the risk of osteoporosis 7.5 fold seems clinically relevant. However as the precise interrelationships between vitamin $D$ deficiency, osteoporosis and COPD is still not clarified, this should be investigated further. The awareness of (chest) physicians regarding the importance of vitamin $D$ deficiency should be raised, not only because of the important effect of vitamin $D$ on bone status, but also because of its possible non-calcemic effects (e.g. inflammation, muscular dysfunction and co-morbidities) in COPD patients. ${ }^{39}$ Moreover, Kuchuk and colleagues found in postmenopausal women with osteoporosis a positive relationship between vitamin $D$ levels with a threshold at $50 \mathrm{nmol} / \mathrm{L}$ and BMD at the trochanter. ${ }^{34}$ Combined with the fact that we found both lower $\mathrm{T}$-scores at the trochanter and vitamin $\mathrm{D}$ deficiency to be independent predictors of osteoporosis, theoretically both risk factors could be 
reduced by vitamin $D$ supplementation. In the current study we could not evaluate the effect of vitamin $D$ supplementation, because only 3 patients used the prescribed vitamin $D$ during the 3 years of follow up. Randomized, placebo controlled, clinical trials are needed to investigate the influence of vitamin $D$ supplementation on bone status and on non calcemic effects in COPD patients.

A lower baseline T-score at the level of the trochanter was also independently increasing the risk of osteoporosis. In a 4-year follow up study in patients with sarcoidosis, the T-score at the level of the femoral neck was an independent risk factor for new and/or progressive vertebral fractures. ${ }^{13}$ This difference in T-scores at the trochanter and femoral neck area respectively, as significant risk factor, could be due to the fact that patients with COPD and sarcoidosis were investigated resulting in different patient characteristics. However, in both studies T-score at the hip proofed to be a significant risk factor as opposed to T-score at the lumbar spine. A lower T-score at the lumbar spine did not increase the risk of osteoporosis in the current study, although a trend was found. Indeed, BMD at the lumbar spine could theoretically be erroneously elevated due to vertebral deformity ( $<20 \%$ reduction in height), thereby condensing the bone structure and elevating bone density.

Interestingly, patients who developed osteoporosis over a 3-year period of time in the present study had a higher proportion of vitamin $D$ deficient patients at baseline and showed a greater deterioration in their $\mathrm{FEV}_{1}$ as compared to those who did not develop osteoporosis (Table 2). Moreover, osteoporosis is highly prevalent in patients with COPD, ${ }^{4}$ raising the question whether this is the result of co-morbidity, some metabolic syndrome or the result of common genetic susceptibility. Indeed, the ADAM19 gene may play a role in the development of COPD ${ }^{40}$ as well as osteoporosis. ${ }^{41}$ Moreover, a common genetic susceptibility for vitamin $\mathrm{D}$ deficiency and COPD was found by Janssens and colleagues. ${ }^{42}$ In their study they found that vitamin $\mathrm{D}$ levels were reduced by $25 \%$ in homozygous carriers of the rs $7041 \mathrm{~T}$ allele and that these carriers exhibited an increased risk for COPD. Moreover, since there is an established link between vitamin $D$ levels and $F E V_{1},{ }^{37}$ there could be an interrelationship between vitamin $\mathrm{D}$ levels, more rapid decline of $F E V_{1}$ and osteoporosis in COPD. One might speculate that patients who had a rapid decline in their FEV1 might were less active because of this deteriorating lungfunction. Because of this inactivity they might also be 
more prone to developing osteoporosis. However, to date, no data exist in the English-language literature on the interaction between the change in FEV1 and change in physical activity levels in patients with COPD. Nevertheless, physical inactivity also occurs in about $75 \%$ of the patients with GOLD stage II, ${ }^{43 ; 44}$ or following lung transplantation. ${ }^{45}$ These data suggest that the cross-sectional relationship between the degree of airflow limitation and the degree of daily physical activity is limited and most probably worse when this relationship is studied using the changes over time. Finally, the increase in osteoporosis the current study was mostly due to an increase in vertebral fractures, and not a decline in BMD. Whether inactivity also cause an increase in vertebral fractures remains to be determined.

In the general population smoking is one of the risk factors for osteoporosis. ${ }^{6}$ Indeed, we found that more pack years of smoking was a significant risk factor for osteoporosis in the current study. However, significance disappeared in multivariate analysis.

\section{Methodological limitations}

Some methodological limitations should be mentioned. Primarily, the group of patients used to determine risk factors for osteoporosis had a moderate size $(n=48)$. Consequently, results from regression analysis should be interpreted with caution. However, the current results imply an important role of baseline vitamin $\mathrm{D}$ and low $\mathrm{T}$-score at the hip, which seems very reasonable. Therefore, the need to focus on vitamin D deficiency in COPD patients should once more be stressed. ${ }^{39}$ Secondly, more follow up studies in COPD patients with osteoporosis based on the combination of DXA-scan and vertebral fractures are needed to confirm our preliminary results. Thirdly, vitamin $D$ values were obtained from May until December. Therefore, the seasons could have influenced the levels of vitamin $D$ and consequently, the prevalence of vitamin $D$ deficiency. However, no significant difference of vitamin $D$ levels or vitamin $D$ deficiency between months were encountered (see online data supplement). Fourthly, different DXA-scans were used at baseline and follow up. However, the same standard operation procedures were used and both scans were calibrated using a phantom at a daily base. In addition, both DXA-scans were compared with the same phantom on the same day and the difference in mean BMD was less than $1 \%$ (see online 
data supplement). Therefore, measurements performed on both DXAscans are comparable and differences are due to changing BMD. Fifthly, morphometry using spine radiographs and DXA were performed at baseline and at follow up. A limitation of morphometry by DXA is that there is a lower sensitivity for milder fractures. ${ }^{46}$ Therefore, the vertebral fractures at follow up could be an underestimation. Sixthly, no physical activity assessment was done. However, we did include the six minutes walking distance which might be used as a surrogate marker for physical activity, especially in COPD patients with a walking distance of about 400 meters. ${ }^{47}$ Furthermore MRC dyspnoea score did not change significantly during the course of this study. In case patients might become less active because of a worsening lung function, one might expect that the MRC score would also have increased. Finally, a healthy age-matched control group was lacking. Therefore, it remains currently unknown whether and to what extent the progression of osteoporosis is COPD specific. However, in postmenopausal women with osteoporosis $7.1 \%$ had a new vertebral fracture after 3 years of treatment with placebo. ${ }^{48}$ Compared to the $20 \%$ of patients with new vertebral fractures in the current study progression of osteoporosis could be COPD specific. Then again, progression of osteoporosis has also been found in HIV-infected patients, patients with rheumatic diseases and patients with sarcoidosis. ${ }^{13 ; 49 ; 50}$

\section{Clinical relevance}

One of the strengths of our study is the collection of follow up data after a period of 3 years. Moreover, we diagnosed osteoporosis with DXA-scan and X-spine combined. Finally, we included patients in all GOLD stages, whereas most other studies did not include patients with GOLD I COPD. ${ }^{5 ; 9 ; 12 ; 38}$

Because of the high prevalence of osteoporosis in COPD patients we advise physicians to evaluate all COPD patients for osteoporosis. This evaluation should be performed by DXA-scan and X-spine, because osteoporosis will be missed in a significant proportion of patients when assessing BMD exclusively without including the presence of vertebral fractures. In addition, we advise physicians to determine vitamin $D$ levels in all COPD patients and to start supplementation in case of deficiency. This approach has also been suggested by others. ${ }^{51}$ Whether this prevents patients to develop osteoporosis warrants further research. 
Finally, follow up can best be performed by assessing vertebral fractures once a year. In patients with vitamin D deficiency and/or osteopenia at the level of the hip BMD should be assessed every 3 years. 


\section{Reference List}

(1) Rabe KF, Hurd S, Anzueto A, Barnes PJ, Buist SA, Calverley P et al. Global strategy for the diagnosis, management, and prevention of chronic obstructive pulmonary disease: GOLD executive summary. Am J Respir Crit Care Med 2007; 176(6):532-555.

(2) Spruit MA, Pennings HJ, Janssen PP, Does JD, Scroyen S, Akkermans MA et al. Extra-pulmonary features in COPD patients entering rehabilitation after stratification for MRC dyspnea grade. Respir Med 2007; 101(12):2454-2463.

(3) Spruit MA, Watkins ML, Edwards LD, Vestbo J, Calverley PM, Pinto-Plata V et al. Determinants of poor 6-min walking distance in patients with COPD: the ECLIPSE cohort. Respir Med 2010; 104(6):849-857.

(4) Graat-Verboom L, Wouters EF, Smeenk FW, van den Borne BE, Lunde R, Spruit MA. Current status of research on osteoporosis in COPD: a systematic review. Eur Respir J 2009; 34(1):209-218.

(5) Kjensli A, Falch JA, Ryg M, Blenk T, Armbrecht G, Diep LM et al. High prevalence of vertebral deformities in COPD patients: relation to disease severity. Eur Respir J 2009; 33(5):1018-1024.

(6) WHO Scientific Group on the Prevention and Management of Osteoporosis. Prevention and Management of Osteoporosis: report of a WHO scientific group. http;//whqlibdoc who int/trs/WHO_TRS_921 pdf [ 2007

(7) Graat-Verboom L, Spruit MA, van den Borne BE, Smeenk FW, Wouters EF. Whole-Body versus Local DXA-Scan for the Diagnosis of Osteoporosis in COPD Patients. J Osteoporos 2010; 2010:640878.

(8) Graat-Verboom L, van den Borne BE, Smeenk FW, Spruit MA, Wouters EF. Osteoporosis in COPD outpatients based on bone mineral density and vertebral fractures. J Bone Miner Res 2011; 26(3):561-568.

(9) Jorgensen NR, Schwarz P, Holme I, Henriksen BM, Petersen LJ, Backer V. The prevalence of osteoporosis in patients with chronic obstructive pulmonary disease: a cross sectional study. Respir Med 2007; 101(1):177-185.

(10) Scanlon PD, Connett JE, Wise RA, Tashkin DP, Madhok T, Skeans M et al. Loss of bone density with inhaled triamcinolone in Lung Health Study II. Am J Respir Crit Care Med 2004; 170(12):1302-1309.

(11) Mineo TC, Ambrogi V, Mineo D, Fabbri A, Fabbrini E, Massoud R. Bone mineral density improvement after lung volume reduction surgery for severe emphysema. Chest 2005; 127(6):1960-1966.

(12) Ferguson GT, Calverley PM, Anderson JA, Jenkins CR, Jones PW, Willits LR et al. Prevalence and progression of osteoporosis in patients with COPD: results from the TOwards a Revolution in COPD Health study. Chest 2009; 136(6):14561465. 
(13) Heijckmann AC, Drent M, Dumitrescu B, de VJ, Nieuwenhuijzen Kruseman AC, Wolffenbuttel $\mathrm{BH}$ et al. Progressive vertebral deformities despite unchanged bone mineral density in patients with sarcoidosis: a 4-year follow-up study. Osteoporos Int 2008; 19(6):839-847.

(14) American Thoracic Society and European Respiratory Society. COPD Guidelines. Standards for the diagnosis and treatment. http://www ersnet org/lrPresentations/copd/files/main/index html [ 2004 [cited 2007 Aug. 23]; Available from: URL:http://www.ersnet.org//rPresentations/copd/files/main/index.html

(15) Charlson M, Szatrowski TP, Peterson J, Gold J. Validation of a combined comorbidity index. J Clin Epidemiol 1994; 47(11):1245-1251.

(16) ATS statement: guidelines for the six-minute walk test. Am J Respir Crit Care Med 2002; 166(1):111-117.

(17) Genant HK, Wu CY, van KC, Nevitt MC. Vertebral fracture assessment using a semiquantitative technique. J Bone Miner Res 1993; 8(9):1137-1148.

(18) Holick MF. Vitamin D deficiency. N Engl J Med 2007; 357(3):266-281.

(19) Norman AW, Bouillon R, Whiting SJ, Vieth R, Lips P. 13th Workshop consensus for vitamin D nutritional guidelines. J Steroid Biochem Mol Biol 2007; 103(35):204-205.

(20) Hofbauer LC, Schoppet M. Clinical implications of the osteoprotegerin/RANKL/RANK system for bone and vascular diseases. JAMA 2004; 292(4):490-495.

(21) Walsh NC, Gravallese EM. Bone remodeling in rheumatic disease: a question of balance. Immunol Rev 2010; 233(1):301-312.

(22) Viguet-Carrin S, Garnero P, Delmas PD. The role of collagen in bone strength. Osteoporos Int 2006; 17(3):319-336.

(23) Barnes PJ, Celli BR. Systemic manifestations and comorbidities of COPD. Eur Respir J 2009; 33(5):1165-1185.

(24) Agusti AG. COPD, a multicomponent disease: implications for management. Respir Med 2005; 99(6):670-682.

(25) Franciosi LG, Page CP, Celli BR, Cazzola M, Walker MJ, Danhof M et al. Markers of disease severity in chronic obstructive pulmonary disease. Pulm Pharmacol Ther 2006; 19(3):189-199.

(26) Particelli F, Mecozzi L, Beraudi A, Montesi M, Baruffaldi F, Viceconti M. A comparison between micro-CT and histology for the evaluation of cortical bone: effect of polymethylmethacrylate embedding on structural parameters. J Microsc 2011. 
(27) Szulc P, Debiesse E, Boutroy S, Vilauphiou N, Chapurlat R. Poor trabecular microarchitecture in male current smokers: the cross-sectional STRAMBO study. Calcif Tissue Int 2011; 89(4):303-311.

(28) Leech JA, Dulberg C, Kellie S, Pattee L, Gay J. Relationship of lung function to severity of osteoporosis in women. Am Rev Respir Dis 1990; 141(1):68-71.

(29) Yang HL, Zhao L, Liu J, Sanford CG, Jr., Chen L, Tang T et al. Changes of pulmonary function for patients with osteoporotic vertebral compression fractures after kyphoplasty. J Spinal Disord Tech 2007; 20(3):221-225.

(30) Jorgensen NR, Schwarz P, Holme I, Henriksen BM, Petersen LJ, Backer V. The prevalence of osteoporosis in patients with chronic obstructive pulmonary disease: a cross sectional study. Respir Med 2007; 101(1):177-185.

(31) Nuti R, Siviero P, Maggi S, Guglielmi G, Caffarelli C, Crepaldi G et al. Vertebral fractures in patients with chronic obstructive pulmonary disease: the EOLO Study. Osteoporos Int 2008; 20(6):989-998.

(32) Papaioannou A, Parkinson W, Ferko N, Probyn L, loannidis G, Jurriaans E et al. Prevalence of vertebral fractures among patients with chronic obstructive pulmonary disease in Canada. Osteoporos Int 2003; 14(11):913-917.

(33) Holick MF. Vitamin D deficiency. N Engl J Med 2007; 357(3):266-281.

(34) Kuchuk NO, van Schoor NM, Pluijm SM, Chines A, Lips P. Vitamin D Status, Parathyroid Function, Bone Turnover and Bone Mineral Density in Postmenopausal Women with Osteoporosis in Global Perspective. J Bone Miner Res 2008.

(35) Andersson I, Gronberg A, Slinde F, Bosaeus I, Larsson S. Vitamin and mineral status in elderly patients with chronic obstructive pulmonary disease. Clin Respir J 2007; 1(1):23-29.

(36) de BJ, Romieu I, Anto JM, Mendez M, Rodriguez E, Balcells E et al. Dietary habits of firstly admitted Spanish COPD patients. Respir Med 2009; 103(12):1904-1910.

(37) Black PN, Scragg R. Relationship between serum 25-hydroxyvitamin d and pulmonary function in the third national health and nutrition examination survey. Chest 2005; 128(6):3792-3798.

(38) Forli L, Halse J, Haug E, Bjortuft O, Vatn M, Kofstad J et al. Vitamin D deficiency, bone mineral density and weight in patients with advanced pulmonary disease. $\mathrm{J}$ Intern Med 2004; 256(1):56-62.

(39) Janssens W, Lehouck A, Carremans C, Bouillon R, Mathieu C, Decramer M. Vitamin D Beyond Bones in COPD: Time to Act. Am J Respir Crit Care Med 2009; 179(8):630-636.

(40) Hancock DB, Eijgelsheim M, Wilk JB, Gharib SA, Loehr LR, Marciante KD et al. Meta-analyses of genome-wide association studies identify multiple loci associated with pulmonary function. Nat Genet 2010; 42(1):45-52. 
(41) Styrkarsdottir U, Halldorsson BV, Gretarsdottir S, Gudbjartsson DF, Walters GB, Ingvarsson $T$ et al. New sequence variants associated with bone mineral density. Nat Genet 2009; 41(1):15-17.

(42) Janssens W, Bouillon R, Claes B, Carremans C, Lehouck A, Buysschaert I et al. Vitamin $D$ deficiency is highly prevalent in COPD and correlates with variants in the vitamin D-binding gene. Thorax 2010; 65(3):215-220.

(43) Watz H, Waschki B, Boehme C, Claussen M, Meyer T, Magnussen H. Extrapulmonary effects of chronic obstructive pulmonary disease on physical activity: a cross-sectional study. Am J Respir Crit Care Med 2008; 177(7):743751.

(44) Watz $\mathrm{H}$, Waschki B, Meyer T, Magnussen $\mathrm{H}$. Physical activity in patients with COPD. Eur Respir J 2009; 33(2):262-272.

(45) Langer D, Gosselink R, Pitta F, Burtin C, Verleden G, Dupont L et al. Physical activity in daily life 1 year after lung transplantation. J Heart Lung Transplant 2009; 28(6):572-578.

(46) Chapurlat RD, Duboeuf F, Marion-Audibert HO, Kalpakcioglu B, Mitlak BH, Delmas PD. Effectiveness of instant vertebral assessment to detect prevalent vertebral fracture. Osteoporos Int 2006; 17(8):1189-1195.

(47) Pitta F, Troosters T, Spruit MA, Probst VS, Decramer M, Gosselink R. Characteristics of physical activities in daily life in chronic obstructive pulmonary disease. Am J Respir Crit Care Med 2005; 171(9):972-977.

(48) Boonen S, Adachi JD, Man Z, Cummings SR, Lippuner K, Torring O et al. Treatment with Denosumab Reduces the Incidence of New Vertebral and Hip Fractures in Postmenopausal Women at High Risk. J Clin Endocrinol Metab 2011.

(49) Bonjoch A, Figueras M, Estany C, Perez-Alvarez N, Rosales J, del RL et al. High prevalence of and progression to low bone mineral density in HIV-infected patients: a longitudinal cohort study. AIDS 2010; 24(18):2827-2833.

(50) Hoes JN, Jacobs JW, Hulsmans HM, De Nijs RN, Lems WF, Bruyn GA et al. High incidence rate of vertebral fractures during chronic prednisone treatment, in spite of bisphosphonate or alfacalcidol use. Extension of the alendronate or alfacalcidol in glucocorticoid-induced osteoporosis-trial. Clin Exp Rheumatol 2010; 28(3):354359.

(51) Lehouck A, Boonen S, Decramer M, Janssens W. COPD, bone metabolism, and osteoporosis. Chest 2011; 139(3):648-657. 


\section{Chapter VIII}

\section{General discussion and conclusions}




\section{Introduction}

Chronic obstructive pulmonary disease (COPD) is characterized not only by a progressive, partially reversible airflow limitation, but also by significant extrapulmonary effects ${ }^{1}$. These extrapulmonary effects may contribute to the morbidity and mortality in COPD patients. Like loss of muscle mass ${ }^{2}$ and increased arterial stiffness ${ }^{3}$, osteoporosis is one of these extrapulmonary effects. This $\mathrm{PhD}$ thesis focused on the prevalence, methods of diagnosis and the correlating factors of osteoporosis in COPD patients.

\section{Prevalence of osteopenia and osteoporosis in COPD}

To get a better insight into the current knowledge of osteoporosis in COPD a systematic review of the literature was performed using MEDLINE/Pubmed and the Cochrane database (chapter II). In the identified studies, osteoporosis was diagnosed based only on bone mineral density (BMD). Some investigators assessed the prevalence of osteopenia which varied from $27-67 \%$ resulting in an overall prevalence of $38 \%{ }^{4-11}$. The overall prevalence of osteoporosis was $35 \%$ (varying from $9-69 \%)^{3-15}$. The prevalence of osteoporosis in COPD patients was higher as compared to healthy subjects ${ }^{3-5 ; 9}$ and as compared to other pulmonary diseases $^{7 ; 12 ; 14 ; 15}$.

In chapter III, we used whole-body DXA-scans in patients with COPD entering pulmonary rehabilitation to assess the prevalence of osteopenia and osteoporosis defined according to Boyanov ${ }^{16}$. The prevalence's of osteopenia and osteoporosis were $41 \%$ and $21 \%$, respectively. In chapter IV, whole-body DXA-scans (osteoporosis according to Boyanov ${ }^{16}$ ) were compared to local DXA-scans of the lumbar spine and the hip (osteoporosis according to the World Health Organization, $\mathrm{WHO}^{17}$ ). Prevalence of osteopenia using whole-body and local DXA scan was $37 \%$ and $46 \%$, respectively. Moreover, prevalence of osteoporosis increased from $23 \%$ to $39 \%$ when local DXA-scan was used instead of whole body DXA-scan.

Besides a low BMD osteoporosis is also characterized by microarchitectural deterioration which cannot be assessed by DXA-scan. A strong relationship between microarchitectural deterioration and 
severity of vertebral fractures has been found ${ }^{18}$. Therefore, in chapter $\mathrm{V}$ prevalence of osteopenia and osteoporosis were assessed by local DXAscan and vertebral fractures. This resulted in a prevalence of osteopenia of $46 \%$ including patients with vertebral fractures and of $29 \%$ excluding vertebral fractures.

Prevalence of osteoporosis increased after 3 years follow up from $47 \%$ to $61 \%$ mostly due to an increase in vertebral fractures (chapter VII).

In the studies for this thesis assessing the prevalence of osteoporosis a control group of subjects without COPD was lacking (chapters III, IV, V and VII) In a prospective population based cohort study (the Rotterdam study), inhabitants of a district of Rotterdam (Ommoord) of 55 years or older were included ${ }^{19}$. Prevalence of osteoporosis based on BMD of the femoral neck was $12 \%$ for men and $29 \%$ for women ${ }^{19}$. Moreover, prevalence of vertebral fractures was $7 \%$ at baseline and $11 \%$ at follow $\mathrm{up}^{20}$. Therefore, prevalence of osteoporosis based on both DXA-scan and vertebral fractures is higher in COPD patients as compared to a Dutch population. Another important clinical problem in COPD patients are nonvertebral fractures. Although the studies for this thesis were not designed to address this problem, Bours and colleagues found that $10 \%$ of the patients aged 50 years or elder visiting the emergency room of a hospital in the Netherlands with a recent fracture, had COPD ${ }^{21}$.

The relatively high prevalence of osteoporosis in COPD patients could be due to a shared underlying pathophysiological mechanism and/or to shared risk factors for both diseases. However, given the high prevalence of osteoporosis in COPD patients an intrinsic mechanism is suspected.

\section{Diagnosis of osteoporosis}

There are several methods to diagnose osteoporosis. The preferred method to diagnose osteoporosis in COPD patients had not been assessed before.

Because the DXA-scan is technically highly developed and most thoroughly validated biologically BMD by DXA-scan is most often used to diagnose osteoporosis ${ }^{17}$. BMD by DXA-scan can be measured at multiple sites. In pre- and post menopausal women without COPD DXA-scan of the hip and lumbar spine resulted in a higher proportion of osteoporosis 
than a whole body DXA-scan ${ }^{21}$. In chapter IV we compared whole body DXA-scan to local DXA-scan in COPD patients. In order to correct for the different methodology osteoporosis was defined according to Boyanov ${ }^{16}$ for the whole body DXA and according to the WHO for the local DXA$\operatorname{scan}^{17}$. Whole body DXA-scan was found to underestimate the prevalence of osteoporosis. Therefore osteoporosis in COPD patients should be based on local DXA-scan. A major limitation of the DXA-scan is that microarchitectural deterioration cannot be assessed.

BMD can also be assessed by ultrasound. However, by ultrasound an estimation of BMD is made; it is not a true measurement ${ }^{17}$. Finally, BMD can be assessed by computer tomography (CT) scan. An advantage of BMD by CT-scan is that true volumetric density is measured. However, major disadvantages of CT as compared to DXA-scan are a high radiation exposure, high costs and difficulties with quality control ${ }^{17}$.

In chapter $\mathrm{V}$ vertebral fractures were assessed as a surrogate for microarchitectural deterioration ${ }^{18}$. Indeed, by diagnosing osteoporosis on BMD by local DXA scan only, $36 \%$ of the osteoporotic patients based on vertebral fractures were missed. This is in line with studies in patients with sarcoidosis ${ }^{22}$, inflammatory bowel disease ${ }^{23}$ and COPD $^{8}$. Most vertebral fractures are located at thoracic vertebrae 8 and 12 and can therefore be identified on a lateral X-ray of the thorax. Unfortunately, only $34 \%$ of the patients with a thoracic vertebral fracture were identified in a routine clinical setting (chapter $\mathrm{V}$ ). Once more an indication that the awareness of (chest) physicians of the high prevalence of osteoporosis in COPD patients should be raised.

Therefore, our data are in accordance with the advise of the international society for clinical densitometry to diagnose osteoporosis based on local DXA-scan combined with vertebral fractures ${ }^{24}$.

\section{Correlating factors of osteoporosis in COPD}

COPD and osteoporosis are both chronic conditions. As we explained in chapter $I$ it is not clear whether the increases in prevalence of osteoporosis in COPD as compared to healthy subjects is the consequence of a shared underlying pathophysiological mechanism or the result of shared risk factors. The end organ damage in chronic 
diseases can be considered as the result of continuous interaction by common (modifiable and non-modifiable) and intermediate risk factors ${ }^{25}$. For COPD and osteoporosis there are risk factors that both diseases have in common (table 1). These factors will be discussed in the next section.

Table 1: Risk factors for end organ failure in osteoporosis and COPD

Common risk factors

Intermediate risk factors

Modifiable Non-modifiable

\begin{tabular}{ccc}
\hline Nutrition & Genetic & Systemic inflammation \\
Physical inactivity & Aging & Vitamin D deficiency \\
Smoking & Gender & Repair \\
& & Visceral fat \\
\hline
\end{tabular}

\section{Nutrition and body composition}

A low body weight and hence low BMl is a well known risk factor for osteoporosis in the general population ${ }^{17 ; 26}$. As a consequence there is decreased mechanical loading on the bones which can induce loss of bone mass as was seen in astronauts ${ }^{27}$. Indeed, low BMI was found to be a risk factor of osteoporosis in COPD in a systematic review of the literature (chapter II). Moreover, in chapters V and VI lower BMI was also found to increase the odds ratio for osteoporosis.

Earlier and recent research strengthened the role of body composition in the disease manifestation and prognosis of $\mathrm{COPD}^{2 ; 28-31}$. Low body weight has been defined as an independent risk predictor of mortality in COPD patients ${ }^{28 ; 29}$ and low muscle mass, assessed by measurement of fat free mass, is positioned as an even better predictor for mortality than BMI in these patients ${ }^{31 ; 32}$. Moreover, low muscle mass is associated with decreased health status in COPD patients ${ }^{33 ; 34}$. Previous studies reported a high prevalence of low body weight and fat free mass in COPD patients, ranging from $20 \%$ in clinical stable outpatients to $41 \%$ in 
patients eligible for pulmonary rehabilitation ${ }^{4 ; 35}$. Low fat free mass is considered as one of the characteristic findings of cachexia ${ }^{2 ; 36}$.

Besides malnutrition, cachexia can be the result of a protein imbalance resulting in predomination of breakdown over sythesis ${ }^{37}$. Pseudouridine (PSU) is widely used as a marker of protein breakdown. The advantage of using PSU to assess protein breakdown is that it is neither metabolized further nor reused by the body and does not require dietary limitations ${ }^{38}$. Indeed, in children receiving growth hormone treatment a significant negative correlation was found between changes in urine PSU concentrations and in plasma ornithine concentrations (a traditional marker of tissue anabolism) ${ }^{39}$. Protein imbalance as a cause for cachexia was shown by an increased PSU in patients with a low fat free mass index (FFMI), a low fat free mass (FFM) and impaired skeletal muscle function ${ }^{4 ; 40}$. This increased protein breakdown will not only result in reduced muscle mass, but can also induce loss of bone tissue. In favor of this theory Bolton and colleagues found that patients with a low FFMI did not only have increased PSU levels, but also a lower BMD ${ }^{4}$. In this study a low FFMI was also correlated to interleukin-6 (IL-6) indicating that systemic inflammation might be a link between low body composition and osteoporosis in COPD. However, Broekhuizen and colleagues did not find a significant relation between systemic inflammation and body composition $^{41}$.

Increased mechanical loading could be the reason that an overweight and obese BMI are protective of osteoporosis in COPD (chapters III and $\mathrm{VI})$. Due to mechanical loading bone formation is stimulated probably by osteocytes acting as mechanosensors responding to motion of fluid in the lacunae and canaliculi in bone ${ }^{42}$. This leads to a positive balance in the bone remodeling cycle and hence an increased BMD.

Another factor in the process of protection from osteoporosis by being overweight or obese could be leptin. Leptin is a member of the cytokine family produced primarily in adipocytes ${ }^{43}$. It circulates in the blood and its levels are directly proportional to the amount of body fat (adipose people have increased levels of circulating leptin ${ }^{43 ; 44}$. Leptin inhibits appetite by its action on receptors in the hypothalamus. Moreover, leptin promotes bone formation by increasing proliferation and differentiation of osteoblasts $^{45}$. This effect could be enhanced in obese COPD patients since circulating levels of leptin are higher in female COPD patients as 
compared to age, gender and BMI matched healthy subjects ${ }^{46}$. On the other hand, negative effects of leptin on bone metabolism have also been found. Therefore, leptin could have a biphasic effect on bone: increasing bone formation at lower serum levels but suppressing bone formation at higher levels ${ }^{47}$. In COPD patients a significant positive correlation between BMD and serum leptin levels was found, however, this effect was not independent of body mass ${ }^{48}$. In a recent study Pobeha and colleagues found lower levels of serum and adipose tissue expression of leptin in COPD patients with osteoporosis as compared to patients without osteoporosis ${ }^{49}$. In concordance with the previous study ${ }^{48}$ significant correlations were found between serum leptin levels as well as adipose tissue leptin levels and BMD which also disappeared after inclusion of BMI or FFMI in the regression models ${ }^{49}$. Therefore, the effects of leptin on BMD in COPD patients seem to be dependent on body composition.

In the general population alcohol consumption of more than 3 units a day increases the risk of osteoporosis ${ }^{17}$. However, in the chapters V, VI and VII no significant influence of alcohol on the risk of osteoporosis in COPD patients was found. This might be due to the fact that most patients did not use more than 3 units of alcohol a day (e.g. mean units of alcohol per day were 1.08 and 1.10 in chapter $V$ and VI respectively and $92 \%$ and $90 \%$ of the patients in chapter V and VI used 3 units of alcohol a day or less, respectively). Hence, the power might be too small to elucidate the influence of alcohol.

Recently, a traditional dietary pattern (characterized by higher intakes of red meat, processed meat, boiled vegetables, added fat, coffee, beer and potato and lower intakes of soy products, low-fat dairy products, tea, breakfast cereal, brown rice, pizza, juice, and fruit) was associated with an increased prevalence of COPD and a lower $\mathrm{FEV}_{1}{ }^{50}$. The DASH (Dietary Approaches to Stop Hypertension) diet (characterized by an increased intake of fruit, vegetables, low-fat dairy foods, whole grains, poultry, fish, and nuts and a reduced intake of fats, red meat, sweets, and sugar-containing beverages) was shown to significantly reduce bone turnover which improves bone mineral status ${ }^{51}$. Therefore, unhealthy food behavior, in particular low intake of fruit and low-fat dairy foods and high intake of red meat (which the two diets of the aforementioned studies have in common), could induce or worsen COPD as well as osteoporosis. 
In summary, further studies are needed to explore the role of nutrition, body composition and intermediary factors as the role of the adipokines in the pathogenesis of osteoporosis in COPD.

\section{Physical inactivity}

Physical inactivity is another risk factor for osteoporosis ${ }^{17}$. The precise mechanism of osteoporosis due to inactivity is not clear yet. Nevertheless, human and animal studies have shown that (long-term) disuse leads to loss of $\mathrm{BMD}^{52}$, compromised bone architecture ${ }^{53}$, reduced bone mechanical properties ${ }^{54}$, and consequently, increased risk of bone fracture $^{55}$. Moreover, physical inactivity causes sarcopenia ${ }^{56}$. In addition to the role that sarcopenia may play in bone loss, lower-limb muscle weakness exerts a powerful influence on hip fracture incidence because of its effect on the risk of falls ${ }^{57}$. Physical activity, and especially weight bearing activity has been shown to have a positive effect on $\mathrm{BMD}^{58 ; 59}$. Indeed, astronauts experience a decreased BMD in weight-bearing bones $^{27}$. The dose-response relationships between exercise and bone strength and the form and duration of exercise warrant further research ${ }^{58}$.

Patients with COPD have been shown to be physically less active as compared to healthy controls. Patients showed lower walking time, standing time, and movement intensity during walking, as well as higher sitting time and lying time ${ }^{60}$. On average, 30 to $50 \%$ of the patients with COPD walked less than 30 min per day ${ }^{60 ; 61}$, which is the recommended minimum quantity of regular physical activity to maintain or even develop physical fitness ${ }^{62}$. Physical inactivity occurs throughout all GOLD classes, with highest prevalence in GOLD stage IV patients ${ }^{63 ; 64}$.

Physical activity is an important predictor of hospitalization and mortality in COPD ${ }^{63 ; 65 ; 66}$. Moreover, physical inactivity most probably contributes to the development and maintenance of lower-limb muscle weakness, sarcopenia and exercise intolerance in patients with COPD $2 ; 60 ; 67 ; 68$. To date, impact of physical inactivity on bone health in COPD has not been established, but seems very likely. In addition, patients with COPD also have a high susceptibility to falls due to sarcopenia-induced balance disturbances ${ }^{69}$ causing an additional risk for bone fractures. 
In the studies performed for this thesis daily physical activity levels were not measured directly. Exercise capacity was tested by a 6-minute walking test (6MWT), which might be used as a surrogate marker for daily physical activity, especially in COPD patients with a 6MWT of about 400 meters $^{60}$. No significant influence of 6MWD on osteoporosis was found in our studies (Chapters III, V, VI and VII). However, static hyperinflation increased the odds ratio for osteoporosis in chapter $\mathrm{VI}$. Static and dynamic hyperinflation are important determinants of exercise related dyspnea in $\mathrm{COPD}^{70}$. Dynamic hyperinflation in COPD patients already occurs during real life activities and is independent of GOLD stage $^{70}$. This hyperinflation worsens during the performance of more intense activities ${ }^{63}$. Moreover, dynamic hyperinflation increases in COPD patients during a $6 \mathrm{MWT}^{71 ; 72}$ and hyperinflation at rest is an independent predictor for the distance walked during this $6 \mathrm{MWT}^{71}$.

The precise relationship between physical inactivity, 6MWT, static and dynamic hyperinflation and osteoporosis in COPD patients currently remains unknown. Therefore, studies with direct measurements of physical activity in COPD patients are warranted to further investigate the role of physical inactivity on the development of osteoporosis in COPD. This is in line with the shift of interest from exercise capacity testing to measuring daily physical activity levels in general COPD research ${ }^{73}$.

\section{Smoking}

In the general population smoking increases the risk of osteoporosis ${ }^{17}$. Indeed, in multiple case control studies a 2-4 fold increased odds ratio for osteoporotic fractures in smokers compared to non-smokers was found ${ }^{74}$. The underlying mechanism by which smoking induces osteoporosis is not clear yet. A lower BMI could be responsible for the increased prevalence of osteoporosis since smokers have a lower body weight as compared to non-smokers ${ }^{75}$. However, Ward and colleagues could not confirm this theory in their meta-analysis ${ }^{76 ; 76}$. Women who smoke have earlier menopause as compared to their non-smoking peers and age at menopause is a strong predictor of osteoporosis ${ }^{75 ; 76}$. Cigarette smoke has also been found to adversely affect hormones and enzymes engaged in the regulation of bone metabolism like parathormone and alkaline phosphatase ${ }^{76}$. Whatever the underlying mechanism, there seems to be a dose effect of smoking since the effect on BMD is found in men and 
women of higher age with a long term smoking history ${ }^{75 ; 76}$. In addition, in young adults, significant effects of smoking on bone mass were found when only heavy smokers were included in the analysis ${ }^{76}$. Moreover, the impact of smoking on bone status is mainly associated with the number of smoking years in elderly men ${ }^{77}$. Finally, smoking has a more deleterious effect on bone mass in men as compared to women and men have been found to have greater tobacco intake as compared to women ${ }^{76}$. On the other hand, oral contraceptives or estrogen replacement therapy may have interfered with the influence of cigarette smoke on bone in women. Only little or conflicting data is available on a possible association between smoking, dose, duration, length of time after cessation, type of tobacco and fracture risk $^{78}$.

Smoking is the most important risk factor for COPD ${ }^{1}$. Smoking induces parenchymal destruction by inflammation. This parenchymal destruction, shown by low attenuation areas on high resolution computer tomography (HRCT), occurs already in an early stage of $\operatorname{COPD}^{79 ; 80}$ and is increased in COPD patients with more packyears smoked ${ }^{80}$. FEV 1 is a poor reflection of the degree of emphysema assessed by $\mathrm{HRCT}^{79 ; 81}$. In fact, parenchymal destruction (hence gas transfer) precedes $\mathrm{FEV}_{1}$ decline by many years ${ }^{81}$. Recently Bon and colleagues found an inverse correlation between quantitative emphysema assessed by HRCT and BMD by DXAscan of the hip and lumbar spine ${ }^{82}$. In addition, they found that visual assessed emphysema was an independent predictor of osteopenia and osteoporosis. These findings are in concordance with two other studies that also found a significant inverse correlation between emphysema and $\mathrm{BMD}^{83 ; 84}$. In the studies performed for this thesis no influence of smoking status (e.g. current versus ex-smokers and pack years smoked) on the odds ratio of osteoporosis in COPD patients was found. However, when osteoporosis was based on BMD only, significantly more COPD patients with osteoporosis had emphysema as compared to COPD patients without osteoporosis (Chapter VI). In the other studies for this thesis no lung imaging (by HRCT) was done.

In conclusion, smoking is a risk factor that both COPD and osteoporosis have in common. In future research lung imaging is a necessary determinant in order to better understand osteoporosis in COPD. 


\section{Genetics}

There is a strong genetic influence on BMD, however the results of genetic influence on BMD change are conflicting ${ }^{85}$. Multiple genes with a possible influence on BMD have been identified. Most notably are genes that play a role in the RANKL/RANK/OPG pathway (e.g. TNFSF11 and TNFRSF11B).

Osteoporosis and COPD could be the result of a common genetic susceptibility. This could be a genetic susceptibility to cigarette smoke inducing both COPD and osteoporosis, but could also be a direct susceptibility to COPD as well as osteoporosis. For instance, an association between single nucleotide pairs on the ADAM 19 gene and hip BMD was found ${ }^{86}$. Furthermore, an association between single nucleotide pairs on the ADAM 19 gene and $F E V_{1} / F V C$ was found ${ }^{87}$. Recently, another important study was published showing that vitamin D levels are reduced by $25 \%$ in homozygous carriers of the rs7041 allele ${ }^{88}$. Moreover, these carriers exhibited an increased risk for COPD. Therefore, osteoporosis due to vitamin D deficiency and COPD could be related to a genetic predisposition rather than the outcome of a hypothesized cause-effect relationship between COPD and osteoporosis $^{89 ; 90}$.

Because chronic diseases are complex and intertwined interactions between gene-environment, socio-economic and co-morbidities leading to individual-specific complex phenotypes instead of considering an organic based chronic disease, chronic diseases itself should be considered $^{91}$. This all leads to a complex of networks (social network, disease network and metabolic network) intertwined in these chronic diseases $^{92}$. Bousquet and colleagues suggest new phenotypes to be based on statistical modeling of all the complex components of chronic diseases onset, persistence and prognosis(see figure 1$)^{91}$. This approach may open new avenues in our understanding of chronic diseases.

\section{Aging and accelerated aging}

In chapters III and IV increasing age was found to increase the prevalence of osteoporosis. Indeed, in the general population higher age is considered a risk factor for osteoporosis ${ }^{17}$. In healthy adults, bone 
turnover is in balance meaning that bone resorption equals bone formation ${ }^{17 ; 93}$. With increasing age bone formation is decreased and resorption is increased leading to bone loss in the elderly ${ }^{93}$. This negative balance in bone homeostasis is influenced by different intrinsic factors like peak bone mass accrual in youth, alterations in hormonal and biochemical status and genetics but also by extrinsic factors like nutrition and smoking.

Figure 1

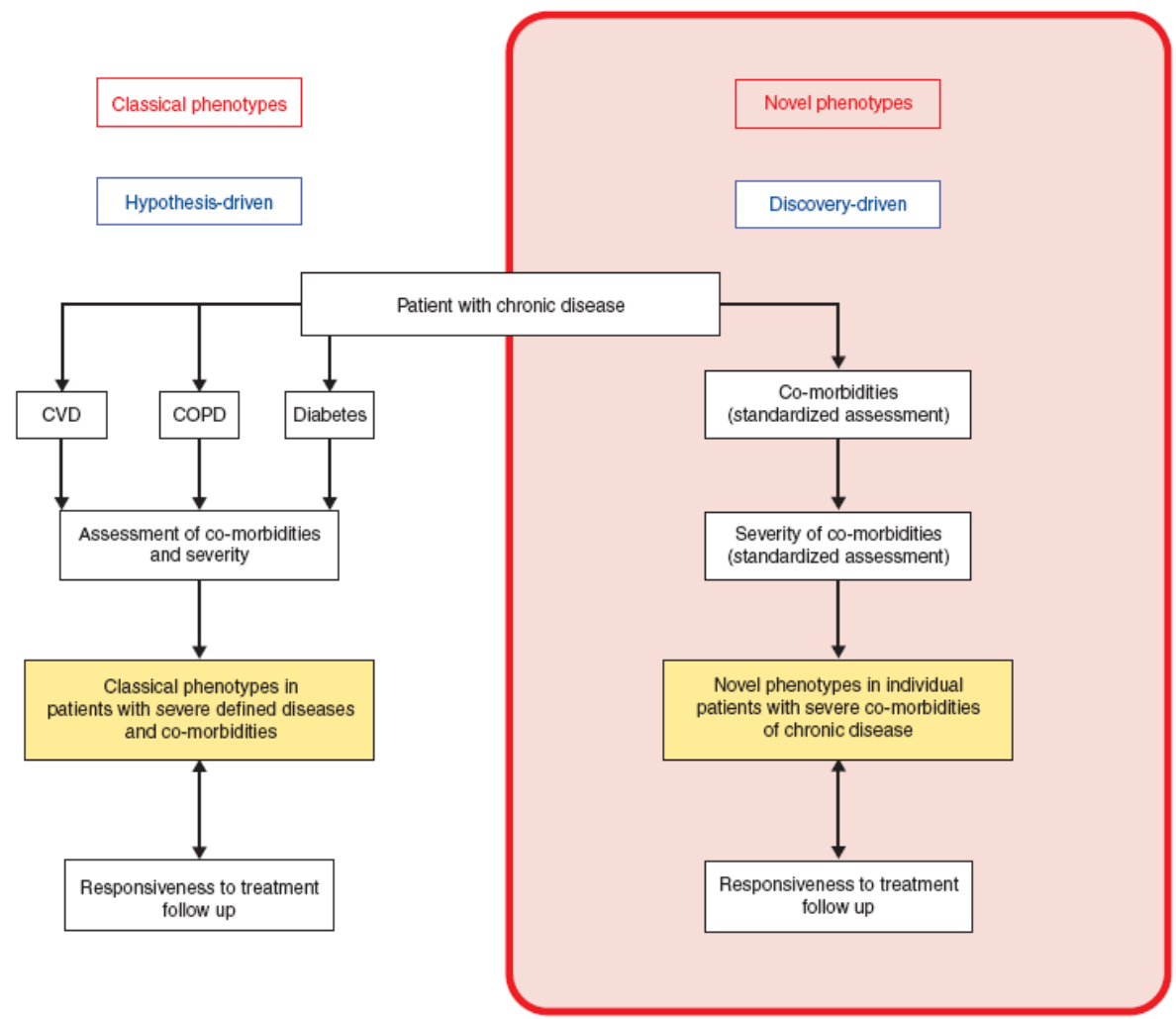

Adapted, with permission, from Bousquet and collaegues, Genome Medicine 2011;3(7):43

Aging is defined as the progressive decline of homeostasis after the reproductive phase of life is complete, leading to increasing morbidity and mortality ${ }^{94}$. Hence, aging makes people more vulnerable to many chronic diseases ${ }^{95}$. These age related diseases are often associated with low 
levels of chronic inflammation. It is not clear whether inflammation induces chronic diseases or chronic diseases cause inflammation in the aging process. This low-grade inflammation observed in aging and ageassociated diseases is called inflamm-aging. Indeed, many cytokines have been found to be increased during senescence and some of them stimulate osteoclast activity (e.g. IL-6, TNF- $\alpha$ and IL-1).

Lung aging and emphysema have shared underlying mechanisms such as inflammation, oxidative stress and cell apoptosis ${ }^{96}$. Therefore, in COPD patients there could be accelerated aging leading to loss of function and structure on a tissue level as is seen in $\operatorname{COPD}^{94 ; 96 ; 97}$. Shortening of telomere length, which is thought to be a marker of (accelerated) ageing, was found in lung tissue as well as peripheral tissue of COPD patients ${ }^{97}$. Shortening of telomere length was also found to be correlated to bone mineral density ${ }^{98 ; 99}$. Given the results of the previously discussed studies, accelerated aging might play an important role in the underlying pathophysiology of osteoporosis and COPD.

In addition to the possible effect of accelerated aging, normal aging may impair tissue repair mechanisms which will be discussed in the paragraph about repair. Whether and to which extend aging and accelerated aging with consequent inflamm-aging are a joint factor in COPD and osteoporosis warrants further research.

\section{Systemic Inflammation}

Prevalence of osteoporosis has been found to be increased in various inflammatory diseases like inflammatory bowel disease ${ }^{23}$, sarcoidosis $^{22 ; 100}$ and (rheumatic) arthritis $^{101}$, which may suggest that systemic inflammation contributes to the development of osteoporosis. Indeed, even a small rise in the level of systemic inflammation can precipitate bone loss and emerge as an independent and strong risk factor for fractures ${ }^{102}$. In chronic inflammatory conditions the immune system is activated which leads to the production of molecules with a negative effect on bone homeostasis. Enhanced osteoclastogenesis and increased bone resorption are key features of inflammatory bone loss, while bone formation is blunted rather than enhanced in inflammatory diseases ${ }^{103}$. Osteoclastogenesis is enhanced by increased recruitment of osteoclast precursors from the bone marrow and induced differentiation 
of osteoclasts from their precursor cells by cytokines and prostaglandins (e.g. receptor activator of nuclear factor $\mathrm{KB}$ ligand (RANKL) is expressed by cytokines enhancing osteoclastogenesis, see chapter I). The mechanism by which bone formation is suppressed in chronic inflammatory diseases are not clear yet. However, tumor necrosis factor $\alpha$ (TNF- $\alpha$ ) can induce the proteins Dickopf 1 and sclerosin which are potent inhibitors of the Wnt pathway thus blunting bone formation (see chapter 1).

In COPD patients evidence of low-grade chronic systemic inflammation has been found ${ }^{90}$. This systemic inflammation is very heterogeneous as indicated by different levels of increased cytokines, acute phase proteins and other circulating cells identified in various studies ${ }^{90 ; 104 ; 105}$. In a cross sectional study including 409 COPD patients and 231 subjects without COPD C-reactive protein (CRP) and monocyte chemo attractant protein (MCP)-4 were independently increased in male subjects with COPD ${ }^{106}$. In a study comparing 48 COPD patients to 48 matched controls several cytokines and chemo attractants were increased in COPD patients as compared to healthy subjects (some of these increased biomarkers are: IL-15, TNF $\alpha$, interferon gamma and IL-17) ${ }^{107}$.

As discussed before in inflammatory diseases expression of RANKL is increased by cytokines. In the Bergen cohort study, OPG was found to be dysregulated in COPD patients: OPG was significantly lower in COPD patients as compared to subjects without COPD; surprisingly higher plasma OPG levels were significantly associated with low $\mathrm{FEV}_{1}$ and COPD exacerbations in the previous year ${ }^{106}$. In 40 COPD patients awaiting lung transplantation Bon and colleagues found a direct relationship between systemic inflammatory proteins (IL-4 and TNF- $\alpha$ ) and markers of bone metabolism (C-telopeptides of type I collagen (CTX) and $\mathrm{N}$-terminal procollagen propeptide (PINP) $)^{108}$. Unfortunately, in the Bergen cohort study bone status was not assessed and in the study by Bon and colleagues OPG levels were not measured ${ }^{106 ; 108}$. Therefore, the possible link between bone status, inflammation and the OPG/RANK/RANKL system in COPD patients is not proven yet.

Inflammatory cytokines influence the Wnt-signaling pathway as has been shown in patients with artrithis ${ }^{101}$. Recently, decreased Wnt/ $\beta$-catenin signaling was found to be involved in lung parenchymal destruction and impaired repair mechanisms in emphysema ${ }^{109}$. As discussed in chapter I 
Wnt-signaling plays an important role in bone formation by activating osteoblasts ${ }^{110 ; 111}$. The involvement of the Wnt-pathway on osteoporosis in COPD warrants further investigation.

In this thesis no significant relation between markers of inflammation and osteoporosis in COPD patients was found. However, we only looked at CRP and leucocytes, not at other markers like IL-4 and TNF- $\alpha$. Moreover, we did not assess markers of bone metabolism. Finally, the OPG/RANK/RANKL system and the Wnt/B-catenin pathway were not assessed.

In conclusion, research studying the OPG/RANK/RANKL system and the $W n t / \beta$-catenin pathway in relation to inflammation and bone turnover in COPD patients is warranted.

\section{Vitamin $D$ deficiency}

By exposure to sunlight, from diet and dietary supplements humans get vitamin $\mathrm{D}^{112}$. In the liver vitamin $\mathrm{D} 3$ is metabolized to 25 -hydroxyvitamin $\mathrm{D}$ which is the major circulating metabolite of vitamin $D$ and used to determine vitamin $D$ status. In the kidneys 25-hydroxyvitamin $D$ is further metabolized to its active form 1,25-dihydroxyvitamin $D$ by the enzyme 1a-hydroxylase. Vitamin D increases the efficiency of intestinal calcium absorption through the interaction of 1,25-dihydroxyvitamin $D$ with the vitamin $\mathrm{D}$ receptor. In case of vitamin $\mathrm{D}$ deficiency decreased calcium absorption causes compensatory increase in parathyroid hormone (PTH) hence, secondary hyperparathyroidism. PTH enhances the tubular reabsorption of calcium and stimulating the kidneys to produce 1,25dihydroxyvitamin D. Receptors in osteoblasts recognize 1,25dihydroxyvitamin $D$ causing increased expression of RANKL. RANKL binds to RANK on preosteoclasts hereby transforming preosteoclasts into mature osteoclasts (chapter I). Osteoclasts cause osteopenia and osteoporosis by dissolving the mineralized collagen matrix in bone. Indeed, a high prevalence of low vitamin D levels were found in postmenopausal women with osteoporosis ${ }^{113}$. Daily intake of vitamin $D$ is 200 $\mathrm{IU}$ for adults up to 50 years of age, $400 \mathrm{IU}$ for adults $51-70$ years of age and $600 \mathrm{IU}$ for adults of 71 years or older is recommended by the Institute of Medicine ${ }^{114}$. To prevent falls and fractures supplementation with at least $700 \mathrm{IU}$ of vitamin $\mathrm{D}$ is advised ${ }^{115}$. In 16 COPD patients 
vitamin $D$ intake was found to be far below the local recommended intake $^{116}$. This was confirmed in a larger study including 275 COPD patients (recruited during their first COPD related hospital admission) ${ }^{117}$.

Prevalence of vitamin $D$ deficiency in COPD patients in the studies for this thesis varied from $32 \%$ through $51 \%$ (chapters $\mathrm{V}, \mathrm{VI}$ and $\mathrm{VII}$ ). In the follow up study vitamin $D$ was found to be an independent risk factor for osteoporosis (chapter VII). Moreover, in chapter V increased PTH levels due to secondary hyperparathyroidism increased the odds ratio for osteoporosis. In contrast, in chapter VI no significant difference in vitamin $\mathrm{D}$ levels between COPD patients with and without osteoporosis was found. This could be due to the fact that vitamin $D$ deficiency correlates with $\mathrm{FEV}_{1}{ }^{118}$, and the cases and controls included in the study all had GOLD II COPD hence, the same mean FEV ${ }_{1}$ (chapter VI).

Figure 2 Calcemic and non-calcemic effects of vitamin D

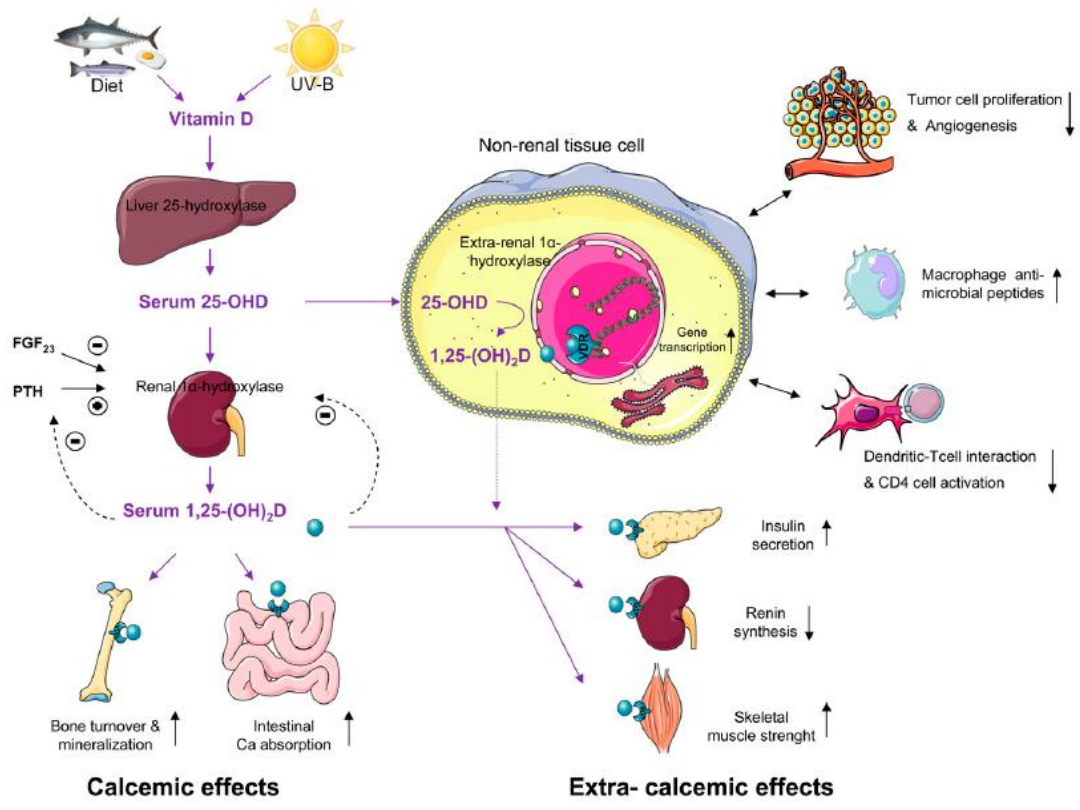

Adapted, with permission, from: Janssens and colleagues AJRCCM 2009; 179(8):630-636

In addition to the effects of vitamin $D$ on bone non-calcemic effects of vitamin $D$ are described ${ }^{119 ; 120}$. Besides in the kidneys $1-\alpha$-hydroxylase is 
found in other tissue like skin, bone and in immune cells ${ }^{120}$. Expression of 1- $\alpha$-hydroxylase in these extra renal tissues is regulated by immune signals (instead of mediators of calcium- and bone homeostasis). High local 1,25-hydroxyvitamin $D$ concentrations have autocrine and paracrine functions. Moreover, 1,25-hydroxyvitamin D controls genes involved in the regulation of cellular proliferation, differentiation and apoptosis.

Finally, 1,25-hydroxyvitamin $\mathrm{D}$ is an immune modulator and stimulates the immune response to an infection. Indeed, vitamin D deficiency has been linked to many diseases like malignancy, type I diabetes, rheumatoid arthritis, the metabolic syndrome, congestive heart failure and tuberculosis. Examples of these non-calcemic effects of vitamin $D$ deficiency in COPD patients are inflammation and muscular dysfunction ${ }^{120 ; 121}$. In summary, vitamin $D$ deficiency has both calcemic and non-calcemic effects. The interrelations between vitamin D deficiency, osteoporosis and COPD should further be investigated.

\section{Repair}

In osteoporosis, the protease-antiprotease balance plays an important role, hence the development of promising new therapies like odanacatib, a specific inhibitor of the osteoclast protease cathepsin $\mathrm{K}^{122}$. Moreover, as discussed in the previous paragraph inflamm-aging and accelerated aging, amongst others, due to oxidative stress play a role in osteoporosis.

Bone is constantly being remodeled (chapter I). In case of injury of bone tissue (e.g.) micro-fractures activation of osteocytes and later osteoblasts initiated by osteoclasts occurs and bone tissue is repaired. The activation of this repair process can be initiated by different pathways (e.g. the OPG/RANK/RANKL pathway, Wnt/ß-catenin pathway).

Recently, Kneidinger and colleagues found diminished Wnt/ $\beta$-catenin signaling to be involved in impaired repair capacity in emphysema ${ }^{109}$. As discussed before, the $\mathrm{Wnt} / \beta$-catenin pathway activates osteoblasts and therefore, has an important role in bone remodeling and repair of microfractures ${ }^{110 ; 111}$.

Emphysema is characterized by tissue destruction suggesting an imbalance between destruction and repair mechanism ${ }^{123}$. There are a 
number of proposed mechanisms of impaired repair of lung parenchyma ${ }^{109 ; 123 ; 124}$. In a review article oxidant injury and lung inflammation are proposed to compromise repair of alveolar structure ${ }^{124}$. Moreover, derangements of the protease-antiprotease balance contribute to this inappropriate repair of lung parenchyma in emphysema. In 12 COPD patients and 10 subjects without COPD undergoing lung surgery (18 subjects because of lung tumor resection, 4 COPD patients underwent lung reduction surgery) fibroblast from COPD patients were found to have diminished repair responses as compared to age and smoking history matched controls ${ }^{125}$.

The studies for this thesis were not designed to investigate the possible role of impaired repair mechanisms in osteoporosis and COPD. The impaired repair mechanisms of lung parenchyma and bone in relation to diminished $\mathrm{Wnt} / \beta$-catenin signaling warrants further investigation.

\section{Endogenous hormonal factors}

It is well established that hormonal factors play an important role in the development of osteoporosis. Indeed, the role of estrogen deficiency in the pathogenesis of postmenopausal osteoporosis had been recognized for many years ${ }^{17 ; 126}$. Estrogen inhibits bone resorption hence, postmenopausal estrogen deficiency results in increased bone resorption ${ }^{126}$. Estrogen deficiency may also be important in men given the fact that serum estrogen concentrations are correlated with bone mass in older men ${ }^{127 ; 128}$ and testosterone therapy to increase bone mass in men is correlated more closely with an increase in serum estrogen than serum testosterone concentrations ${ }^{129}$.

Hormones from the hypothalamic-pituitary axis may also be involved in bone homeostasis. Indeed, growth hormone or insulin-like growth factor (IGF-I) deficiency result in diminished bone mass ${ }^{130}$. In accordance with the previous is the fact that low serum IGF-I concentrations were found in men with idiopathic osteoporosis ${ }^{131}$. IGF-I is thought to play a role in both the acquisition of bone mass during adolescence as well as the increased bone loss at higher age ${ }^{132}$. However, results of studies with growth hormone and IGF-I have been disappointing. Therefore, the role of growth hormone or IGF-I in most patients with osteoporosis is probably small $^{132 ; 133}$. 
Patients with hyperthyroidism can have high bone turnover and low $\mathrm{BMD}^{134}$. However, no consistent evidence for the role of thyroid hormones in the pathogenesis of osteoporosis has been found.

To date, little is known about endogenous hormonal disturbances in COPD. Hypogonadism might play a role in COPD. Indeed, in male COPD patients, a higher prevalence of hypogonadism has been found as compared to healthy age-matched men ${ }^{135}$. In addition, smoking has been shown to cause hypogonadism ${ }^{136}$. Finally, it has been speculated that low-grade systemic inflammation, oral corticosteroids and/or hypoxemia partially contribute to the development and/or maintenance of hypogonadism in $\mathrm{COPD}^{137-140}$. In a study of 130 COPD patients, no correlation was found between bone mass and serum testosterone ${ }^{141}$.

In COPD patients IGF-I levels were found to be low ${ }^{137}$. Moreover, COPD patients have been shown to have a decreased IGF-I/growth hormone ratio as compared with age-matched healthy controls, suggesting the presence of an acquired growth hormone resistance in COPD ${ }^{142}$. To the best of our knowledge, the possible role of IGF-I in the pathogenesis of osteoporosis in COPD has not been studied yet.

Several studies have investigated thyroid hormone levels in COPD patients because of its possible role in the development of muscle atrophy. However, these studies have conflicting results ${ }^{137}$. Because of the conflicting results in levels of thyroid hormone in COPD patients and because no consistent evidence for the role of thyroid hormones in the pathogenesis of osteoporosis had been found it is not likely that thyroid function is involved in the pathogenesis of osteoporosis in COPD.

In conclusion, very little is known about the possible interrelations between hormonal status, COPD and bone status.

\section{Exogenous hormonal factors}

It is well known that the use of corticosteroids increases the risk of osteoporosis. This is due to an uncoupling of bone formation and resorption $^{110}$. 
Inhaled corticosteroids pose a dose related adrenal suppression ${ }^{143}$ which is a well known risk factor for osteoporosis ${ }^{144}$. However, studies on the effects of inhaled corticosteroids on bone have conflicting results. In meta-analyses, Richy and colleagues found that inhaled corticosteroids did have deleterious effects on markers of bone turnover and BMD in patients with asthma or COPD ${ }^{145}$ whereas, Jones and colleagues did not find a significant effect on BMD or increased fracture risk in patients with asthma or COPD ${ }^{146}$.

In chapter II one study was identified that found a significant decrease in BMD in COPD patients using an inhaled corticosteroid as compared to COPD patients using placebo for 3 years ${ }^{147}$. However, fractures and diagnosis on osteoporosis were not increased in these patients. In the TOwards A Revolution of COPD Health Study (TORCH) no significant influence of inhaled corticosteroids as compared to placebo on bone metabolism was found in COPD patients followed up for 3 years ${ }^{148}$. In the other studies performed for this thesis, no influence of inhaled corticosteroids on the prevalence of a low BMD and/or vertebral fractures was found (chapters III, IV, V, VI and VII). This could be due to the fact that in the studies in this thesis corrections for other co-variables like disease severity and body composition measures were made. These covariables are probably more important in the underlying pathophysiology of osteoporosis in COPD patients as compared to the influence of corticosteroids themselves. Indeed, de Vries and colleagues found that the influence of inhaled corticosteroids disappeared after correction for the degree of airflow limitation ${ }^{149}$.

Patients with oral corticosteroid induced osteoporosis show fewer osteoblasts and an increased prevalence of osteocyte apoptosis as compared to healthy subjects ${ }^{150}$. Apoptosis of osteocytes is associated with decreases in skeletal angiogenesis, bone interstitial fluid and bone strength ${ }^{151}$ possibly resulting in the loss of bone strength in corticosteroidinduced osteoporosis which occurs before loss of $\mathrm{BMD}^{152}$. Indeed, in COPD patients using oral corticosteroids the fracture risk was increased more than reflected by decrease of $\mathrm{BMD}^{153}$. Despite the fact that the use of oral corticosteroids in COPD patients is not recommended ${ }^{154 ; 155}$, they are often prescribed in stable COPD.

In the studies performed for this thesis, no influence of oral corticosteroids was found on the prevalence of osteoporosis (chapters III, 
IV, V, VI and VII). Again, this might be due to other, more important, factors in the underlying pathophysiology of osteoporosis in COPD patients. Moreover, different corticosteroid regimens were shown to have different effects on BMD in COPD patients ${ }^{6}$ Moreover, no influence of oral (as well as inhaled) corticosteroids was found when osteoporosis was defined not only by BMD but also by vertebral fractures (chapter V). This is in line with a recent study where no difference between oral- and inhaled corticosteroids use was found between COPD patients with- and without vertebral fractures ${ }^{156}$.

In summary, conflicting results on the influence of inhaled-and oral corticosteroids on bone in COPD patients have been found.

\section{Methodological considerations}

Some general methodological considerations about the studies for the thesis have to be made. Firstly, no control group of healthy subjects was included. However, other studies already showed an increased prevalence of osteoporosis in COPD patients as compared to healthy subjects (chapter II). Moreover, as described earlier, the prevalence of osteoporosis in the COPD patients included in the studies for this thesis was higher as compared to the prevalence in a Dutch population ${ }^{19}$. Secondly, no control group of COPD patients treated by their general physician was included. Studies comparing COPD patients treated in primary care to COPD patients visiting a chest physician should clarify whether the high prevelance of osteoporosis is also found in COPD patients treated by their general practitioner.

Secondly, the studies are mostly cross sectional, therefore, interpretation of correlating factors should be with caution for they are not true risk factors. Finally, as discussed in this chapter a lot of possible contributing factors in the complex interrelation between osteoporosis and COPD were not investigated because the studies for this thesis were not designed to do so. Examples of these factors are bone markers, more markers of inflammation, OPG/RANK/RANKL and the Wnt-pathway. 


\section{Clinical implications, conclusions and recommendations}

Despite the methodological considerations some important findings were done.

Firstly, the prevalence of osteoporosis in COPD patients starting pulmonary rehabilitation or visiting an outpatients clinic is high. Therefore, all COPD patients treated in the second- or third line of care should be screened for osteoporosis.

Secondly, only few osteoporotic COPD patients were treated with physician prescribed bone medication (18\% and $20 \%$ in chapter III and V respectively). Therefore, the awareness of (chest) physicians of the high prevalence of osteoporosis in COPD should be raised. This can be done by emphasizing that COPD is a multicomponent disease. Moreover, chest physicians should be stimulated to inspect/measure the thoracic vertebrae when a lateral X-ray of the thorax is made. Finally, the advise to screen for osteoporosis in COPD patients should be included in guidelines. In the $3^{\text {rd }}$ revision of the CBO guideline on osteoporosis and fracture prevention of the Netherlands ${ }^{157}$ this is already incorporated. These guidelines should be actively implemented. This way, treatment to prevent fragility fractures can be started early in case of osteoporosis. Indeed, in a recent review Lehouck and colleagues suggest a more active approach in the diagnosis of osteoporosis in COPD patients because of the high prevalence ${ }^{158}$. The prevention of fractures in COPD patients is especially important because of the decrease in pulmonary function due to vertebral fractures ${ }^{159 ; 160}$ and the increased operation risk in case of a hip fracture ${ }^{161-163}$. Moreover, patients with COPD have a higher number of self-reported falls during walking compared with healthy subjects ${ }^{164}$. Therefore, osteoporotic COPD patients are prone to fall-related fractures while walking ${ }^{165}$.

Finally, osteoporosis in COPD patients should be diagnosed by the combination of local DXA-scan and the assessment of vertebral fractures. Moreover, given the calcemic and non-calcemic effects of vitamin $D^{112 ; 119 ; 120}$, all COPD patients should be screened for vitamin D deficiency.

The high prevalence of osteoporosis in COPD patients used to be attributed to the use of corticosteroids by these patients. However, the current thesis shows that the underlying pathophysiology of osteoporosis 
in COPD is very complex and by far not clear yet. Therefore, more large prospective studies including healthy subjects are warranted. These studies should focus on possible contributing factors as discussed in this chapter (e.g. accelerated aging, genetics, physical inactivity, systemic inflammation).

Because there is no straightforward explanation for the high prevalence of osteoporosis in COPD patients and because complicated underlying processes are involved in both diseases it is difficult to intervene. Even the standard treatment for osteoporosis conform the guidelines is only prescribed in a small percentage of COPD patients with osteoporosis (chapter III and V). Once more we stress the importance of further research in order to understand the pathophysiology and pathogenesis of osteoporosis in COPD. This way new treatments aimed at both COPD and osteoporosis might become available. 


\section{Reference List}

(1) Rabe KF, Hurd S, Anzueto A, Barnes PJ, Buist SA, Calverley P et al. Global strategy for the diagnosis, management, and prevention of chronic obstructive pulmonary disease: GOLD executive summary. Am J Respir Crit Care Med 2007; 176(6):532-555.

(2) Schols AM, Broekhuizen R, Weling-Scheepers CA, Wouters EF. Body composition and mortality in chronic obstructive pulmonary disease. Am J Clin Nutr 2005; 82(1):53-59.

(3) Sabit R, Bolton CE, Edwards PH, Pettit RJ, Evans WD, McEniery CM et al. Arterial stiffness and osteoporosis in chronic obstructive pulmonary disease. Am J Respir Crit Care Med 2007; 175(12):1259-1265.

(4) Bolton CE, lonescu AA, Shiels KM, Pettit RJ, Edwards PH, Stone MD et al. Associated loss of fat-free mass and bone mineral density in chronic obstructive pulmonary disease. Am J Respir Crit Care Med 2004; 170(12):1286-1293.

(5) Dimai HP, Domej W, Leb G, Lau KH. Bone loss in patients with untreated chronic obstructive pulmonary disease is mediated by an increase in bone resorption associated with hypercapnia. J Bone Miner Res 2001; 16(11):21322141.

(6) Dubois EF, Roder E, Dekhuijzen PN, Zwinderman AE, Schweitzer DH. Dual energy X-ray absorptiometry outcomes in male COPD patients after treatment with different glucocorticoid regimens. Chest 2002; 121(5):1456-1463.

(7) Forli L, Mellbye OJ, Halse J, Bjortuft O, Vatn M, Boe J. Cytokines, bone turnover markers and weight change in candidates for lung transplantation. Pulm Pharmacol Ther 2008; 21(1):188-195.

(8) Jorgensen NR, Schwarz P, Holme I, Henriksen BM, Petersen LJ, Backer V. The prevalence of osteoporosis in patients with chronic obstructive pulmonary disease: a cross sectional study. Respir Med 2007; 101(1):177-185.

(9) Karadag F, Cildag O, Yurekli Y, Gurgey O. Should COPD patients be routinely evaluated for bone mineral density? J Bone Miner Metab 2003; 21(4):242-246.

(10) Mineo TC, Ambrogi V, Mineo D, Fabbri A, Fabbrini E, Massoud R. Bone mineral density improvement after lung volume reduction surgery for severe emphysema. Chest 2005; 127(6):1960-1966.

(11) Vrieze A, de Greef MH, Wijkstra PJ, Wempe JB. Low bone mineral density in COPD patients related to worse lung function, low weight and decreased fatfree mass. Osteoporos Int 2007; 18(9):1197-1202.

(12) Aris RM, Neuringer IP, Weiner MA, Egan TM, Ontjes D. Severe osteoporosis before and after lung transplantation. Chest 1996; 109(5):1176-1183. 
(13) Incalzi RA, Caradonna P, Ranieri P, Basso S, Fuso L, Pagano F et al. Correlates of osteoporosis in chronic obstructive pulmonary disease. Respir Med 2000; 94(11):1079-1084.

(14) Katsura H, Kida K. A comparison of bone mineral density in elderly female patients with COPD and bronchial asthma. Chest 2002; 122(6):1949-1955.

(15) Tschopp O, Boehler A, Speich R, Weder W, Seifert B, Russi EW et al. Osteoporosis before lung transplantation: association with low body mass index, but not with underlying disease. Am J Transplant 2002; 2(2):167-172.

(16) Boyanov M. Estimation of lumbar spine bone mineral density by dual-energy Xray absorptiometry: standard anteroposterior scans vs sub-regional analyses of whole-body scans. Br J Radiol 2008; 81(968):637-642.

(17) WHO Scientific Group on the Prevention and Management of Osteoporosis. Prevention and Management of Osteoporosis: report of a WHO scientific group. http;//whqlibdoc who int/trs/WHO_TRS_921 pdf [ 2007

(18) Genant HK, Delmas PD, Chen P, Jiang Y, Eriksen EF, Dalsky GP et al. Severity of vertebral fracture reflects deterioration of bone microarchitecture. Osteoporos Int 2007; 18(1):69-76.

(19) Schuit SC, van der KM, Weel AE, de Laet CE, Burger H, Seeman E et al. Fracture incidence and association with bone mineral density in elderly men and women: the Rotterdam Study. Bone 2004; 34(1):195-202.

(20) van der KM, de Laet CE, McCloskey EV, Hofman A, Pols HA. The incidence of vertebral fractures in men and women: the Rotterdam Study. J Bone Miner Res 2002; 17(6):1051-1056.

(21) Bours SP, van Geel TA, Geusens PP, Janssen MJ, Janzing HM, Hoffland GA et al. Contributors to secondary osteoporosis and metabolic bone diseases in patients presenting with a clinical fracture. J Clin Endocrinol Metab 2011; 96(5):1360-1367.

(21) Arlot ME, Sornay-Rendu E, Garnero P, Vey-Marty B, Delmas PD. Apparent pre- and postmenopausal bone loss evaluated by DXA at different skeletal sites in women: the OFELY cohort. J Bone Miner Res 1997; 12(4):683-690.

(22) Heijckmann AC, Huijberts MS, de VJ, Menheere PP, van d, V, Kruseman AC et al. Bone turnover and hip bone mineral density in patients with sarcoidosis. Sarcoidosis Vasc Diffuse Lung Dis 2007; 24(1):51-58.

(23) Heijckmann AC, Huijberts MS, Schoon EJ, Geusens P, de VJ, Menheere PP et al. High prevalence of morphometric vertebral deformities in patients with inflammatory bowel disease. Eur J Gastroenterol Hepatol 2008; 20(8):740-747.

(24) The international society for clinical densitometry: Official positions 2007. 2009.

Ref Type: Internet Communication 
(25) WHO. Preventing chronic diseases: a vital investment. WHO global report 2005. Global report [ 2005

(26) Kanis JA, Johnell O, Oden A, Johansson H, McCloskey E. FRAX and the assessment of fracture probability in men and women from the UK. Osteoporos Int 2008; 19(4):385-397.

(27) Cavanagh PR, Licata AA, Rice AJ. Exercise and pharmacological countermeasures for bone loss during long-duration space flight. Gravit Space Biol Bull 2005; 18(2):39-58.

(28) Celli BR, Cote CG, Marin JM, Casanova C, Montes de OM, Mendez RA et al. The body-mass index, airflow obstruction, dyspnea, and exercise capacity index in chronic obstructive pulmonary disease. N Engl J Med 2004; 350(10):1005-1012.

(29) Landbo C, Prescott E, Lange P, Vestbo J, Almdal TP. Prognostic value of nutritional status in chronic obstructive pulmonary disease. Am J Respir Crit Care Med 1999; 160(6):1856-1861.

(30) Schols AM, Slangen J, Volovics L, Wouters EF. Weight loss is a reversible factor in the prognosis of chronic obstructive pulmonary disease. Am J Respir Crit Care Med 1998; 157(6 Pt 1):1791-1797.

(31) Vestbo J, Prescott E, Almdal T, Dahl M, Nordestgaard BG, Andersen T et al. Body mass, fat-free body mass, and prognosis in patients with chronic obstructive pulmonary disease from a random population sample: findings from the Copenhagen City Heart Study. Am J Respir Crit Care Med 2006; 173(1):79-83.

(32) Hitzl AP, Jorres RA, Heinemann F, Pfeifer M, Budweiser S. Nutritional status in patients with chronic respiratory failure receiving home mechanical ventilation: impact on survival. Clin Nutr 2010; 29(1):65-71.

(33) Ischaki E, Papatheodorou G, Gaki E, Papa I, Koulouris N, Loukides S. Body mass and fat-free mass indices in COPD: relation with variables expressing disease severity. Chest 2007; 132(1):164-169.

(34) Mostert R, Goris A, Weling-Scheepers C, Wouters EF, Schols AM. Tissue depletion and health related quality of life in patients with chronic obstructive pulmonary disease. Respir Med 2000; 94(9):859-867.

(35) Wouters EF, Creutzberg EC, Schols AM. Systemic effects in COPD. Chest 2002; 121(5 Suppl):127S-130S.

(36) Baarends EM, Schols AM, Mostert R, Wouters EF. Peak exercise response in relation to tissue depletion in patients with chronic obstructive pulmonary disease. Eur Respir J 1997; 10(12):2807-2813.

(37) Engelen MP, Schols AM, Does JD, Wouters EF. Skeletal muscle weakness is associated with wasting of extremity fat-free mass but not with airflow obstruction in patients with chronic obstructive pulmonary disease. Am J Clin Nutr 2000; 71(3):733-738. 
(38) Itoh K, Aida S, Ishiwata S, Sasaki S, Ishida N, Mizugaki M. Urinary excretion patterns of modified nucleosides, pseudouridine and 1-methyladenosine, in healthy individuals. Clin Chim Acta 1993; 217(2):221-223.

(39) Bohles H, Brendel L, Forster H, Trager K, Vogt J, Georgieff M. The effect of human growth hormone therapy on $\mathrm{L}$-(methyl-2H3)-leucine turnover and urinary pseudouridine concentration in patients with Ullrich-Turner syndrome. Eur J Pediatr 1996; 155(4):275-280.

(40) Bolton CE, Broekhuizen R, Ionescu AA, Nixon LS, Wouters EF, Shale DJ et al. Cellular protein breakdown and systemic inflammation are unaffected by pulmonary rehabilitation in COPD. Thorax 2007; 62(2):109-114.

(41) Broekhuizen R, Wouters EF, Creutzberg EC, Schols AM. Raised CRP levels mark metabolic and functional impairment in advanced COPD. Thorax 2006; 61(1):17-22.

(42) Bergstrom I, Parini P, Gustafsson SA, Andersson G, Brinck J. Physical training increases osteoprotegerin in postmenopausal women. J Bone Miner Metab 2011.

(43) Dardeno TA, Chou SH, Moon HS, Chamberland JP, Fiorenza CG, Mantzoros CS. Leptin in human physiology and therapeutics. Front Neuroendocrinol 2010; 31(3):377-393.

(44) Li MD. Leptin and beyond: an odyssey to the central control of body weight. Yale J Biol Med 2011; 84(1):1-7.

(45) Reid IR. Fat and bone. Arch Biochem Biophys 2010; 503(1):20-27.

(46) Breyer MK, Rutten EP, Vernooy JH, Spruit MA, Dentener MA, van der KC et al. Gender differences in the adipose secretome system in chronic obstructive pulmonary disease (COPD): A pivotal role of leptin. Respir Med 2011; 105(7):1046-1053.

(47) Kawai M, Devlin MJ, Rosen CJ. Fat targets for skeletal health. Nat Rev Rheumatol 2009; 5(7):365-372.

(48) Vondracek SF, Voelkel NF, McDermott MT, Valdez C. The relationship between adipokines, body composition, and bone density in men with chronic obstructive pulmonary disease. Int J Chron Obstruct Pulmon Dis 2009; 4:267277.

(49) Pobeha P, Ukropec J, Skyba P, Ukropcova B, Joppa P, Kurdiova T et al. Relationship between osteoporosis and adipose tissue leptin and osteoprotegerin in patients with chronic obstructive pulmonary disease. Bone 2011; 48(5):1008-1014.

(50) McKeever TM, Lewis SA, Cassano PA, Ocke M, Burney P, Britton J et al. Patterns of dietary intake and relation to respiratory disease, forced expiratory volume in $1 \mathrm{~s}$, and decline in 5-y forced expiratory volume. Am J Clin Nutr 2010; 92(2):408-415. 
(51) Lin PH, Ginty F, Appel LJ, Aickin M, Bohannon A, Garnero P et al. The DASH diet and sodium reduction improve markers of bone turnover and calcium metabolism in adults. J Nutr 2003; 133(10):3130-3136.

(52) Lane NE, Kaneps AJ, Stover SM, Modin G, Kimmel DB. Bone mineral density and turnover following forelimb immobilization and recovery in young adult dogs. Calcif Tissue Int 1996; 59(5):401-406.

(53) Li CY, Price C, Delisser K, Nasser P, Laudier D, Clement M et al. Long-term disuse osteoporosis seems less sensitive to bisphosphonate treatment than other osteoporosis. J Bone Miner Res 2005; 20(1):117-124.

(54) Kaneps AJ, Stover SM, Lane NE. Changes in canine cortical and cancellous bone mechanical properties following immobilization and remobilization with exercise. Bone 1997; 21(5):419-423.

(55) Kanis J, Oden A, Johnell O. Acute and long-term increase in fracture risk after hospitalization for stroke. Stroke 2001; 32(3):702-706.

(56) Evans WJ. Skeletal muscle loss: cachexia, sarcopenia, and inactivity. Am J Clin Nutr 2010; 91(4):1123S-1127S.

(57) Marcus R. Relationship of age-related decreases in muscle mass and strength to skeletal status. J Gerontol A Biol Sci Med Sci 1995; 50 Spec No:86-87.

(58) Suominen $\mathrm{H}$. Muscle training for bone strength. Aging Clin Exp Res 2006; 18(2):85-93.

(59) Wallace BA, Cumming RG. Systematic review of randomized trials of the effect of exercise on bone mass in pre- and postmenopausal women. Calcif Tissue Int 2000; 67(1):10-18.

(60) Pitta F, Troosters T, Spruit MA, Probst VS, Decramer M, Gosselink R. Characteristics of physical activities in daily life in chronic obstructive pulmonary disease. Am J Respir Crit Care Med 2005; 171(9):972-977.

(61) Pitta F, Troosters T, Probst VS, Lucas S, Decramer M, Gosselink R. Potential consequences for stable chronic obstructive pulmonary disease patients who do not get the recommended minimum daily amount of physical activity. J Bras Pneumol 2006; 32(4):301-308.

(62) Pate RR, Pratt M, Blair SN, Haskell WL, Macera CA, Bouchard C et al. Physical activity and public health. A recommendation from the Centers for Disease Control and Prevention and the American College of Sports Medicine. JAMA 1995; 273(5):402-407.

(63) Watz H, Waschki B, Boehme C, Claussen M, Meyer T, Magnussen $\mathrm{H}$. Extrapulmonary effects of chronic obstructive pulmonary disease on physical activity: a cross-sectional study. Am J Respir Crit Care Med 2008; 177(7):743751.

(64) Watz H, Waschki B, Meyer T, Magnussen $\mathrm{H}$. Physical activity in patients with COPD. Eur Respir J 2009; 33(2):262-272. 
(65) Garcia-Aymerich J, Lange P, Benet M, Schnohr P, Anto JM. Regular physical activity reduces hospital admission and mortality in chronic obstructive pulmonary disease: a population based cohort study. Thorax 2006; 61(9):772778.

(66) Waschki B, Kirsten A, Holz O, Muller KC, Meyer T, Watz H et al. Physical activity is the strongest predictor of all-cause mortality in patients with chronic obstructive pulmonary disease: a prospective cohort study. Chest 2011.

(67) Seymour JM, Spruit MA, Hopkinson NS, Natanek SA, Man WD, Jackson A et al. The prevalence of quadriceps weakness in COPD and the relationship with disease severity. Eur Respir J 2010; 36(1):81-88.

(68) Walker PP, Burnett A, Flavahan PW, Calverley PM. Lower limb activity and its determinants in COPD. Thorax 2008; 63(8):683-689.

(69) Beauchamp MK, Hill K, Goldstein RS, Janaudis-Ferreira T, Brooks D. Impairments in balance discriminate fallers from non-fallers in COPD. Respir Med 2009; 103(12):1885-1891.

(70) Hannink JD, van Helvoort HA, Dekhuijzen PN, Heijdra YF. Dynamic hyperinflation during daily activities: does COPD global initiative for chronic obstructive lung disease stage matter? Chest 2010; 137(5):1116-1121.

(71) Callens E, Graba S, Gillet-Juvin K, Essalhi M, Bidaud-Chevalier B, Peiffer C et al. Measurement of dynamic hyperinflation after a 6-minute walk test in patients with COPD. Chest 2009; 136(6):1466-1472.

(72) Marin JM, Carrizo SJ, Gascon M, Sanchez A, Gallego B, Celli BR. Inspiratory capacity, dynamic hyperinflation, breathlessness, and exercise performance during the 6-minute-walk test in chronic obstructive pulmonary disease. Am J Respir Crit Care Med 2001; 163(6):1395-1399.

(73) Wouters EF, Franssen FM, Spruit MA. Survival and Physical Activity in COPD: A Giant Leap Forward! Chest 2011; 140(2):279-281.

(74) Zhang J, Chen F, Yun F, Chen J. Low level nicotine: a novel approach to reduce osteoporosis incidence. Med Hypotheses 2010; 74(6):1067-1068.

(75) Kanis JA, Johnell O, Oden A, Johansson H, De Laet C, Eisman JA et al. Smoking and fracture risk: a meta-analysis. Osteoporos Int 2005; 16(2):155162.

(76) Ward KD, Klesges RC. A meta-analysis of the effects of cigarette smoking on bone mineral density. Calcif Tissue Int 2001; 68(5):259-270.

(77) Tamaki J, Iki M, Fujita Y, Kouda K, Yura A, Kadowaki E et al. Impact of smoking on bone mineral density and bone metabolism in elderly men: the Fujiwara-kyo Osteoporosis Risk in Men (FORMEN) study. Osteoporos Int $2011 ; 22(1): 133-141$.

(78) Dimai HP, Chandran M. Official Positions for FRAX((R)) Clinical Regarding Smoking From Joint Official Positions Development Conference of the 
International Society for Clinical Densitometry and International Osteoporosis Foundation on FRAX((R)). J Clin Densitom 2011; 14(3):190-193.

(79) D'Anna SE, Asnaghi R, Caramori G, Appendini L, Rizzo M, Cavallaro C et al. High-Resolution Computed Tomography Quantitation of Emphysema Is Correlated with Selected Lung Function Values in Stable COPD. Respiration 2011.

(80) Grydeland TB, Dirksen A, Coxson HO, Pillai SG, Sharma S, Eide GE et al. Quantitative computed tomography: emphysema and airway wall thickness by sex, age and smoking. Eur Respir J 2009; 34(4):858-865.

(81) Stockley RA, Mannino D, Barnes PJ. Burden and pathogenesis of chronic obstructive pulmonary disease. Proc Am Thorac Soc 2009; 6(6):524-526.

(82) Bon J, Fuhrman CR, Weissfeld JL, Duncan SR, Branch RA, Chang CC et al. Radiographic emphysema predicts low bone mineral density in a tobaccoexposed cohort. Am J Respir Crit Care Med 2011; 183(7):885-890.

(83) Engelen MP, Schols AM, Lamers RJ, Wouters EF. Different patterns of chronic tissue wasting among patients with chronic obstructive pulmonary disease. Clin Nutr 1999; 18(5):275-280.

(84) Ohara T, Hirai T, Muro S, Haruna A, Terada K, Kinose D et al. Relationship between pulmonary emphysema and osteoporosis assessed by CT in patients with COPD. Chest 2008; 134(6):1244-1249.

(85) Mitchell BD, Yerges-Armstrong LM. The genetics of bone loss: challenges and prospects. J Clin Endocrinol Metab 2011; 96(5):1258-1268.

(86) Styrkarsdottir U, Halldorsson BV, Gretarsdottir S, Gudbjartsson DF, Walters $\mathrm{GB}$, Ingvarsson $\mathrm{T}$ et al. New sequence variants associated with bone mineral density. Nat Genet 2009; 41(1):15-17.

(87) Hancock DB, Eijgelsheim M, Wilk JB, Gharib SA, Loehr LR, Marciante KD et al. Meta-analyses of genome-wide association studies identify multiple loci associated with pulmonary function. Nat Genet 2010; 42(1):45-52.

(88) Janssens W, Bouillon R, Claes B, Carremans C, Lehouck A, Buysschaert I et al. Vitamin $D$ deficiency is highly prevalent in COPD and correlates with variants in the vitamin D-binding gene. Thorax 2010; 65(3):215-220.

(89) Barnes PJ. Genetics and pulmonary medicine. 9. Molecular genetics of chronic obstructive pulmonary disease. Thorax 1999; 54(3):245-252.

(90) Barnes PJ, Celli BR. Systemic manifestations and comorbidities of COPD. Eur Respir J 2009; 33(5):1165-1185.

(91) Bousquet J, Anto JM, Sterk PJ, Adcock IM, Chung KF, Roca J et al. Systems medicine and integrated care to combat chronic noncommunicable diseases. Genome Med 2011; 3(7):43. 
(92) Barabasi AL. Network medicine--from obesity to the "diseasome". N Engl J Med 2007; 357(4):404-407.

(93) Syed FA, Ng AC. The pathophysiology of the aging skeleton. Curr Osteoporos Rep 2010; 8(4):235-240.

(94) Ito K, Barnes PJ. COPD as a disease of accelerated lung aging. Chest 2009; 135(1):173-180.

(95) Cannizzo ES, Clement CC, Sahu R, Follo C, Santambrogio L. Oxidative stress, inflamm-aging and immunosenescence. J Proteomics 2011.

(96) MacNee W, Tuder RM. New paradigms in the pathogenesis of chronic obstructive pulmonary disease I. Proc Am Thorac Soc 2009; 6(6):527-531.

(97) Lee J, Sandford A, Man P, Sin DD. Is the aging process accelerated in chronic obstructive pulmonary disease? Curr Opin Pulm Med 2011; 17(2):90-97.

(98) Bekaert S, Van P, I, De MT, Zmierczak H, Kaufman JM, Van OP et al. Telomere length versus hormonal and bone mineral status in healthy elderly men. Mech Ageing Dev 2005; 126(10):1115-1122.

(99) Valdes AM, Richards JB, Gardner JP, Swaminathan R, Kimura M, Xiaobin L et al. Telomere length in leukocytes correlates with bone mineral density and is shorter in women with osteoporosis. Osteoporos Int 2007; 18(9):1203-1210.

(100) Heijckmann AC, Drent M, Dumitrescu B, de VJ, Nieuwenhuijzen Kruseman AC, Wolffenbuttel BH et al. Progressive vertebral deformities despite unchanged bone mineral density in patients with sarcoidosis: a 4-year follow-up study. Osteoporos Int 2008; 19(6):839-847.

(101) Diarra D, Stolina M, Polzer K, Zwerina J, Ominsky MS, Dwyer D et al. Dickkopf-1 is a master regulator of joint remodeling. Nat Med 2007; 13(2):156163.

(102) Schett G, Kiechl S, Weger S, Pederiva A, Mayr A, Petrangeli M et al. Highsensitivity C-reactive protein and risk of nontraumatic fractures in the Bruneck study. Arch Intern Med 2006; 166(22):2495-2501.

(103) Schett G, Saag KG, Bijlsma JW. From bone biology to clinical outcome: state of the art and future perspectives. Ann Rheum Dis 2010;69(8):1415-1419.

(104) Agusti AG. COPD, a multicomponent disease: implications for management. Respir Med 2005; 99(6):670-682.

(105) Franciosi LG, Page CP, Celli BR, Cazzola M, Walker MJ, Danhof M et al. Markers of disease severity in chronic obstructive pulmonary disease. Pulm Pharmacol Ther 2006; 19(3):189-199.

(106) Eagan TM, Ueland T, Wagner PD, Hardie JA, Mollnes TE, Damas JK et al. Systemic inflammatory markers in COPD: results from the Bergen COPD Cohort Study. Eur Respir J 2010; 35(3):540-548. 
(107) Pinto-Plata V, Toso J, Lee K, Park D, Bilello J, Mullerova H et al. Profiling serum biomarkers in patients with COPD: associations with clinical parameters. Thorax 2007; 62(7):595-601.

(108) Bon JM, Zhang Y, Duncan SR, Pilewski JM, Zaldonis D, Zeevi A et al. Plasma inflammatory mediators associated with bone metabolism in COPD. J Cron Obstruct Pulmon Dis 2010; 7:186-191.

(109) Kneidinger N, Yildirim AO, Callegari J, Takenaka S, Stein MM, Dumitrascu R et al. Activation of the WNT/beta-catenin pathway attenuates experimental emphysema. Am J Respir Crit Care Med 2011; 183(6):723-733.

(110) Hardy R, Cooper MS. Bone loss in inflammatory disorders. J Endocrinol 2009; 201(3):309-320.

(111) Patel MS, Karsenty G. Regulation of bone formation and vision by LRP5. N Engl J Med 2002; 346(20):1572-1574.

(112) Holick MF. Vitamin D deficiency. N Engl J Med 2007; 357(3):266-281.

(113) Kuchuk NO, van Schoor NM, Pluijm SM, Chines A, Lips P. Vitamin D Status, Parathyroid Function, Bone Turnover and Bone Mineral Density in Postmenopausal Women with Osteoporosis in Global Perspective. J Bone Miner Res 2008.

(114) Standing Committee on the Scientific Evaluation of Dietary Reference INtakes Food and Nutrition Board loM. Vitamin D. Dietary reference intakes for calcium, phosphorus, magnesium, vitamin D, and fluoride. Washington, DC: National Academy Press; 1999. 250-287.

(115) van den Bergh JP, Bours SP, van Geel TA, Geusens PP. Optimal use of vitamin D when treating osteoporosis. Curr Osteoporos Rep 2011; 9(1):36-42.

(116) Andersson I, Gronberg A, Slinde F, Bosaeus I, Larsson S. Vitamin and mineral status in elderly patients with chronic obstructive pulmonary disease. Clin Respir J 2007; 1 (1):23-29.

(117) de BJ, Romieu I, Anto JM, Mendez M, Rodriguez E, Balcells E et al. Dietary habits of firstly admitted Spanish COPD patients. Respir Med 2009; 103(12):1904-1910.

(118) Black PN, Scragg R. Relationship between serum 25-hydroxyvitamin d and pulmonary function in the third national health and nutrition examination survey. Chest 2005; 128(6):3792-3798.

(119) Herr C, Greulich T, Koczulla RA, Meyer S, Zakharkina T, Branscheidt M et al. The role of vitamin $\mathrm{D}$ in pulmonary disease: COPD, asthma, infection, and cancer. Respir Res 2011; 12:31.

(120) Janssens W, Lehouck A, Carremans C, Bouillon R, Mathieu C, Decramer M. Vitamin D Beyond Bones in COPD: Time to Act. Am J Respir Crit Care Med 2009; 179(8):630-636. 
(121) Janssens W, Mathieu C, Boonen S, Decramer M. Vitamin D deficiency and chronic obstructive pulmonary disease: a vicious circle. Vitam Horm 2011; 86:379-399.

(122) Rachner TD, Khosla S, Hofbauer LC. Osteoporosis: now and the future. Lancet $2011 ; 377(9773): 1276-1287$.

(123) Rennard SI, Togo S, Holz O. Cigarette smoke inhibits alveolar repair: a mechanism for the development of emphysema. Proc Am Thorac Soc 2006; 3(8):703-708.

(124) Sharafkhaneh A, Hanania NA, Kim V. Pathogenesis of emphysema: from the bench to the bedside. Proc Am Thorac Soc 2008; 5(4):475-477.

(125) Togo S, Holz O, Liu X, Sugiura H, Kamio K, Wang X et al. Lung fibroblast repair functions in patients with chronic obstructive pulmonary disease are altered by multiple mechanisms. Am J Respir Crit Care Med 2008; 178(3):248260.

(126) Cummings SR, Browner WS, Bauer D, Stone K, Ensrud K, Jamal S et al. Endogenous hormones and the risk of hip and vertebral fractures among older women. Study of Osteoporotic Fractures Research Group. N Engl J Med 1998; 339(11):733-738.

(127) Greendale GA, Edelstein S, Barrett-Connor E. Endogenous sex steroids and bone mineral density in older women and men: the Rancho Bernardo Study. J Bone Miner Res 1997; 12(11):1833-1843.

(128) Slemenda CW, Longcope C, Zhou L, Hui SL, Peacock M, Johnston CC. Sex steroids and bone mass in older men. Positive associations with serum estrogens and negative associations with androgens. J Clin Invest 1997; 100(7):1755-1759.

(129) Anderson FH, Francis RM, Peaston RT, Wastell HJ. Androgen supplementation in eugonadal men with osteoporosis: effects of six months' treatment on markers of bone formation and resorption. J Bone Miner Res 1997; 12(3):472-478.

(130) Wuster C, Blum WF, Schlemilch S, Ranke MB, Ziegler R. Decreased serum levels of insulin-like growth factors and IGF binding protein 3 in osteoporosis. J Intern Med 1993; 234(3):249-255.

(131) Kurland ES, Rosen CJ, Cosman F, McMahon D, Chan F, Shane E et al. Insulin-like growth factor-I in men with idiopathic osteoporosis. J Clin Endocrinol Metab 1997; 82(9):2799-2805.

(132) Rosen CJ, Donahue LR. Insulin-like growth factors and bone: the osteoporosis connection revisited. Proc Soc Exp Biol Med 1998; 219(1):1-7.

(133) Ravn P, Overgaard K, Spencer EM, Christiansen C. Insulin-like growth factors I and II in healthy women with and without established osteoporosis. Eur J Endocrinol 1995; 132(3):313-319. 
(134) Jodar GE, Munoz-Torres M, Escobar-Jimenez F, Quesada CM, Luna del Castillo JD, Olea N. Identification of metabolic bone disease in patients with endogenous hyperthyroidism: role of biological markers of bone turnover. Calcif Tissue Int 1997; 61(5):370-376.

(135) Van VM, Spruit MA, Verleden G, Kasran A, Van HE, Pitta F et al. Hypogonadism, quadriceps weakness, and exercise intolerance in chronic obstructive pulmonary disease. Am J Respir Crit Care Med 2005; 172(9):11051111.

(136) Yardimci S, Atan A, Delibasi T, Sunguroglu K, Guven MC. Long-term effects of cigarette-smoke exposure on plasma testosterone, luteinizing hormone and follicle-stimulating hormone levels in male rats. Br J Urol 1997; 79(1):66-69.

(137) Creutzberg EC, Casaburi R. Endocrinological disturbances in chronic obstructive pulmonary disease. Eur Respir J Suppl 2003; 46:76s-80s.

(138) Kamischke A, Kemper DE, Castel MA, Luthke M, Rolf C, Behre HM et al. Testosterone levels in men with chronic obstructive pulmonary disease with or without glucocorticoid therapy. Eur Respir J 1998; 11(1):41-45.

(139) Semple PD, Beastall GH, Watson WS, Hume R. Serum testosterone depression associated with hypoxia in respiratory failure. Clin Sci (Lond) 1980; 58(1):105-106.

(140) Semple PD, Beastall GH, Watson WS, Hume R. Hypothalamic-pituitary dysfunction in respiratory hypoxia. Thorax 1981; 36(8):605-609.

(141) Iqbal F, Michaelson J, Thaler L, Rubin J, Roman J, Nanes MS. Declining bone mass in men with chronic pulmonary disease: contribution of glucocorticoid treatment, body mass index, and gonadal function. Chest 1999; 116(6):16161624.

(142) Koehler F, Doehner W, Hoernig S, Witt C, Anker SD, John M. Anorexia in chronic obstructive pulmonary disease--association to cachexia and hormonal derangement. Int J Cardiol 2007; 119(1):83-89.

(143) Lipworth BJ. Systemic adverse effects of inhaled corticosteroid therapy: A systematic review and meta-analysis. Arch Intern Med 1999; 159(9):941-955.

(144) Devogelaer JP, Crabbe J, Nagant de DC. Bone mineral density in Addison's disease: evidence for an effect of adrenal androgens on bone mass. $\mathrm{Br}$ Med J (Clin Res Ed) 1987; 294(6575):798-800.

(145) Richy F, Bousquet J, Ehrlich GE, Meunier PJ, Israel E, Morii H et al. Inhaled corticosteroids effects on bone in asthmatic and COPD patients: a quantitative systematic review. Osteoporos Int 2003; 14(3):179-190.

(146) Jones A, Fay JK, Burr M, Stone M, Hood K, Roberts G. Inhaled corticosteroid effects on bone metabolism in asthma and mild chronic obstructive pulmonary disease. Cochrane Database Syst Rev 2002;(1):CD003537. 
(147) Scanlon PD, Connett JE, Wise RA, Tashkin DP, Madhok T, Skeans M et al. Loss of bone density with inhaled triamcinolone in Lung Health Study II. Am J Respir Crit Care Med 2004; 170(12):1302-1309.

(148) Ferguson GT, Calverley PM, Anderson JA, Jenkins CR, Jones PW, Willits LR et al. Prevalence and progression of osteoporosis in patients with COPD: results from the TOwards a Revolution in COPD Health study. Chest 2009; 136(6):1456-1465.

(149) de Vries F, van Staa TP, Bracke MS, Cooper C, Leufkens HG, Lammers JW. Severity of obstructive airway disease and risk of osteoporotic fracture. Eur Respir J 2005; 25(5):879-884.

(150) Weinstein RS. Clinical practice. Glucocorticoid-induced bone disease. N Engl J Med 2011; 365(1):62-70.

(151) Weinstein RS, Wan C, Liu Q, Wang Y, Almeida M, O'Brien CA et al. Endogenous glucocorticoids decrease skeletal angiogenesis, vascularity, hydration, and strength in aged mice. Aging Cell 2010; 9(2):147-161.

(152) Seeman E, Delmas PD. Bone quality--the material and structural basis of bone strength and fragility. N Engl J Med 2006; 354(21):2250-2261.

(153) Langhammer A, Forsmo S, Syversen U. Long-term therapy in COPD: any evidence of adverse effect on bone? Int J Chron Obstruct Pulmon Dis 2009; 4:365-380.

(154) Schols AM, Wesseling G, Kester AD, de VG, Mostert R, Slangen J et al. Dose dependent increased mortality risk in COPD patients treated with oral glucocorticoids. Eur Respir J 2001; 17(3):337-342.

(155) Walters JA, Walters EH, Wood-Baker R. Oral corticosteroids for stable chronic obstructive pulmonary disease. Cochrane Database Syst Rev 2005;(3):CD005374.

(156) Majumdar SR, Villa-Roel C, Lyons KJ, Rowe BH. Prevalence and predictors of vertebral fracture in patients with chronic obstructive pulmonary disease. Respir Med 2010; 104(2):260-266.

(157) CBO Richtlijn Osteoporose en Fractuur Preventie. Derde herziening (2011). http://www cbo nl/Downloads/1318/Definitieve\%20richtlijn\%20osteoporose\%2028-04-2011 pdf [ 2011

(158) Lehouck A, Boonen S, Decramer M, Janssens W. COPD, bone metabolism, and osteoporosis. Chest 2011; 139(3):648-657.

(159) Leech JA, Dulberg C, Kellie S, Pattee L, Gay J. Relationship of lung function to severity of osteoporosis in women. Am Rev Respir Dis 1990; 141(1):68-71.

(160) Yang HL, Zhao L, Liu J, Sanford CG, Jr., Chen L, Tang T et al. Changes of pulmonary function for patients with osteoporotic vertebral compression fractures after kyphoplasty. J Spinal Disord Tech 2007; 20(3):221-225. 
(161) Bapoje SR, Whitaker JF, Schulz T, Chu ES, Albert RK. Preoperative evaluation of the patient with pulmonary disease. Chest 2007; 132(5):1637-1645.

(162) Smetana GW. Preoperative pulmonary evaluation. N Engl J Med 1999; 340(12):937-944.

(163) Trayner E Jr, Celli BR. Postoperative pulmonary complications. Med Clin North Am 2001; 85(5):1129-1139.

(164) Roig M, Eng JJ, Macintyre DL, Road JD, Fitzgerald JM, Burns J et al. Falls in people with chronic obstructive pulmonary disease: An observational cohort study. Respir Med 2010.

(165) Morden NE, Sullivan SD, Bartle B, Lee TA. Skeletal health in men with chronic lung disease: rates of testing, treatment, and fractures. Osteoporos Int 2011; 22(6):1855-1862. 
Summary 


\section{Summary}

Chronic Obstructive Pulmonary Disease (COPD) is characterised by persistent airflow limitation associated with an enhanced chronic inflammatory response in the airways and the lung to noxious particles or gases. Exacerbations and comorbidities contribute to the overall severity in individual patients. One of these comorbidities is osteoporosis. Osteoporosis is a systemic skeletal disease characterized by a low bone mass and microarchitectural deterioration leading to increased bone fragility and hence increased risk of fracture. The studies in this thesis investigate the prevalence, and correlating factors of osteoporosis in COPD patients (chapter I).

Chapter II is a systematic review of the literature. The prevalence of osteoporosis based on bone mineral density (BMD) varied 9-69\%, prevalence of osteopenia varied $27-67 \%$. Prevalence of osteoporosis was higher in COPD patients as compared to healthy subjects. Moreover, prevalence of osteoporosis was higher in COPD patients as compared to patients with some other chronic pulmonary diseases. Correlating factors of osteoporosis in COPD were measures of body composition, disease severity and use of corticosteroids. Because most studies were cross sectional causality has not been proven. Effects of treatment of osteoporosis in COPD patients only were not studied.

In chapter III 554 COPD patients consecutively entering pulmonary rehabilitation were studied. Diagnosis of osteoporosis was based on whole-body DXA-scan, T-score $<-2.35$. Prevalence of osteoporosis and osteopenia ( $T$ score between -2.35 and -0.9 ) were 21 and $41 \%$ respectively. Over $80 \%$ of COPD patients with osteoporosis did not use pharmacological treatment. Independent correlates of osteoporosis were higher age and cachexia. Overweight and obese patients had a decreased risk of osteoporosis.

The best location for BMD measurement in COPD patients had not been determined before. Therefore, in chapter IV the prevalence of osteoporosis in 168 COPD patients entering pulmonary rehabilitation assessed by whole body DXA-scan was compared to the prevalence assessed by DXA-scan of the hip and lumbar spine (local DXA-scan). Whole body DXA-scan underestimated the prevalence of osteoporosis. Indeed, $25 \%$ of the 130 patients without osteoporosis as determined by 
whole body DXA-scan did have osteoporosis based on local DXA-scan. The relative risk of having osteoporosis on local DXA-scan in case of a normal whole-body DXA-scan was 6.4 times higher than the risk of having osteoporosis on whole body DXA-scan in case of a normal local DXA-scan. In conclusion, in COPD patients BMD should be measured at the hip and lumbar spine and the lowest T-score of these 2 locations should be used to diagnose osteoporosis.

Osteoporosis is not only characterized by a low BMD but also by microarchitectural deterioration which is not measured by DXA-scan. Therefore, in chapter $\mathbf{V}$ we diagnosed osteoporosis based on local DXAscan and vertebral fractures. Half of the 255 included COPD outpatients of a large teaching hospital in the Netherlands had radiological evidence of osteoporosis. Prevalence of osteoporosis was not significantly different after stratification for GOLD stage. Correlates of osteoporosis were age, body mass index (BMI) and higher parat hormone.

The prevalence of osteoporosis in COPD patients is high, even in moderate COPD. To assess risk factors for osteoporosis a case control study was done (chapter VI). Forty-nine GOLD stage II COPD patients with osteoporosis were compared to 49 GOLD stage II patients without osteoporosis. Diagnosis of osteoporosis was based on DXA-scan and vertebral fractures. A lower $\mathrm{BMI}$ and higher RV\%TLC independently increased the odds ratio for osteoporosis. Additionally, an overweight and obese BMI were protective of osteoporosis.

To identify true risk factors prospective studies are needed. Therefore, chapter VII is a follow up study. Ninety patients were followed up for 3 years after their initial study inclusion. DXA-scan and vertebral fractures were re-assessed. Prevalence of osteoporosis increased from $47 \%$ to $61 \%$ mostly due to new vertebral fractures. Risk factors for osteoporosis were vitamin $\mathrm{D}$ deficiency and a lower T-score at the trochanter of the hip at baseline.

To conclude, the studies in this thesis show that the prevalence of osteoporosis in COPD patients is high, even in patients with mild and moderate COPD (chapter VIII). Most osteoporotic COPD patients were not treated with physician prescribed bone medication. Therefore, awareness of the high prevalence of osteoporosis seems to be low and should be raised. The best way to diagnose osteoporosis in COPD 
patients is assessing BMD by DXA scan of the hip and lumbar spine and combining this with the assessment of vertebral fractures. The underlying pathophysiology of osteoporosis in COPD is very complex and the studies in this thesis were not designed to clarify this. To assess risk factors and clarify the underlying pathophysiological mechanisms more large prospective studies are warranted including healthy subjects. When the pathophysiology and pathogenesis of osteoporosis in COPD is further clarified better screening and follow up advises might be given and new treatments aimed at both COPD and osteoporosis might become available. 


\section{Samenvatting}




\section{Samenvatting}

COPD wordt gekenmerkt door een persisterende luchtwegobstructie. Deze luchtwegobstructie is geassocieerd met een versterkte chronische inflammatoire respons in de luchtwegen en de longen als reactie op schadelijke prikkels of gassen. Exacerbaties en comorbiditeiten dragen bij aan de ernst voor individuele patiënten. Een van deze comorbiditeiten is osteoporose. Osteoporose wordt gekenmerkt door een lage bot massa en verstoring van de microarchitectuur van het bot. Hierdoor wordt het bot fragieler en is er een verhoogd risico op fracturen. In dit proefschrift werd onderzoek gedaan naar de prevalentie en correlerende factoren voor osteoporose bij COPD patiënten (hoofdstuk I).

Hoofdstuk II is een systematisch overzicht van de literatuur die voorhanden was over osteoporose bij COPD patiënten. De prevalentie van osteoporose gebaseerd op bot minerale dichtheid (BMD) varieerde van $9-69 \%$ en de prevalentie van osteopenie van $27-67 \%$. Een aantal onderzoekers vergeleek COPD patiënten met een controle populatie. De prevalentie van osteoporose bleek groter te zijn bij de COPD patiënten. Ook in vergelijking met patiënten met andere chronische longaandoeningen bleek de prevalentie van osteoporose bij COPD patiënten groter te zijn. Lichaamssamenstelling, ernst van de COPD en het gebruik van corticosteroïden bleken het risico op osteoporose te verhogen bij COPD patiënten. Een causaal verband kon niet worden bewezen aangezien de meeste onderzoeken cross-sectioneel waren. $\mathrm{Er}$ werden geen onderzoeken gevonden waarbij de effecten van de behandeling van osteoporose bij COPD patiënten was onderzocht.

In hoofdstuk III werden 554 COPD patiënten die gingen startten met klinische pulmonale revalidatie onderzocht. Er werd een DXA scan van het hele lichaam gemaakt en bij een T-score van -2,35 of lager werd de diagnose osteoporose gesteld. De prevalentie van osteoporose was $21 \%$ en de prevalentie van osteopenie ( $T$ score tussen $-2,35$ en $-0,9$ ) $41 \%$. Meer dan $80 \%$ van alle COPD patiënten met osteoporose bleek niet medicamenteus te worden behandeld. Onafhankelijke correlerende factoren voor osteoporose bij COPD waren: hogere leeftijd en cachexie. Bij patiënten met overgewicht of obesitas was de kans op het hebben van osteoporose significant lager.

De beste locatie in het lichaam om de BMD te meten was nog niet onderzocht bij COPD patiënten. Daarom werd in hoofdstuk IV bij 168 
COPD patiënten die startten met pulmonale revalidatie de prevalentie van osteoporose gebaseerd op een DXA scan van het hele lichaam vergeleken met de prevalentie van osteoporose gebaseerd op een DXA scan van de heup en lumbale wervelkolom (lokale DXA scan). Een DXA scan van het hele lichaam onderschatte de prevalentie van osteoporose. Een kwart van de 130 patiënten die geen osteoporose hadden op basis van de DXA scan van het hele lichaam bleken wel osteoporose te hebben op basis van de lokale DXA scan. Bij een DXA scan van het hele lichaam worden veel vals negatieve scans gevonden. Op basis van dit onderzoek wordt geadviseerd om bij COPD patiënten de BMD te meten aan de heup en de lumbale wervelkolom en de laagste T-score te gebruiken om osteoporose te diagnosticeren.

Osteoporose wordt niet alleen gekarakteriseerd door een lage bot massa, maar ook door een verstoring van de microarchitectuur van het bot. Deze verstoring van de microarchitectuur wordt niet gemeten door een DXA scan. Als surrogaat voor de verstoorde microarchitectuur werden in hoofdstuk $\mathbf{V}$ wervelfracturen zonder voorafgaand hoog energetisch trauma genomen. Osteoporose werd gediagnosticeerd op basis van de T-score (met behulp van een lokale DXA scan) en/of het hebben van wervelfracturen. De helft van alle 255 COPD patiënten die onder behandeling waren bij longartsen werkzaam in een groot opleidingsziekenhuis in het zuiden van Nederland bleken osteoporose te hebben. De prevalentie van osteoporose was niet significant verschillend na stratificatie voor GOLD stadium. Correlerende factoren voor osteoporose bij COPD die in dit onderzoek werden gevonden waren: leeftijd, body mass index (BMI) en een hoger parathormoon in het serum.

Om meer inzicht te krijgen in de risico factoren voor osteoporose bij COPD patiënten werd een case control onderzoek gedaan (hoofdstuk VI). Omdat de prevalentie van osteoporose ook bij patiënten met een matig ernstig COPD hoog is werden GOLD II COPD patiënten geïncludeerd. Negenenveertig COPD patiënten met osteoporose op basis van een lokale DXA scan en/of wervelfracturen werden vergeleken met 49 COPD patiënten zonder osteoporose. Een lagere BMI en een hogere RV\%TLC verhoogden de kans op osteoporose. Ook in dit onderzoek werd weer een beschermend effect van overgewicht en obesitas gevonden. 
Om daadwerkelijke risico factoren te identificeren zijn prospectieve onderzoeken nodig. Hoofdstuk VII beschrijft dan ook de resultaten van een follow up onderzoek. Bij 90 COPD patiënten werden na 3 jaar de onderzoeken herhaald. De prevalentie van osteoporose steeg van $47 \%$ naar $61 \%$ na 3 jaar voornamelijk doordat er meer wervelfracturen optraden. Risico factoren voor osteoporose waren vitamine $D$ deficiëntie en osteopenie van de trochanter.

Concluderend laten de onderzoeken in dit proefschrift zien dat de prevalentie van osteoporose bij COPD patiënten hoog is zelfs bij patiënten met een mild en matig COPD (hoofdstuk VIII). De meeste COPD patiënten met osteoporose gebruikten geen medicijnen om het fractuur risico te verkleinen. Het lijkt erop dat (long)artsen zich niet bewust zijn van de hoge prevalentie van osteoporose bij COPD patiënten. Dit bewustzijn moet worden gewekt. De beste manier om osteoporose te diagnosticeren bij COPD patiënten is door de BMD van de heup en de lumbale wervels te meten en dit te combineren met onderzoek naar het al dan niet bestaan van wervelfracturen. De onderliggende pathofysiologie van osteoporose bij COPD is complex en zeker nog niet opgehelderd. De onderzoeken voor dit proefschrift waren niet opgezet om dit verder te doorgronden. Om deze onderliggende mechanismen te onderzoeken zijn grote prospectieve onderzoeken nodig met een controle populatie zonder COPD. Het is belangrijk om de pathofysiologie en pathogenese van osteoporose bij COPD verder te verhelderen omdat er op die manier betere adviezen ten aanzien van screening en follow up kunnen worden gegeven. Mogelijk dat hierdoor nieuwe behandelingen zouden kunnen worden ontwikkeld gericht op zowel de behandeling van COPD als van osteoporose. 
Dankwoord 


\section{Dankwoord}

Wat ben ik blij dat het eindelijk tijd is om iedereen te bedanken. Het heeft bloed, zweet en tranen gekost, maar met medewerking van ieder van jullie op zijn/haar eigen manier heb ik het toch voor elkaar gekregen: mijn proefschrift. Misschien dat ik wat mensen vergeet, daarvoor bij voorbaat vast mijn excuses: jullie weten zelf ook wel dat het zonder jullie steun niet was gelukt.

Prof. dr. EFM Wouters. Geachte professor Wouters, hartelijk dank voor het vertrouwen en met name voor het altijd weer net iets dieper in de materie duiken tijdens de overleg momenten die wij hadden. Ondanks uw enorm drukke schema vond $u$ toch de mogelijkheid om regelmatig overleg te hebben. $U$ heeft natuurlijk uw sporen al ruimschoots verdiend met name door COPD als systeemziekte te zien in plaats van een puur pulmonale aandoening, ik ben erg blij dat $u$ me de kans heeft gegeven een van de systemische verschijnselen van COPD iets verder te mogen uitzoeken.

Dr. M.A. Spruit. Beste Martijn, wat was ik blij toen ik een afspraak met je had: je vertelde me dat er een enorme database was van COPD patiënten voordat ze met hun revalidatie traject gingen starten en dat van al die patiënten een DXA-scan was gemaakt. Wat een teleurstelling dat je ziek was toen we onze eerste afspraak hadden. Vanaf de tweede afspraak is dit ruimschoots goed gemaakt. Wat heb ik veel gehad aan jouw manier van werken! Zet maar iets op papier, dan voorzie jij dat onmiddellijk van commentaar en kom je iedere keer weer met nieuwe manieren om ergens tegen aan te kijken. Jij zorgt ervoor dat mensen scherp blijven. Daarnaast weet je ook goed richting te geven en prioriteiten te stellen want zelfs voor een vrouw valt het toch niet mee om meerdere dingen tegelijk te doen.

Dr. B.E.E.M. van den Borne. Best Ben, jij bent iemand die altijd grootse plannen heeft en dat met enorm enthousiasme kan brengen. Vaak met zo veel enthousiasme dat het moeilijk is om je te wijzen op de praktische bezwaren die er zo nu en dan aan kleven. Als ik het even niet meer zag zitten omdat er weer eens iets misgelopen was zei jij vrolijk dat ik dat soort frustraties eigenlijk op zou moeten schrijven en lachte je ze weg met de boodschap dat iedere promovendus dit meemaakt. Ik heb ze niet opgeschreven: ik denk liever aan het feit dat ondanks dit soort tegenslagen dit boekje hier nu toch is. 
Dr. F.W.J.M. Smeenk. Beste Frank, bedankt voor het snel lezen en van commentaar voorzien van alles wat ik geschreven heb. Altijd sneller dan verwacht belde je of vroeg je me na de overdracht even mee te lopen om een en ander door te nemen. En tot op het allerlaatste moment ben je ontzettend betrokken geweest. Ik vind het dan ook erg jammer dat er geen drie copromotores mogen zijn, het voelt nu alsof je te kort wordt gedaan. Ik heb veel gehad aan jouw inzichten, als ik helemaal vastliep in mijn gedachten-cirkels wist jij me daar uit te halen. Wat ik vooral zo bewonder is dat je ontzettend begaan bent met zowel je patiënten als met je (opleidings-)assistenten. Dat je ondanks je drukke schema toch aandacht hebt voor de persoon achter de assistent. Deze kwaliteiten maken je tot de goede opleider die je bent.

J.P.H.M. Creemers. Beste Jacques, jij bent degene geweest die me tijdens mijn wetenschappelijke stage al vroeg of ik geen longarts wilde worden. En jij bent het ook geweest die, toen ik bijna klaar was met mijn co-schappen, via Jeannette en mijn schoonmoeder mijn telefoonnummer achterhaalde om te informeren of ik al longarts wilde worden. Toen ik op gesprek kwam stelde jij voor dat ik promotie onderzoek zou gaan doen. Beste Jacques, bedankt voor het vertrouwen in mij. Jij was er van overtuigd dat ik kon promoveren en zie hier: je had gelijk!

Natuurlijk ook dank aan de rest van de maatschap longziekten: R.H.H. van Balkom en P.L.M.L. Wielders. Roland en Pascal bedankt voor de interesse, de tips en het makkelijk toegankelijk zijn voor vragen. Ook wil ik jullie beiden nog complimenteren met de manier van het bespreken van patiënten: altijd uitgebreid en leerzaam! En Pascal natuurlijk ook bedankt voor de hulp bij het regelen van de financiën. En dan de chef de clinique: H.G.J. de Beer. Beste Hans, bedankt voor de vrolijke noot en natuurlijk ook voor de begeleiding in de kliniek. M. Rietdijk-Smulders: beste Margriet, bedankt voor de interesse en voor het meedenken met de stellingen!

Dr. E.J. Martens. Beste Lies, dank je wel voor al je hulp zowel op statistisch gebied alsook in het schrappen van al die woorden en zinnen die nu eenmaal in het Engels/Amerikaans totaal overbodig zijn.

Dr. A.B. Donkers-van Rossum. Beste Astrid, geweldig hoe jij vol enthousiasme meteen mee dacht en mee literatuur opzocht zodat we een schema konden opstellen om emfyseem te kwantificeren op HRCTscans. Dank ook voor het beoordelen van alle HRCT's met mij. Ik heb er 
erg veel van geleerd! Ik zie er naar uit om tijdens het longstation en het onderwijs interstitiële longziekten weer veel van je op te steken.

F.H. Jansen. Beste Frits, fijn dat ik altijd met vragen over werveldeformaties weer bij jou terecht kon. Ook dank voor het taalkundig corrigeren van een aantal van de hoofdstukken van dit proefschrift. Geweldig hoe je, vrijwel meteen nadat er een DXA-scan in het Catharina Ziekenhuis was, regelde dat ik hier intensief gebruik van kon maken. En uiteraard ook dat de DXA-scan van het Diagnostisch Centrum zo snel vergeleken werd met de DXA-scan uit het ziekenhuis, waardoor de BMD metingen voor het follow up onderzoek inderdaad hier gedaan konden worden. Hierbij moet ik natuurlijk ook Elly van Hugten niet vergeten te bedanken voor het regelen van de BMD metingen. Beste Elly, bedankt voor de goede planning, ik vond de samenwerking erg prettig. Tevens wil ik natuurlijk de radiologie assistenten bedanken voor het maken van alle foto's van de wervelkolom, de DXA-scans en IVA's en alle HRCT's.

Dr. E.J. Schoon. Beste Eric, bedankt voor de gesprekken die wij hebben gehad toen ik begon met mijn onderzoeken. Fijn dat jij me van goede adviezen voorzag bij het opzetten van mijn onderzoeken en vooral ook voor de enthousiaste manier waarop jij over osteoporose kan vertellen!

Dr. M.C. Blonk. Beste Marion, fijn dat jij altijd tijd maakt om mee te denken over het te voeren beleid bij patiënten met osteoporose. Geweldig dat je zoveel doet om je patiënten zo snel mogelijk te zien en te helpen. Mijn complimenten voor de manier waarop jij (in samenwerking met Frits) de osteoporose polikliniek hebt opgezet.

Ook de longfunctie afdeling heeft veel voor mij betekend. Bedankt voor de looptesten de "Bimmetjes", het innemen van de vragenlijsten en het doorsturen van de patiënten naar het lab. Jullie zijn een goed team en een fijne afdeling om te komen. Loes, jou wil ik nog eens extra bedanken. Te gek hoe ik patiënten altijd even tussendoor mocht laten komen omdat ze toevallig net een afspraak in het ziekenhuis hadden. En iedere keer dat ik belde omdat ik een longfunctie weer eens niet kon inzien zorgde jij er meteen voor dat je ze voor me opzocht en uitdraaide. Goed dat je de opleiding hebt afgerond en blijf vooral zo enthousiast!

Longresearch. Ik heb met veel plezier bij jullie gewerkt. Jullie zijn een goed team, houd dat vast! Speciale dank aan Anne en Engelina voor het invoeren en archiveren van een hele sloot gegevens. Jeannette, bedankt 
voor het continu zorgen, niet alleen voor de patiënten, maar zeker ook voor ons. Je wordt gemist op de afdeling! Birgit bedankt voor de tips rondom het motor rijden. Corlianne dank voor het luisterend oor en mee uitrekenen van de doseringen corticosterö̈den. Robert bedankt voor het oplossen van alle problemen die er met mijn computer waren (of de problemen die ik met de computer had...). Joris en Renske, bedankt voor het werk dat jullie hebben gedaan tijdens jullie wetenschappelijke stage. Fijn om jou nu als collega te hebben Joris. Cecile, het valt niet mee om te promoveren, maar je ziet het: het kan echt. Ik heb heel veel gehad aan jou statistische kennis. Ik wil jou en Mark ook heel hartelijk bedanken voor de hulp met een aantal figuren, lief dat jullie daar zelfs samen een avond aan wilden besteden! Cecile, heel veel succes met de rest van je promotie en met het vinden van een baan, dat moet goed komen. Lisette, je ziet het: osteoporose bij COPD patiënten is erg boeiend om te onderzoeken. Zoals altijd met onderzoek denk ik dat ik met mijn proefschrift zeker voldoende vragen heb opgeroepen die nog onderzocht moeten worden op dit gebied. Daarmee ben je al goed op weg. Veel succes ook in Schotland!

Arts-assistenten longziekten. Graag wil ik alle arts-assistenten die de afgelopen tijd zijn gekomen en gegaan bedanken voor de prettige samenwerking. Daarbij wil ik jullie ook bedanken voor het feit dat jullie altijd wilden luisteren naar mij als er weer eens iets tegen zat en wilden helpen met klinische werkzaamheden als ik dringend aan mijn proefschrift moest werken. Ondanks de wisselende samenstelling (dat krijg je als je al bijna 8 jaar als arts-assistent werkt) heb ik het idee dat de sfeer in de groep goed is. Ik hoop dat we dit zo kunnen houden!

Ook de arts-assistenten en alle specialisten waar ik tijdens mijn vooropleiding mee heb gewerkt wil ik natuurlijk danken voor de samenwerking.

Longpoli. Dank voor de steun en het meeleven. Altijd fijn om bij jullie te zijn voor het regelen van afspraken, de polikliniek, maar vooral ook om met jullie bij te praten en op de hoogte te blijven van alles wat er speelt! Anja, jou wil ik nog even speciaal bedanken voor het bellen en maken van een aantal afspraken voor patiënten voor mijn onderzoek.

CIRO Horn. Uiteraard wil ik iedereen die de onderzoeken doet voorafgaand aan het starten van pulmonale revalidatie hartelijk bedanken hiervoor en dan vanwege mijn onderzoek met name ook nog de 
longfunctie afdeling en Trineke Hofstra en Ans Suntjens voor de BMD metingen. Daisy, jou wil ik nog even speciaal bedanken voor het snelle antwoorden op vragen rondom het maken van het proefschrift. Veel succes met je promotie 22 maart dit jaar! Marie Brayer en Mieke Celis, jullie werken beiden niet meer in CIRO, maar bedankt voor al die keren dat ik bij jullie heb gezeten en dat we samen hebben zitten zwoegen op onze onderzoeken. Heel veel succes met alles waar jullie op dit moment mee bezig zijn. Erica Rutten, bedankt voor de samenwerking tijdens het schrijven van de artikelen over comorbiditeiten bij COPD en voor het kritisch lezen van mijn proefschrift en het stellen van vragen. Veel succes met het begeleiden van Lisette en veel geluk met je gezin! Alle anderen die ik heb gezien en makkelijk toegankelijk waren, altijd tijd hadden voor een praatje en de mensen die op congressen kwamen luisteren naar mijn presentaties: heel hartelijk bedankt!

Diagnostisch Centrum Eindhoven. Hartelijk dank voor de goede samenwerking en het maken van de DXA-scans. Met name wil ik nog even Joke en Marlies bedanken voor het coördineren van de samenwerking.

Natuurlijk mag ik alle patiënten die hebben deelgenomen aan de onderzoek niet vergeten. Allemaal hartelijk dank, zonder jullie waren de onderzoeken en dus dit proefschrift, er niet geweest.

Mijn paranimfen Ellen van Veenendaal en Kim Crijns. Ellen, ik heb zo veel bewondering voor jou! Als het werk geen uitdaging meer voor je is zoek je iets nieuws waar je helemaal voor gaat. Je bent niet bang om nieuwe dingen te leren en andere richtingen op te gaan. En dat alles met een gezin met 3 kinderen. Nogmaals hartelijk gefeliciteerd met het openen van jullie camping "Het Goeie Leven": ik weet zeker dat het een succes gaat worden! Kim, jij bent een hele fijne collega met een grote inzet. Daarbij heb ik het gevoel dat het ook op persoonlijk vlak goed klikt tussen ons. Fijn om samen met jou de rest van de opleiding tot longarts te kunnen doen.

Mijn schoonouders. Lieve Loek en Trudie, geweldig hoe jullie mij vanaf het eerste moment hebben opgenomen in jullie gezin: vanaf dag 1 heb ik me ontzettend welkom gevoeld. Ik heb zoveel bewondering voor de manier waarop jullie iedereen in zijn eigen waarde laten. Bedankt voor de steun die jullie me hebben gegeven en nog steeds geven. Fijn dat jullie altijd voor ons klaar staan! 
Mijn schoonzus en mijn nichtje. Lieve Nicole, ook jij bedankt voor alle steun. Lief om mij nog een hart onder de riem te steken! Ook jij bedankt dat je alles laat vallen om te helpen als dat nodig is. Lieve Daimy, "tante Lies" heeft eindelijk weer wat meer tijd om leuke dingen met jou te gaan doen. Want ik weet niet hoe het met jou zit, maar ik vindt dat dat zeker vaker moet gebeuren!

Mijn ouders. Lieve Hans en Jeanneke, bedankt voor de fijne jeugd die jullie me gegeven hebben en voor jullie trots.

Mijn zus en haar vriend. Anna en Jos, ik wens jullie veel geluk met Isa. Ook voor alle vrienden: bedankt voor het begrip dat ik hele dagen, avonden en soms zelfs nachten niet achter mijn computer uit te halen was. Dat is nu gelukkig voorbij.

Lieve Loek, zonder jou was ik waarschijnlijk niet eens aan dit promotie onderzoek begonnen. Jij zei meteen dat ik zo'n kans niet moest laten schieten. Wat zul je daar vaak spijt van hebben gehad! Na al die jaren kan ik eindelijk de avonden, weekenden en zelfs vakanties dingen met jou gaan doen in plaats van te werken aan dit proefschrift. Het is onmogelijk om jou te bedanken voor alles wat je voor me doet. Nooit gedacht dat iemand zo onvoorwaardelijk voor mij zou kunnen gaan! Jij bent alles voor mij. Lieve Loek, nu gaan we weer samen genieten!

Lieve Femke, wat jij met mij gedaan hebt is niet te beschrijven! Gelukkig ben ik klaar met promoveren op het moment dat jij nog te klein bent om mee te krijgen hoe veel tijd ik daar in heb gestoken. Lieve Femke, ik hoop dat je altijd zo vrolijk blijft. Je vader en ik houden zielsveel van jou! 
Dankwoord 
Curriculum Vitae 
Lidwien Graat-Verboom werd op 15 juni 1977 geboren te Eindhoven. Na haar eindexamen Atheneum in 1996 aan het Van Maerlantlyceum te Eindhoven behaalde zij in 1997 haar propedeuse medische biologie aan de Universiteit van Amsterdam. Aansluitend ging zij geneeskunde studeren aan de Universiteit van Amsterdam. Onder leiding van J.P.H.M. Creemers en R.J.E. Grouls deed zij in 2001 een wetenschappelijke stage op de afdeling longziekten en de ziekenhuis apotheek van het Catharina Ziekenhuis Eindhoven. In februari 2004 behaalde zij haar artsen diploma waarna ze in maart 2004 begon als ANIOS longziekten in het Catharina Ziekenhuis te Eindhoven.

In april 2005 begon zij met haar promotie onderzoek op de researchafdeling longziekten van het Catharina Ziekenhuis te Eindhoven, onder leiding van Dr. FWJM Smeenk (Catharina ziekenhuis Eindhoven), Dr BEEM van den Borne (Catharina ziekenhuis Eindhoven), Dr MA Spruit (CIRO Horn) en Prof. dr. EFM Wouters (Maastricht Universitair Medisch Centrum). De resultaten daarvan staan beschreven in dit proefschrift.

Met 5 jaar klinische en wetenschappelijke ervaring begon zij in maart 2009 aan haar vooropleiding interne geneeskunde in het Catharina Ziekenhuis Eindhoven (opleider dr B. Bravenboer). Sinds juni 2011 is zij bezig met haar opleiding tot longarts die zij in het Catharina Ziekenhuis te Eindhoven zal afronden.

Zij is bijna 10 jaar getrouwd met Loek Graat en samen hebben zij sinds 1 jaar een dochter: Femke. 